\title{
Christine Scholle
}

\section{Das Duell \\ in der russischen Literatur}

Wandlungen und Verfall eines Ritus

Verlag Otto Sagner München · Berlin · Washington D.C.

Digitalisiert im Rahmen der Kooperation mit dem DFG-Projekt „Digi20“

der Bayerischen Staatsbibliothek, München. OCR-Bearbeitung und Erstellung des eBooks durch den Verlag Otto Sagner:

http://verlag.kubon-sagner.de

() bei Verlag Otto Sagner. Eine Verwertung oder Weitergabe der Texte und Abbildungen, insbesondere durch Vervielfältigung, ist ohne vorherige schriftliche Genehmigung des Verlages unzulässig. 
ARBEITEN UND TEXTE ZUR SLAVISTIK $\cdot 14$ HERAUSGEGEBEN VON WOLFGANG KASACK

\author{
Christine Scholle
}

\title{
Das Duell in der russischen Literatur
}

Wandlungen und Verfall eines Ritus

München. Verlag Otto Sagnerin Kommission 


\section{$276.1431 \quad 14$}

Die vorliegende Arbeit entstand auf Anregung von Herrn Frof. Dr. Horst-Jürgen Gerlgk, dem lch wertvolle Hinwelae vercaike. Herm Prof. Dr. Wolfgang Kasack bin 1ch fur die freundlicie Aufnahme in seine Reihe "Arbeiten und Texte zur Slavist:k' sehr verpllichtet.

Als Dissertation angenommen von der Neuphilologischen Fakultät der Universität Heidelberg aufgrund der Gutachten vor Prof. Dr. Horst-Jürgen Gerigk und Prof. Dr. Bodo Zelinekr

Alle Rechte vorbehalten

Gesamtherstellung Walter Kle1kamp • Köln

ISBN $387690 \quad 1227$

72137312 
INHA IT

ERSTER TEIL

I DAS DUELL AIS EHRENZWEIKAMPF. KURZER GESCHICHTLICHER ABRISS DIESER INSTITUTION UND SKIZZIERUNG IHRER ENTWICKLUNG IN RUSSLAND......................... 1

II ZUR UNTERSUCHUNG DES DUELIS IN DER RUSSISCHEN LITERATUR: THEORETISCHES FUNDAMENT UND METHODE........... 14

ZWEITER TEII - WERKANAIYSEN

A. S. Puǧkin, "Der SchuB" ....................... 18

A. S. Pugkin, "Eugen Onegin" ..................... 32

A. S. Puskin, "Die Hauptmannotochter" ............... 52

M. Ju. Lermontov, "Ein Held unserer Zeit"............. 68

I. S. Turgenev, "väter und Söhne"................... 91

L. N. Tolstoj, "Krieg und Frieden".................. 103

F. M. Dostoevskij, "Die Dämonen" .................... 135

A. P. Cechor, "Das Duell" .......................... 151

A. I. Kuprin, "Der Zweikampl" ..................... 165

M. P. Arcybåer, "Sanin"........................ 174

DRITTER TEIL

I SCHLUSSBETRACHTUNG. BESONDERHEITEN DES RUSSISCHEN LITERARISCHEN DUELLS - AUCH IM VERGIEICH ZUM DUELL IN ANDEREN IITERATUREN......................... 183

II BIBLIOGRAPHIE ... . . . . . . . . . . . . . . . . . . . . 187 
...es ist in unserer Zeit ublich geworden, sich über derartige Veranstaltungen lustig zu machen. Man tut nicht recht daran, meine ich, und ich versichere Sie, das Leben war schöner, bot jedenfalls einen edleren Anblick damals - unter anderem gewiB auch darum, weil man es manchmal aufs Spiel setzen muBte fuir irgend etwas, das in einem höheren oder wenigstens anderen Sinn möglicherweise gar nicht vorhanden oder das wenigstens den Einsatz, nach heutigem $\mathrm{Ka}$ gemessen, eigentlich nicht wert war, für die Ehre zum Beispiel oder für die Tugend einer geliebten Frau oder den guten Ruf einer Schwester, und was dergleichen Nichtigkeiten mehr sind...

Arthur Schnitzler, "Der Sekundant" 
I DAS DUELL ALS EHRENZWEIKAMPF. KURZER GESCHICHTLICHER ABRISS DIESER INSTITUTION UND SKIZZIERUNG IHRER ENTWICKLUNG IN RUSSLAND

In der vorliegenden Untersuchung geht es um das Duell als Ehren$z$ weikampf, d. h. um einen Kampl mit tödlichen Waffen "zweier Fersonen, welcher auf ihre Privatautorität hin, nach vorheriger Verabredung (über Zeit, Ort, Waffen usw.) stattfindet." ${ }^{1}$ Die

"1. v. Fürich, "Das Duell" (1886), S. 2. - Mit seiner Definition des Duells (im strafrechtlichen Sinn) schließt v. Fürich folgende Zweikämple aus:

a) Zweikämpfe, die auf öffentliche Autorität hin stattfanden und Kriegsersatz waren. Beispiele aus der Geschichte: der Kampf Davids mit Goliath, der Horatier mit den Curatiern usw.

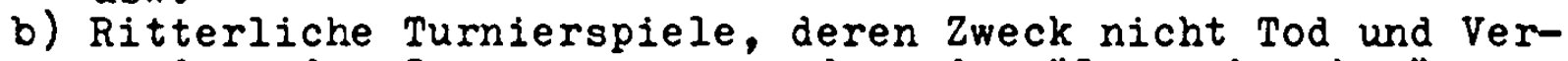
wundung des Gegners war, sondern das "Lanzenbrechen". Schwere Verletzungen kamen vor, waren aber weder beabsichtigt noch vorauszusehen.

c) tbungen auf dem Fechtboden, die mit Schutzmaßnahmen durchgefuhrt wurden, sowie studentische Bestimmungsmensuren.

d) Kämpfe zwischen Einzelpersonen, die nicht auf Verabredung, sondern beispielsweise auf einen plötzlichen Wortwechsel hin erfolgten.

Viele Verfasser von Duellabhandlungen schließen überdies das sog. amerikanische Duell aus, so $0 . v$. Schulmann in "Duell und Strafgesetz" (1914), S. 2: "Bestimmungsmensur und amerikanisches Duell liegen auBerhalb des Rahmens dieser Arbeit, erstere - weil sie in das Gebiet des Sports $z u$ verweisen ist, letzteres - weil seiner äuBeren Form nach uberhaupt keinen Zweikampe darstellend." - Es sei hier darauf hingewiesen, daB man unter "amerikanischem Duell" $n$ i $c h t$ $z u$ verstehen hat, was $A$. Kohut, einer weit verbreiteten Meinung folgend, in seinem "Buch berihmter Duelle" (1888) beschreibt: "In jenem Lande, wo aus aller Herren Länder allerlei zweideutige Elemente...zusammenströmen, sind die europäischen Kampimittel veraltet; dort greift man zum Messer, Karabiner und Revolver auf offener Straße und zur schwarzen Kugel im Geheimen." (S. 48) - In Amerika wurden Duelle regelgerecht nach europäischen Kodizes durchgefuhrt, vgl. dazu Don C. Seitz, "Famous American Duels" (1966): Chapter II, The Code. R. Baldick geht in seinem Buch "The Duel" (1965) auf das "amerikanische Duell" ein: "This was a duelling method rather similar to 'Russian roulette' and for many years was considered in Europe to be a peculiarly American way of settling a quarrel." (S. 136) - Vgl. auch v. Below "Duell in Deutschland" (1896), S. 67: "Das sog, amerikanische Duell giebt es in Amerika bekanntlich nicht." 
Frage nach dem Ursprung dieser Art von Duell wurde im 19. Jahrhundert - dem Jahrhundert einer üppig wuchernden Duelliteratur durchaus nicht einmiutig beantwortet. Zwar konstatierte W. $v$. Fürich im Jahre 1886 noch als Selbstverständlichkeit, daB das Duell "auf d e u $\mathrm{t}$ s $\mathrm{h}$ e m Boden, bei den alten Germanen aufgesproBt" sei ${ }^{1}$ - doch bildeten die deutschen Historiker um die Jahrhundertwende in der Frage, ob das Duell eine u $r$ germanische oder eine $u n$ germanische Sitte sei, zwei polemisch gegeneinander zu Felde ziehende Lager. Auf der einen Seite stellten Georg von Below und seine Anhänger den germanischen Ursprung des Duells entschieden in Abrede. "Frivol Blut zu vergieBen ist nicht die Art des Deutschen Rittertums" - so lautete eine der provozierenden Thesen von Belows, ${ }^{2}$ der das moderne Duell aus dem Traditionszusammenhang von gerichtlichem Zweikampf, Fehderecht und Turnier herauslöste und darauf hinwies, dab das früheste Vorkommen des Ehrenzweikamples in Spanien belegt sei. Von der spanisch-italienisch-französischen Krankheit sei Deutschland vor allem ab dem 17. Jahrhundert angesteckt worden, von da ab habe man sich in Deutschland "wegen einer Chansonettensängerin von unzweifelhaft zweifelhaftem Rufe" duelliert. (S. 39) Die informative historische Abhandlung

1 ebd., S. 5. Den germanischen Ursprung des Duells beweist auch ausführlich eine anonyme Schrift aus dem Jahre 1846: "Das Duell als Emancipation der Ehre". In beiden Abhandlungen wird u. a. auf den Ehrbegriff der alten Kulturvölker eingegangen. Dazu der streitbare v. Fürich: "Der Grieche und Römer hatte überhaupt kein Gepühl für jenes höchst zweideutige Etwas, was unsere moderne Gesellschaft "Ehre" n e n n $t$. Nicht als ob sie gleichgiltig gegen Ruhm und Schande, gegen gute und schlechte Handlungen, mit einem Worte: gegen die w a h $r$ e Ehre gewesen wären: im Gegenteil i h $r$ Begriff von der Ehre war ein zu hoher, als dab sie geglaubt hätten, die Ehre könne durch den ersten besten Bramarbas verletzt werden. Bei Römern und Griechen ging der Einzelne im Staat auf: das Heil und die Wohlfahrt des Staates waren Ehrensache eines jeden Bürgers, und seine Privatehre bestand darin, dem Vaterlande treu zu dienen und uberall seine $P$ Pl i c h $t$ zu thun...ebd., S. 4 .

2G. v. Below, "Das Duell und der germanische Ehrbegriff" (1896), S. 21 . 
von Belows bot durch Passagen emphatischen und irrationalen Argumentierens reichlich Stoff für Gegenangriffe: "M u $B$ t e nicht der Wahnsinn des Duells zuerst in der Heimat des Ritters von der traurigen Gestalt, dem nach Cervantes Versicherung das 'Gehirn ausgetrochnet' war, auftauchen?" (S. 30 f.) - Auf der Gegenseite stand die Gruppe um Hans Fehr, die an dem althergebrachten (und $m$. E. uberzeugenden) standpunkt vom germanischen Ursprung des Duells festhielt und zu dem SchluB kam, daB der moderne Ehrenzweikamp sich in Spanien, Italien, Frankreich und Deutschland ziemlich gleichzeitig herausbildete. ${ }^{1}$ In aller Kürze sei die Entstehungsgeschichte des Duells nach Fehr hier dargestellt, der Kamplart also, bei der "zwei Männer nach erfolgter Herausforderung einander mit Waffen gegenüberstehen, bis einer Sieger bleibt oder beide rom Kample abstehen." (S. 4 f.)

Fehr beginnt seine historische Rückschau mit Berichten Tacitus' von germanischen Zweikämpfen, deren Ausgang als Auspicium für den Ausgang einer Schlacht angesehen wurde, und mit alten nordischen Sagen, die von Zweikämpfen "um den Besitz eines Weibes, um Grundstucke, um Gut und Geld" erzählen, nach dem Motto "Der Starke hat das Recht!" (S. 5) - Das nordische Recht kannte auch schon einen Ehrenzweikampf: wenn einem Mann gewisse "Scheltworte" zugerufen worden waren und er es nicht wagte, seine angegriffene Ehre mit Waffen $z$ verteidigen, war er "weder eid- noch zeugenfähig, weder für Mann noch Frau." (5. 6) Diese Urzweikämple waren auBergerichtliche, erlaubte Selbsthilfe.

Nach der Völkerwanderung wuchsen die deutschen Stämme aus Icsen völkerschaftlichen Gemeinschaften mehr und mehr zu Staaten heran. Die erwachende Staatsgewalt stand dem außergerichtlichen Zweikamp feindlich gegenuber, da er aber tief verwurzelt war und sich nicht einfach beseitigen lieB, nahm sie ihn unter die prozessualen Beweismittel auf. Auch die Kirche sah sich gezwungen, den Zweikampf anzuerkennen und machte ihn zum Gottesurteil: der Christengott sollte im Zweikampl den Schlechten untergehen, den Gerechten siegen lassen. In nachfränkischer

H. Fehr, "Zweikampl" (1908). 
Zeit war der Zweikampf als Gottesurteil selbstverständlich geworden: die Behauptung einer Partei sollte durch den Kampf als wahr bewiesen werden. Der Kampe war nicht Endzweck, sondern Mittel, ein richtiges Urteil herbeizufüren. War er zu Ende, lieB der Richter das gefundene Urteil vollstrecken. Der gerichtliche Zweikampl des Mittelalters zeigte schon gewisse Merkmale des modernen Duells: der Grundsatz der $E$ b e $n$ b ii $r t i g k$ e i $t$ war stark ausgeprägt, nur Angehörige gleichen Standes kämpeten miteinander; nur der $f \mathrm{r} i \mathrm{e}$ und $r$ e $\mathrm{n} e$ Mann war zum Kampf zugelassen: gegen Knechte und solche, die durch "Meintaten" ihren Namen befleckt hatten, kämplte man nicht (Satisfaktionsfähigkeit des modernen Duells); im sächsischen Reichsgebiet muBte die Kampfklage von einer beleidigenden Handlung beGleitet sein - Voraussetzung des Kampfes war ein (nicht widerrechtlicher) Angriff auf die Ehre des Gegners; ${ }^{1}$ auch die F $\circ \mathrm{rma} l$ i $t$ ä $t$ e $n$ des Ordals entsprachen in Manchem dem modernen Duell: beide Kämpfer wurden gleichmäBig bandagiert und mit Waffen ausgerustet; beide bekamen einen Sekundanten, der nur in ganz bestimmten Fällen einspringen durfte; licht und Schatten waren so $z u$ verteilen, daB kein Kämper im Vorteil war; im Kamplring wurde Frieden geboten, und auf Befehl des Unparteiischen, des Richters, begann der Kampf. (Sachsenspiegel)

Gegen Ende des Mittelalters verschwand der Zweikampf aus den ordentlichen Gerichtsverfahren - wegen Umbildung des ProzeBverfainrens und vor allem auf kirchlen Druck hin (Konzil von Trient). Die Idee des unmittelbaren Eingreifen Gottes in den Kampe verblabte - man verlangte die "Wahrnehmung des $z u$ beweisenden Faktums und daher die Zeugenaussage." (S. 15) Der Zeugenbeweis verdrängte den Kamplbeweis.

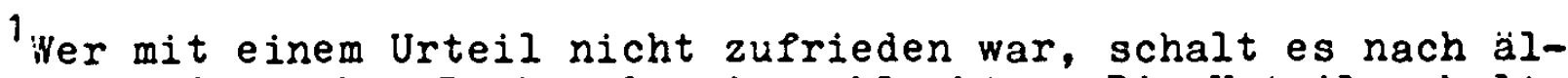
terem deutschen Recht als ein schlechtes. Die Urteilsschelte richtete sich gegen die Person des Schöfen, der das Urteil gefunden hatte. Er muBte mit dem Scheltenden kämpfen. Nach Pranzösischem Recht mußte der Charakter der Schelte ehrenruhrig sein - der Kampf um das Urteil ist hier deutlich ein Ehrenzweikampf. (S. 11) 
Aus dem ordentlichen ProzeB verdrängt, verflüchtigte sich der gerichtliche Zweikampf "in besondere Kamplgerichte und feierte darin seine letzte Blüte." (S. 17) In einzelnen deutschen Städten bildeten sich ständige Kamplgerichte aus, $z$. B. in Nürnberg, Augsburg, Schwäbisch-Hall, Breslau. Durch das Zurücktreten des Ordalglaubens gewann der Zweikampf aber ein anderes Gesicht. Das Kampfgericht in Nünberg (Kampfordnung von 1410) stand Rittern und Bürgern offen. Gekämpft wurde um des Beweises willen. Der stärkere hatte das Recht im Rücken, ohne daB noch ein unmittelbarer Schutz Gottes aneenommen wurde. Der Richter fällte nach dem Kampl das Urteil, gegen das es keine Appellation gab. In Schwäbisch-Hall (Kampfordnung von 1544) waren nur noch rittersmäßige Leute zugelassen. Kamplgut war die Ehre. Kampfsachen waren Beleidigungen und sonstige Streitigkeiten. Die Idee des Beweises trat hier zurück hinter den Gedanken, für eine erlittene Ehrverletzung Genugtuung zu bekommen. Das Gericht war nur noch Zuschauer und Schirmer des Kampfplatzes. Der Kampf war $E n$ d zweck und ging auf leben und Tod.

In diesen Kampfgerichten offenbart sich eine deutliche tbergangsstufe zum Duell. "Nur durch das Institut der Kampfgerichte" geht nach Fehr das Duell auf den Ordalzweikampf zuruick. (S. 19)

Die zweite Wurzel des modernen Duells sieht Fehr im mittelalterlichen Privatduell, einer Form der Reaktion gegen Ehrverletzungen, ${ }^{1}$ die in vier verschiedenen Kreisen praktiziert wurde: in ritterschaftlichen Kreisen, ${ }^{2}$ im Kreise des deutschen Heeres und im Lebenskreis der Bauern und Bürger. Bei Privatzheikämpfen zwischen Söldnern im Heer wurde der Hauptmann "um

1 Fehr glaubt nicht, dab Fehde und Zweikampf letztlich in einem ristorischen Zusammenhang stehen: "Auch die $F$ e $h$ d e mag gegen gewisse Verletzungen und Beschimpfungen angewandt worden sein, wiewohl sich das Fehdegericht des späteren Mittelalters nur noch auf den Fall der Tötung bezog." (S. 23) 2 Als Beispiel führt Fehr u. a. einen Ehrenhandel zwischen Könif Karl VIII von Frankreich und dem deutschen König Maximilian an, der aus einem Dokument der königlichen Kanzlei vom 25. August 1492 hervorgeht und durch einen Zweikampf beigelegt w? rden sollte. 
Schirm, Schutz und Anweisung des Kamplplatzes" gebeten. (S. 24) Das Bauernduell wurde durch das sog. Ausheischen eingeleitet. Der beleidigte Bauer begab sich vor das Haus seines Gegners und forderte inn mit mehr oder weniger groben Worten zum Kampl heraus. "Verspottungen, Beschimpfungen, Realinjurien aller Art bildeten wohl den Hauptfall des Ausheischens. Der in seinem Gefuhl verletzte Bauer forderte Genugtuung mit der Waffe in der Hand, Mann gegen Mann draußen... auf dem Felde." (S. 26) Der Zweikampf im bürgerlichen Kreis ist nur mit Quellen aus Norddeutschland $z u$ belegen: mit Statuten des lübischen Rechts aus dem 13. Jahrhundert. Die Stadtrechte sahen für Herausforderungen aber harte Geldstrafen vor, so daB sich das Privatduell hier bald verlor. - Der mittelalterliche Staat bestrafte das Duell als solches nicht. "Die Rechtsordnung setzte sich nur in so weit in ein bestimmtes, negatives Verhältnis zum Privatzweikampe, als sie...die Herausforderung, in schlichter oder beleidigender Form unter Strafe stellte." 1

Neben diesen beiden deutschen Wurzeln des modernen Duells sieht Fehr eine dritte, Premdländische: das aus Frankreich ubernommene Turnier. ${ }^{2}$ Das Turnier blieb nicht immer harmloses Waffenspiel. "Das Mittelalter uberliefert...eine Fülle von Ernstturnieren, und der Austrag von Ehrensachen mag dabei eine nicht geringe Rolle gespielt haben." (S. 22) In der Turnierordnung von Heilbronn (1485) konnte jemand "auf die Schranken gesetzt" werden wegen "Keineic, falschem Zeugnis, MiBachtung von Brief und Siegel, Flucht aus dem Heere, Verleumdung vop Frauen und JungPrauen, Entfuhrung, Wucher" usw., wegen ehrenruhriger Dinge also. (S. 37) Eine eigentliche Bestrafung konnte vom Turnierrichter vorgenomen werden gegen Ehebrecher, Lügner und Betruger,

1 In dem "Bedurfnis des Menschen, seinem Gegner unmittelbar, ohne Vermittelung des Staates, des Richters, gegenüberzutreten" und in der "Mangelhaftigkeit der Gerichtszustände im Mi:telalter" sieht Fehr die Hauptursachen fur die Umgehung des Rechtsweges. (S. 27)

2 "Doch tritt dieses Premde Element hinter dem einheimischen schon deshalb stark zuruick, weil das Turnier auf enge ritterschaftliche Kreise beschränkt war, während das Duell alle Stinde umfabte." (S. 32) 
gegen alle, "die in anderen sachen, wider Ehre und wider Adel thetten..." (ebd.) Nach dem Wegfall von Turnieren und TurnierGerichten wurde wahrscheinlich manche Ehrensache im Duell ausgetragen. "Der Adel sah sich zur Erledigung solcher Streitigkeiten auf den Weg des Kamples oder des ordentlichen Gericktes gedrängt. Aber gerade letzterer Weg mochte ihm vielfach unsympathisch gewesen...sein...". (s. 38)

Wärend in Deutschland bis um 1500 das Privatduell nicht allzu häufig auftrat, mehrten sich die Duelle im 16. Jahrhundert in Deutschland wie in den romanischen Ländern ${ }^{1}$ - erheblich und führten in gewissen Kreisen allmählich zu einem Duellzwang. Man war jeden Augenblick bereit, zum Degen ${ }^{2}$ zu greifen, um auch die geringste Beleidigung mit Blut abzuwascren: "On se tue pour rien. Die Sitte ist zur Unsitte geworden und hat fast ganz Europa ergriffen." (S. 28) - Das 16. Jahrhundert war auch insofern bedeutsam für die Entwicklung des Duells, als es das Zweikampfverbrechen schuf und die sog. Duellmandate hervorbrachte. Es wurden Verbote erlassen, die die Herausforderung 0 d e $r$ den Zweikampf als solchen bestraften, mochte er zu Verwundungen und Tod gefuhrt haben oder nicht. Den Anfang in der Geschichte der deutschen Duellgesetzgebung - die nach Fehr vielfach über "das RechtsbewuBtsein weiter Kreise" hinwegschritt (S. 31) - machten die sächsischen Konstitutionen des Kurfursten August von 1572. Doch konnten weder staatliche noch kirchliche liaßnabmen ${ }^{3}$ der Verbreitung des Duells etwas anhaben. Im 18. und 19. Jahrhun-

"Es scheint mir, daB sich auch in Frankreich die Sitte des modernen 2 weikampes nicht vor der Mitte des 16 . Jahrhunderts eingebürgert hat. Bis dahin waren die öffentlichen Kämpfe mit Rrlaubnis des Fürsten die $\mathrm{K}_{e g e l}$ und das erste Duellmandat fincet sich im Jahre 1566." (S. 35)

2

"Ferner fiel fruchtbare Saat auf den Duellboden durch die PfleEe der Fechtkunst. In vielen Städten Deutscklands begann, nacentlich seit dem 16. Jahrhundert ein systematischer Fechtunterricht, geleitet von gepriften Fechtmeistern." (S. 38)

${ }^{3}$ vgl. dazu die zitierten schriften von $0 . v_{\text {. Schulmann, }} . v$. Fürich, G. v. Below und A. v. Boguslawski "ihre und Duell" $(1896)$. 
dert $^{1}$ wurden die Gebräuche des Zweikamples in Kodizes fixiert, ${ }^{2}$ und noch im Jahre 1908 konnte Hans Fehr schreiben: "Vielleicht schenkt uns die neue Gesetzgebung einen besseren Ehrenschutz und macht damit den Zweikampl für viele Fälle entbehrlich. Ausrotten kann sie ihn aber nicht. Es wird immer Menschen geben, deren leidenschaftliches Temperament gerade nach dieser Sühne verlangt, es werden sich immer Fälle ereignen, in denen das Gefül sich sträubt, eine Genugtuung durch die Vermittlung des Richters zu emplangen." 3

1 "Zuerst schlug man sich nur auf blanke Waffe; in Frankreich auf StoB, in Deutschland auf Hieb und StoB. Im 18. Jahrhundert fing man an, die Pistole in Gebrauch zu nehmen, doch erlangte sie erst Anfang des 19. Jahrhunderts das Uebergewicht in Deutschland, insbesondere in militärischen Kreisen..." (A. v. Boguslawski, "Ehre und Duell", S. 92).

21777 entstand der Irische Kodex, "adopted in Ireland... by a convention of gentlemen delegated from Tipperary, Galway, Sligo, and Roscommon, designed for use throughout the Green Island." (Don Seitz, "Famous American Duels", S. 40) "An English code was published in 1824 by Knight and Lacey. The author's name is not given...". (ebd.. S. 46) Der beruibmte Kodex des Grafen Chateauvillard erlangte internationale Anerkennung: "Graf Chateauvillard, Mitglied des Pariser Jockey-Club, hat in Folge einer an ibn gerichteten Aufforderung... sich der Aufgabe unterzogen, die Gebräuche und Vorschriften des Duells zu fixiren, die unter dem Titel 'Essai sur le duel' im Jahre 1836 zu Paris erschienen." (Einleitung zum "Duell-Codex" von G. Hergsell, 1897) Auf Chateauvillard bezog sich nicht nur die gleichfalls beruinmte Duellabhandlung von A. Croabbon, "Science du point d'honneur" (1894) - auch deutsche Schriften gehen auf Chateauvillard zurick: der "Duell-Codex" von Hergsell, das "Duellbuch" von H. Kufahl und J. Schmied-Kowarzik (1896) und die "Konventionellen Gebräuche beim Zweikampe" von M. v. Wedel (1909). Derartige Kodizes wurden "zum Schutze für Alle als Schranken wider Ueberfall und Rachsucht" verfaBt. (Hergsell) Die in ihnen beschriebenen herkömmlichen Duellarten galten als vorschriftsmäBig und "legal" - Abweichungen davon fielen unter die "Ausnahmeduelle".

${ }^{3} V_{g l}$. die Einleitung zu G. Hergsells "Duell-Codex" : "...abgesehen davon, dass die Selbsthilfe nicht überall verwerflich ist, wie uns die Zulässigkeit der Nothwehr und des Besitzschutzes bezeugen, ist nicht zu uibersehen, dab die Gesetze Minnern mit hochentwickeltem Ehrgefuhl nach deren Ueberzeugung bisweilen nicht ausreichenden Schutz gegen ihnen selbst oder ihnen nahestehenden Personen widerfahrenen Unbilden gewähren." 
DaB das Duell im 20. Jahrhundert nach zwei Weltkriegen und tiefgreifenden gesellschaftichen Umschichtungen nicht mehr existiert, kann gewiB nicht als Kulturleistung verbucht werden. Die Ehrbegriffe der Schicht, die diese Institution trug, wären in der heutigen Massengesellschaft nicht mehr unterzubringen. "Man kann breite Massen mit Gesinnungen überfordern" ${ }^{1}$ - wäre wohl die Antwort unserer Tage auf Gustar Hergsells These: "Es giebt nur ein Mittel, das Duell abzuschaffen - man schaffe das Enrgefunl ab." 2

Zum $D$ u e $I I$ i $n$ R $B I$ a $n$ d ist vom historischen Standpunkt aus wenig Interessantes $z u$ sagen, denn "erstens, ist das Duell nicht slavischen Ursprungs und, zweitens, hat es hier nie die Verbreitung erlangt, wie beispielsweise in Deutschland, von Frankreich ganz zu schweigen." 3 Das russische Duell entbehrt indes nicht einiger erwähnenswerter Besonderheiten:

1) Zunächst ist es ein wohl einmaliges Kuriosum, daB die russische Duellgesetzgebung $v$ or dem Duell existierte: erst geraume Zeit nach der Veröffentlichung des ersten Duellgesetzes aurch Peter den Großen lassen sich Zweikämpfe nachweisen. Sein Ziel, "in Moskau die kultivierten Sitten Europas einzufüren," 4 realisierte Peter der Große unter anderem durch die "bedingungslose Rezeption ganzer westeuropäischer Gesetzbücher...Das Kriegsreglement v. 30. März (10. April) 1716, in welchem die ersten Bestimmungen uber den Zweikampl enthalten sind, ist auch nichts weiter, als eine Uebertragung westeuropäischer Gesetze auf einen Boden, der dazu noch gänzlich unvorbereitet war. Das 49. Kap. dieses Gesetzbuches, das 'Patent von Duellen und ange fangenen losen Händeln', erklärt in den

\footnotetext{
1A. Gehlen, "Urmensch und Spätkultur" (1964), S. 72. Zu Gehlens Definition von Gesinnung vgl. S. 166 dieser Arbeit.

2 Vorwort zur ersten Auflage des "Duell-Codex". 30. v. Schulmann, "Duell und Strafgesetz", S. 49. 4Zitiert nach: G. Stökl, "Russische Geschichte" (1962), S. 345 .
} 
$\S \oint 11$ - 18 den Zweikampf fur ein Verbrechen und bedroht ihn mit den schwersten Strafen." ${ }^{1}$ Nachdem das Duell sich aber einmal durchgesetzt hatte, war es - wie in Europa - durch keinerlei Repressivmaßnahmen abzuschaffen: Peter der Große hatte sein Land zum Westen hin geöffnet, seine Nachfolger auf dem russischen Thron sorgten durch adelsfreundiche Politik dafur, daß sich der russische Adel bei gesetzlich verankertem Recht auf MüBiggang ${ }^{2}$ der Nachahmung westlicher, insbesondere französischer Lebensart hingeben konnte.

2) Ein weiteres, bemerkenswertes Charakteristikur des russischen Duells geht aus dem berümten Duellbuch von Croabbon hervor: "Ie duel a été sévèrement défendu en Russie depuis le règne de Pierre le Grand... Est-ce à dire que les Russes ne se battent pas? Ies faits sont là pour etablir le contraire. Moins frequentes que chez nous, leurs rencontres sont en revanche plus meurtrières. L'arme choisie est presque toujours le pistolet, et le duel, celui a marcher." 3 Im AnschluB an die Feststellung, daB russische Duelle von exzeptioneller Gefährlichkeit seien, fragt Croabbon bezeichnenderweise nach den in RuBland geltenden Kampfregeln und gelangt $z u$ einem wenig zufriedenstellenden Ergebnis: "Quels usages les Russes observent-ils dans leurs rencontres? Nous n'avons pas pu le savoir positivement. Le si bon et regrette prince Dolgoroukow, alors gouverneur de Moscou, avec lequel nous avons eu l'honneur de tirer souvent au pistolet à vichy, nous a bien donne des details interessants sur la partie anecdotique et sur la répression, mais ne s'est jamais prononcé

10. v. Schulmann, ebd.

${ }^{2}$ Schon zu Zeiten der Regentin Anna befreiten die Offiziersschulen die Adligen von dem Zwang, ihren Dienst als Gemeine begirnen $z u$ müssen. $A b 1736$ blieb bei mehreren Söhnen einer von der auf 25 Jahre begrenzten Dienstpflicht befreit. Kaiserin Elis8beth privilegierte den Adel sozial und ökonomisch: die Verfusungsgewalt über die Bauern wurde erweitert, eine Adelsbank gewährte billige Kredite etc. Peter III setzte 1762 die Aufhebung der Dienstpflicht des Adels durch, Katharina faBte alle Adelsprivilegien in der "Zalovannaja gramota" zusammen, die dem Alelsstand auch vollkommene Freiheit der Selbstverwaltung gewährte. (stökl)

3. Croabbon, "Science du point d'honneur", S. 404. 
sur la question des règles du duel. Nous croyons que ce sont celles de Chateauvillard, plus ou moins altérées par des usages =orcément non codifiés." 1 Durch das Fehlen kodifizierter Reseln, die - das sei noch einmal betont - als schutz für Alle, als "Schranken wider Ueberfall und Rachsucht" und "als ein Ausfluss der Cultur und ritterlichen Gesinnung" angesehen wurden (Hergsell), stand dem sog. Ausnahmeduell mit der erhöhten Gefahr eines tödlichen Kampfausgangs also nichts im Wege.

3) Um eine dritte Eigentümichkeit des Duells in RuBland deutlich werden zu lassen, muB zuvor auf die Einführung der Ehrengerichte und die Spezialbestimmungen für den Zweikampf der Offiziere in Preußen eingegangen werden, die auf Verordnungen von 1843 und 1874 zurückgehen. Die Verordnungen Friedrich Wilhelms IV von 1843 bezeichneten es als Aufgabe der Ehrengerichte, "die Ehre des Einzelnen und der Genossenschaft zu wahren." Das aus dem ganzen Offizierkorps bestehende Ehrengericht befaßte sich mit Fälien "unpassenden Benehmens an einem öffentlichen Ort... Trunkenheit" etc., ${ }^{2}$ aber auch mit Ehrenstreitigkeiten von Offizieren. Offenbar bestand die Absicht, eine ehrengerichtliche Entscheidung ${ }^{3}$ anstelle des Duells zu setzen. Die Absicht blieb allerdings erfolglos: wenn die Streitenden zu erkennen gaben, daß sie "bei dem Ausspruch des Ehrengerichtes wegen der eigenthümlichen Verhältnisse des offizierstandes sich nicht beruhigen zu können" glaubten, waren die Verhandlungen zu schließen und die Kontrahenten auf die strafen des Zweikampfes aufmerksam $z$ machen. In den weitaus mei-

"I'administration de la Bibliothèque impériale de Saint-PEtersbourg nous informe que les seuls ouvrages sur le duel en Russie possédes par cet établissement sont les suivants: "Ies Duels", par G. L. E. Saint-Pétersbourg, 1837. "Ie Duel et la Cour de cassation", par A. Lochwitsky. Sait-Pétersbourg, 1858. - (Ce travail est un tirage á part des "Annales de la patrie", Ir. 10,11, 12 de l'année 1858.) La brochure toute récente ce Seversky: "Osobennaja Cast russkago ugolovnago prava". Cette liste ne contient aucun ouvrage relatif aux regles du cuel." (Croabbon, S. 26)

${ }^{2}$ igl. dazu A. v. Boguslawski, "Ehre und Duell", s. $59 \mathrm{ff.}$ 3as Ehrengericht konnte erkennen auf: "Freisprechung; eine Warrung; Entlassung aus dem Dienst; Entfernung aus dem offizierctande; Verlust des Rechts, die Un'orm zu tragen... auf Entlernung aus dem Wohnort...". 
sten Fällen kam es zum Zweikampf. - In den Verordnungen vom Mai 1874 war der Gedanke aufgegeben, "durch den ehrengerichtlichen Spruch das Duell zu ersetzen oder einzuschränken." Bei Ehrenstreitigkeiten hatten die Offiziere nun ihren Ehrenrat ${ }^{1}$ zu informieren. Der Ehrenrat erstattete dem Kommandeur Meldung und unternahm einen Versöhnungsversuch. Falls dieser miBlang, hatte er dafür Sorge zu tragen, daB die "Bedingungen des Zweikampfes zur Schwere des Falles in keinem MiBverhältnis" standen. A. . Boguslawski betont ausdrücklich, daß weder Ehrenrat noch Ehrengericht ein Duell anordnen konnten. Die Entscheidung für oder wider den Zweikampf 1 ag letztlich bei den Kontrahenten.

Analog zu diesen Verordnungen wurden im Jahre 1894 in der rugsischen Armee Ehrengerichte eingefubrt, die aber - und hierin lag ein wesentlicher Unterschied - auf Duell $z$ w a $\mathbb{B}$ erkannten. ${ }^{2}$ otto $v$. Schulmann bemerkt dazu: "Während die Tendenz aller modernen Strafgesetzbücher dahin geht, den Zweikampf unter Strafe zu stellen und seiner Verbreitung nach Möglichkeit vorzubeugen, tritt uns in der Militärgesetzgebung RuBlands der Duellzwang als gesetzlich anerkanntes Rechtsinstitut entgegen. Andere Staaten haben es vorgezogen einen komplizierteren Weg einzuschlagen: eine gesetzliche Anerkennung des Duellzwanges wurde abgelehnt, dem praktischen $\mathrm{Zwang}$ dafur aber der weiteste spielraum gestattet." 3

In den russischen Gesetzbuichern endete die Geschichte des Zweikamples so abrupt, wie sie begonnen hatte. In der Großen sowjetenzyklopädie steht $z$ lesen: "Das sowjetische Strafrecht enthält keine Paragraphen zum Duell, weil das Duell ein Begriff

${ }^{1}$ Durch die Wahl des Offizierkorps bestand der Ehrenrat "aus 1 Hauptmann, 1 Premier- und 1 Sekondlieutenant...".

2" 13 maja 1894 byli izdany 'Pravila o razbiratel'stve ssor, slucajułcichsja v oficerskoj srede'. Pravila podXerkivali objazatel'nost' D. dlja oficerov, esli sud obscestra oficerov scital èto neobchodimym. Otkaz ot D. vlëk uvol'nenie so sluzby. Pravila 1894 byli podtverzdeny zakonom 21 janv. 1912.": Bol' Saja Sovetskaja Enciklopedija, Bd. 15 (1952), S. 321. 30. v. Schulmann, "Duell und Strafgesetz", S. 55. 
ist, der der sozialistischen Moral fremd ist." 1 Zieht man die eigenartige Ausformung des Duells auf russischem Boden in Betracht - wie sie aus der zitierten Duelliteratur hervorgeht drängt sich indes die Frage auf, ob das Duell nicht schon fur die vorrevolutionäre Moral ein Fremdkörper war.

1 bd. - In der neuesten Ausgabe der Großen Sowjetenzyklopädie vird auf das Duell nur noch in einigen wenigen zeilen eingeCangen. Die kurze Erläuterung der historischen Bedeutung des Iuells und die Angaben zur Etymologie von "duél" " sind ungenau und unrichtig. Vgl. Band 8 (1972), S. 557. 
II ZUR UN'TERSUCHUNG DES DUELLS IN DER RUSSISCHEN LITERATUR: THEORETISCHES FUNDAMENT UND IEETHODE

Viele der reichen und müBigen Adligen im RuBland des 18. und 19. Jahrhunderts waren zugleich Schriftsteller: es ist somit nicht verwunderlich, daB das Duell in der russischen Literatur reichen Niederschlag Pand. ${ }^{1}$ Von Interesse ist nun die Frage nach der küntlerischen Auseinandersetzung mit dem Duell: sehen Turgener und Tolstoj diese Einrichtung noch mit den gleichen Augen wie Pułkin und Lermontov, die im Duell den Tod fanden? Wie stellen sich Dostoevskij und Čechov in den siebziger und achtziger Jahren zum Zweikamp als aristokratischer Form der KonPliktlösung? Um die Bedeutungswandlungen des Duells in der russischen Gesellschaft von ca. 1830 bis ins 20. Jahrhundert aus der kritischen Sicht ${ }^{2}$ bedeutender Repräsentanten dieser Gesellschaft möglichst klar hervortreten zu lassen, soll vorliegender Untersuchung als theoretisches Fundament die Institutionenlehre Arnold Gehlens zugrunde gelegt werden, wie sie insbesondere in "Urmensch und Spätkultur" (Frankfurt a. M./Bonn, 1964) und "Anthro-

${ }^{1}$ Peter Brang ist der Ansicht, daß das Duell "in ihren Werken eine unvergleichlich gröBere Rolle spielt als etwa in der deutschen oder französischen Literatur." Vgl. seinen Artikel: Der Zweikampe im russischen Leben und in der russischen Literatur. In: Zeitschrift für Slavische Philologie 29 (1961), S. $315-345$.

2. Wegen der gebotenen Detailliertheit der Interpretationen können im Folgenden nur die für unser Thema repräsentativsten Werke im Blickzentrum stehen. Es geht also vornehmlich um jene Herke der russischen Literatur, die eine eigenständige Auseinandersetzung mit der Problematik des Duells aufweisen und zu deren Untersuchung und Beurteilung eine Analyse des Duells folglich Wesentliches beitragen kann. Nicht behandelt werden Duelidarstellungen unter der Einwirkung der französischen Aufklärungsliteratur (Fonvizin), relativ problemlose parodistische Duelldarstellungen (N. V. Gogol', A. Ja. Kul'Cickij), Werke, in denen das Dueil als eine Episode neben anderen $z u$ wenig Material für eine detaillierte Untersuchung bietet (vgl. $z_{j}$. B. I. S. Turgenevs Erzählungen "Bretër" und "Tri portreta") und die Dueliiteratur, die Peter Brang als "selbstverständiches Requisit der damaligen Erzählungsliteratur" bezeichnet: Werke von A. Bestužev-Marlinskij, F. V. Odoevskij, N. F. Pavlov u. a. Vgl. dazu in dem zitierten Artikel besonders die S. 328 und 3361 . 
pologische Forschung" (Reinbek bei Hamburg, 1961) dargelegt ist. Wehlen geht hier aus vom Menschen als instinktverlassenem Wesen. "Wenn es wahr ist, daB der Mensch...durch AuBenereignisse, durch meue Daten in seinem Verhalten bestimmbar ist, wenn es wahr ist, $d a B$ er in seinem Instinktbereich verarmt und verunsichert ist, dann wird ja sozusagen die Verfuhrbarkeit zu einem der Hauptmerkmale. Und nun ist bekanntlich diejenige Instanz, die Direktiven und Stabilisationskerne im Menschen setzt, die mit dem wort Moral bezeichnete, deren Sinn darin besteht, die Sicherheit und Unstörbarkeit des Verhaltens auf einer gegenseitigen Vertrauensbasis zu garantieren. Dabei hat sich...gezeigt, daB die In $s$ i $t u t i \circ n$ e $n$ einer Gesellschaft, ihre Einrichtungen, Gesetze und Verhaltensstile...als $A$ u $B$ e $n$ $s$ i $t z$ e $n$, als Halt gebende Verbindungsstücke zwischen den Menschen funktionieren, daB sie erst die Innenseite der Moral zuverlässig machen." ("Anthropologische Forschung", S. 23 f.) Gehlen beschreibt die Institutionen als helfende Fiktionen: "Die Formen, in denen die Menschen miteinander leben oder arbeiten, in denen sich die Herrschaft ausgestaltet oder der Kontakt mit dem tbersinnlichen - sie alle gerinnen zu Gestalten ei-

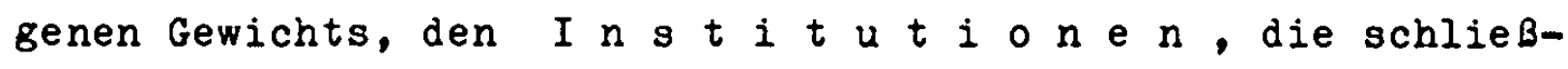
lich den Individuen gegenüber etwas wie eine Selbstmacht gewinnen, so dab man das Verhalten des einzelnen in der Regel ziemlich sicher voraussagen kann, wenn man weiB, von welchen Institutionen er eingefaBt ist." (ebd., S. 71)

Zur Definition des im Untertitel unserer Arbeit verwandten Begriffs "Ritus" vgl.: International Encyclopedia of the Social Sciences, Bd. 13, Ed. David L. Sills (USA 1968), S. 520 P.: "...rite (ritual), ceremony (ceremonial), and custom (customary)...have been used interchangeably to denote any noninstinctive predictable action or series of actions that cannot be justified by a rational means-to-ends-type of explanation..." und: G. Hartfiel, "Wörterbuch der Soziologie" (Stuttgart, 1972). Hartfiel definiert "Ritual" als eine "expressiv betonte Handlung mit groBer RegelmäBigke1t des Auftretens in gleicher Situation und mit immer gleichen Ablauf. R-e sind zumeist traditionell 'festgefahren'. Beim Auftreten oder bei der Annähe- 
rung entspr. Situationen tendieren die Verhaltenspartner spontan bzw. ohne bes. Entscheidung $u$. ohne Nachdenken über Funktion $u$. damit 'Sinn' ihres Tuns zum R."

Im Folgenden wird die Bezeichnung "Duell" je nach Erfordernis: des Kontextes sowohl in der Bedeutung von "Ritual" als auch in der Bedeutung von "Institution" verstanden. Das Duell als Ritus" setzt das Duell als Institution voraus. Mit anderen Worten: die Institution "Duell", in der sich die Ehrenvorstellungen des3 Adels niederschlagen, verwirklicht sich jeweils in einem ganz bestimmten Ritus.

Hunderte von erlauchten Duellteilnehmern beweisen, daB das Duell in RuBland $z u$ einer bestimmten zeit bei einer bestimmten Schicht akzeptierte Verhaltensnorm war - eine Institution im Sinne Gehlens. Auch zur Frage der allmählich wachsenden Funktionsunfähigkeit dieser Institution können Gehlens Forschungsergebnisse herangezogen werden. Der unmittelbare Effekt des $A b-$ baus von Institutionen besteht nach Gehlen "in einer $v$ e r u n $s$ i he $r$ u $g$ der betroffenen Personen, und zwar bis in die Tiefe hinein: die Desorientierung ergreift die moralischen und geistigen Zentren, weil auch dort die Gewibheit des Selbstverständichen gestrandet ist." ("Anthropologische Forschung", S. 72)

Die Einsichten Gehlens werfen Licht auf die Behandlung des Duells in der russischen Literatur des 19. Jahrhunderts, auf die Analyse der zeitgenössischen Wirklichkeit durch den jeweiligen Künstler. - In den Werkanalysen der vorliegenden Untersuchung sind zwe1 Fragen von vorrangigem Interesse: wie steht es um die Güligkeit der Institution "Duell" in dem jeweiligen literarischen Kontext - und welcher Art ist die rituelle Gestaltung des Duells. Wie sich zeigen wird, ist die Abweichung von den Riten traditioneller und bekannter Duell-Kodizes noch kein Anzeichen für eine grundsätzliche Unverbindlichkeit der Institution "Duell". Erst der Verfall des Ritus läbt den Verpall der Institution erkennen.

Die genannten Schwerpunktfragen werden nicht isoliert behandelt. Die Umstände, die zum Duell fuhren und das Duell selbst sind jeweils in eine Gesamtinterpretation des Werks eingebettet. 
Jedes einzelne Diell gelangt erst durch seinen Hintergrund und seine stellung in eirem bestimmten Handlungsrabmen zu voller bedieutungsmäBiger Geltung - so wie das Werkganze durch die Besondierheiten des Zweikampfes wesentliche Akzente erhält.

DaB der eigentümichen historischen Entwicklung des Duells auf russischem Boden ein besonders geartetes literarisches Duell entspricht, soll nach AbschluB der Werkanalysen in einer SchluBbetrachtung festgestellt werden. 
A. S. Puškin, "Der SchuB"

1. Es lst bekannt, daB Puskin in zahlrelche Duellaffairen verwickelt war und dab er im Zweikampe den Tod fand. ' In dreien seiner Werke findet sich eine künstlerische Stellungnahme zum Duellproblem. 2

"Der SchuB" ist die erste Erzählung im Rahmen der 1830 erschienenen "Geschichten des verstorbenen Ivan Petrovid Belkin". Obwohl "Der SchuB" nachweislich auf einem wirklichen Duellerlebnis Puskins beruht, ${ }^{3}$ schiebt Puskin in einem Vorwort Ivan Petrovic Belkin als den Autor aller Erzählungen vor und präsentlert sich selbst nur als Herausgeber. Jede Zeile des umständlichen Vorwortes läßt mehr und mehr den wirklichen Verfasser der Erzählungen vergessen, um in naiv anmutender Akribie auf das Leben und Sterben des angeblichen Autors Belkin einzugehen. Die komplizierte Art der Informationsbeschalfung luber Belkin - der Herausgeber wendet s1ch zunächst ohne Erfolg an die Erbin des Verstorbenen, diese empilehlt inn weiter an einen ehemaligen Freund Belkins, der einen ausfuhrlichen, vom Heraus-

${ }^{1}$ Vgl. V. Setschkaref1, "A. Puschkin" (1963), S. 15: "In Ki ̌iner nahm Puškin sein allzu lustiges Leben wieder auf. Es war in dieser Beziehung wie in Petersburg: e in lebhafter Freundeskreis und Gelage, Frauen, Streiche aller Art, Duelle.." und: "Die Duellust Puskins war schon immer erstaunilich gewesen und deutet auf einen krankhaften point d'honneur, der teilweise mit seinem ausgesprochenen Adelsstolz, teilweise mit seinem SelbstbewuBtsein als Dichter, inmitten einer nicht verstehenden Menge zusammenhängt." (ebd., S. 39) In dem Duell mit Georges d'Anthès am 27. Januar 1837 wurde Puskin so schwer verletzt, daB er zwei Tage darauf starb. Vgl. L. Grossman, "Puskin" (1960), S. 49111.

${ }^{2} \mathrm{Vgl}$. J. Thomas Shaw: Pushkin's 'The Shot'. In: Indiana Slaric Studies III (1963), S. 128: "The development of Pushkin's 1deas with regard to the duel, in his life and in his artistic works, might well make the subject of a separate study. In his mature works, Pushkin presents the incitement to a duel as morally reprehensible..At the same time, neither in life nor in his works did Pushkin countenance the idea of accepting a deliberate offenge...".

3.Wie der Grap im "SchuB" erschien Puskin zum Duell mit Zubor (im Frühahr 1822) Kirschen essend auf dem Rendezvous-Platz. 
gieber im Vorwort abgedruckten Brief schreibt, jedoch anonym bleibien möchte, was der Herausgeber wiederum naiv verständnisvoll kommentiert - und wiederholte Hinweise auf die Ehrenhaftigkeit a.ller im Vorwort genannten Personen sind um Wahrscheinlichkeit biemuiht. Diesen Eindruck verstärkt der anonyme Briefschreiber durch seine Bemerkung, Belkin habe immer den Wahrheitsgehalt der $v$ on ihm niedergeschriebenen Geschichten - die ihm selbst erzählt wurden - betont. Aus einer FuBnote des pedantischen Hera usgebers geht hervor, von wem Belkin welche Geschichte erfuhr: eigentümlicherweise werden nicht voll ausgeschriebene Namen angegeben, sondern Beruf oder Stand und die Initialen der entsprechenden Personen. So wurde "Der SchuB" von einem Oberstleutnant I. I. P. erzählt. Diese beiläufig in einer Fußnote gegebene Information erweist sich als der springende Punkt des komplizierten und in seiner Treuherzigkeit so unbedarft wirkenden Vorspanns: "Der Schuß" ist aus der Sicht eines Armeeangehörigen erzählt, dem die Duellproblematik vertraut ist. Wer mit dem Bild des im Vorwort detailliert beschriebenen, schriftstellernden Gutsbesitzers Ivan Petrovič Belkin vor Augen ${ }^{1}$ an die Lektüre der Geschichte herangeht, wird böse überrascht!

2. Die der Geschichte vorangestellten Epigraphe aus der zeitgenössischen Literatur spielen auf Pistolenduelle an. Jedes Motto unterstreicht auf seine Heise die Normalität des Zweikamples: Baratynskijs "Wir'schossen uns" durch den lakonischen Ton, Marlinskijs "Ich schwor, ihn nach Duellrecht zu erschieBen..." durch die Bekräftigung des Institutionencharakters - man denkt an schriftlich fixierte Duellbedingungen und peinlich genaue Protokolle.

Dann beginnt der Ezähler - der bereits erwähnte Oberstleutnant - im ersten Teil der Geschichte den Hintergrund auszumalen,

\footnotetext{
${ }^{1}$ V. G. Belinskif hat sich vielleicht auch durch die Art des Vorwortes dazu verleiten lassen, die "Geschichten des verstorbenen Ivan Petrovið Belkin" herablassend als Märchen und Anekdoten zu bezeichnen, die man sich gemütlich beim Kaminfeuer erzähle. Poln. sobr. soč., Bd. 1 (1953).
} 
vor dem sich die zu berichtenden Ereignisse abspielen. Er tut damit noch nichts Besonderes, denn - so bemerkt er "das Leben eines Armeeoffiziers ist bekannt." 1 Der Erzähler berichtet also von dem eintönigen Leben des Regiments, das keinerlei gesellschaftliche Zersteuung bietet, in dem es nichts als offiziersuniformen $z u$ sehen gibt. Vor diesem absolut grauen Hintergrund hebt sich jede Besonderheit scharf $a b$, und damit ist der Erzähler schon bei der Beschreibung des einzigen Zivilisten inmitten von Militärs angelangt. Es handelt sich um jemanden, der Russe zu sein scheint, aber einen ausländischen Namen trägt (den der Leser nicht erfährt), und der vom Erzähler willkürlich Silvio genannt wird.

Mit der Charakterisierung dieses Silvio läßt Puškin seinen Erzähler den dämonischen Modetyp der Romantik, den Byronschen

${ }^{1}$ A. S. PuYkin, "Sobr. sot. v 10 tt.", Bd. VI (1950), S. 85. Alle Zitate stammen aus dieser Ausgabe. -

Jan van der Eng verweist auf die literarische Tradition, die Puskin verarbeitet: "Dans $L e$ c o u $p$ d e p i s tol $\mathrm{l}_{t}$ Puškin joue avec des procédés littéraires qui sentent Byron, Davydor et Marlinskij. Le debut de la nouvelle montre beaucoup de details dans le genre de Davydov: le bivouac des hussards, le champagne qui coule à flots chez Sil'vio. Les premiers renseignements sur le passé du héros orientent le lecteur sur des exploits à la Davydor: 'Autrefois il avait servi dans les hussards et avec succès'. Mais en même temps sa situation fait penser plutôt à celle d'un byronien. Ce sont les signes de sa superiorité qui encitent à cette comparaison: sa morosité taciturne, son caractère rude...la sugestion de son audace impitoyable, de duels meurtriers." Les récits de Belkin, Analogie des procédés de construction. In: The Tales of Belkin by A. S. Puskin, Dutch Studies in Russian Literature 1 (1958), S. 11. 
Helden ${ }^{1}$ darstellen: Silvio ist ein Mann mit geheimnisvoller Vergangenheit, niemand weiB, warum er sich beim Regiment aufhält, niemand wagt, danach zu fragen. Man vermutet in seiner vergangenheit ein Duell mit unglücklichem Ausgang, denn Silvio hat es in seiner Lieblingsbeschältigung, dem Pistolenschießen, zu solcher Meisterschaft gebracht, dab die offiziere von einer "unglaublichen" und "schrecklichen" Kunst sprechen. (S. 86)

Auch Silvios äußere Erscheinung entspricht dem dämonischen Klischee der Romantik: er ist düster, bleich, hat funkelnde Augen, ist schwarz gekleidet und wird vom Erzähler einmal so-

${ }^{1}$ Zur Charakteristik und Herkunft dieses Helden vgl. A. Hauser, "Sozialgeschichte der Kunst und Literatur" (1972), S. 735 f.: "Der Byronsche Held, dieser späte Nachfolger des fahrenden Ritters...beherrscht die literatur des ganzen 19. Jahrhunderts und treibt noch in den Kriminal- und Gangsterfilmen unserer Tage sein Unwesen... Auf dem Wege von Lazarillo de Tormes zu Humphrey Bogart bezeichnet der Byronsche Held nur eine 2wischenstation. Der Schelm war schon lange vor Byron zum ruhelosen Wanderer geworden...zum ewigen Fremdling unter den Menschen, der sein verlorenes Glück suchte und nicht fand, zum bitteren Menschenhasser, der sein Schicksal mit dem Stolz eines gefallenen Engels trug. Alle diese Momente waren bereits bei Rousseau und Chateaubriand vorhanden, neu an dem von Byron gezeichneten Bild sind eigentlich nur die dämonischen und narziBtischen Züge. Der romantische Held, den Byron in die Literatur einfuhrt, ist ein mysteriöser Mann; in seiner Vergangenheit.ist ein Geheimnis, eine furchtbare sünde, ein verhängnisvoller Irrtum oder ein nicht wiedergutzumachendes Versäumnis. Er ist ein Geächteter.... Es geht Verdammnis und Verderben von ihm aus. Er ist schonungsios gegen sich und erbarmungslos gegen andere...". -

Vgl. auch M. Praz, "Liebe, Tod und Teufel" (1963), Kap. II, Die Metamorphosen Satans, S. 56 f.: "Rebellen großen Stils, Enkel von Miltons Satan und Brüder von Schillers 'Räuber' beginnen die malerischen, gotisch stilisierten Hintergrinde der englischen Schauerromane gegen Ende des 18. Jahrhunderts zu bevölkern. Diese Banditen in Kleinformat, die in den Landschaftsbildern im Stile von Salvator Rosa, wie sie damals Mode waren, ein anmutiges Dekorationsmotiv bildeten, belebten die Bücher der Anne Radcliffe... und nahmen gigantisch-satanisches AusmaB an...". - Von Byron sagt Praz, er habe den Typus des Rebellen, "des fernen Nachkommen von Miltons Satan", zur vollendung gebracht. 
gar als dem leibhaftigen Teufel ähnlich empfunden. (S. 90 ${ }^{1}$ Allein aufgrund dieses ÄuBeren - so bemerkt der Erzähler - hätte man Silvio nie für feige gehalten, obwohl er sich nicht an den üblichen Duellunterhaltungen beteiligte. Diese Bemerkung bedeutet für den Hintergrund der Erzählung:

a) für jeden normalen Offizier gehört das Duell in Theorie und Praxis zum Alltag, andernfalls hält man ihn für feige;

b) sich nicht zu duellieren, feige zu sein, ist in den Augen der jungen offiziere verächtlich. (Der Altersunterschied zwischen Silvio und den Offizieren wird zu Beginn der Erzählung betont: sie halten den Dreibigjährigen schon für einen alten Mann.)

3. Der Leser wartet nun mit Spannung darauf, daB es im 2usammenhang mit der soeben vorgeführten dämonischen Gestalt Silvios zu irgendeinem Ereignis kommt. "Eines Tages..." - so beginnt der Erzähler den zweiten Kreis zu ziehen um den im Titel angekündigten SchuB - eines Tages treffen zwei besondere Umstände zusammen. Zunächst läßt Silvio sich beim üblichen Gelage und iiblichen Kartenspiel in der Offiziersrunde zum Mitspielen uiberreden, obwohl er das Kartenspiel als potentiellen AnlaB zu Konflikten im Allgemeinen meidet. (Wenn er einmal an einem Spiel teilnimmt, ist er darum bemüh, jeden Streit im Keim zu ersticken. Der Leser erfährt später, daß dieses Verhalten Silvios nicht auf philanthropische Motive zuruckzuführen ist.) Der zweite auBergewöhnliche Umstand ist die Anwesenheit eines erst küzlich zum Regiment hinzugekommenen offiziers, der in den Umgang mit dem geheimnisvollen Silvio noch nicht einge-

${ }^{1} \mathrm{Vgl}$. zwei Helden aus Byrons Romanzen: Der Giaour ist blaß, seine Augen blitzen, er hat eine geheimnisvolle Vergangenheit und erinnert an einen gefallenen Engel: "If ever evil angel bore/ The form of mortal such he wore...". In: "Works of Lord Byron in Four Volumes" (1823), Bd. 2, S. 252.

Der Korsar ist ebenfalls blaß, niemand tritt inm zu nahe: "Too close inquiry his stern glance rould quell..."; ebd., Bd. 3, S. 16. - Alle Zitate stammen aus diesen Bänden. 
weint ist. Durch ein MiBverständnis kommt es zu einer handgreifIichen Beleidigung Silvios. Was nun alle Anwesenden (und der durch den bisherigen Erzählungsverlauf in seiner Erwartung geIenkte Leser) voraussehen - die Forderung nach Genugtuung im Duell - tritt nicht ein. Die Reaktion der Offiziersjugend zeigt eindeutig, daB die Institution "Duell" in diesem Kreise stabil ist: sie weist die wesentlichen Merkmale einer Institution nach Arnold Gehlen auf, an dessen Thesen nun erinnert sei:

a) Das Verhalten des einzelnen kann ziemlich sicher vorausgesagt werden, wenn man weik, von welchen Institutionen er eingefabt ist;

b) Institutionen greifen bis in die Wertvorstellungen und Willensentschlüsse durch, diese verlaufen dann "mit der Uberzeugungskraft des Natürlichen." 1

Diese Thesen erhellen das Verhalten der offiziersgemeinschaft:

a) Niemand zweifelt daran, daB Silvio den Beleidiger zum Duell herausfordert; ${ }^{2}$ dieser ist bereit, Genugtuung zu leisten. Jedermann ist erstaunt, daß der Beleidiger am Leben bleibt und Silvio sich mit einer Entschuldigung begnügt;

b) da Silvio nicht erwartungsgemäß handelt, wird er von der Jugend für feige gehalten, verachtet und gemieden. Nur dadurch, daB man Silvios konziliantes Verhalten allmählich wieder vergibt - wie eine schlechte Tat, über die Gras wächst - kann er seinen gesellschaftlichen Einfluß zurückgewinnen.

Bis zu diesem Zeitpunkt hat PuSkin in seiner Erzählung einen bestimmten Gesellschaftkreis gezeigt, in dem entsprechend einer spezifischen Vorstellungswelt agiert und reagiert wird. In Vorbereitung auf das noch zu Erzählende hat er dem Leser damit Maßsiäbe für das "Normale" in die hand gegeben. Der angekündigte Schuß ist ja immer noch nicht gefallen, und der Erzähler

\footnotetext{
"Vgl. A. Gehlen, "Anthropologische Forschung" (1961), s. 711 . 2 Angesichts von Silvios Schießkunst rechnet jeder sogar mit dem Tod des Beleidigers. (Im zwanzigsten Jahrhundert liest sich die lässige Erörterung einer zu erwartenden baldigen Vakanz im offizierskorps makaber, vgl. S. 88.)
} 
rückt jetzt in einem dritten Kreis der Geschehnisse dem Zentrum näher.

4. Wiederum wird durch den Zusammenfall zweier besonderer Tatbestände der Gang der Erzählung vorangetrieben.

Einmal hat der Erzähler als einziger Silvio nicht verziehen, auf eine Ehrenrettung im Duell verzichtet zu haben. Da er Silvio besonders bewunderte, ist seine Verachtung umso tiefer was Silvio sehr bedruckt.

Zum zweiten erhält Silvio einen Brief, dessen Siegel er ungeduldig und mit glänzenden Augen erbricht. Ohne Angabe von Grüden kündigt er seine Abreise an und lädt die Offiziere des Regiments $z$ einem Abschiedsessen ein. Ganz besonders eindringlich besteht er auf dem Besuch des Erzählers. Aus diesem Grund erwartet der Leser mit Spannung die Aufklärung des Geheimnisses un silvio.

5. Die Enthüllung dieses Geheimnisses bekommt - der dämonischen Gestalt Silvios gemäB - einen etwas schaurigen Rahmen: die nackten, von vielen Schiebübungen durchlöcherten Wände von Silvios Wohnung, in der der Erzähler nach dem Fortgang der Gäste allein mit Silvio zuruickbleibt. Die Rolle des Erzählers übernimmt jetzt Silvio. Düster, bleich und mit glühenden Augen wirkt er auf seinen ehemaligen jungen Verehrer schon vor jeglicher Erklärung so unheimlich - "ich saß mit gesenktem Kopp da und schwieg" S. 90) daB der Leser seinem Werben um Verständnis kaum Chancen einräumt. Silvios erste Eröffnung, er habe auf ein Duell mit seinem Beleidiger verzichtet, um sein Leben keiner Gefahr auszusetzen, vergrößert die Distanz: "Ich sah Silvio erstaunt an. Ein solches Bekenntnis brachte mich völlig aus der Fassung." (s. 91) Lag doch die ehrenreinigende Kraft des Duells ${ }^{1}$ gerade

\footnotetext{
"Im "Duellbuch" von Kufahl und Schmied-Kowarzik (1896) heiBt es unter Hinweis auf die gerichtlichen Zweikämple des Mittelalters: "Der ubertragene Begriff der Reinigung hat...seine Quelle in jener Zeit. Man reinigte sich durch einen Eid von einem Verdachte, einer Beschuldigung, und da der Kampl an Stelle des Eides trat, waren beide Reinigungsmittel (Purgatio vulgaris, der gerichtliche Zweikampl, Purgatio canonica, der Reinigungseid)." (s. 208)
} 
darin, daB man sein Leben aufs Spiel setzte in einem Kampl mit tödlichen Waffen! ${ }^{1}$ Der Erzähler erfährt dann, warum Silvio um sein Le ben so besorgt ist, daB er Kartenspiel, Streitigkeiten und Duellen aus dem Wege geht: sechs Jahre zuvor, in der Zeit seines draufgängerischen Lebens als Husar, als Duelle für ibn an der Tagesordnung waren, hatte Silvio aus Neid und Eifersucht einen gesellschaftlich erfolgreicheren Kameraden durch fortgesetzte Beleidigungen zum Duell provoziert. Den SchuB seines Kontrahenten beantwortete er jedoch nicht mit einem Gegenschuß, sondern brach das Duell plötzlich ab. Die lässige Haltung seines Gegners, der Kirschen essend dastand und ihm die steine entgegenspuckte, minderte Silvios langersehnte Genugtuung darüber, das Leben des Todfeindes in der Hand $z u$ haben. Er bat darum, seinen SchuB $z u$ einem beliebigen späteren Zeitpunkt abgeben zu dürfen. ${ }^{2}$ - Der

${ }^{1}$ Alle Duellkodizes (besonders der von $G$. Hergsell) betonen, daB nur ein Duell unter Einsatz des Lebens mit $t \ddot{o} d i \mathrm{c}$ b e $n$ Haffen als solches anzuerkennen ist.

${ }^{2}$ Bei dem sechs Jahre zuruickliegenden Duell zwischen Silvio und dem Grafen handelt es sich um ein "Pistolenduell mit festem Standpunkte". Laut Kodex von G. Hergsell (der die Kodizes des Grafen Chateauvillard, des Grafen du Verger Saint-Thomas, von A. Tavernier und A. Croabbon berücksichtigt und von dem kürzer gefabte Kodizes wie der von Kufahl/Schmied-Kowarzik oder i. v. Wedel nicht abweichen) darf die Entfernung zwischen den beiden Standplätzen 15 bis 35 Schritte betragen. Die hier abgemessene Distanz von 12 schritten ist regelwidrig und läBt das Duell bereits unter die Ausnahmeduelle fallen. Doch wird nicht nur in diesem Punkt gegen die Konvention verstoßen. Normalerweise durften die Duellanten ke in Wort wechseln, der GegenschuB hatte innerhalb von einer Minute zu erfolgen, der Kampf durfte nur aus triftigem Grund und nur von den sekundanten unterbrochen werden (Silvio hat drei, der Graf einen Sekundanten mitgebracht). Die Ohrfeige, die Silvio bekommen hat, gilt als Beleidigung 3 . Grades und gibt ihm das Recht auf Waffenwahl, Duellartwahl und Bestimmung der Distanz. Entgegen konventionellen Regeln erhält Silvio auch das Recht auf den ersten Schuß - auf den er verzichtet, um eine möglichst ruhige Hand $z u$ bekommen. Daß der Graf Kirschen essend auf dem Kamplplatz erscheint und allen Launen Silvios nachgibt (den ersten SchuB durch Los zu bestimmen, das Duell nach seinem SchuB abzubrechen), zeugt von seinem völligen Desinteresse an diesem Zweikampf. - Der Graf vergibt den 2wischenfall auch - wie seine tberraschung im zweiten Teil der Erzählung beweist, während sich in Silvio der "böse Gedanke" (S. 93) an Rache festfriBt und ihn sechs Jahre lang beschäftigt. 
Ezähler hört weiter, daß Silvios einziger Lebensinhalt seit secins Jahren darin besteht, einen geeigneten Zeitpunkt abzuwarten, um mit dem noch ausstehenden SchuB seine Rache zu befriedigen. Als geeigneten Zeitpunkt sieht Silvio den Tag an, an dem sein Gegner um sein Leben mehr füchtet, als beim ersten $J_{\text {uell. Diesen }}$ Zeitpunkt hält er mit der bevorstehenden Heirat des Kontrahenten fuir gekommen.

In dem Duell, dessen Fortsetzung Silvio jetzt winscht, geht es nicht mehr primär um Ehrenrettung - das wäre ein Duell im Einklang mit der Konvention. Silvio sieht das Duell nicht nur als das von der Gesellschaft sanktionierte und erwartete Mittel zur Bereinigung von Konflikten und zur Wahrung der persönlichen Ehre, sondern er möchte als erster in jeder Gruppe, als der er sich von Jugend auf gefühlt hat (S. 91 f.), bei einem Duell seine stark ausgeprägte persönliche Eitelkeit befriedigt sehen: der Gegner muß Todesangst zeigen, sonst setzt Silvio sich über die Institution "Duell" hinweg. Wie anomal diese Auffassung vom Duell ist, läßt sich wieder aus der Reaktion des zuhörenden Erzählers entnehmen: "Sonderbare, widerspruchsvolle Gefühle bewegten mich." (S. 94) Der Erzähler, dem als Offizier das Duell als Plattform zur Lösung von Konflikten selbstverständlich ist, findet die Haltung Silvios nicht selbstverständich. Er vergleicht Silvio mit einem Tiger, der in seinem Käfig hin- und hergeht: mit diesem Vergleich belegt er nicht seinesgleichen, sondern jemanden, den er für den Gefangenen seiner Rachevorstellune - und deshalb für gefährlich hält.

An diesem spannungsreichen Höhepunkt des ersten Teils der Geschichte fährt Silvio in Verfolgung seines Ziels davon. ${ }^{1}$ Der

${ }^{1} \mathrm{~J}$. van der Eng weist daraue hin, daß sich Silvio hier von einem Byronschen Helden unterscheidet: "Si tout comme un heros byronien, Sil'vio est obsedé par le desir de se venger, il n'est pas superieur l'homme sans moeurs et sans réligion \& Byron. Son projet de vengeance, tel qu'il l'explique a l'interlocuteurnarrateur, montre plutôt son inferiorite vis-à-vis de son antagoniste: sa vengeance semble inspiré du ressentiment de ne pas posséder les avantages intellectuels et sociaux de son rival." In: Les récits de Belkin. Dutch Studies in Russian I1terature 1 (1958), S. 13. 
Leser weiB nun, was für ein Schuß es ist, der da noch aussteht.

6. Zwischen dem ersten und zweiten Teil der Geschichte liegen füf Jahre. Der Erzähler hat das Offiziersleben mit einem bescheidenen Dasein auf dem Lande eingetauscht. ${ }^{1}$ Mitten in seiner Beschreibung der Eintönigkeit und Langeweile des Landlebens bringt Puskin sich in einer Fußnote als den pedantischen Herausgeber dieser Belkingeschichte in Erinnerung: er gibt weitere Bemerkungen des Erzählers an, die dieser in einer Erstausgabe der Geschichte zu seinem langweiligen Tagesablauf gemacht haben soll. Dieses geschickt eingebrachte Spannungstief dauert indes nicht lange. Mit der Erwähnung reicher Gutsnachbarn, die nach langer Abwesenheit zurückerwartet werden, weckt der Erzähler im Leser wieder neugierige Erwartung. Der erste Besuch des Erzählers bei seinen reichen Nachbarn bringt ihn in eine etwas märchenhafte Situation: er wartet in einem prunkvollen Arbeitszimmer, die Tür geht auf, herein kommt ein schöner, freundlicher Graf, gefolgt von einer schönen Gräfin. Der Erzühler ist verwirrt und verschuichtert. Seine Schüchternheit ist notwendig, damit der Faden der Geschichte wieder aufgenommen werden kann: der Erzähler geht, um seine Schüchternheit zu überwinden, im $Z i m m e r$ auf und $a b$ und entdeckt plötzlich ein Bild mit zwei Kugeleinschüssen. Er verliert seine Schüchternheit und kommt als ehemaliger offizier unwillkürlich auf den besten Schützen zu sprechen, den er je gekannt hat: Silvio. Der Name wirkt elektrisierend auf den Grafen und seine Frau. Der Leser spürt, daß er nun an das Zentrum der Geschichte herangekommen ist. Ein paar Fragen und Antworten machen klar, daß der Graf Silvios ehemaliger Kontrahent ist - der Graf bezeichnet das durchschossene Bild als Zeugnis ihrer letzten Begegnung. Nicht nur seine Worte, sondern auch die wachsende Erregung, die sich seiner und der Grälin bemächtigt, lassen ahnea, daß es sich um eine außergewöhnliche Begegnung gehandelt hajen muB.

${ }^{1}$ DaB der Erzähler und - wie sich im weiteren Verlauf der Erzahlung zeigt - Silvios ehemaliger Kontrahent, der Graf, nach einer duellierfreudigen Periode in jungen Jahren ruhige Gutsbesitzer werden, macht den rachelüternen Silvio zum Sonderling. 
7. Puškin legt Silvios letztes Auftauchen um des unheimlichen Eindrucks willen auf einen Abend. ${ }^{1}$ Es wird so eingerichtet, dab der Graf nach einem abendlichen Ausritt allein, vor seiner Frau, nach Hause kommt, wo inm ein unbekannter Besucher gemeldet wird, der im dämmerigen Arbeitszimmer wartet, dessen Gesicht von einem Bart bedeckt wird und aus dessen Seitentasche eine Pistole ragt. Als der Graf seinen Besucher erkennt, reagiert er wie auf eine Gespenstererscheinung: er schreit auf, und die Hare stehen ihm zu Berge. (S. 99) Sofort und ohne Kommentar miBt er zwölf Schritte $a b$ und bittet, den ausstehenden SchuB schnell, vor der Rückkehr der Gräfin, abzugeben. Auf die zweimalige Bitte um rasches Handeln reagiert Silvio jedoch betont zögernd er weidet sich an der Nervosität seines Gegners, bittet um Licht, zielt, läßt die Hand wieder sinken, besteht schlieblich mit zynischen Worten auf einer Wiederholung des $g$ a $n z$ e $n$ Duells und inszeniert mit nochmaligem Loswerfen um den ersten Schuß ein zeitraubendes Spiel mit Leben und Tod, dem der Graf

${ }^{1}$ Den letzten Teil der Geschichte erzählt der Graf. Zur Erzähltechnik Pußkins sagt B. Ejchenbaum in "O poézi1" (1969), S. 31: "...mit Hilfe feiner Kunstgriffe hält Pułkin den Lauf der Noveile auf... Bei einfacher Fabel kommt es so zu einem komplizierten Sujetbau. Den "SchuB" kann man auf einen einfachen Nenner bringen - die Geschichte des Duells Silvios mit dem Grafen. Aber Puskin schafft, erstens, einen Erzähler, dessen Person die Zerlegung der Novelle in zwei Entwicklungen und deren wechselseitige Verzögerung (Anfang des zweiten Kapitels) motiviert; zweitens wird die Novelle - neben dem Autor - von zwei Brzählem vorgetragen: von Silvio selbst und dem Gralen...Silvios Charakter spielt eine sekundäre Rolle, nicht umsonst wird am Ende nur noch nebenbei von seinem weiteren Schicksal berichtet. Die Besonderheit dieser Novelle liegt in inrer Gangart begruindet, in ihrer Entwicklung, in ihrer orientierung am Sujetbau." - Dieser rein formalistische Ansatz Ejchenbaums wird dem "Schuß" sicher nicht gerecht.

Zum Sujetbau sagt J. van der Eng m. E. richtig: "La legereté de la nouvelle n'exclut pas la profondeur. Par profondeur j'entends ici qu'aucun de narrateurs n'explique à fond la personalite de Sil'vio et qu'ensemble ils sont encore plus éloignés du fond de son être." In: Les récits de Belkin. Dutch Studies in Russian Literature 1 (1958), S. 65.

Die Schlußfolgerung van der Engs scheint allerdings zu einfach: "...je suppose tout simplement que Sil'vio ne peut pas tuer proidement un homme." (ebd., S. 81) 
sich merkwirdigerweise nicht entziehen kann. Er hat seine Sinne nicht mehr in der Gewalt- ("Der Kopf drehte sich mir", S. 100) - und gibt seinen SchuB wie unter hypnotischem EinfluB ab. Silvio erinnert wieder an Byronsche Helden, an den Giaour, in dessen Augen ein magischer Zauber liegt: "Oft will his Glance the gazer rue/ For in it lurks that nameless spell/ Which speaks, itself unspeakable...". (S. 249) Oder - als er zum zweiten llal auf den Grafen zielt und diesem ganz schreckIich erscheint - an den Korsaren: "And where his frown of hatred darkly lell/ Hope withering fled - and Mercy sigh'd farewe11!" (S. 17)

Der Leser erwartet, daß der entscheidende Schuß Silvios nun fällt, 1 doch es kommt nicht dazu. Die Gräfin stürzt zu Tode erschrocken ins Zimmer, und der Sinn des Duells erfült sich für Silvio darin, den Grafen und die Gräfin in verzweifelter Angst umeinander zu sehen. Silvio tut, was der Graf unter allen Umständen zu verhindern suchte: er zielt auf den Grafen im Beisein seiner Frau. ther die Wirkung ist er so befriedigt, daB

${ }^{1}$ D. Blagoj glaubt Silvios Verialten im Einklang mit dem Duellrecht. Vgl. "Masterstvo Pułkina" (1955), S. 234 f. Die Ereignisse in der Novelle stehen jedoch außerhalb jeden Duellrechts. GemäB dem Kodex von $G$. Hergsell kann ein durch $u n$ $v \circ r h$ e $r$ g e $s$ e $h$ e Umstände unterbrochenes Duell auf eine spätere stunde oder auf den nächsten $T$ a $g$ verschoben werden. Ein sechs Jahre später ohne Sekundanten fortgesetztes Duell ist regelwidrig - ebenso das abermalige Loswerfen um den ersten SchuB, da fur jede Beleidigung nur einmal Genugtuung verlangt werden kann. Jeder Kodex betont, daB Ausnahmeduelle abgelehnt werden können.

Im übrigen kann man wie $U$. Busch in seiner Auseinandersetzung mit D. Blagoj sagen: "Wir haben uns....an den Bericht des Grafen zu halten... und brauchen uns dabei nicht...auf das damals geltende Duell-Recht zu besinnen." (Puskin und Sil'vio. In: Slawistische Studien zum V. Internationalen SlawistenkongreB in Sofia 1963 (1963), S. 416)

Die Aussage von Pubkins "SchuB" wird in der Tat ohne Wissen un das auBerfiktionale Duellrecht klar. Eine Kenntnis der in den Kodizes fixierten Regeln $v e r d e t u l i c h t$ höchstens die Anomalität der Ereignisse im "SchuB". 
der schuB entfallen kann.' Silvio schieBt nur noch einmal spielerisch auf das Bild im Arbeitszimmer und verläBt die szene wie ein Gespenst: die Dienerschaft starrt ihn schreckerfüllt an und wagt nicht, ihn zurückzuhalten. Die Grälin liegt in Ohnmacht der Graf kommt erst nach Silvios Verschwinden wieder zu sich. Wiederum denkt man an Byrons Giaour: "On - on he hasten'd, and he drew/ My gaze of wonder as he flew:/ Though like a demon of the night/ He pass'd and vanish'd from my sight...". (S. 221) Die Gestalt Silvios ist unwirklich wie der SchuB, der der Geschichte inren Namen gibt. Sein Zweck war, Angst zu erzeugen, geschossen wird nicht. Seine Assoziation mit einer Bemerkung von Mario Praz, der die romantische Literatur unter dem Aspekt ihres erotischen Emplindens untersucht hat, zum mal du siècle liegt nahe: "...das spezifische Kennzeichen heiBt Sadismus." 2

8. Puگkin, dem die Institution "Duell" im Leben selbstverständlich war, stellt das Duell auch im "SchuB" als intakte Institution dar. Um zu zeigen, daB er diese Institution fur problematisch hält, geht er einen umständlichen Weg: der Oberstleutnant I. L. P. liefert einen realistischen Hintergrund, den der angebliche Autor Belkin, der behauptet hatte, die Geschichten seien zum $g r o ̈ B t$ e $n$ T e $i l$ wahr, mit Requisiten aus der zeitgenössischen Schauerliteratur belebt. Als Herausgeber dieser Verschmelzung von Realität und Dämonie figuriert ein pedantischer Pułkin. Der wirkliche Autor Puskin hat mit diesem Kunstwerk vorsichtig und versteckt formuliert, welchem MiBbrauch die Institution "Duell" bei Egoisten und Sadisten aus-

${ }^{1}$ In der sowjetischen Forschung ist der Verzicht auf den SchuB vielfach als Verzicht auf Rache gewertet worden. Vgl. $z$. B. D. Blagoj, "Masterstvo Puskina" (1955) oder A. Slonimskij, Masterstvo Puskina" (1963). Der letzte Satz der Geschichte hat dieselben Forscher in diesem positiven silvio noch einen heldischen Freiheitskämpfer sehen lassen. U. Busch weist in dem Forschungsbericht seines Aufsatzes (in: Slawistische Studien zum $V$. Internationalen Slawistenkongre $B$ in Sofia 1963) überzeugend nach, daB solche spekulationen vom Text her nicht gerechtfertigt sind.

2M. Praz, "Liebe, Tod und Teufel" (1963), S. 116. 
gesetzt sein konnte. Vielleicht sah Puskkin in der Möglichkeit zu ungestraftem grausamen oder sadistischen Handeln sogar das geheime Wesen der Institution "Duell".

Gegen Ende des neunzehnten Jahrhunderts war es einem Ambrose Bierce möglich, in seiner Erzählung "Die Mittelzehe des rechten Fußes" sehr of $f$ e $n$ zu schreiben: "Tie dün die Decke von 'Ritterlichkeit' war, unter der sich die Brutalität eines Sittenkodex versteckte, der solche Begegnungen möglich machte, werden wir noch sehen." 1

1A. Bierce, "The Middle Toe of the Right Foot", in: "Ghost and Horror Stories of Ambrose Bierce" (1964), S. 180. - Auch fur Bierce war das Duell noch eine persönliche Erfahrung: sein Sohn Day wurde 1889 in einem Pistolenduell eines Mädchens wegen getötet. In der erwähnten Kurzgeschichte geht es um ein Dueli mit Messern in einem dunklen Raum: ein zugespitzt formulierter Protest gegen die Institution "Duell".

Vgl. A. Kohut, "Buch berühmter Duelle" (1888), S. 49: "Ein amerikanisches Duell, von welchem man 80 oft liest, und bei dem die Duellanten sich ein Bein an einen Baum hätten anbinden lassen, um nicht davon laufen zu können, und dann mit Bowie-Hessern aufeinander losgehackt, bis sie sich gegenseitig...'aufgezohren' hatten, ist wohl nie vorgekommen und nur eine Variation eines Duells, welche Eugen Sue in seinem uberspannten Roman 'Ces enfants de l'amour' erzählte. 
A. S. Puškin, "Eugen Onegin"

1. Den 'Roman in Versen' "Eugen Onegin", an dem Puškin insgesamt acht Jahre - von 1823 bis 1831 - arbeitete, nannte er sein bestes Werk. ${ }^{1}$ Diese Wertung bezog sich sicherlich nicht nur auf sprachliche und stilistische Eigenheiten des Romans, auf die zeitgenössische Kritiker besonders eingingen. ${ }^{2}$

Da in "Eugen Onegin" - wie im "Schuß" - das Duell von besonderer Bedeutung ist, soll bei dem folgenden Versuch einer Antwort auf die Frage nach der Intention des Romans die Untersuchung der Haltung Onegins im Duell wesentliche Hilfe bieten.

2. Getarnt als Zitat aus einem (nicht existierenden) Brief, präsentiert in modischem Französisch und somit in seiner Schärfe gemildert, stellt das dem Roman vorangesetzte Motto ${ }^{3}$ praktisch schon eine Verurteilung des Helden dar: er ist eitel, gleichgültig gegen seine guten wie seine bösen Taten, d. h. amoralisch, und er ist richtiger Selbsteinschätzung in der Gesellschaft nicht fähig. Puskins Kunst besteht hier und in den folgenden Romankapiteln jedoch darin, das harte Urteil nicht hart auszusprechen, sonderm in spielerischem, ausgewogenen Nacheinander von Agieren und Reflektieren der einzelnen Personen, seinem ei-

${ }^{1} \mathrm{~V}_{\mathrm{gl}}$. den Brief Puškins an A. A. Bestužr vom 24. März 1825. 2 Eine besondere Idee, ein Anliegen Puškins, konnte man im "Eugen Onegin" nicht entdecken. Der Kritiker des "Moskovskif telegraf" verstieg sich sogar zu der Behauptung: "...der Dichter hatte überhaupt kein Anliegen, als er den 'Onegin' schrieb." Der "Syn otedestva" äußerte sich in ähnlicher Weise, vgl. "Puskin", Kollektivnaja monografija pod red. B. P. Gorodeckogo, N. V. Izmajlova, B. S. Mejlacha (1966), S. 417 - 436. Der "Moskovskij vestnik" hielt den Helden für ein "durch und durch gewöhnliches und nichtiges Geschöpf". Bestužer und Ryleev betrachteten Onegin als einen durchschnittlichen jungen Menscien der vornehmen Gesellschaft, vgl. S. $13-32$, ebd.

3"Pétri de vanité il avait encore plus de cette espèce d'orgueil qui fait avouer avec la même indifférence les bonnes comme les mauvaises actions, suite d'un sentiment de supériorité, peutêtre imaginaire": A. S. Pǔkin, Poln. sobr. sot. v desjati tt., Bd. V (1964).

Im Folgenden wird nur nach dieser Ausgabe zitiert. 
genen Hervortreten als Erzähler und dem Zurücktreten aller Romanfiguren in Passagen reiner Landschaftspoesie ${ }^{1}$ eine leidenschaftslose, aber sehr präzise Wertung sich herausbilden zu lassen. 2 Diese Wertung ist so unaufdringlich, daß nur ständig wache Beobachtung eine deutliche Konturierung der Romanfiguren feststellt. Wie der Leser an den Roman heranzugehen hat, wird in der ersten Strophe des ersten Kapitels nahegelegt. Diese Strophe, die die tberlegungen Onegins während der Heimreise zu seinem Onkel beinhaltet, ist nicht willkürlich aus ihrem eigentlichen Kontext, 51 strophen zu früh, dem Leser vor Augen gefuhrt: Onegin beginnt in scheinbar respektierlichem Tone des todkranken Onkels zu gedenken, evoziert dabei indes bei jedem literarisch gebildeten Russen seiner Zeit das Bild des Esels aus der Krylovschen Fabel, die mit fast den gleichen Worten anfängt. ${ }^{3}$ Nach dieser Doppelzüngigkeit zeigt der Rest der Strophe in amuisierendem Unterhaltungston die Diskrepanz wischen Onegins Denken und seinem Sprechen und Handeln. Dem Leser wird also eine Orientierungshilfe gegeben. Von der ersten Zeile des Romans an wird empfohlen zu bedenken, daß nicht alles so gemeint ist wie es gesagt wird.

3. Der Held, den Puškin dann vorstellt, scheint zunächst ein Allerweltsheld zu sein. Er verschmilzt mit der Gesellschaft, mit Pułkin (der selbst als Figur im Roman auftaucht), mit dem zeitgenössischen Leser, indem ihm ein Geburtsort gegeben wird,

\footnotetext{
${ }^{1} \mathrm{Vgl}$. Kap. 5, II Oder Kap. 7, I.

"Wie Ejchenbaum den "SchuB" - reduziert V. Šklorskij den "Eugen Onegin" in seiner Bedeutung auf die verwandten Kunstgriffe: "Das wahre Sujet des 'Eugen Onegin' ist nicht die Geschichte ron Onegin und Tatjana, sondern das spiel mit dieser Pabel." In: "OŁerki po poetike Puskina" (1969), S. 211. Auch hier muB 3 gesagt werden, daB reiner Pormalismus Pußkin nicht gerecht wird. Vgl. A. S. Pushkin, "Evgenij Onegin", the Russian text edited with introduction and commentary by Dmitry Cizerskij (1967), S. 210 :"Even later generations of Russians would not miss the parallel with the first line of Krylov's fable 'Ose $I$ i muzhik' (1819): 'Osel byl samykh chestnykh pravil'."
} 
der metonymisch fur "Gesellschaft" gebraucht wird: Petersburg. Der Held hat weiterhin die in der höheren Gesellschaft ubliche Erziehung durch "Madame" und "Monsieur" genossen. Diese namenlosen Titel sind ersetzbar - persönliche Kindheitserinnerungen Onegins werden nicht erzählt.

Onegin ist aber nicht nur repräsentativ für die Petersburger Gesellschaft, sondern er ist ein "Dandy" - ein europäischer Typ. ${ }^{1}$ therdruß und Kelancholie, die Onegin plagen, nachdem er das Leben in vollen zligen genossen hat, sind romantisches Allgemeingut. ${ }^{2}$ Wie Childe Harold möchte Onegin fremde Länder bereisen und sich so abwenden von dem, was das teben eines jungen Mannes seines Standes traditionellerweise ausmacht: Liebe, Kartenspiel und Duell. Pußkins allgemeine Charakterisierung dieses Helden läßt den damaligen Leser empfinden: Onegin ist um mit Lermontov zu sprechen - "ein Held unserer Zeit".

4. Noch bevor das erste Romankapitel abgeschlossen ist, wird jedoch sichtbar, daB Onegin den für ihn bereitgestellten Rahmen eines Vertreters der Petersburger Gesellschaft und Dandys der zwanziger Jahre nicht mit lebendigem Leben ausfullt. Eine erste Reserviertheit des Lesers Onegin gegenüber erzeugt Puskin bereits in den Strophen $V$ bis VIII durch seine Technik des Lobes an der falschen Stelle und der euphemistischen Umschrei-

1 pułkin sagt allerdings: "Wie ein Londoner Dandy a $\mathrm{n} g \mathrm{e} z$ o $g$ e $n$..." (Kap. 1, IV); er läßt Onegins Dandysmus in gewissen Außerlichkeiten erscheinen, denen der Dandysmus als Geisteshaltung, wie Baudelaire ihn beschreibt, nicht zugrunde liegt. Für Baudelaire ist der Dandysmus eine Art von Religion. Für deren Anhänger "sind alle äuBerlichen, komplizierten Umstände, denen sie sich unterwerfen, von der makellosen Toilette zu allen Tages- und Nachtzeiten bis zu den gefährlichsten sportlichen toungen, nur eine Gymnastik, dazu angetan, den Willen zu stärken und die Seele zu disziplinieren." In: "Charles Baudelaire in Selbstzeugnissen und Bilddokumenten", Rowohlts Monographien (1967), S. 64.

${ }^{2} \mathrm{Vgl}$. Canto I, Strophe IV von "Childe Harold's Pilgrimage": "But long ere scarce a third of his pass'd by/ Torse than adversity the childe befell/ He felt the fuliness of satiety/ Then loathed he in his native land to dwell/ Which seem'd to him more lone than Eremite's sad cell." 
bung: was Purkin als "glückliches Talent" Onegins bezeichnet, die Fühigkeit, alle Themen leicht anzutippen und im Ernstfall zu schweigen sowie die geschickte Handhabung lateinischer Floskeln - empeindet der Leser als Hochstapelei. Wenn Pußkin dre1 Strophen lang ein derartiges Bild Onegins aufbaut und zu Beginn der Strophe VIII gesteht, aus Zeitmangel nicht aufzählen zu können, was Onegin sonst noch alles wisse, bedeutet das dem inzwischen eingestimmten Leser: es gibt von keinen Kenntnissen Onegins zu berichten. ${ }^{1}$ Auf diese negative Bilanz in Bezug auf Onegins Wissen folgt eine mit den gleichen Kunstmitteln erreichte negative Beurteilung der Gefuhlswelt Onegins. Onegins "Genie" in der "Wissenschaft der zärtlichen Ieidenschaft" wird - visuell effektroll abgesetzt durch die Pünktchen der fehlenden Strophen IX und XIII/XIV - detailliert als Kunst der Verstellung beschrieben. Onegin hat also weder wahres Wissen noch wahres Gefül.

Puskin greift bel der Zeichnung der Hauptgestalt seines Romans auf einen Typus zurück, der im Leben und in der Iiteratur der Zeit Hode war. ${ }^{2}$ Er skizziert in den Strophen XIV 19. sogar eine verwand te Lebenshaltung des jungen Puskin und onegins in Bezug auf modische strömungen, ${ }^{3}$ macht aber die spezi-

${ }^{1}$ Pułkin moralisiert an keiner Stelle des Romans. Es bleibt dem Leser uberlassen, aus dem Handlungsablauf die Werteskala zu erkennen und den Tonfall des Dichters richtig auszunutzen.

${ }^{2} \nabla g 1$. im 1. Kap. die semantischen Felder "skuka" (naskulit', narodit' son, nadoest', zernut', utomit', bezdel'e, duserna¿a pustota, len'), "spilin" (chandra, toska, ugrjumyj, tomit'aja, tomny j) und "modan (modnyj, vkus, odezda, narjad, tualet, dandy, erant).

${ }^{3}$ Iie Romanfigur Puskin wird jedoch in wesentlichen Punkten von Cnegin abgesetzt. Puir Purkin ist die ländliche Stille Inspirationsquelie zu schöplerischer Arbeit (Kap. 1, LVI), Onegin langweilt sich auf dem Lande. Onegin ist $z u$ harter schriftstellerischer Arbeit nicht lähig (XIIII), sogar seine lektüre ist Iruchtlos (XIIV). Die standesgemäBe Verwandtschaft zwischen Cnegin und Puskin veranlaBt D. Blagoj zu der Feststeliung: "Dacurch erklärt sich auch die 'herzliche Liebe' des Dichters zu seinem Helden...der Dichter betont besonders angelegentlich die positiven Seiten Onegins... Edelmut, Stolz, Ehre..." " "Sociologija trorXestra puskina" (1969), S. 98. Blagoj berucksichtigt die Puskinsche Ironie nicht. Da er sein Augenmerk zu sehr euf die Klassenzugehörigkeit Onegins lenkt, entgehen thm die besonderen Eigenschaften eines negativen Vertreters dieser Klasse. 
fische - nicht modisch bedingte - Leere dieses Typus, die für die spätere Duellsituation von entscheidender Bedeutung ist, in einem frühen Stadium des Romans augenfällig.

5. Um Onegin in entscheidenden Situationen als handelnde Person sich profilieren zu lassen, wechselt Puskin den Schouplatz. Onegin wird durch den Tod seines Onkels als dessen Alleinerbe im zweiten Kapitel mit einer neuen - ländlichen - Umgebung konfrontiert. Zunächst ergibt sich ein Kontakt mit den benachbarten Gutsbesitzern, dann mit Lenskif, schlieblich mit den Larins.

Der Kontakt mit den Nachbarn bricht bald ab. Durch offene MiBachtung ihrer Umgangsformen beleidigt Onegin sie. Durch unkonventionelle, inm als Zeitvertreib dienende Maßnahmen in der Wirtschaftsfihrung ruft er ihr Mibtrauen hervor. Onegin gilt bald als nicht sehr ungänglich - Tatjana bestätigt das in ihrem Brief: "No govorjat, vy neljudim." (s. 70)

Die Bekanntschaft mit Lenskij beruht darauf, dab dem sentimentalen Poeten die prosaische Arbeit eines Gutsbesitzers Premd ist, dab ihn die an praktischen Problemen interessierte Unterhaltung der Gutsbesitzer ästhetisch nicht befriedigt. Der müBiggehende Onegin ist der einzige, der für Lenskif ein offenee Ohr hat. Die Rolle Onegins in dieser Freundschaft ist passiv: er hört nur $z u$, lächelt herablassend und versucht nicht einmal, seinen schwärmerischen Dlchterfreund immer zu verstehen. Eine wirkliche Bindung besteht nicht. ${ }^{1}$

Der Kontakt zu den Larins wird von Onegin weder bewuBt gesucht noch gepplegt. Er entsteht zufällig durch die vermittlung Lenskijs und beschränkt sich auf drei Besuche, die zu den entscheidenden Konflikten des Romans führen.

Der erste Besuch bei den Larins (3. Kap., Strophe III) soll

1 Puskin betont die eigentliche Hohlheit dieser Freundschaft in der abschließenden Coda der Strophe XIII (Kap. 2): "So werden die Ieute...durch MUBiggang Freunde."

Es ist oft auf die Sentenzhaftigkeit der beiden letzten Zeilen der Puskinstrophe hingewlesen worden, vgl. $z$. B. D. Tschižewskij, "Russische Literaturgeschichte des 19. Jahrhunderts" $(1964)$, S. 60 . 
reiner Zeitvertreib sein: Onegin folgt einer Zufallslaune und schließt sich Lenskij zu einem Besuch bei der Familie an. Der Besuch berihrt Onegin nicht weiter: die Strophe III bricht bezeichnenderweise nach der achten Zeile ab. Die wenigen Worte, die Onegin auf der Heimfahrt seinen Eindrücken bei den Larins widmet, sind eine Beleidigung für Lenskijs Gefühle ${ }^{1}$ und ein sehr abstraktes, im Konditional ausgesprochenes Lob für Tatjana: wenn er Dichter wäre wie Lenskij, würde er Tatjana wählen.

Der zweite Besuch bei den Larins erfolgt für Onegin nolens volens: er muß ein lästiges Zuviel an Kontakt abschütteln, das sich - von ihm ungewollt und nicht vorhergesehen - aus dem ersten Besuch ergeben hat: Tatjana hat sich in ihn verliebt und erwartet eine Antwort auf ihren Brief. Dies ist die erste persönliche Entscheidung, vor die der Leser Onegin gestellt sieht: doch sieht er ihn nicht im Kampf mit sich selbst vor einem Scheideweg, sieht ihn nicht für und wider argumentieren. Zur Schilderung seiner Reaktion reicht eine Strophe (Kap. 4, XI). Tatjanas ruhrendes Bild entsteht vor Onegin, ohne dab er etwas damit zu tun hätte, und vergangene Gefüle steigen kurz in inm auf, ohne daß Tatjana etwas damit zu tun hätte. Für den statisch in sich ruhenden Onegin bedeutet der Brief Tatjanas nicht Getroffensein und Entscheidung, sondern nur die Frage, wie die von vornherein feststehende Ablehnung am einleuchtendsten $z u$ formulieren ist. So entsteht die kalte Oneginsche Predigt (Kap. 4, XII - XVI), die die vorherigen unverbindlichen verhältnisse wieder herstellt und nach der er sich zuruickzieht.

Es vergehen einige Monate bis zu Onegins drittem Besuch bei den Larins. 2 Der Besuch (anläßlich Tatjanas Namenstagsfest) erfolgt wiederum durch Vermittlung Lenskijs und auf Einladung Olgas und ihrer Mutter, die den eigentlichen Grund von Onegins zweitem Besuch nicht kennen. Onegin akzeptiert, weil Lenskij

${ }^{1}$ Onegin charakterisiert Olga Larina, in die Lenskij verliebt 1st, so: "Sie hat ein rundes, schönes Gesicht - wie dieser dumme Mond an diesem dummen Horizont." (Kap. 3, V)

${ }^{2}$ Vährend Onegins zweitem Besuch sammeln die Mädchen in Garten Beeren (Kap. 3, XXXIX). - Die zweite Strophe des flun:en Kapitels beginnt mit: "Zima!...". 
versichert, es handele sich bei Tatjanas Namenstagsfeier um ein Pest im Familienkreis. Statt dessen trifft Onegin (Kap. 5, XXV ff.) auf eine groBe Gesellschaft und muB mit ansehen, wie seine Anwesenheit Tatjana verwirrt. Es folgt die bisher eindeutigste Illustration von Onegins Asozialität. Onegin ärgert sich über die inm aufgezwungene Geselligkeit großen Stils und fühlt sich gestört durch die besonderen Gefühle, die Tatjana für ihn hegt. Für diesen doppelten Ärger rächt er sich einmal, indem er die Festgesellschaft in Gedanken karikiert, zum anderen, indem er Ienskij vor aller Augen durch sein Werben um Olga brüskiert. Der Leser sieht Onegin hier zum ersten Mal von sich aus aktiv handeln. Sein Handeln ist destruktiv und hat fatale Folgen, es leitet den Wendepunkt im Geschehen des Romans ein. Puškin hat im zweiten Kapitel (insbesondere in den Strophen VII bis $X$ ) dargelegt, daB Lenskif seinem Alter (18 Jahre) und seiner idealistischen Erziehung entsprechend, Liebe, Freundschaft und Ehre alles bedeuten. Ienskij fuhlt sich durch Onegin nun in einem MaBe verletzt, daB er ihn zum Duell fordert.

6. Die charakteristischen Merkmale dieses Duells sind:

a) Die Forderung durch Lenskif erfolgt automatisch und wird von Onegin automatisch akzeptiert.

b) Beiden Kontrahenten wird nach Erledigung dieser Anfangsformalitäten klar, daB das Duell sinnlos ist.

c) Das Duell findet trotzdem statt.

d) Es nimmt den denkbar schlimmsten Ausgang: Lenskif wird tödlich getroffen.

Die Punkte a) bis c) sind durch das bisherige Romangeschehen erklärbar - der Punkt d) nicht:

a) Lenskifs und Onegins Verhalten illustrieren das Funktionieren einer intakten Institution. Der Schritt zum Duell bedarf bei Lenskif keines Nachdenkens. Lenskij entschliebt sich nicht eigentlich dazu, sondern das Bild des Duells taucht wie von selbst vor ihm auf - Lenskij gibt ihm nur nach. Das fuinfte Kapitel endet mit den Zeilen: "Ein Paar Pistolen, zwei Kugeln - weiter nichts - sollen plötzlich sein Schicksal ent- 
scheiden."

Auch die schriftliche Forderung, die an Onegin ergeht, hat mit der Person Lenskijs nichts $z u$ tun. Lenskij, der sich normalerweise in langatmigen, von Metaphern und Vergleichen durchsetzten Reden ausdrückt, zu deren Charakterisierung Pułkin immer wieder das Wort "tuman" bereithält, setzt eine in kühler Klarheit gehaltene Forderung auf (vgl. Kap. 6, IX: die Forderung wird als kurz, böplich, klar udn kalt beschrieben). Es wird deutlich, daB Lenskij sich hier am Verhaltensmuster eines vertrauten Ritus orientiert.

Die Reaktion Onegins ist ebenso blitzscinnell, undurchdacht und kurz wie die Forderung Lenskijs. Er tritt ans Fenster, uberlliegt Lenskijs Schreiben, wendet sich sogleich an den Sekundanten Zareckij und sagt "ohne weitere Worte", er sei "jederzeit bereit." (Kap. 6, IX)

Diese schematische Handlungsweise der zwei Freunde, die in ihrem sonstigen Verhalten als so verschieden voneinander wie "Eis und Flamme", "Woge und Stein" bezeichnet wurden (Kap. 2, XIII), veranschaulicht die Entlastungsfunktion der Institution "Duell", die nach Gehlen allen Institutionen eigen ist. "Solche kulturellen verhaltensmuster oder In $s$ i $t u t i o-$ $n$ e $n$ bedeuten für das Individuum eine $E n t l$ a $s t u n g$ von allzu vielen Entscheidungen, einen Wegweiser für die Fülle von Eindrücken, von denen der weltoffene Mensch überflutet wird." 1

b) Es ist hauptsächlich Eifersucht, die Lenskij zur Forderung Onegins treibt. Lenskij ist vor Eifersucht nicht mehr er selbst ("sam ne svoj", Kap. 5, XLIV); in romantischer Raserei erscheint das bevorstehende Duell inm wie ein "Fest" (Kap. 6, XII). Das Duellmotiv Eifersucht wird bei Lenskijs Wiedersehen mit 0lga (Kap. 6, XII, XIV) jedoch nachdrücklich entkräftet: "Es schwanden Eifersucht und Ärger vor dieser Klarheit des Blickes...". Ein dreimaliges "pred ètoj" signalisiert Lenskijs allmähliche Entspannung. Die Forderung ist aber iberbracht, und

1A. Gehlen, "Anthropologische Forschung" (1961), S. 71. 
Lenskif denkt sich statt des spontanen Duellmotivs, das entfällt, nun eines aus: in blumigen Phrasen stellt er sich als Retter von Olgas angeblich bedrohter Ehre dar. Nach Lenskijs innerem Monolog (XVIII) resümiert Pułkin in den letzten zwei Zeilen knapp und ironisch: Lenskif hält am Duell fest. Puskins: ironisches Eingreifen als Erzähler charakterisiert Lenskijs iruneren Monolog als das Hirngespinst eines Poeten. Von Lenskij als Musensohn kann zum bevorstehenden Duell also keine vernunftdiktierte Haltung erwartet werden. ${ }^{1}$ Das Duell bedeutet für ihn nun Gelegenheit zu theatralischer Pose und zu elegischer Poesie. Puškin läßt Lenskijs in der Nacht vor dem Duell geschriebene Elegie mitten im Satz "bei dem modischen Wort I d e a l ..." (XXIII) abbrechen und bekundet damit noch einmal sinnfällig, wie er Lenskij aufgefabt haben möchte: sympathisch, doch unrealistisch und unfertig. Die substanzlosigkeit Lenskijs stellt Puškin als altersbedingt dar, er ironisiert sie in nachsichtigem, fast liebevollen Tone. Sie ist fur den Handlungsverlauf insofern entscheidend, als damit das gröBere Gewicht und die größere Verantwortung bei Onegin liegen.

Onegin wird durch die Forderung zum Duell (nach Tatjanas Brief) zum zweiten Mal in seiner Ruhe gestört. Die Besonderheit dieser Konfliktsituation besteht darin, daB der durch eine funktionierende Institution vorgezeichnete $\mathrm{Heg}$, den Onegin mit der Annahme der Forderung eingeschlagen hat, seinen persönlichen Uberlegungen widerspricht (Kap. 6, X). Es reut ihn, mit Lenskijs Gefühlen gespielt zu haben. Er gelangt zu der Uberzeugung, daB ein Duell hier uberhaupt nicht am Platze ist: es wäre nicht ein Kampf Gleichwertiger, ein bellum duorum, da der Beleidigte noch ein halbes Kind ist. Ehrenvoll wäre es in diesem Fall, das Duell aus rationellen Grüden zu verhindern. Die theoretische Einsicht Onegins bleibt jedoch obne Effekt. Onegin erweist sich ein zweites Mal als unfähig zu persönlichem

${ }^{1}$ Die Beilegung eines Duells war nichts Ungewöhnliches. G. Hergsell schreibt dazu in seinem "Duell-Codex": "Man ist durchaus nicht entehrt, wenn man sein Unrecht einsieht, noch weniger, wenn dasselbe auf MiBverständnissen beruht...". (S. 52) 
Engagement. Er ist nicht imstande, eine mechanisch vor sich gegangene Reaktion durch echtes Handeln zu annullieren und bei einer gesellschaftlichen Routinehandlung sein eigenes Gesicht zu zeigen, weil er prinzipiell von sich als $h$ a $n$ de $l n-$ d e $r$ Person absieht. Da Onegin unfähig ist, das Noment innerer Trägheit zu uberwinden, zieht er sich fatalistisch auf die Position zuríck, es sei zu spät, den einmal initilerten Handlungsablauf des Duells zu stoppen. Diese Position sichert er uberdies mit der These $a b$, ein eventueller Duellabbruch werde falsch ausgelegt. Hierbei stutzt Onegin sich ausschlieblich auf den früheren ublen Leumund von Lenskijs Sekundant Zareckij. Obwohl zu Anfang des sechsten Kapitels (VIII) festgestellt wurde, daß Onegin Zareckijs gesunden Menschenverstand schätze, konzentriert Onegin sich jetzt hartnäckig auf Zareckijs schlechte Eigenschaften: "On zol, on spletnik, on rečist..." (XI). Mit dem dreimaligen "on" und dem dreimaligen Herausstreichen von Zareckijs bösem Charakter lenkt Onegin von sich ab und gestattet sich die bequeme SchluBfolgerung, die Gegenwart eines solchen Mannes verbiete unkonventionelles Handeln. An diesem scheinbaren Respekt Onegins vor der in Zareckif inkarnierten öffentlichen Meinung schließt Puskin im abschließenden Zweizeiler eine allgemein gehaltene Bemerkung uber die Macht der offentlichen Meinung in der menschlichen Gesellschaft an. Man solite sie nicht als Plädoyer für Onegin mibverstehen, ${ }^{1}$ die seine Verhaltensweise unter die allgemeinen menschlichen Schwächen einreiht und damit pauschal entschuldigt, ${ }^{2}$ denn onegin ist ja

${ }^{1}$ Nabokor spricht in seinem Kommentar zum "Eugen Onegin" in Bezug auf "pruźina Cesti" und "ložnyj styd" (XXVIII) von literarischen Allgemelnplätzen der Zeit.

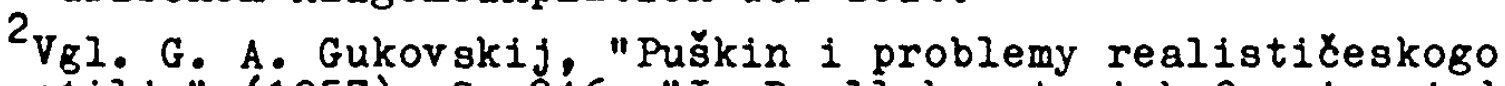
stilja" (1957), S. 246: "Im Duell beugt sich Onegin wieder dem Gesetz der Gesellschaft und der 'großen Welt', die ihn formten...". Onegin wird hier nur als Produkt seiner Umwelt betrachtet und nicht als Individuum beurteilt.

Totales Unverständnis in Bezug auf die Duellsituation findet sich bei N. I. Brodskij, "Evgenij Onegin" (1964). Brodskij miBt die Institution "Duell" mit sowjetischen MaBstäben und geht nicht von ihrer innerfiktionalen Gultigkeit aus. 
gerade nicht voll in die Gesellschaft integriert, sondern hält sich abseits. ${ }^{1}$ Der Grund, warum das theoretisch als Irrsinn betrachtete Duell effektiv von Onegin nicht verhindert wird, liegt in seinem leeren, zu engagiertem positiven Handeln unfähigen Charakter. Pułkin hat eine derartige Auffassung von Onegin bis zur Strophe XI des sechsten Kapitels mit zu vielen Details belegt, als dab man Onegins Verhalten jetzt nur durch ge-sellschaftliche $\mathrm{Zwänge}$ motiviert betrachten könnte.

DaB Zareckij als Lenskijs Sekundant fungiert, wirkt sich dop-pelt negativ aus: Zareckij liefert nicht nur den Vorwand für Onegins Pesthalten am Duell, sondern er ist fur die Rolle eines Sekundanten nicht geeignet. Obwohl Puskin zweimal versichert, daB aus Zareckij im Endeffekt ein ehrenwerter Mann geworden ist (Kap. 6, IV und VII), widmet er sich bei der Vorstel.lung Zareckijs zum gröBten Tell dessen früheren Flegeleien, so daß der negative Eindruck beim Leser überwiegt. Diesen Einçruck bestätigt Zareckij bei fortschreitender Handlung. Zumindest passiv fröhnt er noch seinem früheren sport des Inszenierens von Duellen: er unternimmt nichts, um Onegin und Lenskij vom Zweikampf abzubringen, was klassische Pflicht eines Sekundanten war. ${ }^{2}$ Im Gegenteil: er überreicht die Forderung Lenskijs grinsend (Kap. 6, VIII) und ohne Kommentar (IX). Von der Reaktion Onegins berichtet er Lenskif in gespreiztem Tonfall (XII). Auch unmittelbar vor Beginn des Zweikamples unternimmt Zareckij nicht den obligatorischen und ublichen versöhnungsversuch (vgl. S. 38 im "Duell-Codex" von Hergsell). Durch den Charakter dieses Sekundanten wirkt sich Onegins Passivität noch folgenschwerer aus.

1 In Kap. 2, $\mathrm{V}$ heiBt es, daß Onegin seine Nachbarn beleidigt; in Kap. 5, XII sehen "alle mit Erstaunen" sein unziemliches Benehmen; in Kap. 8 wirbt Onegin um die verheiratete Tatjana, die in diesem Zusammenhang von "Schande" spricht (XIIV).

2Vgl. den "Duell-Codex" von G. Hergsell: "In diesem Falle kann man das allbekannte und grüdlich wahre Wort von Alphonse Karr wiederholen: 'Es sind nicht die Kugeln und die Degenspitzen, welche tödten, es sind die Secundanten." Und: "Es ist die Pflicht der Secundanten, dahin zu wirken, die Angelegenheit, wenn möglich, auf friedilchem Tego beizulegen...". (S. 36 und 38 ) 
c) Obwohl also beide Duellanten den anberaumten Zweikampl nicht als Mittel zur Bereinigung eines wirklich existenten Konfliktes sehen, finden sie sich mit ihren Sekundanten am Kamplplatz ein. ${ }^{1}$ Das Desinteresse des duellerfahrenen Onegin (vgl. Kap. 1, XXXVIII) manifestiert sich schon vor Beginn der Kampfvorbereitungen in einem $z$ weifachen VerstoB gegen libliche Regeln: er verspätet $\mathrm{sich}^{2}$ und bringt als sekundanten seinen Diener Guillot mit. 3 Während die ungleichen Sekundanten - im Grunde nur Zareckif - die technischen Einzelheiten des Kampfes festlegen, stehen die Kontrahenten sich gesenkten Blikkes gegenüber. Damit bricht endgültig Jeder persönliche Kontakt zwischen ihnen ab. Es stehen sich nicht wehr die - in Freundschaft verbundenen oder eben erst verfeindeten - Individuen Onegin und Lenskij gegenuber, sondern, um Onegins Worte zu gebrauchen $(X)$, Spielbälle von Vorurteilen. Von dem Noment an, da Onegin und Ienskij die Blicke senken und damit als individuell denkende und handelnde Personen zurücktreten, bis zum Schuß Onegins, könnte man den Duellschauplatz mit einem Marionettentheater vergleichen: Onegin, Lenskif und der Mann ohne Herz, 4 Zareckij, bewegen sich nicht nach eigenem Willen, sondern die Fäden der Handlungsführung werden zentral gelenkt -

1 lenskif steht um sieben Uhr morgens auf (XXIV). Dies ist die einzige Zeitangabe.

2 tuf die Pflicht rechtzeitigen Erscheinens am Kampfplatz weisen alle Duellkodizes hin. Vgl. Hergsell, S. 48: "Auf dem Yamplplatze selbst braucht keine der beiden Parteien länger als $f$ u $f z e$ $n$ i n $t$ e $n$ auf den Gegner zu warten."

${ }^{3}$ Eei den Sekundanten muBte es sich um standesgleiche Personen tandeln, vgl. S. 36 im Kodex von Hergsell. - Guillot schaut den Vorgängen verwirrt zu (XXIX). Als Angehörigem einer niederen Gesellschaftsschicht ist ihm das Dueli nicht nur prinzipiell unverstëndlich, sondern er kann aus seiner Dienerstellung heraus auch keine Kritik an Onegin uben. Mit der Wahl dieses Sekundanten entfällt die letzte Möglichkeit vernünftigen Einspruchs. Pułkin betont das Herr-Diener-Verhältnis in der Strophe XXV: dreimal taucht "sluga", zweimal "velit" auf. Nabokov findet die Strophe aus diesem Grunde plump. Man solite ajer bedenken, daB damit noch einmal die Haltung Onegins zum Diell bekundet wird.

4V3l. Strophe VIII. Nabokov sieht hier einen Hinweis auf die Anoral Zareckijs. 
hier von einem bestimmten Duellritus, dem "Pistolenduell mit Vorrucken" oder "mit Barrieren". Angesichts dieser Leblosigkeit blendet Puskin in einer Digression (XXVIII) zuruck auf die Freundesbeziehung Onegins und Ienskifs der jügsten Vergangenheit. Die Strophe beginnt mit "Vragi!" - sie ist ein Appell, aus dem "schrecklichen, unverständlichen Traum" zur Besinnung zu kommen, das Rollenspiel als solches zu erkennen - und endet mit der resignierenden Einsicht, daB gerade das Offizielle an dieser Feindschaft kein persönliches Einlenken erlaubt. Die Pistolen werden also geladen, die Duellanten entledigen sich ihrer Mänte ${ }^{2}$ und werden 32 Schritte voneinander entfernt aufgestellt $(X X I X)$. Das Kommando des Sekundanten läßt sie aufeinander losgehen. Beide gehen zunächst vier, dann fünf Schritte vor - hier zielt Onegin schon. Er schieBt, als sich die Distanz auf 14 Schritte verringert hat.

d) Der Schuß Onegins ist eine nicht erwartete Ungeheuerlichkeit. Er ist nicht nur unvereinbar mit der Konvention, ${ }^{3}$ die den ersten Schuß bei diesem Duell Ienskif zugestanden hätte, sondern paßt auch nicht zu seiner vorher demonstrierten Haltung: Onegin hatte sich weder innerlich noch äußerlich auf das Duell vorbereitet. ${ }^{4}$ wie ist sein vorheriges totales Desinter-

${ }^{1}$ Von den beiden Endpunkten der Entfernung, die gewöhnlich 35 bis 40 Schritte beträgt, werden 10 Schritte abgeschritten und die entsprechenden Punkte als Barrieren markiert. Die beiden Gegner können bis zur markierten Linie gegeneinander vorrlikken und nach Belieben schießen. Vgl. den Kodex von Hergsell S. 165 11. Das Recht des ersten Schusses hängt vom Grad der Beleidigung $a b$.

2 Mäntel waren abzulegen, damit nicht irgendwelche darin verborgenen Gegenstände Schutz vor Kugeln boten (vgl. S. 162 im Kodex von Hergsell).

${ }^{3}$ Onegin hätte als Beleidiger Lenskijs dessen ersten SchuB uber sich ergehen lassen mlissen. In diesem Sinne, äußert sich auch Nabokov. Vgl. uiberdies den folgenden Passus bei Hergsell: "Nach altfranzösischem Duellcodex ist mit....Erheben der Pistole zum Schusse die Beleidigung vollständig aufgehoben; es braucht durchaus kein BlutvergieBen zu erfolgen." (S. 39)

${ }^{4}$ Onegin schläft in der Nacht vor dem Duell wie ein Toter, $\nabla g l$. die Strophe XXIV: "spal...mertrym snom". Die Form "spit sebe" (Zeile 5) deutet eine ungestörte Gemlitsruhe an. 
esse zu vereinbaren mit einem SchuB, der genau gezielt ist und tödlich trifft? Puzkin löst dieses Rätsel nicht mit einem Kommentar - es mub aus dem Organismus des ganzen Romans in seiner verhängnisvollen Einzelheit $z u$ erklären versucht werden. Nachdem der Schuß gefallen ist, setzt Puskin nur drei Punkte und zieht sich dann auf einen fatalistischen standpunkt zurück: ienskijs stunde hat geschlagen.

7. "Was auch geworden wäre" - so beginnt Pułkin nach einigen ReFlektionen über die Möglichkeiten, die das Leben für den jungen Lenskij bereitgehalten hätte, die Strophe XI im sechsten Kapitel, 1 Ienskij wurde durch Freundeshand getötet. ${ }^{2}$ Es geht Pußkin vor allem un diese Tatsache. Wer er ist, konnte Onegin nur neben dieser idealistisch-farblosen Freundesgestalt (und - wie noch zu zeigen sein wird - neben einer starken Frauengestalt wie Tatjana) zeigen. Mit dem SchuB auf Lenskij hat sich der wichtigste Mosaikstein in das Bild Lenskijs gefügt. Alles Nachfolgende verdeutlicht nur noch den Eindruck, der sich beim Leser über Onegin herausgebildet hat.

Auf die Asozialität Onegins wurde bereits hingewiesen. Durch das Duell wird deutlich, daß Onegin auch amoralisch ist. Er weiB, daB er sich über Lenskijs romantische liebe nicht hätte lustig machen dijfen und $d a \beta$ er das Duell hätte verhindern muissen, aber er macht dieses iissen nicht fur sich verpflichtend. (Ebensowenig bedenkt Onegin bei seiner späteren Verenrung für die verheiratete Tatjana, daß er sie kompromittieren könnte.) Aus seiner absoluten Ungebundenheit heraus ${ }^{3}$ handelt onegin un-

${ }^{1}$ Diese (wenn z. T. auch ironisch gehaltene) Aufzuhlung ist indirekt ein Vorwurf gegen Onegin. Ein indirekter Vorwurf waren auch die schönen Vergleiche des niederfallenden und sterbenden Lenskij mit einem herabrollenden glitzernden Schneeball und mit einer frühzeitig welkenden Blume (XXXI).

${ }^{2}$ schon in den letzten beiden zeilen der strophe XXXIII sagt Puskin deutich, dab es sich hier um Mord handelt.

3has Pułkin im achten Kapitel (XI) allgemein als trauriges Iebensschicksal beklagt, trifft auf Onegin zu: er teilt weder yelnungen noch Leidenschaften der ihn umgebenden wohlanständigen Gesellschaft. 
voraussagbar. Man kann nicht wissen, was ihn in der Duellsituation die Hand zum Mord heben lieb. Man weib jetzt nur, daB dieser unengagierte Held gefährlich ist. Man assoziiert mit Onegin Baudelaires Worte an den Leser, die er seinen "Bumen des Bösen" vorausschickt: "Die Langeweile ists! - Das Auge schwer von willenloser Träne, träumt sie von Blutgeriusten... du kennst es, Leser, dieses zarte Scheusal...". ' In einem seiner "Spleen"-Gedichte nennt Baudelaire den kraftlosen, jungen und dennoch uralten MüBiggänger einen "kranken Grausamen". 2

Tatjanas Traum (Kap. 5, XI - XXI) beweist, daB sie Onegin intuitiv richtig erkannt hat. Sie sieht Onegin in ihrem Traum nicht in menschlicher, sondern in tierischer Gesellschaft, in der er den Ton angibt. Die Strophe XVIII arbeitet seine beherrschende Position durch eine in den ersten vier Zeilen sich wiederholende rhythmische Gegenüberstellung von "on" und "vse" herals. Onegins Augen funkeln dämonisch, er ist niemand Rechenschaft schuldig, nimmt sich, was er will - hier Tatjana - und reagiert brutal auf jeden störenden EinfluB von auBen: mit Gesten und Schimpfen versucht er, die "ungerufenen Gäste" Olga und Lenskif loszuwerden $(X X)$ und ersticht schlieBlich Lenskij.

Puškin, der von Anfang an keinen Zweifel daran läßt, daB Tatjana seine Lieblingsfigur ist, ${ }^{3}$ zeichnet sie im Romangeschehen vor allem dadurch aus, daß sie als einzige vor dem Mord an Lenskij annt, wer Onegin ist. Als Tatjana im siebten Kapitel

\footnotetext{
${ }^{1} \mathrm{Ch}$. Baudelaire, "Blumen des Bösen" (1966), S. 9. 2 ebd.. S. 125.
}

${ }^{3}$ Im zweiten Kapitel setzt er ihr Portrait ab gegen das Klischeebild von 0lga, das er nicht einmal zu Ende zeichnet (XXIII). Im Kontrast zu Olga, die den toten Lenskij bald vergiBt, trägt Tatjana die unerwiderte Liebe zu Onegin lange, ja für immer, mit sich herum. Tatjana - so glaubt Pußkin - hätte das Dueli zwischen Onegin und Lenskif verhindert, wenn sie etwas geahnt hätte (Kap. 5, XVIII). DaB Pußkin oftmals von "milaja Tatjana" und "moja Tatjana" redet (Kap. 3, XV, Kap. 5, XVII, Kap. 7, IV etc.) ist als Zeichen der Zuneigung aufzufassen. - Es gibt aber auch auBerfiktionale Beweise dafür, daB Puskin besonders an Tatjana liegt: in seinem Brief an A. A. Bestuzer vom 24 . März 1825 weist er darauf hin.- In der Strophe XXXVII von Kap. 5 , die in der Erstausgabe gedruckt war und in den weiteren Ausgaben fehlt, nennt Puskin Tatjana liebenswerter als Homers Helena. 
b.ei der Lektuire von Onegins Büchern über seinen Charakter nachdenkt, wird ihr Traumerlebnis zur bewußten Einsicht. Puskin sagt, sie beginne ihn jetzt "Gott sei Dank" etwas "klarer" zu verstehen (XXIV). Tatjana schliebt von Onegins Buchern, die Helden wie den Giaour und Don Juan darstellen - Pułkin spricht ausdruicklich von deren amoralischer seele (XXII) - auf den charakter des Besitzers. Sie hält ihn für einen seltsamen und gefährlichen Sonderling, fragt sich, ob er ein Geschöpf des Himmels oder der Hölle sei. Einer wirklichen Charakterisierung entzieht sich Onegin. Der Moskauer im Gewande des Childe Harold, das nichtige Phantom, die Parodie - dies alles sind Worte Tatjanas (XXIV) - hat keine eigene Substanz. Somit muB die Frage, warum Onegin den SchuB abgab, unbeantwortet bleiben. Es bleibt nur die Feststellung seiner Gefährlichkeit. Im achten Kapitel (VIII) sagt Puškin, welches der endgültige Standpunkt des Lesers sein wird: er kennt onegin - und er kennt ihn nicht. 1

8. Das achte Kapitel ist durch einen Zeitraum von zwei Jahren von den vorhergehenden Kapiteln abgesetzt. Die Ereignisse sind nicht mehr im FluB, sondern es wird eine Bestandsaufrahme präsentiert, unterbrochen von einigen Rückblicken. Tatjana ist die Frau eines Fürsten geworden - ihr Schicksal ist, wie sie selbst sagt, entschieden (XIVII). Die Konsolidierung der Verhältnisse - von Olgas Heirat war schon im siebten Kapitel (X) berichtet worden, Tatjanas Leben verläuft nun in bestimmten Bahnen und Onegin, der nach Lenskijs Tod auf Reisen gegangen war, bleibt der ruhelose Wanderer, der in dieser oder jener Rolle (Kap. 8, VIII) auftaucht und verschwindet - läßt pußkin eine

1Vgl. V. Setschkareff, "Alexander Puschkin" (1963), S. 127, zu Onegin: "Kalter Egoismus, Gleichgultigkeit, Langeweile und die Sucht, sie zu betäuben, sind die Achsen, um die sich die Welt dreht. Es gibt Epochen, in denen diese Situation deutlich hervortritt. Die Betäubungssucht ist im Anfang recht harmlos, wie bei Onegin - wenn er auch aus Langeweile zufällig seinen Freund totet - doch in ihren letzten Konsequenzen wird sie zu einer gefährlichen, das Leben in Frage stellenden Dämonie und die Reihe Onegin - Pecorin... - und Stavrogin, der unheimliche Held von Dostojerskijs "Teufeln" ist durchaus folgerichtig." 
Spur direkter werden und in Worten eine Bilanz ziehen, die er in der Handlung bereits vorweggenommen hat. Die Strophen $X$ undi $X I$ enthalten Puškins Ansichten über ein sinnvoll gestaltetes Leben, nachdrücklich vorgetragen durch die wiederholung von "blažen, kto..." und "grustno...čto...". Pư̌kin sagt hier, daß gewisse Regeln und stereotype Entwicklungsstufen für jeden notwendig sind, der auf ein sinnerfülltes Leben zurückblicken möchte. Zu jedem Alter paßt ein bestimmter Iebensmodus ( $v$ dvatcat'...v tridcat'...v pjat'desjat..."). Eine solche, von bestimmten Institutionen (Ehe, kirchliche und profane Bräuche) eingefabte Lebensweise war im zweiten Kapitel am Beispiel von Tatjanas Eltern demonstriert worden. Tatjana kündigt an (XIVII), daß sie - wenn auch auf höherer gesellschaftlicher Ebene (XLVI) - den gleichen Weg gehen wird. Ein wertvoller und geachteter Mensch kann man nach Puskin nur in einer Gemeinschaft sein, mit der man sich in wesentlichen Punkten identifiziert und die man innerhalb gewisser Institutionen mitträgt. Für Onegin, der nach wie vor nirgends integriert ist, der "bez služby, bez ženy, bez del..." lebt, findet Pußkin entsprechend nur sehr un-menschliche Bezeichnungen: er nennt ihn eine satanische MiBgeburt, einen traurigen Narren, einen Dämon (XII). Onegin spielt nur modische Gastrollen, und vor der Mode als etwas Äußerlichem, Vergänglichen und Unsubstantiellen warnt Pǚkin: einmal ausdrucklich in Worten ${ }^{1}$ (VIII) und zudem in Form der Ablehnung, die Onegin durch Tatjana erfährt.

Als offenherziges verliebtes Mädchen hatte Tatjana Onegin nicht $z u$ fesseln vermocht. Als Dame der Gesellschaft, die sich "comme il faut" verhält (XIV), läBt sie Onegin auBer sich geraten. Das Eingeständnis der Liebe Onegins in seinem Brief an Tatjana (XXXII) wirkt dubios - es komt mehr selbstmitleid als Liebe darin zum Ausdruck. Als Onegin seine frühere Ablehnung Tatjanas motiviert, schwingen falsche Töne mit: es ist nicht so, daB er ihrer Liebe nicht $z u$ glauben wagte - sie hat ihn nie interesgiert. Den Tod lenskijs bringt er fälschlicherweise in ur-

\footnotetext{
"Worte wie "moda, ovet, vkus" etc. werden den ganzen Roman tindurch ironisch benutzt, auch in Bezug auf Tatjana: z. B. ubersetzt Puskin ihren Brief aus dem modischen Französich.
} 
sächlichen Zusammenhang mit der Ablehnung Tatjanas. ${ }^{1}$ Was Onegin mit seinem Brief an die verheiratete Tatjana bezweckt, wird nicht klar. Auch in dieser dritten Konfliktsituation (nach Tatfanas Brief und dem Duell) kommt Onegin von seiner Person nicht 10s. Er würde sich gefallen als Verehrer einer angesehenen Fürstin - er gefällt sich in Selbstmitleid, als er abgewiesen wird. Tatjanas Haltung versucht er nicht zu ergruinden. Tatjana analysiert sein Verhalten richtig: es ist der äuBere Glanz um ihre Person, der Onegin anzieht, nicht sie selbst. Wenn schon diese Tatsache sie schmerzt - da sie Onegin fa immer noch liebt so empfindet sie überdies Onegins unwürdiges Benehmen, 2 das auf ihre Stellung keine Rücksicht nimmt, ${ }^{3}$ als traurig: der liebeskranke Onegin handelt kühner als der gesunde onegin ${ }^{4}$ - sagt Pußkin.

Nach Tatjanas Abweisung läBt Puškin seinen Helden einfach fallen, und der Leser denkt - sich auf die erste Strophe des Romans zuruickbesinnend - dab Onegin seines Onkels Beispiel, das ihm doch als Lehre für andere erschien, nicht gefolgt ist: während der

1"Ełð̌e odno nas razluxilo.../ Nestastnoj žertvoj Lenskif pal..." (S. 181).

${ }^{2}$ Onegins Verliebtheit wird als kindisch beschrieben: "on kak ditfa vlfublen" (XXX); als lakaienhafte Ergebenheit: "on sčast-

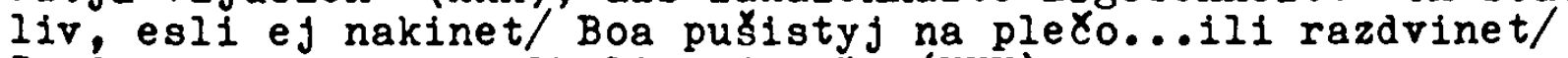
Pred neju pestryj polk livrej...". (XXX)

3 Vgl. XIV; D. Blagof reduziert Tatjanas Entscheidung auf den berechnenden Wunsch, als Frau eines "bekannten und reichen Flirclologifa tvoř̌estva Puskina", S. 135. - Vgl. dagegen B. S. Mejlach, "Pułkin", Kollektivnaja monografija pod. red. B. P. Gorodeckogo...(1966), S. 435: "Zwar liebt sie imnoch, aber das, was sie von ihm weiB (die kalte, moralisierende Antwort auf ihren Brief, der Flirt mit Olga, der Mord an Lenskif, dann der Besuch in Onegins Haus, der so viele Zweifel an dem geliebten Mann in ihr weckte) motiviert ausreichend die für sie selbst nicht leichte Haltung gegenüber seiner verspäteten Liebe."

${ }^{4} \mathrm{Vgl}$. Onegins Haltung in Kap. 6: er muB erst von dem Bild des niederfallenden Lenskif schockiert werden, um auf ihn zuzulazfen und zu handeln. Der einige sekunden vorher noch lebendif vor ihm stehende Preund konnte Onegin zu keinem Engagement bewegen. So beginnt Onegin - in Kap. 8 durch das glanzvolle Bild Tatjanas aufgerüttelt - erst zu handeln, als es auch hier schon zu spät ist. Beide Male muB ihm erst zu Bewußtsein gebracht werdez, dab er etwas $v$ e r l o r e n hat. 
Onkel zumindest am Sterbebett Hochachtung von seiner Umgebung erzwang, wird Onegin nach unrühmlichen Taten unrühmlich entlassen.

9. Es wird in "Eugen Onegin" also ein AuBenseiter der Gesellschaft dargestellt. Seine Asozialität und Amoral werden am deutlichsten in der Duellsituation vor Augen gefuhrt. Onegin miBbraucht die Institution "Duell" - das bringt Puskin in einer Abschweifung (Kap. 6, XXXIII 1.) explizit zum Ausdruck. Pußkins Duellkritik läuft hier nicht auf eine Polemik gegen die Institution "Duell" in toto hinaus: gegen ein ehrliches Duell hat er nichts einzuwenden. 1 Seine Kritik gilt - wie im "SchuB" - dem MiBbrauch dieser Institution. Seine Furcht vielleicht wiederum ihrem geheimen Wesen, das MiBbräuchen Vorschub leistet.

Onegins Mord an Lenskij wird mit gesellschaftlicher Ächtung beantwortet (Kap. 8, XII). Sein Werben um die verheiratete Tatjana wird zurückgewiesen. Eine Gesellschaft mit intakten Institutionen und lebendiger Moral - dafür steht vor allem die Gestalt Tatjanas ${ }^{2}$ - kann einen AuBenseiter wie Onegin verkraften, ohne Schaden zu nehmen: der Roman endet eben deshalb heiter. Der Held wird leichten Tones einfach stehen gelassen. Man kann Pužkins Roman somit verstehen als humorvolies, mit satirischen Untertönen vorgetragenes Plädoyer für ein in historischen Tra-

1 ob Puškins "gesellschaftliches Bewußtsein" über die standesgemäßen Ehrenvorstellungen seiner Zeit hinausgewachsen war wie N. I. Brodskij behauptet - ist nicht sicher. Vgl. "Evgenij Onegin" (1964), S. 248 .

${ }^{2}$ puskkin weist in dem erwähnten Brief an A. A. Bestužev rom 24. März 1825 darauf hin, dab er seinen Roman nicht als Satire aufgefaßt sehen möchte - daB in einer Satire die Gestalt Tatjanas nicht enthalten sein könne. (Vgl. Gogol's satirischen "Revisor": hier wird innerfiktional nicht dargestellt, wie die kritisierte Welt aussehen sollte.)

Die Gestalt Tatjanas spricht auch gegen die Behauptung ron G. A. Gukovskij, in "Eugen Onegin" werde eine Gesellschaft gezeigt, von der nur Böses ausgehe. $\mathrm{Vgl}$. S. 246 in: "Pư̆kin 1 problemy realistileskogo stilja" (1957).

Vgl. auch D. Reeve, "The Russian Novel" (1967), S. 35: "...the 'real hero' of the novel, the typical and genuine Russian, is Tatyana." 
ditionen verwurzeltes Leben ${ }^{\prime}$ und die Institutionen der Gesellsichaft seiner Zeit. Zumindest legt die explizite Natur des Texties eine solche Auffassung nahe.

1 Tatjana glaubt an uberlfeferte Teisheiten (Kap. 5, V); sie praktiziert alte Bräuche (Kap. 5, VIII $f_{\bullet}$ ); sie ist "russkaja dußoju" (Kap. 5, IV). 
A. S. Pußkin, "Die Hauptmannstochter"

1. Der 1836 veröffentlichte Roman "Die Hauptmannstochter" ${ }^{1}$ hat mit dem "SchuB" ein Wichtiges gemeinsam: die Stellung des Autors. Puskin figuriert in beiden Fällen als Herausgeber, der nur veröfentilcht, was andere zu Papier gebracht haben. In beiden Fällen wird der Wahrheitsgehalt des Erzählten quasi dokumentarisch belegt: durch den Brief von Belkins Freund dort und durch einen handgeschriebenen Brief Katharinas II hier. Es wurde bereits dargelegt, daß der solchermaßen auf Distanz gegangene Autor im "SchuB" die Möglichkeit sadistischen MiBbrauchs der Institution "Duell" gestaltet - eine Kritik, die direkt vorzutragen für einen Adligen wahrscheinlich gesellschaftlich unmöglich gewesen wäre. Es ist nun zu untersuchen, wo die Brisanz in der Aussage der "Hauptmannstochter" liegt weshalb Pußkin hier hinter die Aufzeichnungen Grinevs zurücktritt, deren einzelne Kapitel er nur mit passenden Epigraphen versehen haben will. 2

2. Ein Blick auf die Epigraphe zeigt, daß acht von vierzehn Kapiteluberschriften und dem Romantitel selbst Volkslieder oder Sprichwörter vorangestellt sind. Die restlichen Mottos sind Werken russischer Dichter entnommen oder stammen aus Pulkins eigener Feder. ${ }^{3}$ Mit dieser Auswahl der Epigraphe gibt Pußkin

\footnotetext{
"v. Setschkareff sagt von der "Hauptmannstochter", sie sei "ein Musterbeispiel fur das Ergebnis eines fruchtbaren literarischen Einflusses, der als Anregung $z u$ origineller Höchstleistung dient...Der Roman ist...unter dem stärksten EinfluB Talter Scotts geschrieben... Tatsächlich sind viele Situationen aus "Waverley", "Rob Roy", "Old Mortality", "The Fortunes of Nigel", "Woodstock", "Quentin Durward", "Guy Mannering", "The Bride of Lammermoor"...von Pułkin... libernomen worden. Das Thema des 'unschuldigen Verräters', der durch die Macht der Verhältnisse in eine Lage gerät, die ihn kompromittiert, taucht bei Scott immer wieder auf und wird in "old Mortallty" fubrend." In: "Alexander Puschkin" (1963), S. 1831.

${ }^{2}$ A. S. Purkin, "Poln. sobr. sod. $\nabla$ desjati tt.", Bd. VI (1950), S. 541. Alle Zitate werden diesem Band entnommen. ${ }^{3} \mathrm{Vgl}$. die Mottos zu den Kapiteln XI und XIII.
} 
bereits zweierlei zu erkennen:

a) Hier wird etwas spezifisch Russisches thematisiert - im Gegensatz beispielsweise zu "Eugen Onegin" mit Epigraphen aus russischer, französischer und englischer Literatur.

b) Es geht hier nicht um eine geschlossene aristokratische Gesellschaft wie in "Eugen Onegin" und im "SchuB", sonderm das Volk wird eine gewisse Rolle spielen.

Diese letztere Einsicht lenkt automatisch das Augenmerk auf den roten Faden der vorliegenden Untersuchung, die Duellproblematik, und fuhrt zu der apriorischen Feststellung: welche Rolle das Duell in diesem Roman auch spielen mag - es wird als eine an aristokratische Ehrenvorstellungen gebundene Institution keine zentrale Bedeutung haben.

3. Dem Duell in Kap. IV geht bezeichnenderweise keine Volksweisheit als Epigraph voraus. Das Motto fällt aber auch nicht aus wie vor den Duellen in "Eugen Onegin" und dem "Schuß" als Prophezeiung von Ungluick in dusteren petrarkischen Zeilen oder einfach als Ankündigung eines nach selbstverständlichen Regeln ablaufenden Duells. Das Duell wird hier angekundigt in zwei derb komischen Zeilen aus einem Lustspiel Knjaznins.' Es trägt diesem Motto Rechnung. Obwohl die Kontrahenten Grinev und Svabrin sich emsthaft schlagen wollen - Svabrin wechselt die Farbe und geht automatisch vom "Du" zum "Sie" über, als er Satisfaktion verlangt, während Grinev sein Gegenüber vor Hut zerreißen möchte - wird der Zweikampf zur Farce.

4. Zu dieser Farce kommt es aus folgenden Gründen: in der Festung, die für Grinevs militärische Ausbildung zu sorgen hat, gehört auBer inm nur noch Šabrin zum Adel. Infolgedessen ergibt sich schnell ein näherer Kontakt. Vor allem traut Grinev nur Svabrin ein Urteil über seine Gedichte zu. Eine

"Vgl. V. Setschkareff, "Alexander Puschkin" (1963), S. 186: "Die Art wie Savel'it ein Fechtduell beschreibt oder die Reaktion des alten einäugigen Leutnants auf die Bitte, als Sesundant zu fungieren, sind... reizender Humor." 
abfällige Bemerkung über Grinevs Poesie ${ }^{1}$ - vor allem über Mar'ja Ivanorna, den Gegenstand seiner Dichtung - führt zu einem scharfen Wortwechsel und zur Forderung Švabrins. Das für Šrabrin und Grinev selbstverständiche Duell beginnt in außergewöhnliche Bahnen gelenkt zu werden, als Grinev einen nicht Ebenbürtigen bittet, sein Sekundant zu sein. Das Wort "Sekundant" löst bei Ivan Ignat'il durchaus keinen automatischen Verhaltensmechanismus aus. Ivan Ignat'it "gestattet" sich dreimal bezüglich der ihm angetragenen Bitte Fragen zu stellen, wobei allein die Formulierung "smeju sprosit"" seinen gesellschaftlichen standort bezeugt (S. 428). Grinev bemuiht sich vergeblich, diesen mit einer stopfnadel beschäftigten Iran Ignat'it, der gleichsam zur Demonstration seiner verminderten Aufnahmefähigkeit nur mit einem (angestrengt blickenden) Auge ausgestattet ist ${ }^{2}$ und der sich im Haushalt der Kommandantin stets mit sehr handesten Dingen beschäftigt - sei es Wolle abwickeln oder Pilze auf eine Schnur reihen - den abstrakten Ehrenkodex eines Adligen einleuchtend zu machen. Ivan Ignat'it versteht nicht nur nichts, sondern beginnt zu argumentieren.

Nun soll habitualisiertes Handeln nach Arnold Gehlen die Sinnfrage ja suspendieren: "Wer die Sinnfrage aufwiret, hat sich entweder verlaufen, oder er drückt bewuBt oder unbewuBt ein Bedurfnis nach anderen als den vorhandenen Institutionen aus" - schreibt Gehlen. ${ }^{3}$ Im vorliegenden Fall wird die Sinnfrage von allen aufgeworfen, denen die Institution "Duell" standesgemäB als unsinnig erscheint: von Ivan Ignat'iX, vom Kommandanten Mironov, seiner Frau Vasilisa Egorovna und seiner Tochter Mar'ja Ivanovna. Die Haltung der Umgebung verhindert eine regelgerechte Austragung des Duells zwischen Grinev und Šabrin.

\footnotetext{
${ }^{1}$ Bei den einfachen Festungsleuten findet Grinev sowieso kein Verständnis: die Kommandantenfrau kann sich nicht vorstellen, dab man über ein Liedchen streiten kann, und der Kommandant rät Grinev, das Verseschmieden zu lassen, weil es dem Dienst schade. Vgi. S. 4301 .

${ }^{2}$ Als Grinev zum ersten Mal das Haus des Kommandanten betritt, fällt inm auf, daß Ivan Ignat'il einen blauen Flicken auf eine grüne Uniform setzt. (S. 417)

3. Gehlen, "Urmensch und Spätkultur" (1964), S. 61.
} 
D:as Kapitel IV ist indes nicht eine todernste Illustration gerechter Entrustung der Festungsleute, sondern stellt das komischste Kapitel des ganzen Romans dar.

5. Pußkin benutzt zur Erzeugung von Komik ausgiebig das Kunstmittel der Verfremdung. 1 Das Duell wird mit Augen betrachtet, die nichts verstehen. Ein Sekundant ist so in der Interpretation von Ivan Ignat'ič jemand, der zuschaut, wie einer jemand anderen ersticht. Vasilisa Egorovna bezeichnet das Duell als "Mord in unserer Festung." 2 Savel'ič beschreibt die Fechtkunst als "sich mit eisernen Bratspießen stechen und dabei mit den FüBen den Takt stampfen..." (S. 442)

Darüberhinaus nutzt Fuškin die standesgemäBe Logik der Festungsbewohner zur Erzeugung komischer Effekte. In seiner Theorie des Lachens spricht Bergson von Berufslogik: "Ich meine damit bestimmte Denkweisen, die man sich in bestimmten Milieus aneignet und die für ihr Milieu die richtigen, für die übrige Welt durchaus falsch sind. Der Gegensatz aber zwischen spezieller und allgemeinguiltiger Logik erzeugt gewisse komische Wirkungen..." .

So wirkt es komisch, wenn Ivan Ignat'ic das Duell ablehnt, weil er als alter Kämpfer im Schweden- und Türkenfeldzug genug Elend gesehen haben will.

Vasilisa Egorovna argumentiert vom Standpunkt der frommen Hauserau aus, wobei gleichzeitig das für sie charakteristischste Wesensmerkmal, ihre Herrschsucht, ${ }^{4}$ zutage tritt: "Was soll das heiBen? Wie? Was?... Ivan Kuzmix, stell sie sofort unter Arrest! Petr Andreit! Aleksej Ivany

${ }^{1}$ Zum Begriff der Verfremdung, wie er hier verwandt wird, vgl. V. Sklovskij, "Theorie der Prosa" (1964), S. $15 \mathrm{ff}$. ${ }^{2} V_{g l}$ die Beschreibung Vasilisa igorovnas von Švabrins Duell in Kap. III, S. 418: "...er ist mit einem Ieutnant vor die Stadt hinausgefahren, sie nahmen ihre Säbel mit und haben dann aufeinander losgestochen, und Aleksej Ivanyč hat den Leutnant erstochen - und das in Gegenwart von zwei Zeugen!"

3H. Bergson, "Das Lachen" (1948), S. 99.

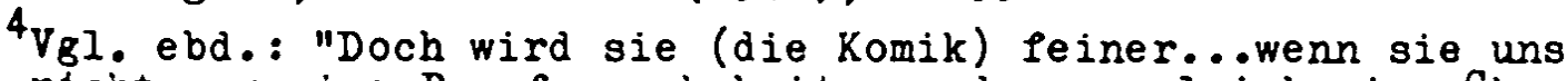
nicht nux eine Berufsgewohnheit, sondern zugleich eine Charaktereigenheit verrät." 
Petr Andreid! Das habe ich von dir nicht erwartet. Schämst du dich nicht? Bei Aleksef Ivanyt will ich nichts sagen...er glaubt ja auch nicht an Gott; aber du?" (S. 432)

Mar'ja Ivanovna sieht das Duell vom Standpunkt des verliebten Mädchens: "Wie seltsam doch die Männer sind! Eines Wortes wegen ...sind sie bereit, sich zu töten und nicht nur ihr Leben, sonderm auch ihr Gewissen zu opfern und das Glück derer, die...". DaB Mar'ja Ivanovna an dieser Stelle abbricht, macht ihren Einwand sentimental und läBt ihn als Argument gegen die Institution "Duell" komisch wirken. (S. 433)

Das Gebaren und die Argumentation der Festungsleute verfehlen nicht ihre Wirkung auf Grinev: er kann sich eines Lächelns nicht erwehren. (ebd.)

6. Es stellt sich die Frage, ob das Verhalten der Festungsleute von PuSkin quasi als durch die Hintertür vorgebrachte Kritik an der Institution "Duell" intendiert ist.

Wenn man zunächst einmal davon absieht, wi e die Festungsbewohner kritisieren, ist zuzugeben, dab ihre nicht durch den Ehrenkodex des Adels befangene Meinung vernüntig ist: man sollte Streitigkeiten nicht mit tödichen Waffen zu begleichen versuchen. Ein wichtiger Grund für die Entstehung von Antiduellbewegungen war immerhin die Tatsache, daß sehr viele Zweikämple tödlich ausgingen. ${ }^{1}$ Doch hat ein Appell an die Ratio wenig Erfolg bei jemandem, für den eine Institution fraglose Selbstverständichkeit ist. Die Reaktion Grinevs rechtfertigt diese These. Er bemerkt: "Die tberlegungen des vernünftigen Leutnants machten mich nicht schwanken. Ich blieb bei meiner Absicht." (S. 429) Nach Anhören aller Predigten sagt er zu Svabrin: "Unsere Angelegenheit kann damit nicht erledigt sein..." - und er-

1Vgl. W. v. Fürich, "Das Duell" (1886), S. 9: "Unter Heinrich II von Frankreich $(1547$ - 59) sollen über 7000 Menschen im Duell getötet worden sein, unter Heinrich IV $(1589$ - 1610) úber 4000 Edelleute. Noch schlimmer wurde es unter der schwachen Maria von Medici: Man schlug sich bei Tag und Nacht, auf der Straße und auf öffentlichen Plätzen,' bis endlich Ludwig XIII die alten strengen Strafen wieder einschärfen und auch zum Theil ausfuhren lieB." 
hält als Antwort: "Selbstverständlich nicht... Sie werden mit Ihrem Blut für Ihre Unverschämtheit zahlen." (S. 433)

Fuir Kritik an der Institution "Duell" - von gesellschaftlich niedrigerer Harte aus formuliert - sind Grinev und Švabrin also taub. Inr Handeln, das trotz Kritik von auBen nichts von seinem Automatismus einbüBt, legt bereits die Behauptung nahe: Puskin stellt die Institution hier als intakt dar.

Diese Behauptung wird durch den Umstand gestützt, daß das Duell, eine reine Männersache, hier hauptsächlich von einer Frau kritisiert und verhindert wird, denn bei den Männern handelt es sich zwar um brave, aber geistig etwas unbewegliche ausführende Organe hausfraulicher Macht. Švabrin weist Vasilisa Egorovna "kaltblütig", d. h. weder getroffen noch komisch berüht, darauf hin, dab die Duellfrage in den Zuständigkeitsberefch des Kommandanten $z u$ fallen habe.

Die Kritik am Duell kommt also in doppelter Hinsicht aus unberufenem Munde: sie ist nicht die Kritik von standesgemäb Gleichen und wird uberdies rom weiblichen standpunkt aus formuliert. Da Puškin sie durch die erwähnten Kunstgriffe noch komisch erscheinen läBt, ist sie zu völliger Wirkungslosigkeit verurteilt.

Der weitere Verlauf der Handlung verlangt natürlich, daß weder Grinev noch Švabrin durch ein Duell ernsthaft verletzt werden. Auch ist es - wie im Folgenden noch zu zeigen sein wird für die künstlerische Aussage der "Hauptmannstochter" wesentlich, dab der Festungskommandant und seine Leute nicht Musterbeispiele wacher Intelligenz sind. $D a B$ aber erzähltechnisch Notwendiges $z u$ einer weiteren schluissigen Aussage zum aktuellen Duellproblem wird und dab diese Aussage wahrhaft komisch gestaltet ist, geht auf das Konto von Puskkins Erzählkunst.

7. Es wurde bereits angedeutet, daB das Duell in der "Hauptmannstochter" nicht von zentraler Bedeutung ist. Der AnlaB zum Duell findet sich gleich zu Beginn der Beziehung zwischen Griner und Švabrin, d. h. auch ziemlich zu Beginn des Romangeschehers. Die Bekanntschaft zwischen Grinev und Svabrin kommt praktisch nur umständehalber zustande: Grinev ist nach Meinung Svabrins das einzige "menschliche Gesicht" in der Festung. (S. 420) 
Auch der Anlab für den Zweikampl ergibt sich wie von selbst aus der Rivalität um das einzige wädchen in der Festung. (Die Duelle in "Eugen Onegin" und im "Schuß" sind ungleich problematischer.) Von den gut elf Seiten des vierten Kapitels ist nicht ganz eine Seite den beiden Duellversuchen gewidmet. Da das Duell mit Rücksicht auf die Umgebung möglichst schnell und unbemerkt vonstatten gehen muß, fehlen konventionelle Riten. Grinev und Svabrin ziehen am vereinbarten Treffpunkt sofort die Degen. Schon in diesem Augenblick wird der erste Duellversuch von Ivan Ignat'id und finf alten Soldaten vereitelt. Der zweite Versuch eines Degenduells wird einen Tag später nach kurzem Kampf durch Savel'it unterbrochen.

Obwohl also dieses Duell kein zentraler Punkt im Romangeschehen ist, an dem die wichtigsten Charaktere sich profilieren, hat es folgende wichtige Funktionen:

a) Es manifestiert, daß Svabrin zum Feind Grinevs geworden ist und deutet schon an, daß dieser Feind ein aktiver Bösewicht ist: beim zweiten Duellversuch sticht Šabrin in dem Augenblick zu, als Grinevs Aufmerksamkeit durch Rufe von außen abgelenkt ist. 1 Die Feindschaft Švabrins Grinev gegenüber und sein unehrenhafter Charakter haben wichtige erzähltechnische Konsequenzen: sie bewirken die zweite Begegnung zwischen Grinev und dem Rebellen Pugałev, als Grinev Orenburg verläBt, um llar'ja Ivanovna vor einer erzwungenen Heirat mit dem Rivalen Švabrin zu retten. ${ }^{2}$ Außerdem denunziert Svabrin Grinev - dieser wird vor Gericht gestellt und kommt nur auf persönlichen Wunsch der Zarin frei.

b) Grinevs Genesung nach füf Tagen Bewußtlosigkeit ist ein erster Beweis seiner Unverletzlichkeit, ein erstes Glied in der

'In der "Hauptmannstochter" stimmen Äußeres und Charakter der Personen überein: Svabrin wird als häBlich bezeichnet ( $S .420$ ), er hat böse Augen (S. 479). Der einäugige Iran Ignat'id ist begriffsstutzig. PugaCev hat zwar ein Diebsgesicht, aber dieses Gesicht ist nicht unsympathisch (S. 410). Es wird immer wieder darauf hingewiesen, daB seine Augen leuchten und lebhaft sind.

${ }^{2} \mathrm{Da}$ die Rettung Mar'ja Ivanovnas nur mit Pugaðevs Hilfe erfolgen kann, erfullt sich so ein Teil der Traumvision Grinevs: Pugs$\chi_{e v}$, der bärtige, grausame Bauer, wird in gewissem Sinne sein "posaženyj otec". 
Kette glücklicher Zufälle, die bei seinen Begegnungen mit Pugater ausschlaggebend sind und ihm - in Form der Furbitte Katharinas II - schlieBlich das Ieben retten. Die glücklichen Zufälle machen das erzählerische Prinzip des Romans aus - ohne sie würden die Geschehnisse nicht vorangetrieben.

c) Als Folge des Duells wird noch einmal die Stimme von Grinevs Vater vernehmlich, dem der Zweikampf durch Švabrin hinterbracht wurde. Als Vater, von dessen neun Kindern nur eines am Leben blieb, äußert er sich zum Duell nicht theoretisch als zu einer Institution, die man billigen oder ablehnen kann. Er sieht das Duell unter dem Blickwinkel der potentiellen Lebensgefahr für seinen einzigen Sohn. In poltrigem Tonfall verbittet er sich derartige Streiche und erinnert - gegen Ende der vorbereitenden Handlung und vor Beginn der Haupthandlung, dem Kosakenaufstand - daran, wozu ein Degen da ist: zur Verteidigung des Vaterlandes. Die väterlichen Vorstellungen sind durchaus gewichtig in diesem Roman, ${ }^{1}$ hatte es doch im llotto zum ersten Kapitel geheiBen: "Und wer ist sein Vater?"

Der Vater ist jemand, dem das Wichtigste in seinem Leben der wilitärdienst war, der seinen noch ungeborenen Sohn bereits als Sergeanten der Garde eintragen läßt. Als der Sohn dann mit siebzehn Jahren seinen Militärdienst antritt, werden ihm vom vater einige gute Ratschläge mit auf den Weg gegeben, die in der Ermahnung gipfeln: "Hüte...Deine Ehre von Jugend auf". Diese Wahnung hat der angebliche Herausgeber Puskin dem ganzen Roman als wotto vorangesetzt, sie gehört mit $z u$ den heimlichen Themen des Romans. Dem offiziellen Thema, der Hauptmannstochter, der gegenseitigen Liebe Mar'ja Ivanovnas und Grinevs, ist innerhalb der vierzehn Romankapitel nur ein Bruchteil des Raumes gevidmet, den die Problematik von Ehre, Anarchismus und Herrsciaft einnimmt.

${ }^{1} V_{\xi}$. N . V Izmajlov, "Istorija russkogo romana v dvuch tt.", Bd. 1 (1962), S. 195: "...Die ganze weitere Geschichte Grinevs stellt - trotz aller Schwierigkeiten und Fehler - die Befolgung der väterlichen Instruktionen...dar...". 
8. Wie sieht die Realität des Militärdienstes aus, der Grinev mit den väterlichen Ratschlägen im ohr gegenübertritt, ${ }^{1}$ was ist zu Grinevs Ausbildungsstätte, der Festung Belogorskaja, und seinem direkten Vorgesetzten, dem Kommandanten Mironov, $z u$ sagen? Der Orenburger General hatte im Zusammenhang mit Belogorskaja von "echtem" Dienst und von Disziplin gesprochen. Wenn man diese Maßstäbe, die sich ja mit denen des Vaters (A. P. Griner) decken, an die Wirklichkeit anlegt, und wenn man sich - wie Grinev das tut - unter der Festung düstere Bastionen, Türme und Wälle vorstellt, möchte man das Kapitel III "verkehrte Welt" nennen. Die Festung ist ein Dörfchen mit Holzzaun. Es gibt nur eine Kanone, die von Kindern mit allem möglichen Unrat vollgestopft worden ist. Der Kommandant ist der Ansicht, daB sein neuer Untergebener beim Exerzieren nicht zuschauen sollte - er läßt nur zu seinem eigenen Vergnügen exerzieren, nent seine Soldaten liebevoll "soldatuski" und "detuski". Diese wissen nicht, wo links und rechts 1st. Es gibt weder Truppenbesichtigungen noch sind Wachtposten zu kontrollieren. Die Kommandantenfrau beurteilt die Lage realistisch, wenn sie zu ihrem Mann sagt: "Weder werden sie (die Soldaten) ausgebildet noch verstehst du selbst etwas vom Dienst. Es wäre besser für dich, zuhause $z u$ sitzen und $z u$ Gott $z u$ beten." (S. 421)Die Festung ist - wie Grinev sagt - allein dem Schutze Gottes überlassen.

Den Festungsbewohnem wird ihre Unzulänglichkeit so wenig bewußt wie den städtischen Beamten ihr Versagen im "Revisor" $(I, 1)$, und darin liegt für den Außenstehenden Komik. ${ }^{2}$ Hinter dieser komischen Darstellungsweise verbirgt sich indes ernsthafte Kritik. In einer 1834 unter dem Titel "Geschichte des Pu-

${ }^{1}$ Den Vorstellungen seines Vaters gemäß soll Grinev ein echter Soldat sein, Pulver riechen, arbeiten, nicht bummeln; wem er den Treueschwur geleistet hat, soll er dienen; seinen Vorgesetzten soll er gehorchen, seine Ehre wahren. (S. 397 ..)

${ }^{2}$ Das durch diese Komik erzeugt Lachen richtet sich gegen die Militärs zur Zeit des Pugacevschen Aufstandes. Bergson spricht von der Erziehungsfunktion des Lachens: "Ist Demutigung sein Zweck, so muB es der Person, der es gilt, eine peinliche Bmpfindung verursachen." In: "Das Lachen" (1948), S. 107). 
gacevschen Aufstandes" erschienenen historischen Abhandlung ${ }^{1}$ sagt Puskin in Bezug auf Pugater und seine verbrecherischen Komplizen: "Und solche Leute erschüterten den Staat!" 2 Die Beschreibung des zaristischen Militärs in der "Hauptmannstochter" evoziert die Feststellung: und solche Leute verteidigten das Land!

9. Grinevs Aufzeichnungen machen sichtbar, welchen Gegebenheiten sich ein junger Offizier gegenübersieht, der zu Zeiten des Pugadevschen Aufstandes in den Dienst der Armee getreten ist. Die Repräsentanten der Landesverteidigung sind entweder spielernaturen (Zurin, Kap. 1), opportunistische, nicht auf das Wohl des Landes bedachte Befehlsgewaltige (der Orenburger General, Kap. X), brave, doch absolut unfähige Festungsverteidiger oder - was Grinev für besonders verwerflich hält illoyale Vertreter des Adels (Šrabrin). Innerhalb dieses morschen Apparates gegenüber den wilden Horden Pugalevs zu überleben, scheint aussichtslos. Deshalb bedare es der bereits erwähnten märchenhaften Zufälle. 3 Die ganze "Hauptmannstochter"

1Vgl. dazu P. Brang, "Pukkin und Krjukov" (1957), S. 22: "Man darf nicht vergessen, daB die therlieferung uber den Pugaðevschen Aufstand damals nur teilweise gesammelt war und in noch geringerem Maße publiziert worden war - dieser Arbeit unterzog sich ja erst Pułkin - da Pugatev offiziell noch immer totgeschwiegen wurde...".

2A. S. Puskin, "Poln. sobr. soc. v desjati tt.", Bd. VIII (1951), S. 182 .

3Vgl. H.-J. Gerigk, "Iiterarisches Gebilde" (1975), S. 192 1.: "Puskins 'Hauptmannstochter' ist der narziBtische Tagtraum eines Untertanenbewußtseins. Der Titel der Erzählung nennt den Hauptgegenstand der erschlossenen Wirklichkeit: die Jauptmannstochter Mar'ja Ivanovna Mironova. Die wirkliche Jauptperson, nämlich das diese Wirklichkeit bestimmende, ererschließende Bewubtse in ist indessen Petr Andreevid Grinev, der Erzähler... In der 'Hauptmannstochter' wird ein Bewußtsein in Anschlag gebracht, das sich angesichts bedrohlichster Staatsgefährdung den freundschaftichsten Umgang mit dem namhaften Haupt des hereinbrechenden Unheils ausdenkt.... Es ist zweifellos die langstreckige...Pointe der Erzählung, dab hier richt selbstherrliche Anpassung zur Darstellung kommt, soncern das schutzsuchen dessen, der schutzlos ist in der Konirontation mit der stets übermächtigen Wirklichkeit." 
kann als utopisches Gedankenspiel des jungen Grinev angesehen werden. ${ }^{1}$ Die wichtigsten Säulen dieses utopischen Gedankengebäudes sind:

a) die Freundschaft des jungen Adligen mit dem Rebellenfihrer Pugalev; sie gründet sich auf eine Episode im zweiten Kapitel: Grinev schenkt dem ihm unbekannten Pugalev seinen Hasenpelz, und Pugalev versichert, daB er diese Freundlichkeit sein "Leben lang" nicht vergessen werde.

b) Die Beseitigung des Verciachtes der Kollaboration Grinevs mit den Rebellen und die Begnadigung Grinevs durch Katharina II.

10. Den (fast unmerklichen) Wendepunkt von der Realität in die Utopie markiert der Schneesturm im zweiten Kapitel. Grinev hat soeben sein Elternhaus verlassen, möchte die gerade erlangte Freiheit zur Schau stellen, miBachtet deshalb den Rat des Kutschers und gerät in einen gefährlichen Schneesturm. Er schläft ein und träumt. Bevor Grinev den Traum erzählt, nennt er ihn "prophetisch" in Bezug auf die "seltsamen Umstände" seines Lebens. (S. 408) In diesem Traum ist die Stelle seines Vaters von einem schwarzbärtigen Bauern usurpiert, der von Blut und Leichen umgeben ist, aber paradoxerweise eine zärtliche Beziehung zu Grinev erkennen läBt. Dieser Traum ist nicht nur prophetisch, weil er die Begegnung Grinevs mit Pugacev und die Besonderheit ihrer Beziehung voraussagt, sondern er hat symbolischen Gehalt, indem er anzeigt, daB Grinev in eine Welt kommt, in der die väterlichen Vorstellungen verćrängt worden sind durch jemanden, der schrecklich und zärtlich zugleich, d. h. unberechenbar ist.

Der Schneesturm bringt - das zeigt die weitere Lektlire des Romans - eine iletamorphose Grinevs: aus dem unverninftigen Pe-

1Vgl. A. Schmidt, "Rosen \& Porree" (1959), S. 301 : "Die subjektive Realität (Erlebnisebene II) ist stärker als die objektive Realität (Erlebnisebene I). Hier liegt ein Gedankenspiel vor, "bei dem in tödlichen Situationen ein E II das tberleben bzw. Sterben erleichtert...". (Als Gedankenspiel bezeichnet Schmidt das Gemisch aus $E$ I und $E$ II). 
trusa ist plötzlich ein Mann mit Prinzipien, ein loyaler 0ffizier seiner Zarin geworden. Darüberhinaus erweist sich Grinev jetzt, da sein Vater mit den unverrückbaren Wertmaßstäben durch e inen unberechenbaren Vertreter ersetzt ist, als kluger Taktiker, der Pugalev gewachsen ist und die Psyche Pugačevs, des Kosaken und angeblichen Peters III, ertastet: mal appelliert ex an die Gefühle, ${ }^{1}$ mal an den Verstand ${ }^{2}$ des Kosaken und mal an das Nachtbewußtsein des Usurpators. ${ }^{3}$ Bei allen Begegnungen zwischen Grinev und Pugalev - die also gleichzeitig Freunde und Feinde sind - waltet der glückliche Zufall: 4

a) Nach seiner Begnadigung durch Pugarev wundert Grinev sich Uiber die "seltsame Verkettung der Umstände" (S. 471): in Erinnerung an den Hasenpelz hat Pugacev ihm das Leben gerettet.

b) In einem "Anfall von Grobmut" (S. 481) geht Pugaxev nicht auf die Geldforderung des Dieners Savel'il ein. (Savel'it hat auf Heller und Pfennig zusammengerechnet, was seinem Herm durch Pugarevs Leute abhanden gekommen ist.)

c) "Glücklicherweise" hört der Usurpator auch nicht hin, als Savel'it zum zweiten llal die Rechnung erwähnt. (S. 505)

d) Als Grinev Kar'ja Ivanovna aus Śvabrins Händen retten will, glaubt er, die "Vorsehung" habe ihn wieder mit PugaCev zusammengefuinrt, damit dieser ihm helfe. (S. 500)

e) "Zum Glück" widerspricht Chlopuška, als Beloborodov Grinev hängen lassen will. (S. 502)

1) Als Grinev mit Pugader zur Festung Belogorskaja fährt, scheint es ihm, als sei er durch eine "seltsame Verknüp-

${ }^{1}$ Pugačev ist $z$. B. empört darüber, daB eine Vlaise von seinen Leuten ungehörig behandelt wird. (S. 500)

2 "therlege doch, kann ich dich als Zaren anerkennen? Du bist ein gescheiter Wensch, du würdest selbst merken, daB ich schwindle." (S. 476) - "Urteile doch selbst...ob ich in Gegenwart deiner Ieute erklären konnte, dab die Tochter der lirronovs lebt." (S. 512)

3"Mein Kope ist in deiner lland: läbt du mich frei, so danke ich dir; läBt du mich hinrichten - ist Gott dein Richter;" (S. 477).

${ }^{4}$ Die Zufälle werden immer logisch erklärt. Sie bewegen sich an der Grenze des Wahrscheinlichen und erscheinen erst in ihrer Gesamtheit als Utopie. 
Pung der Ereignisse Geheimnisvoll" mit Pugacev verbundem. (s. 505)

11. Der utopische Charakter der Aufzeichnungen Grinevs gestattet Puskin, auf Unzulänglichkeiten des Staatsapparates zur Zeit des Pugacevschen Aufstandes hinzuweisen. (Diese Kritik trägt Pułkin überdies nur als Herausgeber vor.) Durch die utopische Freundschaft eines offiziers mit einem Rebellenfuhrer kann Pułkin sich auch zum Anarchismus ${ }^{1}$ im Allgemeinen und zu Pugacer im Besonderen äuBern. Als Wesensmerkmale des Anarchismus erweisen sich in der "Hauptmannstochter" :

a) Die Ignorierung jeglichen Prinzips von Gesetz und Recht, 2 alle Entscheidungen werden nach Lust und Laune getroffen. 3

b) Die Wichtigkeit der Person des Anfuhrers. Pugačer fesselt seine Anhänger nur durch seine Person. Er hat keine revolutionäre Theorie, keine langfristige strategie, die einigend und disziplinierend wirken könnte. Der Kosakenaufstand steht und fällt mit dem Ansehen Pugacevs.

c) Destruktionswille ist die Hauptantriebskraft der Anarchisten. Pugacer sieht instinktiv die Gefahr, daB sich die Zerstörungswut der un ihn gescharten Verbrecherelemente auch einmal gegen den Anführer des Aufstandes richten

1Vgl. P. Avrich, "The Russian Anarchists" (1971), S. 3: "... however much Russian anarchism owed its predecessors in Western Europe, it was deeply rooted in a long tradition of native radicalism stretching back to the peasant revolts of Stenka Razin and Emelian Pugacher, a tradition which was shortly to reach a climax in the kevolutions of 1905 and 1917."

${ }^{2}$ Dieser Tatbestand wird symbolisiert durch das Analphabetentum Pugačevs. Als er die Liste Savel'ils studieren soll, bemerkt er: "Nasi svetlye oxi ne mogut tut nitego razobrat'." (Eine sehr euphemistische Umschreibung). Pugacer spricht von "vran'e" (S. 480), d. h. er hat keinen Begriff von rechtmäßigem Eigentum.

${ }^{3}$ Grinevs Appelle an den Usurpator Pugacev rufen zweimal eine im Wortlaut last übereinstimmende selbstgefällige Reaktion hervor: "Kaznit' tak kaznit', milovat' tak milovat'."

(S. 477) Und: "Kaznit' tak kaznit', Zalorat' tak Zalorat': takov moj obycaj." (S. 513) Nicht umsonst vergleicht das Hotto von Kap. XI Pugacev mit einem Löwen, dessen Natur wild ist und der nur mit vollem Magen ungefährlich ist. 
kann. 1

d) Das Volk, das hinter dem Usurpator und seiner Bande herläuft, lot gesinnungsloser, stumpfer Pöbel, ${ }^{2}$ der beherrscht gein $\mathbf{1} 11$, für RechtmäBigke1t oder UnrechtmäBigke1t aber keine Kriterien kennt.

Die Macht des Usurpators ruht also auf schwankender Grundlage.

Tas sagt Puškin zu Pugąev? Im November 1824 b1ttet er in e1nem Brief aus Michajlovgkoe seinen Bruder I. S. Puskin in Petersburg, ihm einiges Tataachenmaterial über Sten'ka Razin zu verschaffen, "die elnzige poetische Gestalt der russischen Geschichte. ${ }^{3}$ Im selben Monat desselben Jahres möchte er auch über Pugacer Näheres erfahren, 4 und Pugacer - so möchte man sagen ist die einzige poetische Gestalt in der "Hauptmannstochter".

${ }^{1}$ In Kap. XI sagt PugaCer: "Ulica moja tesna...Rebjata mo1 umnitajut. On1 vory...pri pervoj neudace onl svoju seju vykupjat moeju golovoju." (S. 507). - Die in Bezug auf seine Leute skeptische Bemerkung "ulica moja tesna" tut Pugąer auch in Pujking historlscher Abhandlung "Istorija Pugacevan, S. 180. 2Als Pugacer die Pestungsbewohner zwingt, einen Eid auf tha zu lolsten, he1Bt es: "Narod poralil na plosxad'n (S. 464) während Grinev von sich und den Festungsverteldigern sagt: "nas pognali tuda že." purkin betont immer wieder, dab das Volk hinter PugaCer herläuft: "narod brosilsja 28 nim" (S. 467), "narod s krikom brosilsja" (s. 478), "narod...tolpoju bezal za nami" (S. 509). Tährend die Frau des Kommandanten "zlode1" gchre1t, he1Bt es uber das Volk: "narod anjal sapkin (S. 478), nzitel1 rychodili iz domor s chlebom 1 sol' jun (S. 464), "zitel1... podchodili odin $z a$ drugim, celuja raspjatie 1 potom klanjas samozvancu" (S. 466). Röhepunkt der ferächtlichmachung des Volkes lat die Festatellung eines Kosaken (in Kap. VIII), man erkenne die hohe stellung pugaders schon daran, daB ex zum Mittagessen zwel Spanferkel verspeist habe, im Schwitzbad ungewöhnlich hohe Temperaturen aushalte und das auf seiner nackten Brust die kalserlichen Abzeichen zu sehen gewesen selen. (S. 472) - N. V. Izmajlovs Vorurtelle gegenüber dem Volk machen ihn blind fü die Puskinsche Darstellung. Sorohl in "Orenburgskie materialy Pukkina difa 'Istoril Pugacera' 1 'Kap1tanskoj dođk1', in: "Puskin" (1953), S. 297 als auch in seiner Geschichte des russischen Romans, Bd. 1, S. 199 - 201, schätzt er das Volk und die Xomplizen PugaCers positiv ein. ${ }^{3} \nabla_{g l}$. A. S. Pukkin, "Poln. sobr. sod. $\nabla$ degjat1 tt.", Bd. X $(1951)$, S. 108 .

4 ebd., S. 106 (Brief an I. S. Pukkin vom November 1824). 
Wenn Pugacer als Usurpator auch teils grausame Züge hat, ${ }^{1}$ teils einfach als komisch wirkend dargestellt wird, 2 so sind diese Eindrüke doch nicht ganz beherrschend. Das melancholische Lied, das er seine Kosaken anstimmen läBt (S. 474) und das Gleichn1s vom Raben und vom Adler, das er Griner mit "wilder Eingebung" erzählt, um ihm seine Person und sein Handeln zu erklären (S. 507), offenbaren, daB Pugaðev tiefer Empfindungen fähig ist, $\mathrm{daB}$ er von der Richtigkeit seines Handelns überzeugt ist. Er leitet seinen Herrschaftsanspruch einfach aus seiner auBerordentlichen Natur, seinen physischen Kräften her.

Das Kosakenlied zeigt in poetischer Verschlüsselung das Schicksal der Sänger, ohne daB sie sich dessen bewubt sind ${ }^{3}$ in der Poesie des Gleichnisses möchte Pugaðer sich erklären, aber das Gleichnis trifft nicht zu. ${ }^{4}$ Die Kosaken und ihr Anführer wissen also im Grunde nicht, wer sie sind. Sie sind unwissentlich Irregeleitete, 3 deshalb erfuilt Griner das Lied der Kosaken mit "poetischem Schrecken", und deshalb fühlt er sich

${ }^{1}$ Bei der Einnahme der Festung Belogorskaja läBt Pugąer ungeruhrt alle loyalen Festungsbewohner hängen.

${ }^{2} \mathrm{DaB}$ Pugačev keine Ahnung von der RechtmäBigkeit von Institutionen hat, wirkt oft komisch. In Kap. VIII sagt er zu Grinev: "Du glaubst also nicht...daß ich der Zar Petr Fedorovic bin? Nun gut. Aber hat nicht der Kühne Erfolg?" - Es klingt komisch, wenn Pugacev Titel aus dem Bereich institutionalisierter Macht auf seine Räuberbande transponiert und entlaufene Sträflinge mit "General" und "Obersekretär" anredet (Kap. IX, XI). Ebenso wirkt es komisch, wenn Pugače - weil Gold ein Symbol fur Herrschaft ist - seine Hüte mit Goldpapier ausschlägt und inmitten dieses Budenzaubers theatralische Posen einnimmt (Kap. $X I)$.

${ }^{3}$ Den Räuber des Kosakenliedes ereilt schlieblich die gerechte und harte Strafe des Zaren.

${ }^{4}$ Pugacer vergleicht sich mit dem edlen Adler, der sich von frischem Blut nährt und den Aas Iressenden Raben verachtet. Dies Gleichnis trifft nicht zu, weil Pugadev keinen Begriff von Staat und Moral hat. Er schaut Grinev nur schweigend und erstaunt an, als dieser inm das Kalmückenmärchen unter moral1schem Gesichtspunkt erklärt: von Mord und Totschlag leben, heiBt sich von Aas nähren.

${ }^{5}$ Grinev fuhlt sich von der Menge und dem Verräter Šrabrin, die Pugatev umringen, daran gehindert, dem Usurpator bewuBt zu machen, wer er ist. (S. 516) Die Menge und Svabrin werden von Puskin verächtilch dargestelit - Pugacev nicht. 
bei seinem Abschied von Pugater von tiefem Mitleid ergriffen. (S. 516)

Bei allem Beharren Pulkins auf der Notwendigkeit des guten Funktionierens rechtmäBiger Institutionen, auf standesgemäß ehrenhaftem Verhalten innerhalb dieser Institutionen, zeichnet er den Usurpator nicht als rein negative Gestalt, ${ }^{1}$ sondern als unwillkurlich faszinierendes Naturkind, das in seiner Unwissenheit eher bemitleidenswert als verurteilungswüdig ist. ${ }^{2}$ Diese Sicht eines Rebellenfuhrers und die ernsthafte Kritik an den Repräsentanten staatlicher Macht waren eigenwillig genug, um Puskin nur als Herausgeber hinter die Grinevsche Utopie zurücktreten zu lassen.

Die Institution "Duell" - das sei noch einmal betont - steht infolge der Akzente, die das Sujet der "Hauptmannstochter" setzt, nicht im Zentrum des Geschehens. Ihre Gültigkeit bleibt indes auch in diesem Werk Pulkins fraglos. Diese Erkenntnis ist in Bezug auf einen Autor, der sich der Problematik des Duells so sehr bewuBt ist wie Puskin, durchaus bemerkenswert.

1Vgl. P. Brang, "Pułkin und Krjukov" (1957), S. 56: "Xermjajevs ÄuBerungen (in N. I. Cernjajer, "'Kapitanskaja doßka' Pußkinan (Moskau, 1897) treffen sich mit der... Feststellung von Pincuk, daB Puskins Pugąev kein melodramatischer Bösewicht sei, 'als welchen jeder beliebige Verfasser historischer Romane zu Pußkins Zeit ihn dargestellt haben würde, auch keine titanische Figur, sondern einfach ein Mensch, der nach einer Rolle sucht'."

In der "Istorija russkoj literatury", Bd. VI (1953), Hrsg. D. D. Blagoj, B. P. Gorodeckij, B. S. Mejlach, heiBt es: "Noch schwieriger stand es mit der Darstellung der Anhänger Pugačevs und insbesondere Pugacevs selbst im Roman... Puskin ...hat in der "Hauptmannstochter" radikal mit der opfiziösen Tradition, Pugačer selbst als Bösewicht darzustellen, gebrochen." (S. 288)

2 In seiner Iiteraturgeschichte, Bd. 1 (1962), sagt N. V. Izmajlor, Griner beuge sich unwillkuirlich vor der moralischen GröBe Pugaders. (S. 195) Dies trifft nicht zu. Grinev bemitleidet Pugadev, weil dieser infolge seines Unwissens um moralische Prinzipien ins Unglück läuft. 
M. Ju. Lermontov, "Ein Held unserer Zeit"

... when they were got out of the Wilderness, they presently saw a Town before them, and the name of that town is Vanity; and at the Town there is a Fair kept, called Vanity Fair...This Fair is no new erected business, but a thing of ancient standing....at this Pair are all such Merchandise sold as....Honours, Preferments, Titles...Lusts, Pleasures, and Delights of all sorts... And moreover, at this Fair there is at all times to be seen Jugglings, Cheats, Games, Plays, Pools, Apes, Knaves and Rogues, and that of all sorts... There are to be seen, too, and that for nothing, The fts, Murders, Adulteries, False-swearers, and that of a blood-red colour.

John Bunyan, "The Pilgrim's Progress"

Yes, this is VANITY PAIR: not a moral place certainly; nor a merry one, though very noisy.

William Makepeace Thackeray, "Vanity Fair"

1. Lermontor sagt dem Leser nicht wie die Allegorie John Bunyans, um welches zentrale Problem es im "Held unserer Zeit" geht. Auch ist nicht - wie bei Thackeray - ein auf das Thema hinweisendes Vorwort vorangestellt oder ein die Aussage sentenzhaft bekräftigender RomanschluB gegeben. Selbst als Lermontov 1841 eigens ein Vorwort verfaBt, um verständnislose Angriffe auf den 1840 erstmals veröffentlichten Roman zurlickzuweisen, ${ }^{1}$ setzt er

${ }^{1} \mathrm{Vgl}$. B. M. Éjchenbaums Kommentar zu diesem Vorwort in M. Ju. Lermontov, "Poln. sobr. soč.", Bd. IV (1948), s. 464: "(Lermontov)... denkt dabei hauptsächlich an S. P. Sevyrev, der von Pecorin als von einer unmoralischen und verderbten Erscheinung gesprochen hatte, die im russischen Leben nicht existiere und zu der 'Traumwelt gehört, die durch falsche Nachahmung des Westens in uns erzeugt wird'." - Bei den Kritikern, die PeXorin flir ein Portrait Lermontovs und seiner Bekannten hielten, habe Lermontov einep Artikel aus der Zeitschrift "Majak" vor Augen gehabt, sagt Ejchenbaum weiter. - Im Folgenden stammen alle Zitate aus der angegebenen Ausgabe. 
der miBverstandenen Botschaft seines Romans keine eindeutige Interpretation entgegen, sondern deutet nur ironisch an, dab er auf eine sehr weit verbreitete Krankheit hingewiesen habe, die er aber nicht heilen wolle und von der nur Gott wisse, ob sie uberhaupt zu heilen sei. Dieser weisen Skepsis muB sich der Leser wohl anschließen, wenn er ziemlich in der Mitte des Romans die Diagnose der Krankheit - einer Jahrtausende alten, wie Iermontor andeutet - gefunden zu haben glaubt: "Oh Eitelkeit, du bist der Hebel, mit dem Archimedes die Helt aus den Angeln heben wollte!..". (S. 81 )

2. Nun ist der "Held unserer Zeit" kein Roman, in dem kontinuierlich, Punkt für Punkt ein Krankheitsbild aufgezeigt würde, das zwangsläufig zu der genannten Diagnose führen muB. Vielmehr sind funf selbständige Novellen aneinandergereiht, die in zwei Teilen zu einem Roman zusammengefaßt wurden. Die ersten beiden Novellen werden als Reiseerinnerungen des Erzählers ausgegeben die drei übrigen Novellen als vom Erzähler herausgegebene Tagebuchnotizen des Helden PeXorin. Der Einschnitt zwischen dem ersten und zweiten Teil des Romans liegt aber nicht zwischen den Reiseaufzeichnungen und den Tagebuchnotizen, sondern vor der zweiten Novelle des Tagebuchs, "Prinzessin Mary", die etwa so lang ist wie alle ubrigen Novellen zusammen und die auch dem Inhalt nach das Fundament zur Analyse PeCorins darstellt.

Die in funf Novellen geschilderten Ereignisse laufen nicht in Gegenwart oder Vergangenheit kontinuierlich hintereinander ab. In der erzählerischen Gegenwart spielt nur die zweite Novelle des ersten Romanteils: der Erzähler begegnet für einen kurzen Augenblick dem Helden der Béla-Episode der ersten Novelle ${ }^{2}$. Hier gelangt er auch in den Besitz der Tagebuchaufzeichnungen Pečorins. Alle im Tagebuch erzählten Ereignisse haben vor der zuerst erzählten Bèla-Geschichte stattgefunden.

Wenn man schlieblich in Betracht zieht, daB Handlungsort und

${ }^{1}$ Ein Gedanke Pečorins, als er sieht, wie selbstgefällig und unkritisch Grư̌nickij auf seine Schmeicheleien reagiert.

${ }^{2}$ Maksim Maksimyč gibt an (S. 14), daß die von ihm erzählten Ereignisse nun fast füf Jahre zurückliegen. 
Handlungsträger in allen fünf Novellen (bis auf PeCorin) verschieden sind, so ist zuzugeben, daB der Dichter sein Anliegen wahrhaft gut versteckt hat: ${ }^{1}$ man muB den Roman wie ein Suchbild von allen Seiten betrachten, um schlieblich in der Mitte das eigentliche Thema $z u$ finden, um das sich - thematisch dazugehörig und ästhetisch reizvoll - das Beiwerk rankt.

3. Die Lektüre der ersten beiden Novellen hat vor allem einen eindeutigen Effekt: der Leser erwartet neugierig die Enthuillung ron Petorins Charakter in dessen Tagebuch. Obwohl uber Pecorin in diesen beiden Novellen quantitativ nicht wenig ausgesagt ist, wird sein Charakter rätselhaft gehalten. Maksim Maksimy kündigt vor Beginn seiner Erzählung spannungserzeugend an: "Er war ein toller Bursche...nur etwas seltsam...Ja, er war sehr seltsam...". (S. 14) Und: "Es gibt eben wirklich Leute, denen es rom Schicksal bestimmt ist, einige ungewöhnliche Dinge zu erleben!" (S. 15) Entsprechend sind alle Urteile über Pecorin rätselhaft und zwischen "entweder" und "oder" in der Schwebe gehalten. Pečorin sagt über sich selbst: "Ich habe einen unglückseligen Charakter: ob ich durch meine Erziehung so geworden bin oder ob Gott mich so geschaffen hat, ich weiB es nicht...". (S. 36) Und: "Ob ich ein Dummkopf oder ein Bösewicht bin, weiB ich nicht." (S. 37) Maksim Maksimyč muB zugeben: "Ob er wirklich nicht weinen konnte oder sich beherrschte - weib ich nicht." (S. 41) Auch der Erzähler gewinnt kein sicheres Urteil: "Das (Petorins Augen, die nicht lachten, wenn er lachte) ist entweder ein Zeichen schlechten Charakters oder tiefen, beständigen Kumers." (S. 49)

Der Leser beobachtet, mit welch rücksichtslosen Praktiken Pečorin in den Besitz von Bẻla gelangt - er sieht aber auch seine

\footnotetext{
1 In dem 1841 verfaßten Vorwort sagt Lermontor, daB in einem "anständigen Buch" lautes Schimpfen und eindeutiges Moralisieren keinen Platz habe. - AuBerfiktionale Hinweise, die zum VerStändnis des Romans beitragen könnten, existieren nicht. B. M. Ejchenbaum schreibt, daB der Roman weder in Lermontors Briefen noch in Erinnerungen an ihn erwähnt werde. Vgl. S. 243 in "Stat'i o Lermontove" (1961).
} 
zärtliche Liebe zu der schönen Kaukasierin. ${ }^{1}$ Er sieht das Nachlassen dieser liebe und dann die krankhafte Trauer um das gestorbene Mädchen, das Preundliche und doch herzlose Verhalten PeXorins bei seinem Wiedersehen mit Maksim Maksimy - und muB sich vorläufig dem Urteil des alten Stabskapitäns anschlieBen: "Solch ein Mensch war er, Gott allein mag ihn kennen." (S. 27)

4. Zuverlässige Anhaltspunkte zur Beurteilung des bislang geheimnisvollen Pečorin finden sich erst in der "Prinzessin Mary". Die Selbstanalysen Petorins - die daraufhin untersucht werden müssen, ob sie als Leserurteil übernommen werden kön$n^{2}{ }^{2}$ - und insbesondere sein Verhalten sind die entscheidenden Faktoren zum Verständnis seines Charakters. Dramatischer Höhepunkt in der "Prinzessin Mary" ist das Duell zwischen PeCorin und Grusnickij. Nachdem bewiesen sein wird, daß das Duell eine im Gehlenschen Sinne kommentarlos akzeptierte und automatisch funktionierende Institution der fiktionalen gesellschaftlichen Wirklichkeit ist, soll - wie in "Eugen Onegin" und im "SchuB" das Besondere an Petorins Verhalten im Zweikampl gezeigt werden. Das MaB seines Abweichens von der allgemeinen Verhaltensnorm gibt AufschluB über seinen Charakter.

5. Das Wort "Duell" fällt bereits in der zweiten Tagebucheintragung Petorins. Pecorin erfährt vom Kurarzt Verner, welche Gedanken die Prinzessin über Grušnickij hegt: "Die Prinzessin sagte, sie sei liberzeugt, daB dieser junge Mann im Soldatenmantel aufgrund eines Duells degradiert worden sei...". (S. 76)

Diese Vermutung der Prinzessin impliziert die Selbstverstän-

${ }^{1}$ Petorin hetzt Bẻlas Bruder Azamat so auf daß dieser vor Kummer ganz blaB und ausgemergelt aussieht (S.21) und nbleich wie der Tod" verspricht, seine Schwester zu entführen. (S. 22)

2 Dies wird vom Erzähler und von Pedorin suggeriert. Der Erzähler betont in seinem Vorwort zum Tagebuch, Pecorins Aufzeichnungen seien die Selbstanalyse eines reifen Geistes (S. 54), und Pecorin gibt vor, sich selbst immer alles einzugestehen. 
lichkeit des Zweikamples in ihren Kreisen sowie die Tatsache, daß ein Duell als Degradierungsursache dem gesellschaftlichen Ansehen nicht abträglich ist. Es scheint den Betroffenen in den Augen der Prinzessin mit einer Aureole der Romantik zu umgeben und in der Eintönigkeit eines kaukasischen Badeortes etwas Prickelndes an sich $z$ u haben - sonst wäre ihr Interesse an einem Mann im Soldatenmantel kaum zu verstehen. PeCorins Reaktion paBt in dieses Bild: "Ich hoffe, Sie haben sie in diesem angenebmen Irrtum gelassen..." (S. 76)

Für die Iraglose Gültigkeit der Institution "Duell" gibt es indes noch weitere Beweise: der Ehemann von Pecorins eruherer Geliebten Vera, der mitanhört, wie Pecorin den jungen Gruðnickij fordert, ist zu Tränen gerührt, daß dieser sich um der Ehre der Prinzessin willen schlagen will. (S. 124)

Die Reaktion der Obrigkeit nach Pecorins Zweikampl mit Grusnickij zeigt, daB selbst ein Duell mit tödlichem Ausgang den Rahmen des gesellschaftlich Akzeptierten nicht sprengt. Der Kommandant glaubt nicht recht an den vorgetäuschten Unfall Grušnickijs, sagt aber nichts. Bewe1se für ein Duell liegen nicht vor - man sucht sie auch nicht. PeCorins vorgesetzte Behörde veranlaßt nur eine Versetzung und betrachtet den Fall damit als erledigt.

Die Pürstin Ligovskaja äuBert sich bei Pełorins Abschiedsbesuch zum Duell nur nebenbei und ohne besondere Anteilnahme fiur den Gefallenen, der regelmäBiger Gast ihres Hauses war. Ihre eilig vorgetragenen Floskeln drängen schlieBlich mit der Bemerkung "Mich geht das nichts an...ich kann sie nicht verurteilen, weil meine Tochter...die Ursache war" das Duell ganz beiseite, damit das Thema einer eventuellen Heirat Pecorins und der Prinzessin zur Sprache kommen kann. (S. 140 1.)

Insbesondere bestätigt natürlich das Vorgehen der Kontrahenten und ihrer Sekundanten, daß das Duell in der Romanwirklichkeit eine intakte Institution ist. Die Forderung, die Annahme der Porderung, die Verhandlungen der Sekundanten vor dem 2 weikampl und die letzten Pormalitäten auf dem Rendezvous-Platz alles vollzieht sich nach anerkanntem Verhaltensmuster. Die hier dargestellte Wirklichkeit unterliegt den gleichen Ge- 
setzen wie die Lebenswirklichkeit Lermontovs, wie der folgende Abschnitt aus einem Brief des Dichters an seinen militärischen Vorgesetzten N. F. Plautin vom Februar 1840 zeigt: 1 "Da antwortete ich, daB man in RuBland die Gesetze der Ehre so streng beachtet wie uberall und daB wir es noch weniger als andere zulassen, ungestraft beleidigt zu werden." (S. 442)

6. Vor einer Analyse des Duells soll untersucht werden, wie weit die Gestalt PeCorins bis zum Beginn des Zweikamples herausmodelliert ist und aus welchen Gründen Pexorin in ein Duell verwickelt wird.

Mit dem ersten Abschnitt der ersten Tagebucheintragung Pečorins hat es seine besondere Bewandtnis. Petorin - soeben in dem Badeort Pjatigorsk eingetroffen - hat sich noch nicht unter die Kurgesellschaft gemischt. Er betrachtet von seiner Wohnung aus, die an der höchsten Stelle des Ortes und weitab vom Kurbetrieb liegt, die ihn ungebende - wie ein Amphitheater sich aufbauende kaukasische Bergwelt. Er sieht den tief unter ihm liegenden, auf Spielzeuggröße reduzierten Kurort und empfindet diesen Anblick nicht nur als ein eminent ästhetisches Vergnügen, sondern erlebt einen - im Roman einmaligen - Ausbruch von Lebensfreude. DaB Pečrin die Luft frisch und rein wie den KuB eines Kindes empindet, läBt an den Zustand der Unschuld denken, den Katherine Anne Porter als den glucklichen Augenblick des fruhen Morgens beschreibt, "bevor wir alle wach waren und uns ineinander verwirrten wie schlecht ausgeworfene Angelschnure." ${ }^{2}$

Obwohl Petorin sich in diesem momentanen Glücksgefühl pragt "Was will man eigentlich mehr?", gibt er aup seine Frage keine Antwort, sondern es drängt ihn plötzlich, die Kurgesell-

${ }^{1}$ Lermontov war aufgefordert worden, die näheren Umstände seines Duells mit dem Franzosen Barant aufzuklären. Dieses Duells wegen wurde Lermontov in den Kaukasus versetzt. Dort fiel er gut ein Jahr später - im Juli 1841 - in einem Duell mit N. S. Martynov.

2 Katherine Anne Porter, "Pale Horse, Pale Rider" (1967), S. 113. 
schaft kennenzulernen. ${ }^{1}$

7. Während Pexorin den Berg hinabsteigt, um sich zum Elisabethbrunnen, dem Treffpunkt der Gesellschaft zu begeben, ändert sich sein Tonfall. Eben noch fand er schöne Vergleiche fiur die Natur, jetzt wechseln sich Ironie und Sarkasmus ab. ${ }^{2}$ In dem $M a B$, in dem Pecorin die Vogelperspektive aufgibt und äuBerlich auf die Gesellschaft zugeht, distanziert er sich innerlich, so daß er seine Mitwelt nun im libertragenen sinne von oben herab ansieht. Diese Mitwelt - durch PeXorins Brille betrachtet fällt durch einen besonderen Charakterzug auf: jeder möchte anders erscheinen als er ist. Tenn man sich daran erinnert, dab Pecorin die Bergwelt ringsum als Amphitheater empeunden hatte, ist man versucht, den Kurort, in den Pecorin sich nun begeben hat, als Buinne des Amphitheaters zu bezeichnen, 3 auf der es laut erster Tagebucheintragung - Folgendes zu sehen gibt: einige Gecken ${ }^{4}$ als Statisten, Gruß̌nickij, der sich um das Interesse der Furstin und ihrer Tochter bemiiht, in der Hauptrolle, PeXorin, der hier hauptsächlich nur zuschaut, und die Furstin mit der Prinzessin, um die sich das spiel dreht: sie gehen elegant gekleidet in Begleitung eines Moskauer Gecken voriber.

Die Grundregeln, die auf diesem Schauplatz gelten, werden schnell deutlich:

" "Odnako pora." (S. 66) Der Kontakt Pecoring zu seiner Umwelt ist disharmonisch - trotzdem kommt er ohne ihn nicht aus. Fast zwangsläufig manövriert er sich in Schwierigkeiten. Die fatalistische Grundeinstellung des Romans wird hier sebr indirekt zum Ausdruck gebracht.

${ }^{2} \mathrm{Vgl}$. die Beschreibung der Gecken und das Gespräch mit Gruănickif. - Zur Ironie bei Lermontov s. A. Guski, "Iermontovs Konzeption des literarischen Helden" (1970).

${ }^{3}$ PeXorins Beschreibung der Geschehnisse erinnert fortwährend an die Telt des Theaters: "prinimajut akademičeskie pozy"; "govorit...vycurno"; "drapirujutsja v neobyknovennye cuvstra"; "proizvodit' effekt"; "deklamirovat" ; "sbrasyraet tragiceskuju mantiju"; "byt' svidetelem...ljubopytnoj sceny"; "dejstrujuscie lica"; (S. $67 \mathrm{ff.}$ ) etc.

4 Worte wie "frant, erantovstro, dendi, splin, skuka" zeigen, daB dieser Teil des Romans in demselben Milieu spielt wie "Eugen Onegin". 
a) Ob jemand überhaupt eine Rolle spielen kann oder nur Statist ist, hängt von seiner gesellschaftlichen Stellung ab. Die Gecken in Uniform und Zivil, denen Petorin auf dem Wege zur Quelle begegnet, werden - obwohl sie die Provinzhäuser verachten und gewisse Manierismen der höheren Gesellschaft angenomen haben (Pose der Langeweile, Kartenspiel) - von der Gesellschaft nicht akzeptiert. ${ }^{1}$ Sie gehören nur zum Stadtbild.

b) Welche Rolle jemand spielt, hängt davon ab, wie hoch er auf der Stufenleiter gesellschaftlichen Ansehens steht.

Grušnickij, der in der großen Gesellschaft unbekannt ist und sich in das spiel nur hineinmogeln kann, weil er sich für einen degradierten offizier halten läBt, braucht Requisiten (Soldatenmantel, Krückstock) und Einfälle (lautes französisches Parlieren, Kokettieren mit einem scheinbar verletzten Bein), um überhaupt Aufmerksamkeit $z u$ erregen und sich interessant $z u$ machen. Gleich sein erster Auftritt zeigt ihn als Person ohne eigenes Gesicht ${ }^{2}$ und ohne die Fähigkeit, das wahre Gesicht anderer zu erkennen. 3

PeXorin gehört zur besten Gesellschaft. ${ }^{4}$ Er betrachtet die Schauspielerei um ihn herum amisiert und nicht ohne Verachtung. Seine uberlegene Position manifestiert er, indem er Grusnickifs

${ }^{1}$ Auf diese Gruppe trifft $z u$, was der Erzähler in "Bela" Jlaksim ilaksimy $z^{2}$ e erklären versuchte : daB der Heltschmerz (razocarovanie) wie alle Moden in der oberen Gesellschaftsschicht entstanden und dann auf niedere Schichten übergegangen sei, die ihn nun "auptrügen"; (S. 38) hier wird bereits angedeutet, daB PeXorins Problem nicht mehr der LebensüberdruB des "Childe harold" ist. Pedorin bestätigt das durch seine Ironisierung der langeweile - s. sein Gespräch mit Verner vom 13. Mai.

${ }^{2}$ zu Pexorin sagt Grušnickij, ihm liege nichts an einer Bekanntschaft mit der Furstin und inrer Tochter. Gleichzeitig tut er alles, um ihre Aufmerksamkeit $z u$ erregen. (S. 70 11.)

${ }^{3}$ Pe ${ }^{\circ}$ orin hält Grusnickijs Epigramme zwar für amüsant, aber nicht für treffend. Seine Urteile über die Kurgäste sind pauschal, teilweise sogar unsinnig ("...die am Abend Wein trinken, sind unerträglich wie alle Gesunden", S. 69). Später schätzt er die Beziehung PeCorins und der Prinzessin zu ihm falsch ein.

${ }^{4}$ Pečrin bezeichnet sich selbst als jemanden, der in der groBen Gesellschaft lebt. (S. 73) Aus dem Gespräch mit Verner (Tagebucheintrag vom 13. Mai) geht hervor, daB PeXorin Gegenstand des Residenzklatsches ist. Die Fürstin war mit seiner Nutter und "einem halben Dutzend" seiner Tanten befreundet. 
Phrasen improvisierend abwandelt (S. 71), ihm zwecks effektroller Gestaltung seiner Rolle Regieanweisungen erteilt ${ }^{1}$ oder die von Grušnickij verehrte Prinzessin unverschämt anstarrt. Er kann es sich erlauben, einen schlechten Eindruck zu machen.

Pecorins tberlegenheit ist indes nicht absolut. Als er leugnet, von der hilfreichen Geste der Prinzessin Grusnickij gegenüber gerührt worden zu sein, wird er für einen Augenblick selbst zum Schauspieler - und zwar aus dem gleichen Motiv, das Grusnickif Theater spielen läßt und das seiner Meinung nach spezifisch ist fur die Gesellschaftsschicht, der er angehört: aus Eitelkeit. (S. 73)

StandesgemäBe Eitelkeit trägt auch bei der Prinzessin den Sieg davon über spontaneität: sie ist erleichtert, daB ihre mitleidige Geste Grušnickij gegenüber unbeobachtet blieb. Durch ihre unmittelbar nach dem Vorfall am Brunnen zur Schau getragene hochmütige Unnahbarkeit erklärt sie ihre Handlungsweise für tabu.

Die erste Tagebucheintragung in der "Prinzessin Mary" hat hauptsächlich folgende Funktionen:

a) Sie zeigt, daß PeCorin sich permanent - und mit der größten Selbstverständichkeit - bewuBt ist, in einer Gesellschaft von Schauspielern zu sein. Das Motiv zu aller Schauspielerei, die Eitelkeit, hält Pecŏrin für ein typisches Merkmal seiner Gesellschaftsschicht.

b) PeXorin wird zunächst die Sympathie des Lesers gesichert: Grußnickif ist so konzipiert, daB der leser mit Pečorin über ihn lacht.2

8. Die Sympathie des Lesers beginnt jedoch erheblichen Schwankungen ausgesetzt zu sein, als von der zweiten Tagebucheintragung an Pecorin nicht mehr nur als intelligenter Spötter auftritt, der die Lacher auf seiner Seite hat, sonderm nach seinem

\footnotetext{
1 "Sie hat so samtene Augen...1ch rate dir, dir diesen Ausdruck anzueignen, wenn du von ihren Augen sprichst." (S. 71)

${ }^{2}$. Ejchenbaum betont die Kontrastfunktion Grusnickijs in "Iermontov. Opyt istoriko-literatumoj ocenki" (1967), S. 154.
} 
eigenen Handeln und seiner Selbstkritik beurteilt werden muB.

Pedorin - in souveräner gesellschaftlicher Position und mit einem scharfen Verstand begabt - empeindet das eitle Geltungsstreben eines jeden ${ }^{1}$ der inn umgebenden Kurgesellschaft als verächtlich. Er reagiert aber nicht als Mensch, der unabhängig genug ist, sich so zu geben wie er ist, der allen sein wahres Gesicht zeigt, sondern er scheint gegen die Methode der Gesellschaft eine Gegenmethode entwickelt zu haben: er präsentiert sich als Menschenverächter, der von sich behauptet: "... wir (Pečorin und Verner) sind gegen alles ziemlich gleichgültig, auBer gegen uns selbst." (S. 75) Er gibt an, zur Freundschaft unfähig $z u$ sein und legt Wert auf seine vollständige Unabhängigkeit: "tberdies habe ich ja Lakaien und Geld!" (S. 74) Peלorins Anspruch an das Leben ist - wenn man seinen Worten gegenuiber dem Kurarzt Verner ${ }^{2}$ Glauben schenkt - darauf reduziert, gut unterhalten zu werden. Damit das Spiel der ihn umgebenden Narren ${ }^{3}$ nach seinem Geschmack ausfällt, entschlieBt Pecorin sich sogar, als Regisseur und Hauptdarsteller daran teilzunehmen: "Der knoten ist geschuirzt...um das Dénouement

${ }^{1}$ Wenn das Geltungsbedürenis Grußnickijs - als dem Gegenspieler Petorins - auch in besonders zahlreichen Schattierungen herausgearbeitet wird, so ist die allgemeine Verbreitung dieses tbels doch offensichtlich: Die Furstin und ihre Tochter fuhlen sich gekränkt, daß Pedorin nicht gleich in ihrem Hause verkehrt. Die Prinzessin triumphiert innerlich, als Pexorin sich endlich um sie bemuiht. (S. 90) Es erzuirnt sie, daB PeCorin ihre Gesangskuinste nicht lobt. (S. 95) Die Dámengesellschaft auf dem Ball vom 22. Mai neidet der Prinzessin zwar ihre geschmackvolle Toilette, aber die, die sich für die "örtlichen Aristokraten" halten, verbergen ihren Neid, um sich in der Gesellschaft der Prinzessin zeigen zu können.

${ }^{2}$ Verner ist von undefinierbarem Charakter: er heiBt Verner und ist Russe, ist Skeptiker und Materialist, aber auch Dichter, hat das menschliche Herz studiert, kann von seinem Wissen aber keinen Gebrauch machen, lacht gewöhnlich über seine Kranken, aber einmal hat er auch geweint etc. Es paBt zu dem Bild, das Pecorin von sich zeichnen móchte, daß er sich diesen total unengagierten Menschen als Freund wählt. B. Ejchenbaum bezeichnet Verner neben Grušnickij als den zweiten Kontrast zu Pecorin. Vgl. S. 269 in "Stat'i o Lermontove" (1964).

${ }^{3}$ In zweiten Tagebucheintrag sagt Pe Xorin hochmitig: "Bedenken Sie, lieber Doktor...daB es ohne Dummköple sehr langweilig auf der Helt wäre...wir zwei sind gescheite Leute...". 
dieser Komödie werden wir uns schon bemühen." (S. 76) Dies ist seine Reaktion, als er erfährt, daB die Fürstin und ihre Tochter an ihm und an Grušnickij interessiert sind.

Provoziert vom Geltungsbedurfnis seiner Umgebung und auf die Theorie seiner absoluten Gleichgultigkeit und Bindungsunfähigkeit bauend, schwimmt Petorin in der "Komödie", die nun beginnt, gegen den Strom. Er irritiert die von "glänzenden Adjutanten, bleichen Moskovitern und anderen", vor allem aber von Grusnickij umschwärmte Prinzessin. (S. 80) Er kommt "enorm voran" bei seinen Plänen (S. 79), weicht nicht von "seinem System" ab (S. 97), nimmt diese oder jene Miene an ${ }^{1}$ und verwirrt die Prinzessin durch heimliche Zärtlichkeiten (S. 108, 114). Pecorins Spiel hat vor dem Duell zwei Höhepunkte:

a) Er versucht die Prinzessin demonstrativ für sich zu gewinnen, als Gruśnickij gerade zum ofpizier befördert ist und sich ernsthafte Hof enungen macht. (S. 107 f.)

b) Er gibt der Prinzessin, deren Zuneigung er gewonnen hat, zu verstehen, nur mit ihr gespielt zu haben. (S. 118)

Hier, als Gruanickij und die Prinzessin nicht mehr komisch Entlarvte, sondern Opfer sind, distanziert der Leser sich von Pečrin. Pecorin erreicht, was er in seiner Tagebuchaupeichnung vom 3. Juni als Glück definiert hat: "Für jemanden die Ursache seiner Leiden und Freuden $z u$ sein, ohne die geringste Berechtigung dazu zu haben - ist das nicht die süBeste Nahrung für unseren Stolz? Und was ist Glück? Befriedigter Stolz." (S. 99)

Da Pečorin aber nicht glücklich ist, muß nun die Frage nach der Zuverlässigkeit seiner Selbstanalysen und Theorien gestellt werden.

9. Inwieweit Pedorins Urteile uber sich selbst glaubwürdig sind, kann aus seinem Verhalten Vera gegenüber ermessen werden. Peco.rin behauptet von sich, gegen alles gleichgültig zu sein (S. 75),

${ }^{1} \mathrm{Vgl}$. S. $81,90 \mathrm{l}, 96$ und 100. Auf dieses Spiel Pečorins weist $\checkmark$. Levin hin: vgl. 'Ob istinnom smysle monologa Pecorina' in "Tvorcestro M. Ju. Lermontova" (1964). 
unfähig zu sein, sich unter dem Einfluß von Leidenschalten kopflos zu verhalten (S. 98), schon lange nicht mehr mit dem Herzen, sonderm nur noch mit dem Kopf zu leben (S.129) und seine Freiheit uiber alles zu lieben (S. 118). Er bekommt aber starkes Herzkloplen und ist von beklemmender Traurigkeit erfiullt, als er von der Ankunft Veras in Pjatigorsk erfährt (S. 78). ${ }^{1}$ Als er Vera zum ersten Mal sieht, durchläuft seine Adern "ein längst vergessenes Zittern" (S. 83), er ist sogar glücklich über den Schmerz, den er emplindet, als Vera nach diesem ersten Wiedersehen davongeht. Petorin erfüllt sklavisch jeden der Wiunsche Veras. Er verkehrt auf ihren Wunsch im Hause der Fürstin, richtet sein Vernalten dort nach inrem Mienenspiel (S. 104) und fragt Vera sogar: "Stellt dich mein Gehorsam zuprieden?" (S. 94) Nach Veras Verschwinden reitet er wie "ein Wahnsinniger" hinter inr her, er betet, weint, Plucht, lacht und sagt: "...nichts vermag meine Unrune, meine Verzweiflung auszudruicken!...all meine Festigkeit, all meine Kaltblütigkeit waren verflogen wie Rauch;" (S. 138 f.).

Es besteht also eine Diskrepanz zwischen dem Bild, das Pe Co- $^{-}$ rin von sich vermitteln möchte, und dem Eindruck, den der Leser gewinnt. Pecorins Reaktion und Gedanken im Zusammenhang mit Vera geben unwillkülich preis, was er unter der Maske von Kaltblütigkeit vor dem Leser und sich selbst verbergen möchte $:^{2}$

a) PeXorins eigentliches Problem ist seine ungluickliche Liebe zu Vera. Er gesteht mehrere Male ein, dab Vera die einzige

'M. E. Duchesne glaubt, daß der Roman nichts einbüße, wenn man die Liebesbeziehung PeXorin - Vera weglasse. Vgl. "Michel Iourévitch Lermontov" (1910), S. 175. Vgl. dagegen B. Ejchenbaum, "Stat'i o Lermontove" (1961): "..dies ist ein Tagebuch, in dem Vera eigentlich eine wichtigere Rolle spielt als Prinzessin Mary." - Um die Gestalt Veras hat Lermontov sich sehr bemiuht: in einer zweiten Textfassung (der vorliegenden) wurde ihre negative, unterdrückende Funktion deutlich herausgearbeitet. In inrem ursprüglichen Abschiedsbrief forderte Vera nicht den Verzicht Pecorins auf die Prinzessin. Vgl. V. A. Vanujlov, "Roman M. Ju. Lermontova 'Geroj nasego vremeni' (1966), S. 248.

${ }^{2}$ Pečorins Selbsterforschungen in der langen Tagebucheintragung vom 3. Juni und in dem Gespräch mit verner unmittelbar vor dem Duell (S. 129) sind Ablenkungsmanöver. 
Frau ist, die er liebt (S. 85, 138) und daB er darunter leidet, ihre Gegenwart entbehren zu müssen. 1 Pečorin muB ständig Beweise für seine Liebe erbringen, Vorwüre und eifersüchtige Klagen anhören, obwohl keine Hoffnung auf ein glückliches Verhältnis mit Vera besteht: sie ist verheiratet und todkrank. Die Märtyrerpose Veras ${ }^{2}$ nimmt PeCorin ohne Kritik hin. Der Gedanke, $\mathrm{daB}$ Vera ihn nicht um seinetwillen liebt, blitzt in ihm wohl auf, 3 aber er setzt sich nicht damit auseinander. Sogar vor sich selbst gibt er nicht $z u$, daB sein Wunsch nach Liebe unerfuilt ist. 4 Seiner Eitelkeit ist die Version Veras zuträglicher ( ihren Abschiedsbrief), und er beurteilt das Verhältnis in ihrem Sinne schlieBlich so: "Wieso sie mich so liebt, weiB ich wirklich nicht... Ist das Böse so anziehend?" (S. 96 1.)

b) Pecorin, der aufgrund seiner gesellschaftilchen Position gewohnt ist, überall zu glänzen und umschmeichelt zu sein, macht also aus der Not, nicht geliebt zu werden, ${ }^{5}$ die seine unbändige Eitelkeit befriedigende Tugend, über jedes Gefühl erhaben zu sein. ${ }^{6}$ Diese spezielle Art von Eitelkeit, die Pexorins Handeln

$1^{1}$ Ich fühlte das Bedürfnis, meine Gedanken in einem freundschaftlichen Gespräch loszuwerden... aber mit wem? Was Vera jetzt wohl tun mag? dachte ich.. Ich hätte viel darum gegeben, in diesem Augenblick ihre Hand drucken zu dürfen." (S.87 f.) "Warum will sie mir keine Gelegenheit geben, mich allein mit ibr zu treffen?" (S. 108) Vor dem Rendezvous mit Vera denkt Pexorin: "Aha!...endlich geht es doch nach meinem Wunsch." (S. 119)

"Ich habe Deinetwegen alles auf der Welt verloren...;" (S. 138) "...du machst mit mir, was du willst." (S. 120) "Du weiBt, daB ich deine Sklavin bin...;" (S. 95).

${ }^{3}$ Als Vera sich beklagt, daB sie durch Pecorin nur habe leiden muissen, denkt er: "Vielleicht...hast du mich gerade deshalb geliebt: Freuden vergiBt man, Schmerzen niemals...". (S. 83) Als Vera PeCorin auffordert, ihr alles zu gestehen, und betsuert, daB sie nur sein Glück wolle, heiBt es: "Das Blaubte 1ch nicht ganz...". (S. 120)

4nJetzt möchte ich nur noch geliebt werden....mir scheint sogar, ich hätte an einer beständigen Bindung genug: traurige Gewohnheit des Herzens!..." (S. 84)

${ }^{5}$ Vera weiB, daB PeXorin im Grunde unglucklich ist: "Niemand kann so wahrhaft unglúcklich sein wie $\mathrm{Du}$, weil niemand so bemüht ist, sich das Gegenteil einzureden." (S. 137)

6

Der Gedanke, in die Prinzessin verliebt zu sein, steigt in $\mathrm{Pe}-$ čorin wohl auf, er wehrt ibn aber sogleich ab. (s. $109 \mathrm{ff.})$ 
in der Novelle "Prinzessin Mary" diktiert, wirkt sich am folgenschwersten im Duell aus.

10. Die Novelle "Prinzessin Mary" ist als "Jahrmarkt der Eitelkeit" ${ }^{1}$ auf Kampl angelegt. Petorin fühlt sich durch seine Umwelt provoziert - er wiederum fordert Grusnickij und dessen Freunde durch seine aufreizend zur Schau getragene tberlegenheit heraus. Angefangen von Pelorins Gedanken bei seiner ersten Begegnung mit Grušnickij - "Ich liebe ihn (Grußnickij) auch nicht: ich fühle, daB wir irgendwann einmal zusammenstoßen werden... und es einem von uns schlecht ergehen wird" (S. 69) Pinden sich im Tagebuch immer wieder Andeutungen einer zu erwartenden Auseinandersetzung. ${ }^{2}$ Die Gruppe um Grusnickij, vor allem der Dragonerhauptmann, möchte schlieBlich einen Zusammenprall mit Pečorin, der "glaubt, nur er allein gehöre zur groBen Gesellschaft", provozieren und ihm in einem Scheinduell eine Lehre erteilen. (S. 117)

11. Das geplante Scheinduell ist eine Perversion der charakteristischen Merkmale des konventionellen Ehrenzweikamples:

a) Nicht ein Beleidigter soll hier zum Duell fordern, sonderm Grušnickif muß uberredet werden, unter irgend einem Vorwand den Beleidigten zu spielen.

b) Die ehrenrettende Kraft des Duells, die auf einem Kamp mit tödlichen Waffen beruht, wird persifliert durch die Absicht, ungeladene Pistolen zu verwenden.

c) Zweck dieses Duells soll nicht die Wiederherstellung der

"Da das Geschehen in der "Prinzessin Mary" schon in der ersten Tagebucheintragung als Theaterspiel ausgewiesen wird, geniebt der Leser die Szene um den "Zauberkünstler, Akrobaten, Chemiker und Optiker" Aplelbaum als dramatische Ironie. Die ganze Kurgesellschaft ist zur Stelle, "alle ohne Ausnahme" wollen die Tricks der Jahmarktsfigur bestaunen. (S. 119) Grusnickif sitzt bezeichnenderweise in der ersten Reibe und leiht Aplelbaum die nötigen Requisiten aus.

"niele sind rom letzten Ball her noch böse auf mich...jetzt formiert sich offenbar eine regelrechte Bande unter Grusnickifs Kommando gegen mich." (S. 108) - "Das wird Grušickij buBen müssen!" (S. 110) - "All das wird ihm wieder einfallen, wenn es zwischen uns zur Abrechnung kommt." (S.119) etc. 
verletzten Ehre eines Kontrahenten sein, sondern Amüsement: "Das wird uns Spaß machen...", sagt der Dragonerhauptmann, als er sich Petorins Feigheit angesichts der scheinbar schweren Duellbedingungen vorstellt.

Zur Inszenierung dieser Farce kommt es nicht, weil Pecorin nach dem vermeintlichen Tscherkessenüberfall zufällig leuge seiner Verleumdung durch Grušnickij wird und automatisch Genugtuung verlangt. In einer Gesellschaft wie der fiktionalen, die das Duell als bittel zur Ehrenrettung akzeptiert, wäre eine derartige Farce aber jederzeit möglich - Pečorin hätte sich ihr kaum entziehen können. Der Plan des Scheinduells impliziert eine erste Stellungnahme Lermontovs zum Duell: $E \mathrm{~h} r$ e $\mathrm{n}$ handel ist nicht jedermanns Sache und institutionalisierter Ehrenhandel verfürt zu MiBbrauch. ${ }^{1}$

12. Diese Anti-Duellhaltung Lermontors wird in der Darstellung des Zweikampfes $z$ wischen Peðorin und Grušnickij weiterentwickelt. $\mathrm{Zu}$ einer Forderung Gusničkijs ist pecorin, der Duellen sonst eher aus dem Wege geht, ${ }^{2}$ gezwungen, weil Veras Ehemann die ehrabschneidende Geschichte von einem nächtlichen Besuch Pexorins bei der Prinzessin mit angehört hat. Pečorins Reaktion ist gemessen an den Gesetzen der fiktionalen Wirklichkeit - die einzig denkbare. Lermontov läßt aber durchblicken, daß Ehrenkodex-konformes Verhalten mit ehrenhaftem Verhalten nicht identisch ist:

a) An die Forderung schliebt sich eine für Pečorin (und den Leser) komische Szene an: "mit Tränen in den Augen" (S. 124) honoriert ausgerechnet Veras betrogener Ehemann die Bereitschaft Pečorins, die Ehre Junger Mädchen zu verteidigen. Doch ist es nicht nur dieser komisch wirkende Beifall, der das Duell als

${ }^{1}$ Friedrich Bodenstedt, der Iermontov gekannt (und ubersetzt) hat, berichtet, Lermontov sei ein erklärter Feind des Duells gewesen. Vor allem habe er es abgelehnt, aus dem Zweikamps ein Kinderspiel zu machen. Bei seinen Duellen mit Barant und Martynor habe er in die luft geschossen. Vgl. V. A. Manujlor, "Geroj nałego vremeni" (1966), S. 245.

${ }^{2} v_{g l}$. die Bemerkung Gruß̌nickijs S. 116. 
Ehrenhandel unglaubwïrdig macht, sondern

b) die Tatsache, daB Gruśnickij durch einen EllenbogenstoB des kampflustigen Dragonerhauptmanns zur Annabme der Forderung bewegt werden muB.

Während Pe Corin seinen Sekundanten Anweisungen für die auszuhandelnden Duellbedingungen gibt, ${ }^{1}$ läßt Grušnickij sich die Pläne seiner Sekundanten aufdiktieren. Durch seine Schwäche kann der Dragonerhauptmann einen Teil der Bedingungen für das Scheinduell in diesen Zweikamp ubernehmen:

Es soll bei der außergewöhnlich geringen Distanz von sechs Metern für den Schußwechsel bleiben, und Petorins Pistole soll nach wie vor nicht geladen werden. Grubnickij hingegen soll mit geladener Pistole antreten: damit wird das Duell zum Mordplan.

c) Obwohl Pečrin von der Intrige weiB - sein Sekundant hat die Abmachung aus Gesprächsfetzen erraten - entlarvt er die Gegenseite nicht (wie Verner rät), sondern bezieht die Position: "Ich lasse mich von ihnen nicht unterkriegen." (S. 125) Sogar seinen Sekundanten läßt Pečorin im Dunkeln darïber, wie er den Knoten zu durchschlagen gedenkt. Er macht das Duell damit $z u$ einem weiteren Prüstein für seine Uberlegenheit und die eitle These: "Immer wachsam sein...Absichten erraten...den Betrogenen spielen und plötzlich mit einem $S t o B$ das ganze... Gebäude von Listen und Hintergedanken umstüren, - das nenne ich Leben." (S. 108)

13. Das Duell zwischen PeČrin und Grułnickij soll unter folgenden Gesichtspunkten betrachtet werden:

${ }^{1}$ Die Vorbereitungen $z u$ diesem Duell verlaufen zum Teil konventionell. Die Sekundanten setzen die Duellart (Pistolenduell) und Ort und Zeit des Zweikamples fest. (S. 124 f.) Unmittelbar vor dem Duell fordern sie noch einmal zur Versöhnung auf. (S. 129) Alle Spuren des Duells werden später von ihnen beseitigt. Die vereinbarte Distanz von sechs Metern macht das Duell jedoch zum Ausnahmeduell. Vgl. das "Duellbuch" von Kulahl und Schmied-Kowarzik $\left.(189)^{\circ}\right)$ " Bei den Ausnahmeduellen wird hauptsächlich die Distanz in abnormer Weise herabgesetzt..." . (S. 234)

Das Duell soll zwischen vier und füf Uhr morgens in einer Felsschlucht auBerhalb von Pjatigorsk stattinden. 
a) Hie zeigt sich die Diskrepanz zwischen dem, was Pełorin sein möchte, und dem, was er ist?

b) Wie spielt Pečorin seine Rolle?

c) Wie verhält Grušnickij sich?

d) Helche Auswirkungen hat das Duell für Petorin?

Zu a) Mit diesem Duell läBt Perorin sich bewuBt auf ein Glücksspiel ein: das Recht auf den ersten SchuB wird durch Los bestimmt. Die Lebensgefahr, die dadurch für ihn entsteht, erhöht Pečorin aber noch: sein Wunsch nach Aufstellung der Gegner am Rande einer hoch über dem Abgrund hängenden Felsenplatte bedeutet den Tod eines der Duellanten auch bei der geringsten Verletzung.

Pecorin, der sich schon auf dem Weg zum Rendezrous-Platz seinem Sekundanten gegenüber in sarkastischen Worten über die Hertlosigkeit menschlicher Gefuhle und Beziehungen geäußert hatte, möchte vor sich und allen Beteiligten mit seinen makabren Duellbedingungen als nervlich unirritierbar erscheinen. Nach auBen hin zeigt er ein Maximum an Gleichgultigkeit eigenem und fremdem Leben gegenüber. Der Leser empfindet den Versuch Pěcorins, seinem Sekundanten die traurigen Gedanken angesichts des unheimlichen Duells zu verscheuchen, als dramatische Ironte: "Warum sind Sie so traurig, Doktcr?...versuchen Sie mich als Patienten $z u$ sehen, der an einer Ihnen noch unbekannten Krankheit leidet...". (S. 127) Pečorins Frage "Ist die Erwartung eines gewaltsamen Todes nicht schon eine wirkliche Krankheit?" ist - ihm unbewußt - die Diagnose seiner Krankheit: die Aussicht auf einen gewaltsamen Tod in diesem Duell ist das Ergebnis seiner krankhaften Eitelkeit.

Die stoische Ruhe Yecorins gegenuber dieser Aussicht frappiert seine Umgebung, wird vom Leser aber als Maske erkannt: Pecorin ist in der Nacht vor dem Duell von einer "heimlichen Unruhe" beherrscht und vertreibt die "quälende Schlaflosigkeit" durch Lektuire. (S. 127) Der physische Zustand PeCorins widerspricht seiner hochmiutigen These, allzeit bereit zu sein, sich aus dem langweiligen Leben $z u$ entfernen (s. 125). Seine Augen glänzen zwar "stolz und unerbittlich" (S. 127), sind aber von dunklen Schatten in einem bleichen Gesicht uggeben. Sein Mienenspiel 
ist kontrolliert, sein Puls schlägt jedoch fieberhaft. (S. 131)

Von der tiefen seelischen Zerrissenheit Petorins zeugt auch seine totale Hingabe an die Natur am Morgen des Duells. PeXorins Flucht in die Natur signalisiert durchgehend einen Konflikt, den er nicht rationalisiert und nicht bewältigt. Nach seinem ersten Wiedersehen mit Vera treibt es ihn zu einem Ritt in die Steppe. Er gesteht: "Welcher Kummer mein Herz auch beschweren mag, welche Unruhe meinen Geist nicht quält, alles löst sich in einer Minute auf;" (S. 85) So reitet Pečorin in die Berge, nachdem er die Prinzessin während des Ausflugs zum Kol'co-Felsen verwirrt hat und selbst erregt und konfus ist (S. 115), und so meidet er nach dem Duell jede Begegnung mit einem Menschen. 1 Über den Morgen des Duells ist in Pecorins Tagebuch notiert: ".. an diesem Morgen liebte ich die Natur mehr als je zuvor." (S. 128)

Zu b) Bis zu dem Augenblick, da Grusnickijs SchuB fällt, wirkt die von Pecorin zur Schau gestellte liberlegenheit auf Grušnickij irritierend, ${ }^{2}$ während Verner fassungslos erstaunt ist. 3 Doch daB Pečorin am Rande eines Abgrundes, der "dunkel und kalt wie ein Grab erscheint" (S. 132), gleichmüig und unversehrt Grušnickijs SchuB übersteht, macht erst die eine Hälfte seines Triumphes aus. Die andere Hälfte besteht in der Aufdeckung des Duellbetruges und in der Verwirklichung seines Grundsatzes, mitleidlos zu sein, wenn man ihm den Krieg erklärt. (S. 96) Verners Reaktion zeigt die abstoBende Wirkung dieses Triumphes: er erbleicht und wendet sich nach dem tödlichen SchuB auf Grušnickij schweigend und mit Entsetzen ab. (S. 135) Pečorin ist so besessen von der Idee zu zeigen, $d a B$ er seine törichten Feinde

\footnotetext{
${ }^{1} V_{\text {gl }}$. die Analyse von F. D. Reeve: "Pechorin's abuse of other people is torment of himself." In: "The Russian Novel" (1966), S. 51.

" on smutilsja, pokrasnel, potom prinuzdenno zachochotal." (s. 130) "On pokrasnel;" (S. 133) etc.

3"vy strannył ¿elovek!...C to za ochota! podstreljat vas kak pticu...". (S. 130) "Ja vam udivljajus'...". (S. 131) "On posmotrel na menja s udivleniem." (S. 133)
} 
mit ihrem Augenzwinkern ${ }^{1}$ und vielsagenden Lächeln durchschaut, $d a B$ er vergibt, in welchem Maße sein Gegner unebenbürtig und erbarmungswürdig ist. Peðorins scheinbar fairer Versuch, in Grünickij Reue für seine Tat zu erwecken, um ihm dann verzeihen zu können, ist verblendet, da Grusnickij nur zitterndes ausfürendes Organ seiner Sekundanten ist. Grusnickij wird - wie Verner in der ersten Tagebucheintragung scherzend vorhersagt - "ein Opfer" PeXorinscher Eitelkeit.

Zu c) Grušnickij, der sich die Entscheidung für oder wider das Duell und die Duellbedingungen aufdiktieren lieB, erweist sich auch als zu schwach, das spiel mit Pexorin ohne Lenkung von außen durchzustehen. 2 "Ich kann nicht" sagt er, als er auf Pecorin schießen soll. Und es heibt weiter: "Der Schuß ging los" (vystrel razdalsja, S. 133). Die reflexive Verbform deutet darauf hin, wie wenig der Schuß eine Folge von Grušnickijs Willen ist. PeXorin sagt hingegen von sich: "Ich schoß..." (Ja vystreIil, S. 135).

Doch Gruśnickij, der eine komische Figur war, ${ }^{3}$ solange er von Pecorin manipuliert wurde, und der eine jämmerliche Figur ist, als er sich vom Dragonerhauptmann und seinen Freunden dirigieren läBt, tritt nicht in dieser Jämmerlichkeit von der Bühne ab. Pecorins Entlarvung des Duellbetruges wird für ihn zur Katharsis. Mit seinem Eingeständnis des Betruges macht er sich zum ersten Mal frei von allen Einflussen, sein Selbsturteil "ich verachte mich" (S. 135) ist erstmalig schonungslos und ohne jede

1 "Der Hauptmann zwinkerte Grußnickij zu..."; (S. 129) "...sagte der Dragonerhauptmann mit ironischem Lächein." (S. 129) "Der Hauptmann konnte sich kaum halten vor Lachen...". (S. 134)

${ }^{2}$ Der Hauptmann nennt ihn einen Dummkope und Feigling, um ihn zum Handeln zu bringen. Vgl. S. $131 \mathrm{ff.}$

${ }^{3}$ Grušnickijs Unvermögen einer realistischen Einschätzung seiner Person erzeugt Komik: wenn er $z$. B. hochstapelnd die Prinzessin "meine Prinzessin" nennt (S. 105), wenn er "furchtet", mit der Prinzessin die Mazurka eröffnen zu müssen (S. 105), wenn er zu dem ateren und erfahreneren Petorin herablassend sagt: "Ich bitte dich, PeXorin, was hast du für Vorstellungen!" (S. 100) oder "Du dauerst mich, Pecorin!" (S. 100); wenn er selbstgefällig vor dem Spiegel steht und in einen lässigen Redestil verfällt: "Skazi-ka...daj-ka...". (s. 105) 
Spur von Eitelkeit. DaB Petorin angesichts dieser Katharsis und der echten Todesbereitschaft Grusnickijs an seinem Vergeltungsschwur festhält, ist die verhängnisvollste Demonstration seiner Eitelkeit. ${ }^{1}$ Auch ohne Grusnickijs Tod hätte für das Theaterspiel zwischen Pečorin und Grußnickij gegolten: "Finita la comedia." 2

Zu d) Mit dem SchuB auf Grušnickij hat Petorin in einem solchen Maße unnatürlich gehandelt, daß nicht nur sein einziger Freund sich von inm abwendet, ${ }^{3}$ sondern sogar die Natur - sonst seine einzige zuflucht - ihn gleichsam ausstöBt: "Auf meinem Herzen lag ein Stein. Die Sonne schien mir schwach; inre Strahlen wärmten mich nicht." (S. 136) Doch stellt Petorin sein Verhalten auch hier nicht in Frage. Seine Krankheit scheint unheilbar. Der totale nervliche Zusammenbruch in der Steppe, als Pe dorin weint "wie ein Kind", ist Pür inn keine Katharsis. Er bleibt, der er ist, wundert sich über Verners verändertes Verhältnis zu ihm, lehnt eine Verbindung mit der Prinzessin endgültig ab und verläßt den Schauplatz. Er hat - wie er später in der Festung bei Maksim Maksimyč mit unbewuBter Treffsicherheit von sich sagt - "den Becher der Leiden noch nicht geleert." (S. 127)

14. Mit dieser Darstellung des Duells setzt Lermontov die Argumentation Pußkins in "Eugen Onegin" und im "SchuB" fort: die Institution zur Verteidigung der Ehre ist in einer bestimmten Gesellschaftsschicht so fest verankert, dab jeder sich ihren

${ }^{1}$. G. Nazirov spricht von "exécution". "Pétchorine.... condamne Grouchnitski à mort...". In: "Dostofevski" (1973), S. 283. ${ }^{2}$ Den Anfang, den Höhepunkt und das Ende der Beziehungen zwischen Grusnickij und sich beschreibt Pedorin mit termini technici des Dramas: "Der Knoten ist geschürzt..." (Anfang, S. 76); "Seit ich lebe und handle, hat das Schicksal mich immer irgendwie die Lösung des Knotens fremder Dramen besorgen lassen... ich war die unentbehrliche Person des funften Aktes 3 ..." (Höhepunkt, S. 106); "Finita la comedia." (S. 133)

Nach dem Duell hinterläßt Verner eine Notiz für PeCorin: "... Sie können ruhig schlafen...wenn sie können...". (S. 136) Gegen seine Gewohnheit reicht er Petorin nicht mehr die Hand. (s. 139) 
Regeln unterwirft und daß die Prage nach dem Sinn der Institution explizit nicht auftaucht. Eine sehr skeptische Beurteilung der Institution "Duell" ist jedoch in allen drei Werken impliziert: in keinem der Duelle wird nach kodifizierten Regeln um die Wiederherstellung verletzter Ehre gekampet. In jedem Duell wirkt sich eine individuelle Schwäche verhängnisvoll aus: Silvios Rachedurst, Onegins Passivität, Pečorins Eitelkeit.

15. Nun ist der dramatische SchluB der "Prinzessin Mary" nicht auch der SchluB des Romans. Die Dramatik wird entschärft ${ }^{1}$ durch den letzten, der Schicksalsgläubigkeit gewidmeten Teil des Romans, "Der Patalist". 2 Es wurde bereits herausgearbeitet, daß Pečorin ein zutiefst unglücklicher Mensch ist. Durch die eindringliche Betonung der Macht des Schicksals in der letzten Novelle wird das Urteil uber Pecorin insofern weiter gemildert, als es im Sinne des Lermontovschen Vorwortes in einen allgemeinen Rahmen gestellt wird: es gibt - leider, aber wohl unabänderlich - in höheren Gesellschaftsschichten sehr eitle Menschen, einer davon ist Pexorin. Seine Eitelkeit hat zwar durch be-

${ }^{1}$ B. Ejchenbaum hält den RomanschluB mit seiner Hinwendung zu einem philosophischen Thema für sehr kunstvoll: dadurch werde alles Tendenziöse vermieden und dem Roman kein duisterer $A b-$ schluB gegeben. Vgl. "Stat'i o Lermontove" (1961), S. 282 . M. E. Duchesne glaubt dagegen, man könne "Taman" und "Fatalist" bei der Beurteilung des Romansunberücksichtigt lassen. Vgl. S. 163 in "Michel Iourévitch Lermontov" (1910). 2 Anspielungen auf die Macht des Schicksals finden sich auch in den vorhergehenden Novellen. In "Bela": "Es gibt doch wirklich Leute, denen es vom Schicksal vorherbestimmt ist...". (S. 15) In "Maksim Maksimyč" sagt Pečorin: "Was soll man machen? .. jeder muß seinen Weg gehen...". (S. 51) In "Taman" " Iragt PeCorin: "Und warum mußte mich das Schicksal in den frisdlichen Kreis e h $r 1$ c he $r$ S c h m u g g l e r stoBen?" (S. 65) In "Prinzessin hary" sagt Pecorin: "Ich bin von Natur aus so seltsam, daB man das von mir erwarten kann." (S. 112) "Das Schicksal bot mir zum zweiten Mal Gelegenheit, ein Gespräch zu belauschen...". (S. 121) - Vgl. R. G. Nazirov, "Dostolevski" (1973), S. 278: "...les conditions générales de l'existence humaine...pour les romantiques, semblent étre une force fatale...le héros ne se connait pas d'égal parmi les hommes, mais le destin est très au-dessus de ses forces et de ses possibilités, de son titanisme." 
stimmte individuelle Umstände - die Liebe zu Vera - eine besondere Ausprägung erfahren und hat sich durch gewisse gesellschaftliche Verhaltensnormen - das Duell - besonders verhängnisvoll ausgewirkt, aber nicht umsonst beginnt Maksim Maksimy ne Geschichte so: "Es gibt doch wirklich Leute, denen es vom Schicksal vorherbestimmt ist, alle möglichen ungewöhnlichen Dinge zu erleben!" (S. 15) Die Stimme Maksim Maksimycs ist auch am SchluB des "Fatalisten" noch einmal zu hören:" obwohl er als pragmatischer Mensch für die seltsame Geschichte des Leutnant Vulic eine ganz plausible Erklärung findet, ${ }^{2}$ bemerkt er abschließend: "Ubrigens war es inm offensichtlich so vorherbestimmt!.." (S. 152)

In allen Novellen, die dem "Fatalisten" vorausgehen, bleibt ein Problem immer gleich: Pecorin gerät durch seine Eitelkeit in Konflikt mit der Umwelt. In "Taman" drängt ihn nur seine eitle Neugier, sich in die Angelegenheiten der Wirtsleute einzumischen: "...ich ging hinaus, fest entschlossen, dieses Rätsel zu entschlüsseln." (S. 59) Als er das Rätsel gelöst hat, muß er sich sagen: "Wie ein Stein, den man in einen glatten Brunnen geworfen hat, habe ich ibre Ruhe gestört...Mir wurde traurig zumute." (S. 65) Nach den dramatischen Ereignissen in "Prinzessin Mary" bewirkt Pecorin auch in "Béla" nur Unglück. Er ist hochmütig genug, die Frage, ob Béla ihm nachgeben wird oder nicht, zum Gegenstand einer Wette mit Maksim Maksimyč zu machen: "...ich gebe Ihnen mein Ehrenwort, dab sie die meine sein wird...wollen wir wetten?" (S. 26)

Nach dem Tode Bélas weint Pecorin nicht mehr - wie beim Verlust Veras - sondern bricht in ein Iachen aus, bei dem es Maksim Maksimyč eisig überläuft. (S. 42) In "Maksim Maksimyč" schlieblich hat Pečorin sich ganz auf sich selbst zurückgezogen und ist nicht einmal mehr zu einem Gespräch mit dem an-

${ }^{1}$ Die Meinung von Maksim MaksimyC soll etwas gelten: am SchluB der "Béla" - Novelle wendet der Erzähler sich an den Leser: "Geben Sie aber zu, dab llaksim Maksimyč ein Mann ist, der unsere Achtung verdient?.. Wenn Sie das zugeben, werde ich für meine... Geschichte vollauf belohnt sein." (S. 43)

2 "torigens versagen diese asiatischen Hähne oft...". (S. 152) 
hänglichen Stabskapitän bereit.

Seine Eitelkeit - das zeigen alle Novellen - hat weder Pečorin glücklich werden lassen noch andere durch ihn glücklich gemacht. Das erinnert an Thackerays letztes Wort in "Vanity Fair": "Ah! V a n $i$ a $s$ v n 1 t a $t$ u ! which of us is happy in this world? Which of us has his desire? or, having it, is satisfied?..." 
I. S. Turgenev, "Väter und Söhne"

1. "Mir scheint" - so schrieb Alexander Herzen an den Autor der 1862 erschienenen "Väter und Söhne" - "daB die große Kraft Deines Talents nicht in Tendenzschriften liegt." 1 Turgeners zornige junge Männer - vor allem sein Held Bazarov ${ }^{2}$ - wurden von prominenten Kritikern aber nicht nur als literarisch miBlungen angesehen, ${ }^{3}$ sondern gerieten auch ins Kreuzfeuer rein ideologischer Kritik. Konservative wie der Redakteur des "Russkif vestnik", Katkor, witterten in dem Nihilisten Bazarov eine Apotheose des Radikalismus, während Radikale wie Černyšerskij und Pisemskij ihre Gedanken diskreditiert und karikiert fanden. ${ }^{4}$

${ }^{1}$ Zitiert nach I. S. Turgener, "Poln. sobr. soč. i pisem v 28 tt.", Bd. VIII d. Werke (1964), S. 597. Herzen bemerkt weitegr, es wäre für Bazarov besser gewesen, wenn Turgenev "alle Cernyševskifs der Welt" beim Schreiben des Romans vergessen hätte. Im Folgenden wird nur nach der angegebenen Ausgabe zitiert.

${ }^{2} \mathrm{Vgl}$. H. Gifford, "The Novel in Russia" (1964), S. 68: "In the novel $F$ a $t h e r s$ a $n d h i l d r e n$, Turgenev attempted the full-scale portrait of a Russian revolutionary...".

3 I. S. Aksakor, I. N. Tolstoj und A. A. Fet, z. B., fanden den Roman künstlerisch miblungen. Vgl. die zeitgenössische Rezeption des Romans S. 589 - 611 in Bd. VIII der zitierten Ausgabe.

${ }^{4}$ Die Vertreter der radikalen Intelligenz ger fünfiger und sechziger Jahre des 19. Jahrhunderts (z. B. Cermyserskif, Pisarev, Dobroljubov) waren Vorbilder für den Turgenevschen Nihilisten. "Was die drei Genannten verband und ihre Bezeichnung als Nihilisten rechtfertigt, war der radikale weltanschauliche Haterialismus, den sie von Iudwig Feuerbach und den deutschen naturwissenschaftlichen Materialisten Haeckel, Büchner und Moleschott bezogen...Die äußere Form der Opposition hatte sich seit den vierziger Jahren noch kaum geändert: Auch die Nihilisten waren ein kleiner Zirkel von viel lesenden und viel schreibenden Intellektuellen....Es fehlte nur der breite, wean auch nicht immer tiefe Bildungshintergrund, den die adeligen Revolutionäre der dreiBiger und vierziger Jahre noch gehabt hatten. Ohne die Voraussetzung einer familiären Bildungstradition...stürzte sich der wachgewordene Intellekt der jungen "Raznotincy"...auf das angebotene Geistesgut, und in einer Umwelt, die ihnen feindselig und unverständlich erschien, mußten die wißbegierigen Autodidakten jener Wissenschaft verfallen, die alle Welträtsel gelöst zu haben vorgab. Pisarer...ging so weit, im Namen der Naturwissenschaft das Werk Puškins in Grund und Boden zu verdammen..." : G. Stökl, "Russische Geschichte" (1962), S. 568 p1. - Eine Diskussion des Nihilismus-Begriffes findet sich bei W.-H. Schmidt, "Nihflismus und Nihilisten" (1974). 
Zum Vorwurf der Tendenz äuBert sich Turgener in einem Brief 1 an A. A. Fet vom April 1862: "...wie sieht denn die Tendenz in den "V(ätern) und $S$ (öhnen)" aus...? I c $h$ e $i B d$ a $s$ $s e l b s t a n c h t$, denn ich weib nicht, ob ich ihn liebe oder hasse! Das ist die ganze Tendenz!"

Sein künstlerisches Anliegen definiert Turgener einmal so: "Es wäre nichts Besonderes gewesen, ihn (Bazarov) als Ideal darzustellen; aber ihn zum Wolf zu machen und ihn dennoch $z u$ rechtfertigen - das war schwer." 2 ob statt des Wolfes nicht doch nur ein Papiertiger geschaffen wurde, soll in der folgenden Analyse anhand der Schlusselszene des Duells zu klären versucht werden.

2. Es geht in den "Vätern und Söhnen" nicht um eine prinzipielle Frontbildung der Jungen (Arkadif und Bazarov) gegen die Alten (die beiden Väter Nikolaj Petrovic und Vasilif Ivanovid und den Onkel Pavel Petrovid): Arkadif lebt in Harmonie mit seinem Vater und seinem Onkel und mag die Eltern Bazarovs. Bazarov liebt seine Eltern (3. S. 322) und nennt Arkadijs Vater einen "sympathischen Burschen" (S. 210). Zum Konflikt kommt es zwischen den extrem konträren Typen dieser Väter-und-Söhne-Gruppe, auf die Turgenev durch ein detailliert gezeichnetes Portrait aufmerksam macht. ${ }^{3}$ Das Portrait Bazarovs zu Beginn des zweiten

${ }^{1}$ Bd. IV der Briefe, S. 371. In einem Brief an K. K. Slucevskif vom April 1862 betont Turgenev jedoch ausdrücklich, er habe eine dem Leser sympathische Figur schaffen wollen. (ebd., S. 381) - H. Gifford sagt m. E. zu Recht: "But what Turgener said afterwards as apologist - the novel was attacked from all sides - may even confuse what he affirms as author in the story itself." In: "The Novel in Russia" (1964), S. 70.

${ }^{2} \mathrm{Vgl}$. den Briel an A. I. Herzen vom April 1862. Bd. IV der Briefe, S. 383 .

${ }^{3}$ Vgl. D. Tschizewskij, "Russische Literaturgeschichte des 19. Jahrhunderts", Bd. II (1967), S. 43: "Seine psychologischen Darstellungen beginnt der Dichter...mit den Portraits seiner

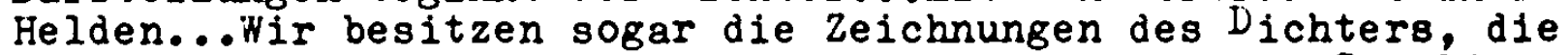
er bei einem Gesellschaftsspiel entwarf und mit der Schilderung des Charakters dieser Menschen begleitete. Der Dichter legte den größten Wert auf die Portraits seiner Helden." 
Kapitels zeigt den Ideologen: ein selbstbewußtes und kluges Gesicht mit breiter Stirn, die Wölbung eines gewaltigen Schädels. (Die Beschreibung Arkadijs beschränkt sich auf "die bekannten Umrisse eines lieben Gesichts...". S. 199) Noch bevor im funften Kapitel die weltanschauliche Diskussion eröfnet wird, läßt Turgenev erkennen, daß Bazarov das Nützliche, Prosaische verkörpert: die Atmosphäre von Freude und Melancholie, die Nikolaj Petrovid durch das Zitieren Pułkinscher Frülingsverse evozieren möchte, kann nicht zum Tragen kommen durch Bazarovs Ruf nach einem Streichholz für seine Pfeife. (S. 206)

Das zweite ausfürliche Portrait zu Anfang des vierten Kapitels kennzeichnet einen ungewöhnlichen Typus der Generation der Väter: den Ästheten Pavel Petrovid, der durch physische Schönheit und Kleidung von erlesener Elleganz als Augenweiłe konzipiert ist. Pavel Petrovid ist ein Dandy, er ist der "reiche, müBige Mann, der, selbst blasiert, keine andere Beschäftigung hat, als auf der Bann des Glücks zu wandeln... der keinen anderen Beruf als den der Eleganz hat" und der sich "immer und zu ailen Zeiten einer deutlich erkennbaren, ganz besonderen Physiognomie" erereut. 1 (Von Nikolaj Petrovič erfährt man nur, daß er einen verstaubten Mantel und karierte Hosen trägt (S. 195) und daB er schon ganz grau, etwas rundlich und gebeugt ist (S. 198). Bazarovs Vater wird als großer hagerer Mann in einem alten aufgeknöpften Militärrock beschrieben, der zerzaustes Haar und eine dünne Adlernase hat (S. 308).)

Der Dandy reicht reicht dem Freunde seines Neffen zur Begrüßung nicht die Hand. Die beiden mißfallen sich - zunächst einmal ästhetisch - von Anfang an. Bazarov witzelt bei Arkadij: "Du hast aber einen seltsamen Onkel... Fingernägel sind das, Fingernägel, die man auf eine Ausstellung schicken könntie!" (S. 210) Und Pavel Petrovid erwidert auf die Feststellung seines Bruders, Bazarov werde bei ihnen zu Gast sein: "Dieser behaarte Bursche?" (S. 209)

'So lautet die Baudelairesche Definition des Dandy. In: "Wharles Baudelaire in Selbstzeugnissen und Bilddokumenten", Rowohlts Monographien (1967), S. 63. 
3. Die Nihilimus-Diskussion beginnt im funften Kapitel in Abwesenheit Bazarovs. Nicht Bazarov fuhrt den Terminus "Nihllist" ein, sondern sein Freund und Schüler Arkadif versieht ihn mit diesem Etikett und definiert ihn als einen Menschen, "der sich allen gegenüber kritisch verhält...der sich keiner Autorität beugt, der kein Prinzip gläubig hinnimmt...n.1 (S. 216) Der ironische Autor legt dem naiven ${ }^{2}$ Arkadij die Horte "Nihilist" und "Prinzip" in den uund, um Pavel Petrovič durch seine Reaktion auf diese Reizworte $z$ charakterisieren. Er unterbricht das Bekenntnis des Dandys zu "Prinsipien", indem er dessen französische Aussprache und Betonung des Wortes hervorhebt, macht sein Urteil durch eine Pranzösiche Phrase und ein Zitat aus Griboedovs "Verstand schafet Leiden" 3 noch wohlklingender und läßt inn quasi als Demonstration einer an Prinzipien orientierten Lebensweise nach "seinem" Kakao klingeln. " Durch Turgeners Ironie wird der exponierteste Vertreter der älteren Generation an keiner Stelle zu einer positiven Gestalt. 5

${ }^{1}$ Gegen diese positive Definition stehen die neutrale von Arkadijs Vater ("Ein Nihilist ist ein Uensch, der nichts anerkennt") und die boshafte des Onkels ("Ein Nihilist ist ein Mensch, der nichts achtet"). Die Kirsanovs kennzeichnen so ihr Verhältnis zu Bazarov.

${ }^{2}$ Den Nihilismus Arkadijs ironisiert Turgenev als nicht ermst zu

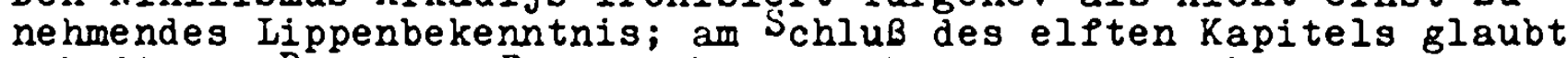
Arkadif z. B. seine Freude über die bevorstehende Reise verbergen zu muissen: "Nicht umsonst war er Nihilist!" (S. 252)

"Vous avez changé tout cela, daj vam bog zdorov'ja i general'skij čin...". (S. 216)

${ }^{4}$ Auf diese indirekte Art ironisiert Turgenev schon zu Beginn der Nihilismus-Diskussion das Verhaftetsein des $D_{\text {andys }}$ in materiellen Dingen: als das Wort "Nihilist" Pällt, bleibt Pave] Petrovid regungslos sitzen, wobei er ein Messer mit einem Stück Butter in die Luft hält. Dann trägt er seine Definition des Nihilisten vor und wendet "sich wieder der Butter zu." (S. 215)

${ }^{5}$ In Kap. VI ist Pavel Petrovid primadonnenhalt beleidigt, dreht sich "langsam" auf dem Absatz herum und geht "langsam" fort. Auf Bazarovs Argumente antwortet er in einer komisch korrumpierten Sprache: "Ja éftim choč dokazat'..". (S. 241) Nach seiner Duellverletzung liegt er mit einem Batisthemd, "stutzerhaften Morgenjäckchen" und Fez bekleidet im bett und phantasiert im Fieber auf Französisch. (S. 356) Er hält sich in Dresden auf, liest keine mussischen Bücher, hat aber slavophile Ansichten. (S. 400) Auf seinem Schreibtisch steht ein silberner Aschenbecher in Form eines bäuerlichen Bastschuhs. (ebd.) 
Die Diskussion im funften Kapitel hat eine doppelte Funktion: einmal offenbart sie die stutzerhafte Hohlheit und intellektuelle Schwäche Pavel Petrovids schon vor dessen Streitgespräch mit Bazarov, zum anderen weckt sie in Pavel Petrovid eine Feindseligkeit ${ }^{1}$ gegenüber Bazarov, die provozierend wirkt und einer der Gründe dafür ist, daß Bazarovs Selbstdarstellung in den Kapiteln VI und $X$ trotzige Polemik zeigt.

4. In der trotzig übersteigerten Reaktion Bazarovs ${ }^{2}$ auf die Phrasen von Arkadijs Onkel findet sich ein Satz, der sein Selbstverständnis am adäquatesten wiedergibt: "Wir handeln kraft dessen, was wir als nützlich anerkennen...". (S. 243) Wie das Stutzertum Pavel Petrovics bleibt allerdings auch das Nützlichkeitsprinzip Bazarovs von der Ironie Turgenevs nicht verschont, ${ }^{3}$ etwa, wenn Bazarov behauptet, ein ordentlicher Chemiker sei zwanzigmal nützlicher als jeder Dichter (S. 219), Raffael sei keinen Kupfergroschen wert (S. 247); wenn er sich daruber amuisiert, daB ein Familienvater von 44 Jahren noch Cello spielt (5. 237), als Physiologe gegen "geheimnisvolle Beziehungen zwischen Mann und Frau" zu Felde zieht (S. 226) oder die Odincova davon zu ubberzeugen versucht, dab ein "menschliches Exemplar" wie das andere sei. (S. 277)

${ }^{1}$ Die argumentatorische Schwäche und Feindseligkeit der Bemerkung "An Prinzipien glaubt er nicht, aber an Frösche glaubt er" tragen Pavel Petrovic einen mitleidigen Blick seines Neffen und ein Achselzucken seines Bruders ein. (S. 217)

2

Bazarov wiederholt in seinem Trotz ganze Sätze seines Gegenspielers: P. P.: "So...habt ihr beschlossen, euch selbst mit nichts ernsthaft zu befassen..." - Baz.: "Und haben beschlossen, uns mit nichts emsthaft zu befassen." P. P.: "Sondern nur zu schimpfen?" - Baz.: "Und zu schimpfen." (S. 245) etc.Vgl. H. Gifford: "The insensibility, the churlish dogmatism and...the provincial arrogance of $B_{a z a r o v}$ - these annoy and they are surely meant to annoy. Herzen refused to accept them as more than adolescent defiance. But though Turgenev's "nihilist"...discomfits the reader, his bad manners are not meant to obscure his good cause." In: "The Novel in Russia" (1964), S. 70, Die $S$ a $c h$ e Bazarovs bleibt indes in der Tat unklar.

${ }^{3} \mathrm{Da}$ Turgener alle Gestalten des Romans mehr oder weniger ironisiert, ist seine Ironie (im Gegensatz zur Puskinschen) dem Ieser keine Hilfe bei der Beurteilung der Personen. 
Der größte Hohn auf Bazarovs Verabsolutierung des Nutzlichkeitsprinzips - den Turgener wahrscheinlich nicht wollte - liegt darin, daB Bazarov seinen eigenen Maximen zuwider handelt: er beneidet seine Eltern im Stillen um ihre romantische ländliche Idylle (S. 322) und verliebt sich in die schöne Odincova. Er, der Pavel PetroviC seiner nicht verwundenen Liebesenttäuschung wegen verspottet hatte (S. 287), verfällt als Resultat seiner unglücklichen Liebe melancholischem MüBiggang. ${ }^{1}$ Bei Feneðka gibt Bazarov sich als Charmeur, winscht sich von ihr eine Rose und spricht in Vergleichen: "Ich mag es, wenn Sie reden. Es ist, als ob ein Bächlein murmelte." (S. 344) Derartige "Schönrederei" hatte Bazarov bei Arkadif verdammt. ${ }^{2}$ Man sieht: Bazarovs Leben steht mit seiner naturwissenschaftlich-positivistischen Lehre nicht in Einklang.

5. Das Auseinanderklaffen von Theorie und Praxis des Nibilisten wird im Duell am augenfälligsten. Nachdem Bazarov in Kap. X zweimal "mit unerschütterlicher Ruhe" bekräftigt hatte, dab er alles verneine, weil es gegenwärtig am nützlichsten sei zu verneinen, ist zu verstehen, daB Pavel Petrovic, der Bazarovs Flirt mit Fenecka zum Anlab für ein Duell mit dem verhaßten Gegner nehmen möchte, zunächst einmal vorsichtig die Meinung Bazarovs zum 2 weikampl elnholt. Seine Frage impliziert, daB er eine Ablehnung des Duells erwartet, eine Erwartung, die der Leser teilt - insbesondere wegen des angreifbaren Charakters der Institution "Duell". Die Antwort des scheinbaren Apologeten der Nutzlichkeit uberrascht - und ist der deutlichste Beweis für den Bruch in der Gestalt Bazarovs: "Vom theoretischen Standpunkt aus ist das Duell ein Unsinn; nun, aber vom praktischen Standpunkt aus sieht die Sache anders aus." (S. 347) Die zweite Unglaublichkeit - vom Selbstverständnis Bazarovs aus betrachtet - ist das sofortige Akzeptieren der Forderung eines

\footnotetext{
1 "Das Arbeitsfieber $I$ i e $B \quad v \circ n$ i $h m a b$, und an seine Stelle traten schwermuitige Langeweile und dumple Unruhe." ( $\mathrm{S}$. 383)

2"Oh mein Freund Arkadif Nikolaevit! - riel Bazarov aus, - um eines bitte ich dich: rasple kein SüBholz." (S. 326)
} 
von ihm als lächerlich empfundenen Dandys. ${ }^{1}$ Drittens verwundert Bazarovs selbstrerständliche Hinnahme des Flirts als Duellmotiv - Pavel Petrovic selbst ist dieses Motiv später peinlich. Die Erwartung des Dandys wird auch in diesem Punkt ubertroffen: er hatte vorsorglich einen Stock mitgebracht, um nötigenfalls für eine handgreifliche Beleidigung sorgen zu können. Das Duellmotir wird expressis verbis nicht einmal genannt, sondern unter vornehmstem Stillschweigen - auch Bazarovs - als solches anerkannt.

Obwohl Bazaror die Forderung Pavel Petroviłs im nachhinein als lächerlich anprangert ${ }^{2}$ und den $Z$ weikampe nach der Verletzung seines Gegners sofort abbricht, ${ }^{3}$ sind seine prinzipielle Haltung zum Duell, die Annahme der Forderung und das Agieren nach ausgehandelten Bedingungen als eklatanter Widerspruch zu seinen Prinzipien anzusehen. ${ }^{4}$

${ }^{1}$ Vgl. dazu M. Gierens S. J., "Ehre, Duell und Mensur" (1928), S. 59: "Die äußerste Sublimierung des Gehaltes der Ehre, die höchste Tendenz zu ihrer VeräuBerlichung findet sich im $D$ a $n-$ d y $s$ m $u s$. Die populäre Auffassung verbindet mit diesem Wort die Vorstellung von einem Menschen, der ganz in äuBerem Beautum aufgeht, in übertriebenster Modesucht und hohlster E1telkeit. Für diesen lächerlichen Typ kann man im Emste nicht einmal die Frage nach Achtung und Ehre stellen. Otto Mann glaubt in seiner Studie 'Der moderne Dandy' in den "klassischen" Vertretern des Dandysmus in England und Frankreich einen Typ schildern zu können, der wenigstens der Beachtung, wenn auch nicht Achtung wert sei. Er sieht in diesem Typ eine Reaktion ästhetisch gerichteter Individuen gegen die Auflösung der Gesellschaft, gegen eine Umwelt, die im Begriffe ist, sich kulturellen Idealen zu entfremden und ganz in Erwerb und Nutzlichkeitstrieb aufzugehen."

2"Pfui Teufel! Wie schön und wie dumm! Was haben wir da für eine Komödie inszeniert! Dressierte Hunde tanzen so auf ibren Hinterpfoten." (S. 349)

3"Jetzt bin ich nicht mehr Duellant, sondern Arzt und muB ror allem Ihre Wunde untersuchen." (S. 353)

${ }^{4}$ Turgeners Rechtfertigung des Duells ändert nichts daran, daB die Gestalt Bazarovs durch den Zweikampf rollends uniuberzeugend wird: "Das Duell mit $P$ (avel) $P$ (etrovi $X$ ) wurde in den Roman aufgenommen, um ganz deutlich die Leere des eleganten höfischen Rittertums zu dokumentieren...". Vgl. Bd. IV der Briefe, S. 379: Brief an K. K. Slučevskij. 
6. Im Rahmen der hier untersuchten Duelle der russischen Literatur stellen "Väter und Söhne" einen Wendepunkt dar. Die Institution "Duell", die bei Puškin und Lermontov eine Selbstverstänlichkeit ist, deren Wesen keiner expliziten Wertung unterliegt und die höchstens mit dem Kunstmittel der verfremdung in komischer Absicht kritisiert wird - s. die Festungsleute in der "Hauptmannstochter" - hat bei Turgener in der Praxis noch Giiltigkeit, d. h. es kommt zum Kugelwechsel, wird theoretisch in ihrem Wert aber angezweifelt und selbst der Lächerlichkeit preisgegeben. Das gilt

a) für die Forderung: Pavel Petrovič fordert Bazarov nicht automatisch, sondern informiert sich erst über dessen Meinung zum Zweikampf; Bazarov erklärt Duelle theoretisch für unsinnig; seine Annahme der Forderung motiviert er ironisch damit, kein Spielverderber sein zu wollen: "Sie sind auf die Idee gekommen, an mir Ihren ritterlichen Geist $z u$ erproben. Ich könnte Ihnen dieses Vergnügen versagen, aber meinetwegen!" (S. 347)

b) Pür die Duellbedingungen: Pavel Petrovič schlägt ein Pistolenduell mit (acht Schritte voneinander entfernten) Barrieren vor. Bazarov verhöhnt diesen Formalismus: "Auf diese Entfernung hassen wir einander." (S. 348) - Beide Kontrahenten stellen ironisch fest, dab man auf Sekundanten verzichten müsse, weil es keine gebe. Bazarov schlägt den Kammerdiener Petr als Augenzeugen "comme il faut" vor. - Bazarov assozilert die von Pavel Petrovič gewünschten Briefchen, die im Falle eines tödlichen Schusses Selbstmord vortäuschen sollen, mit französischen Romanen. - Pavel Petrovič stellt zweimal fest, daß Bazarov wohl scherze (S. 349), wehrt sich aber nicht dagegen. Die infolge anhaltender ironischer Kommentierung entstandene Peinlichkeit der Situation versuchen beide Kontrahenten durch einen betont gedrechselten Sprachstil $z u$ vertuschen. P. P.: "Ich habe die Ehre, mich zu verbeugen." Baz.: "Auf ein angenehmes Wiedersehen, mein werter Herr...". (S. 349)

c) für die Durchfuhrung des Duells: Bazarov wünscht die Distanz abzuschreiten, weil er längere Beine hat. Er verlängert sie ad hoc um zwei Meter, ohne bei Pavel Petrovič auf wider- 
spruch zu stoßen. 1 Der sonst so hyperkorrekte und gegen die Verletzung äuBerer Formen empfindliche Pavel Petrovič ${ }^{2}$ gestattet daruber hinaus nicht nur zweimal, daß Bazarov das ganze Duell für lächerlich erklärt, 3 sondern bestätigt diesen Standpunkt direkt ("Ich leugne nicht die Seltsamkeit unseres Duells") und indirekt: durch seine Versicherung, sich im Ernst schlagen zu wollen. 4 Der Abbruch des Duells liegt in der Luft, wird aber hinausgezögert, um zu zeigen, was in Bazarovs Kopf vor sich geht, als die Pistole seines Kontrahenten auf ihn gerichtet ist. Auch dieser Augenblick, der im "Schuß" und im "Held unserer Zeit" voll unheimlicher spannung ist, vergeht nicht ohne ironischen Kommentar Bazarovs: "Er zielt mir direkt auf die Nase...und wie sorgfältig er das Auge zukneift, der Gauner!" (S. 352) - Als Pavel Petrovic verletzt ist, wirft Bazarov sogleich seine Pistole zur Seite, um sich als Arzt um die Wunde zu kümmern. Er zeigt damit deutich, daB das $S p i$ e 1 des Zweikamples nun aus ist.

7. Die Institution "Duell" war für Turgenev - wie für Puškin und Lermontov - lebendige Wirklichkeit. Im Zweikampl der "Väter und Söhne" ist nachweislich Autobiographisches verarbeitet. 5

"Es handelt sich hier wie in "Eugen Onegin" um ein "Fistolenduell mit Vorrücken". Die Gegner dürfen von den Endpunkten der Entfernung (hier 30 Meter) bis zu den Barrieren vorrücken (also jeweils 10 Meter) und nach Belieben schieBen.

${ }^{2}$ In Kap. IV bemerkt Pavel Petrovic miBbilligend, Arkadijs Benehmen sei erei geworden. In Kap. VI ärgert er sich über Bazarovs unge zwungene Redeweise.

3"Aber geben Sie zu...daß unser Duell ungewönnlich bis zur Lächerlichkeit ist." Und: "Oh! Ich zweifle nicht daran, daß wir entschlossen sind, einander zu vernichten; aber warum nicht daruber lachen...". (S. 352)

4"...ich halte es für meine Pflicht, Sie zu warnen, dab ich mich ernsthaft schlagen will." Und: "Ich werde mich ernsthaft schlagen...". (S. 352)

Im Grunde ist auch die Gestalt des Dandys nicht einheitlich: sein Verhalten im Duell deckt sich nicht mit dem Eindruck, den vorhergehende Kapitel von ihm geschaffen haben.

5 Turgenev wurde im Frühsommer des Jahres 1861 von L. N. Tolstoj zum Duell gefordert (das nicht stattfand). Turgenev berichtet daruber in Briefen an A. A. Fet, P. V. Annenkov, E. E. Lambert; vgl. Bd. IV der Briefe in der zitierten Ausgabe. 
Während die Fiktion Pußkins und Lermontovs implizit jedoch schwerste moralische Bedenken gegen eine gültige Institution erhebt, ist die explizite Kritik Turgenevs an einer nicht mehr unbedingt gultigen Institution ${ }^{1}$ im Grunde flach: Turgenev läBt den "Entlarver" ${ }^{2}$ Bazarov das Duell nur als lächerlich empfinden und es verharmlosend mit ritterlichen Turnierspielen assoziieren (s. Kap. XXV). Der Zweikampf wird als riskantes Gaudium gestaltet, das beim ersten Blutstropfen durch Bazarovs gesunden Menschenverstand abgebrochen wird.

8. Das Duell ist der eindeutigste Beweis dafür, daß Bazarov nicht der Wolf ist, den Turgener schaffen und rechtfertigen wollte, da der Nihilist sein Nutzlichkeitsprinzip vergiBt, sobald er handelt. Bazarov ist somit ein ziemlich lebloses Gebilde aus Theorie und Praxis, ${ }^{3}$ mit dem der Leser sich kaum identi-

${ }^{1}$ Nikolaj Petrovit definiert seinen Bruder Bazarov gegenüber entschuldigend als :hann alten Schlages. (S. 357) Indirekt erklart er das Duell damit für antiquiert. Diesen Schluß läßt auch die Bemerkung des Dieners Prokof'it $z$ u, man habe sich auch zu seiner Zeit geschlagen, aber nur Herren uriter sich, während man Gauner wie Bazarov im Pferdestall habe auspeitschen lassen. (S. 358) Hier wird noch einmal klar, daß man Bazarov ein Duell nicht zugetraut hätte. - Pavel Petrovič versichert vor dem Duell, er habe seit füf Jahren keine Pistole mehr in der Hand gehabt: Duelle sind also nicht an der Tagesordnung.

${ }^{2}$ Pavel Petrovil belegt Bazarov und Arkadij mit diesem Terminus. (S. 245) - Turgenev erklärte seine Beleidigung Tolstojs mit einer Gereiztheit, die durch einen extremen und ständigen Antagonismus ihrer Anschauungen hervorgerufen worden sei. (Brief an Tolstoj vom 28. Mai/9. Juni 1861) Eben diese Erklärung findet Nikolaj Petrovic für das Duell zwischen Bazarov und seinem Bruder. (S. 357)

$3 \mathrm{Vgl}$. die durchaus ähliche Problematik des sozialistischen Realismus, dargelegt in dem Aufsatz "Was ist der sozialistische Realismus?" in: A. Terz, "Der ProzeB beginnt" (1966), S. 152: "Es ist unmöglich, einen positiven, allen Regeln des sozialistischen Realismus entsprechenden Helden zu schaffen und inn gleichzeitig psychologisch zu interpretieren. Das Ergebnis wäre eine Parodie...". - Dostoevskij verspottet die Gestalt Bazarovs in seinen "Dämonen": "Ja ne ponimaju Turgeneva. U nego Bazarov éto kakoe-to fiktivnoe lico, ne suščstvujuß̌ðee vorse ...0 karikatura!" In: "Sobr. soč. v desjati tt.", Bd. 7 (1957), S. 227. 
fizieren kann. Gleichwohl ist er als positiver lield zu betrachten - dies aus zwei Grüden:

Ein Vergleich Bazarovs mit seinen "Schülern" fällt zu seinen Gunsten aus. Bazarov plappert nicht fremde Ideen nach wie Arkadij, 1 er verachtet den Schwätzer Sitnikov und die konfuse emanzipierte Kukfina (die Dostoevskij eine progressive Laus nannte ${ }^{2}$ ).

Der Kern der Aussagen Bazarovs ist bedenkenswert. Bazarov hat als einziger einen offenen Blick für die Probleme des Kirsanovschen Gutes ${ }^{3}$ - die Arkadij überhaupt nicht sieht, von denen Pavel Petrovic sich abwendet (S. 227) und denen Nikolaj Petrovič hilflos gegenübersteht. 4

Wie man mit aus der Leibeigenschaft entlassenen Bauern umzugehen hat - diesem wichtigsten Problem steht indes auch Bazarov hilflos gegenuber. Die Nonsens-Sätze, die er (in kap. XXVII) mit einem Bauern des väterlichen Besitzes spricht, beweisen das. Bazarov ist nur der einzige, dem die Probleme der zeit auf den Nägeln brennen. Daher ruhrt seine Aggressivität. Er sucht nach zukunetsweisenden Vorbildern: "Wenn ich einen Menschen finde, der vor mir nicht kapituliert...dann werde ich meine Meinung über mich ändern." (S. 325)

Bazarov muß aber erkennen, daß die ältere Generation trotz allen Bestrebens, progressiv zu erscheinen, keine richtunesweisenden Gedanken anzubieten hat. Er stirbt, weil es eine "Sache" Bazarovs, d. h. eine konkrete Vorstellung davon, wie Ge-

'Arkadijs Phrase"...wir haben nicht das Recht, uns der Befriedigung des persönlichen Egoismus hinzugeben" ist Bazarov peinlich. (S. 243)

${ }^{2} V_{g l}$. den Kommentar von A. I. Batjuto zu "Väter und Söhne", in: Bd. VIII der Nerke, S. 606 .

${ }^{3}$ Bazarov macht $z$. B. vernünftige Vorschläge zum Baumbestand des Gutes. (S. 234) Das Vieh hält er fur nerur,tergekommen, die Arbeiter für faul. (S. 236)

4 "Ich bin am Ende meiner Kräfte! - rief Nixolaj Petrovic mehr als einmal verzweifelt aus." (S. 337)

Den Verwalter, den Bazarov zu Recht "einen Dummkopf oder Gauner" nennt, bezeichnet Nikola Petroviz als tüchtigen Burschen. (S. 203) 
genwartsprobleme zu lösen wären, ${ }^{1}$ nicht gibt. ${ }^{2}$ Dies scheint Turgenevs Pazit einer Analyse der sechziger Jahre zu sein.

${ }^{1} V_{g l}$. die konzeptlose ältere Generation: Arkadijs Vater ist so um Progressivität bemüht, daß man ihn im Gouvernement den "Roten" nennt (S. 239). Der dumme Beamte Matvej II'i丈 Koljazin hält, sich für einen "Progressisten" (S. 253). Vasilij Ivanovič sagt von sich: "Zumindest versuche ich...wie man sagt, nicht zu versauern, nicht hinter der zeit zuruckzubleiben." (S. 312) Bei Vasilij Ivanovič geht das Streben, vor seinem Sohn progressiv zu erscheinen, bis zur Selbstverleugnung: er mag seine Frömmigkeit nicht zugeben (S. 329) und läBt am Tage der Ankunft seines Sohnes den Vladimirorden von seinem Rock trennen.

2 Von der "Sache" spricht Bazarov selbst. (S. 380) - Von Sitnikov heiBt es im letzten Kapitel ironisch, er treibe sich in Petersburg herum und versuche, die "Sache" Bazarovs weiterzufüren.

Vgl. H. Gifford, "The Novel in Russia" (1964), S. 71 zum Tode Bazarovs: "Bazarov's death, though finely imagined, has no reason unlike Kirillov's death, or Stavrogin's. Herzen was probably right in thinking that Turgenev got rid of Bazarov because he could settle with him in no other way." 
L. N. Tolstoj, "Krieg und Frieden"

1. Um in Tolstojs gewaltigem, 1869 abgeschlossenen Epos "Krieg und Frieden" die Institution "Duell" in ihrer besonderen Eigenart und Bedeutung herauszukristallisieren, scheint der Versuch sinnvoll, alle geschichtsphilosophischen Komponenten des Romans und alle theoretischen Diskussionen Tolstojs zum Krieg knapp zu charakterisieren, um sie dann in den Hintergrund zu rücken und vor ihrer Kulisse die im Rahmen der Duellproblematik bedeutungstragenden Romanszenen $z u$ beleuchten.

Ziel aller romanhaften Darstellung und theoretischen tberlegung Tolstojs zur Geschichte sind offenbar folgende Thesen:

a) Geschichte ist von der Vorsehung bestimmt. - Das soll die Meinung der Mar'ja Dmitrievna zu Anfang des Romangeschehens ${ }^{1}$ ebenso bezeugen wie Tolstojs fatalistische Uberlegungen $z u$ Beginn des dritten Buches. 2

b) Geschichte wird folglich nicht von großen Männern g e m a c h t - Tolstoj zeigt die Szenen der Schlacht bei Borodino mit den Augen des verständnislos lächelnden, hilflosen Zivilisten Pierre Bezuchov und unmittelbar danach aus der Sicht Napoleons, des Oberkommandierenden der französischen Armee, um zu beweisen, daB einer so unwissend und entbehrlich für die Schlacht ist wie der andere. Napoleon weiB nicht, wo sich die

${ }^{1}$ Während eines Namenstagsessens bei Rostovs sagt Mar'ja Dmitrievna: "Alles geschieht nach Gottes Willen: man kann auf dem Ofen liegen und sterben und in der Schlacht durch Gottes Gnade verschont bleiben...". In: I. N. Tolstoj, "Sobr. sol. v 14 tt.", Bd. 4-7 (1951), Buch I, s. 80 - Zitiert wird nach dieser Ausgabe, jeweils mit Angabe von Buch und Seite.

${ }^{2}$ Vom 1. Teil des dritten Buches an befinnen Tolstojs ausführliche theoretische Diskussionen zur Geschichte. "Der Fatalismus ist in der Geschichte unentbehrlich zur Erklärung von Erscheinungen, die der Vernunft widerstreben...": Buch III, S. 8 Die Ereignisse des Kriegsjanres 1812 kommentiert Tolstoj folgendermaßen: "Die Vorsehung hat alle diese Menschen..gezwungen, an der Zustandebringung eines gewaltigen Erlebnisses mitzuwirken, von dem niemand (weder Napole on noch Alexander....) auch nur die geringste Ahnung hatte." (Buch III, S. 103) 
Kämpfe abspielen, die er durch sein Fernrohr beobachtet. Er wird von Adjutanten und Ordonnanzen falsch informiert und gibt infolgedessen sinnlose Befehle. ${ }^{1}$ (Buch III, S. 234 ff.)

c) Alle politischen Aktivitäten sind letztlich absurd. - Als Nikolaj Rostov wïhrend des Tilsiter Friedens die Verbrüderung der vordem verfeindeten Russen und Franzosen erlebt, erineben sich in seiner Seele "schreckliche Zweifel" am Sinn des Krieges. (Buch II, S. 149 ff.) Er erkennt, daB alles Leiden umsonst war. Im Jahre 1809 kämpft Rußland mit seinem ehemaligen Feind Frankreich gegen seinen enemaligen Verbündeten Österreich. Bis zum Janre 1812 haben sich die Freund-Feind-Verhältnisse wiederum dergestalt geändert, daB Napoleon mit seinen Truppen gegen RuBland zieht. Wer heute unschmeichelter Träger politischer Hacht ist, wird morgen als Verräter in die Verbannung geschickt: das zeigt Tolstoj am Lebensweg Speranskijs (Buch II, S. $209 \mathrm{ff}$. und 371 ff.) und am Schicksal Napoleons (Epilog, S. 245 ff.).

2. Das absurde Auf und Nieder des politischen Lebens, des "historischen beeres", 2 ist fur jede der Tolstojschen Figuren be-

${ }^{1}$ Tolstoj ist durchweg um eine Verächtlichmacinung politischer Größen und politischer Arbeit bemüht: er läBt Napoleon das Zittern seiner linken 'Wade als "großes Zeichen" betrachten und reduziert seine Größe so auI Größenwainn. (Buch III, S. 27). Napoleons Gebaren wird als das eines wurdelosen Harlekins charakterisiert, der seine Gesprächspartner als Beweis kaiserlicher Gunst kokettierend am Onr zupft und sein Gefolge mit usurpierten Titeln schmückt. (ebd., S. 35 und S. 220 ff.) kit der Darstellung Napoleons beschäftigt sich ausfürlich I. A. Potapov, "Roman L. N. Tolstogo 'Vojna i mir'" (1970).

Speranskij wird als unnatüliche Kreatur dargestellt; seine politischen Freunde Gervais, Magnickij und Stolypin lachen auf Kommando. Furst Andrej scheint es, als wibten diese Politiker gar nicht, was wanre Fröhlichkeit ist. (Buch II, S. 209 ff.) Wie noch zu zeigen sein wird, rangiert in der Tolstojschen ilerteskala alles Unnatürliche und Unlebendige tief unten. Im AnschluB an das Speranskij-Kapitel - und im Kontrast dazu zeigt Tolstoj, was das Positive an einer Figur wie Nataša ausmacht: "...knjazju Andreju chotelos' videt' doma étu osobennuju, oživlennuju devusku...". (S. 213)

2Vgl. Tolstojs Bemerkung im Epilog: "Das aufgewuihlte historische heer Europas war zur Ruhe gekommen und in seine Ufer zuruckgetreten." (S. 240) 
langvoll. Alle werden unwillkürlich vom Sog der Wellenbewegung mitgerissen, um ihren von der Vorsehung bestimmten Part im geschichtlichen Leben zu spielen: Pierre Bezuchov gerät in Gefangenschaft, Platon Karataev stirbt als Gefangener, Füst Andrej wird in der Schlacht bej Borodino tödlich verletzt, und Petja Rostov verliert sein Leben als Partisane. $\mathrm{zu}$ derartigen Ereignissen kommt es unabhängig vom Willen des einzelnen, denn "das Leben eines jeden lienschen hat zwei Seiten: es gibt das persönliche Leben...und das schicksalhafte ....in dem der Vensch unausweichlich die ihm vorgeschriebenen Gesetze erfullt" - so schreibt Tolstoj zu Beginn des dritten Buches. (S. 8) Er erinnert damit an Goethes "Urworte. Orphisch", 1 die die zwei Aspekte des menschlichen Lebens als "Gesetz" und als "Wandelndes" fassen. Das Wandelnde, das fersönliche Leben, "...Arbeit, Wuße... Liebe, Freundschaft, Haß, Leidenschaften..." nennt Tolstoj "das wirkliche Leben", 2 das die eigentlichen Interessen des Menschen ausmache. Ihm gilt Tolstojs ganz besonderes Interesse, weil sich der Mensch hier als moralisches Wesen profiliert, zu Entscheidungen aufgerufen ist, gestalten kann.

Seinem 1886/87 verfaBten Essay "Uber das Leben" setzte Tolstof forte Kants aus dem "Beschluss" der "Kritik der praktischen Vernunft" als Motto voraus: "Zwei Dinge erfuillen mir das Gemuith mit immer neuer und zunehmender Bewunderung und Ehrfurcht, je öfter und anhaltender sich das Nachdenken damit beschäfigt: der bestirnte Himmel uber mir, und das moralische Gesetz in mir...Das erste fängt von dem Platze an, den $i c h$ in der äusseren Sinnenwelt einnerme, und erweitert die Verknüpfung, darin ich stehe, ins unabsehlich Grosse mit

\footnotetext{
Tie an dem Tag, der dich der Welt verliehen Die Sonne stand zum GruBe der Planeten/ Bist alsobald und fort und fort gediehen/ Nach dem Gesetz, wonach du angetreten./ So muBt du sein, dir kannst du nicht entfliehen,/ So sagten schon Sybillen, so Propheten;/ Und keine Zeit und keine Kacht zerstückelt/ Geprägte Form, die lebend sich entwickelt.// Die strenge Grenze doch umgeht gefällig/ Ein Wandelndes... 2Buch II, 3. Teil, S. 154 und Buch IV, 1. Teil, S. 16.
} 
Welten über Welten und Systemen von Systemen, ubberdem noch in grenzenlosen Zeiten ihrer periodischen Bewegung, deren Anfang und Fortdauer. Das zweite fängt von meinem unsichtbaren selbst, meiner Persönlichkeit an, und stellt mich in einer Welt dar, die wahre Unendlichkeit hat, aber nur dem Verstande spürbar ist, und mit welcher ich mich, nicht wie dort in blos zufälliger, sondern allgemeiner und nothwendiger Verknüpfung erkenne." 1

Der Blick zum gestirnten Himmel in einem Moment moralischen Erwachens markiert in "Krieg und Frieden" leitmotivhaft wesentliche Punkte im FluB der Ereignisse. In vier Schlüsselszenen der vier Bücher des Romans sieht man von der horizontalen, das politische $s c h i c k s$ a $l$ h $f t e$ Leben verkörpernden Bewegung des "historischen Meeres" mit dem Blick zum gestirnten Himmel jeweils eine vertikale Iinie aufsteigen, die einen entscheidenden Augenblick im $p$ e $r$ ö $n I$ i c h e $n$ Leben eines außergewöhnlichen Charakters signalisiert:

a) Am Ende des ersten Buches liegt Furst Andrej Bolkonskij schwerverwundet auf dem Schlachtfeld und denkt angesichts des unendlich hohen Himmels: "Wieso habe ich nur vorher nie diesen hohen Himmel gesehen? Und wie glücklich bin ich, daB ich ihn endlich erlebt habe. Ja! Alles ist nichtig, alles trügerisch auBer diesem unendlichen Himmel...nichts, nichts habe ich bisher gewuBt." (S. 346, 358)

b) Am Ende des zweiten Buches fährt Pierre Bezuchov nach seiner Liebeserklärung an die unglückliche Natała Rostova im Schlitten durch das nächtliche Moskau und sieht $z u$ einem sternenübersäten Himmel auf: "Pierre blickte unverwandt zum Himmel und spürte in seiner seelischen Hochstimmung nichts mehr von der beleidigenden Niedrigkeit alles Irdischen." Den hell strahlenden Kometen des Jahres 1812 empfindet er als Symbol fur die Empfindungen seiner "zu neuem Leben aufgeblühten" Seele. (S. 377)

c) Gegen Ende des dritten Buches betrachtet Pierre Bezuchov nach einer Phase physischer und psychischer Erschöpfuns und ab${ }^{1}$ Zitiert nach: I. N. Tolstoj "O žizni", in: "Poln. sobr. sox.",
pod obšcej redakciej V. G. Gertkova, Sérija pervaja, t. 26 (Moskau, 1936). 
surder politischer Hirngespinste das brennende Moskau und den nächtlichen Himmel mit dem Kometen, der ihn an Natała erinnert: "Während Pierre zum hohen Sternenhimmel blickte, auf den Mond, den Kometen und den roten Feuerschein, empland er eine freudige Ergriffenheit. 'Ach, wie gut das ist, was braucht man mehr?', dachte er." (S. 383)

d) Im vierten Buch erleidet Pierre Bezuchov die entwurdigend rohe Behandlung eines Gefangenen. In dieser Situation ist ihm der Anblick der unendichen Himmelsweite ein Trost: "Pierre blickte zum Himmel, auf die tief zurückweichenden funkelnden Sterne. 'Und all das ist mein, und all das ist in mir, und all das bin ich!', dachte Pierre. 'Und all das haben sie gefangen und in eine mit Brettem verrammelte Bude gesperrt!' Er lächelte..." (S. 110)

3. Es ist kein Zufall, daB mit dieser vertikalen Linie dreimal ein entscheidender Augenblick im Leben Pierre Bezuchovs signalisiert wird: an dieser Figur demonstriert polstoj den ProzeB moralischen Erwachens, und nur diese Figur - so wird gleich in den allerersten Romankapiteln deutlich - ist ihrer Substanz nach fähig, einen solchen ProzeB überhaupt durchzumachen.

Die große Petersburger Gesellschaft, zu der Pierre Bezuchov seiner Herkunft nach gehört, wird in den ersten fün Romankapiteln anläBlich einer Soiree bei dem Hoffräule in Anna Pavlovna Scherer vorgestellt. Die charakteristische Eigentümlichkeit dieser Gesellschaft ist ihre Unlebendigkeit, ihre seelenlose Fassadenhaftigkeit, die Differenz zwischen Schein und Sein, die Tolstof von Anfang an anprangert:

a) Die Begrüßung der Tante des Hoffräuleins kennzeichnet das gesellschaftliche Verhalten als ein hohles, verlogenes, ausschlieBlich auf Riten reduziertes - also eigentlich u $n$ menschliches Verhalten: "Alle Gäste vollzogen die Begrüßungszeremonie mit der lieben Tante, die niemand kannte, die niemanden interessierte, die niemanden etwas anging... Ma tante sprach mit einem jeden in ein und denselben Wendungen ron seinem Befinden, von ihrem Befinden und von dem Befinden Ihrer Majestät." (Buch I, S. 12) 
b) Auf das Unlebendige, Dinghafte an dieser Abendgesellschaft wird durch Vergleiche hingewiesen. Die Gäste sind wie eine "Gesprächsmaschine", bestehend aus gleichmäBig und unaufhörlich summenden "Spindeln". Die Ehrengäste gleichen einem Stück "Rindfleisch", das der übrigen Gästerunde auf appetitliche Weise "serviert" wird. Fürst Vasilij Kuragin redet nach alter Gewohnheit "wie eine aufgezogene Uhr". (ebd., S. 6 und 14 f.)

c) Die Mimik dieser Menschen ist ohne Aussagekraft: Anna Pavlovna hat sich aufgrund ihrer gesellschaftlichen stellung eine enthusiastische Attitüde angewöhnt, die sie unabhängig von ihrem Willen zur Schau stellt. Jedesmal, wenn sie von der Zarin spricht, nimnt ihr Gesicht einen traurigen Ausdruck an. - Auf dem Gesicht der Hélène Kuragina liegt ein "unveränderliches Lëcheln" (S. 16). - Die junge Fürstin Bolkonskaja redet zu ihrem luann "in dem gleichen koketten Tonfall", den sie für Außenstehende bereithält. (S. 19)

In dieser Gesellschaft ist der zwanzigjährige Pierre Bezuchov Debuitant und - das zeigt sein "kluger und zugleich schlichterner, aufmerksamer und natülicher Blick" - Fremdkörper. ${ }^{1}$ Furst Andrej läßt ihn das noch am Abend seines ersten Erscheinens im tonangebenden Petersburger Salon wissen: "...du bist der einzige lebendige Mensch in unserer ganzen Gesellschaft." (S. 38)

4. Lebendig zu sein bedeutet für Pierre Bezuchov vor allem, beeinflußbar, formbar, entwicklungsfähig zu sein gegenuber einer Gesellschaft, die unverändert gleich bleibt:

a) Uber eine Soiree bei Anna Pavlovna im Winter 1805/06 heibt es: "Der Abend bei Anna Pavlorna verlief genau so wie der erste, nur daB die Neuigkeit, die Anna Pavlovna diesmal ihren Gästen vorsetzte...ein Diplomat aus Berlin war...". (Buch I, S. 252)

\footnotetext{
${ }^{1}$ Pierre Bezuchovs kluger und natürlicher Blick PlöBt Anna Parlovna "Unruhe und Angst" e in (Buch I, S. 13). Sie tritt "erschrocken" auf ihn zu, als er den BegrüBungsritus mit der Tante nicht einhält (ebd., S. 14), und es gefällt ihr nicht, daB Pierre Bezuchor sich "zu lebhaft und naturlich" mit dem Abbé unterhält (ebd., S. 18).
} 
b) Auch im Janre 1812 ist das gesellschaftliche Leben das gleiche: "Dieses Leben ist unveränderlich" - schreibt Tolstoj. "Seit 1805 haben wir mit Bonaparte Frieden geschlossen und gegen ihn gekämpft, haben Konstitutionen geschaffen und sie verworfen, aber der Salon Anna Pavlovnas und der Salon Helènes ${ }^{1}$ waren noch immer dieselben..." (Buch III, S. 130)

Gegenuber dieser Gesellschaft also, deren Leben wie eb und je weitergeht, eben weil es kein wirkliches Ieben ist, sondern - so die Tolstojsche Formulierung - "mit Phantomen und Spiegelbildern des Lebens" befaBt ist, ${ }^{2}$ stent Pierre Bezuchor. Von Anfang an fesselt das Interesse des lesers die Frage, wie die Entwicklung des jungen Außenseiters verlaufen wird; ob aus der unbewuBten Lebendigkeit des kindlich-naiven Pierre Bezuchov ${ }^{3}$ eine bewuite Gegenposition wird, oder ob die Gesellschaft den Neuling assimiliert. Die Gesellschaft möchte ihn integrieren. First Vasilij Kuragin wendet sich mit diesem Anliegen ausdrücklich an Anna Pavlovna: "Erziehen sie mir diesen Bären...nichts braucht ein junger Mann so sehr wie die Gesellschaft kluger Frauen." (Buch I, S. 20) Pierres Freund Bolkonskij warnt ihn

${ }^{1}$ Der Salon, den die schöne, aber nachdrücklich als dumm charakterisierte Hélène Bezuchova im Jahre 1809 in Petersburg fürrt, verkörpert vollendet die Diskrepanz von Sein und Schein. Bei ihr emplangen zu werden, gilt als "Auszeichnung des Geistes" (Buch II, S. $180 \mathrm{ff.}$ ). Der Wortvorrat von Kapitel X ist bezeichnend: obman, obmanyvaemye, fokusnik, glupa, glupost', gluposti...Die Salons der Bergs und der Julie Drubeckaja sind gleichermaßen Verkörperung von Verlogenheit und Scheinlebendigkeit (Buch II, S. $215 \mathrm{ff}$. und Buch III, S. 179 fe.).

2Buch IV, S. 5. Tolstoj wiederholt auch zu Beginn dieses Buches: "Peterburgskaja Zizn" కla po staromu;" (ebd.).

${ }^{3}$ Tolstof betont die Kindlichkeit und damit die Beeinflußbarkeit Bezuchovs: "...wenn er lächelte...zeigte sein Gesicht einen kindlichen, guten, sogar etwas dümlichen Ausdruck...". (Buch I, S. 27) - "Fürst Andrej zuckte auf die kindlichen Reden Pierres nur die Schultern." (ebd., S. 33) Hand in Hand mit seiner kindlichen Unfertigkeit geht Pierres Disziplinlosigkeit - Tolstof nennt ihn sogar charakterlos: "...kak èto byvaet s lfud'mi, nazyvaemymi bescharakternymi...". (ebd.. S. 39) Pierre selbst ist sich bewußt, daß er im Vergleich zu seinem Freund Bolkonskij keine Willenskraft besitzt. (S. 38) - Die Schwächen Pierres werden von Tolstoj nachsichtig kommentiert. 
indes eindringlich vor der Gesellschaft: für Bolkonskif sind die Salons von Hoflakaien und Idioten Prequentiert, und "les femmes distinguées" verkörpern für inn Eitelkeit, Stumpfsinn und Nichtigkeit. ${ }^{1}$ Die Schärfe dieses Urteils ist das Ergebnis von Erfahrungen, die Bezuchov noch bevorstehen und die ihn erst ganz allmählich, in dem laße der Verflechtung seines persönlichen Lebens mit der Gesellschaft und ihren Institutionen, zu einem eigenen Urteil kommen lassen. Die Suche Pierre Bezuchovs nach seinem Standort in der Gesellschaft durchläuft mehrere Phasen. Sein Schwanken zwischen natürlichen Impulsen und gesellschaftlich akzeptiertem Verhalten wird in drei szenen in besonders verdichteter Weise demonstriert:

a) Ein kritikloses (wenn auch nicht fragloses) Sich-treibenlassen vom Strom der Gesellschaft zeigt sich in aller Deutlichkeit in der Sterbestunde des alten Grafen Bezuchor. (Buch I, S. 93 ff.)

b) Pierre Bezuchovs äuBerliche Integration in die Gesellschaft und das aufsteigende, aber noch nicht artikulierte Unbehagen an der Manipulation durch seine gesellschaftliche Umgebung wird am sichtbarsten während der Namenstagsfeier der Helène Kuragina. (Buch I, S. 256 ff.)

c) Als HöchstmaB der Vergewaltigung seiner Person erlebt Pierre Bezuchov im nachhinein sein Duell mit Dolochov. Er greift sich als Zeichen des Erwachens aus einem Zustand der Umnachtung an den Kopf und versucht verzweifelt, die Umstände, die zu diesem Duell führten, zu analysieren. Das Duell erweist sich als auslösendes Moment für die Frage nach dem Sinn des Lebens. Inm kommt für den ProzeB des moralischen Erwachens Pierre Bezuchovs, für sein Streben nach lebendigem, wahrhaft menschlichen, nichtautomatisierten Verhalten zentrale Bedeutung $z$.

Alle drei Szenen veranschaulichen mit wachsender Intensität die machtvolle Wirkung von Riten und Zeremonien, die in der

${ }^{1}$ Buch I, S. 37 - Vgl. das treffende Urteil von E. Gunn in "A Daring Coiffeur" (1971), S. 15: "...Prince Andrew...1s the only character... who is neither naive nor cormpt." 
groben Gesellschaft an die Stelle individuellen Fühlens und Handelno getreten sind, gegen die einzig Pierre Bezuchovs Lebendigkeit sich schlieblich aufbäumt, un nicht erstickt zu werden. Für das kontrastierende Gegenüber von blutleeren Riten und lebendigem menschlichen Handeln hat Tolstoj den Leser von den ersten Seiten des Romans an sensibilisiert. Die genannten drei Szenen entfalten diese Thematik in extenso. Höchste Relevanz kommt hierbei der Duellszene und ibren Folgen zu, weil Pierre Bezuchov das Dilemma zwischen vorgegebenem Handeln und dem "moralischen Gesetz in ihm" fortan bewubt als persönlichen Konflikt erlebt, dessen Iösung er sucht.

Auf die drei szenen sei nun der Reihe nach eingegangen: unter dem Aspekt der lebensabtötenden Funktion der in ihnen dargestellten Riten.

5. Der sterbende Gral Bezuchov hat seinen unehelichen Sohn Pierre zu sich rufen lassen. Bevor Pierre in Begleitung seiner Verwanden Anna Michajlovna - die sich im Falle einer Erbschaft Pierres Vorteile erhofft - im Hause seines Vaters eintrifft, wird die seltsame Versammlung beschrieben, die den Tod des alten Grafen erwartet. Um das Haus streichen Sargmacher, die ein gutes Geschäft wittern. Im Emplangszimmer drängen sich geistliche und weltliche Würdenträger, Ärzte und sogar Unbekannte, deren Gesprächsfetzen sensationslüstern ${ }^{1}$ oder trivial ${ }^{2}$ klingen. Der Pranzösische Arzt parliert in "graziöser Pose" über das Wetter, äuBert sich in eitler Selbstzufriedenheit über den Zeitpunkt der Todesstunde, läßt dem Todkranken aber dennoch in einer absurden Zurschaustellung ärztlicher Kompetenz ein Getränk verabreichen. ${ }^{3}$ Der deutsche Arzt fällt durch seine schlechte

"Ich erage mich, ob es nicht zu spät für die letzte olung sein wird?...eragte die Dame...". (Buch I, S. 87)

"Ich habe einen gekannt, der hat siebenmal die letzte olung bekommen." (ebd.) "Wer war denn das, war das der Oberkommandierende selbst?" - Pragte jemand am anderen Ende des Zimmers." (ebd.) "Und an wen geht der ganze Reichtum?" (Buch I, S. 88)

3" Behmen sie ein Glas abgekochtes Wasser und geben sie une pincée cremortartari dazu...(er zeigte mit seinen dinnen Fingern, was une pincée sein solite)." (ebd.) 
Aussprache des Französischen und des Russischen auf, und bei den engsten Verwandten des Sterbenden - dem Fürsten Vasilij Kuragin und der Prinzessin Katerina Semenovna, die beide Pierre als Erben fürchten - hat bereits ein erbittertes und listenreiches Ringen um das Testament eingesetzt. Niemand ist im Innersten vom herannahenden Tod des Grafen betroffen. Es sind die normalerweise diskret gehandhabten Formalitäten einer Sterbestunde, die aufdringlich das Blickfeld beherrschen und die einzig den hinzukommenden Pierre befremden. Er wundert sich über die Gestalten, die um das Haus seines Vaters herumstehen; begreift nicht, warum Anna Michajlovna von seinen Interessen spricht; warum die Mienen des Fürsten Vasilij und der Prinzessin bei seinem Anblick Angst und Verzweiflung ausdrücken; warum Anna Michajlovna ihn, der als unehelicher Sohn wenig Kontakt zu seinem Vater hatte, mahnt, tapfer zu sein; warum man ihm im Empfangszimmer ungewointe Aufmerksamkeit widmet. ${ }^{1}$

Pierre war eigentlich gekommen, um seinen sterbenden Vater zu sehen, "aber...er fuhlte, heute nacht jemand $z u$ sein, der verpflichtet war, irgendeine schreckliche und von allen erwartete Zeremonie zu vollziehen und von allen Leuten Gefälligkeiten entgegennehmen zu müssen. Er...legte seine großen Hände in der naiven Pose einer ägyptischen Statue auf die symmetrisch vorgestreckten Knie und sagte sich, dab dies alles eben so sein muisse und daB er am heutigen Abend - um nicht den Kopf zu verlieren und Dummeiten zu machen - nicht nach seinem eigenen Gutdünken handeln dürfe, sondern sich ganz dem Willen derer überlassen müsse, die ihn leiteten." (Buch I, S. 97)

Im Gegensatz zu seiner Umgebung unterwirft Pierre sich erstaunt und bewubt einem Zeremoniell, das auf Kosten persönlichen, lebendigen Handelns vonstatten geht. Das Zeremoniell fesselt selbst im Sterbezimmer den gröBten Teil seiner Aufmerksamkeit. Vor dem hell erleuchteten verzierten Ikonenschrein zele-

\footnotetext{
${ }^{1}$ In den Kapiteln XIX, XX und XXI des ersten Teils von Buch I wird insgesamt siebzehn mal zum Ausdruck gebracht, daB Pierre nicht versteht, was um ihn herum vorgeht, sich den befremdiichen Umständen aber fügt, weil er glaubt, es músse alles so sein.
} 
brieren Geistliche in prächtigen Gewändern einen feierlichen Gottesdienst. Wie in der Kirche stehen Männer und Frauen getrennt. Alle Anwesenden setzen eine für sie typische Miene auf: Katerina Semenovna starrt mit bösem Blick auf die Ikonen, "als wolle sie sagen, daß sie nicht für sich einstehen könne, wenn sie woanders hinschaue." (Buch I, S. 99) Frömmigkeit und Gottergebenheit auf dem Gesicht des Fürsten Vasilij scheinen ausdrücken zu wollen: "Wenn ihr diese Gefüle nicht versteht, um so schlimer für euch." (ebd.) In Anna Michajlovnas gewichtiger Miene steht zu lesen, "daß sie wisse, was sie tue...". (ebd.) Der Pranzösische Arzt steht in jener ehrerbietigen Pose eines Ausländers da, "die zeigt, daB er trotz Glaubensunterschied die ganze Wüde der vor sich gehenden Zeremonie begreift und sie sogar billigt...". (Buch I, S. 100) Diese ÄuBerlichkeiten zwingen sich Pierres Augen auf und verursachen einen Zustand der Selbstvergessenheit. "...abgelenkt von der Beobachtung der Umstehenden" bekreuzigt er sich mit derselben Hand, in der er die Kerze hält. (ebd.) Willenlos läBt er sich von Anna Michajlovna an das Bett seines Vaters fuhren. Er läßt sich von ihren Augen dirigieren und kann sich nur noch darauf konzentrieren, der ihm zugedachten Rolle in dem vorgeschriebenen Zeremoniell gerecht $z u$ werden: "Pierre nahm wieder die symmetrisch-naive Pose einer ägyptischen Statue an, wobei es ihm offensichtlich leid tat, daß sein plumper und dicker Körper so viel Raum in Anspruch nahm und er seine ganze Kraft anstrengte, um möglichst klein zu erscheinen." (Buch I, S. 102)

Der Allmacht des Zeremoniells muB sich sogar der Sterbende unterziehen, richtiger gesagt, er muß sie erleiden. Seine Hände sind mit der Handfläche nach unten auf die Decke gelegt. 2wischen Mittel- und Zelgefinger hat man eine Kerze gestellt, die ein Diener festhalten muB. Obwohl der Todkranke reglos daliegt und leblos scheint, wird von einer aufdinglichen Fürsorge nicht abgelassen: der Gottesdienst wird unterbrochen, um ihm ein Getränk $z u$ verabreichen. Der Geistliche beglückwuinscht ihn zum Emplang des Sakraments. Umständlich wird er von seinem Sessel zum Bett heribergetragen. Man legt ihn in "feierlicher Pose" auf das Bett. Seine Hände liegen symmetrisch 
mit der Handfläche nach unten auf der Decke. (Buch I, S. 101) Alle Anwesenden beschäftigt das Ritual der Sterbestunde, nicht der Sterbende. Sogar Pierre begreift erst $n$ a $c h$ dem Gottesdienst, als er in unmittelbarer Nähe des Sterbenden sitzt und dessen Gesicht plötzlich zu zucken beginnt, wie nahe sein Vater dem Tod ist. Erst jetzt, als er hilft, den Kranken von einer Seite auf die andere zu legen, kommt es durch die unmittelbare, von keinem Zeremoniell gestörte Nähe $z u$ einem Kontakt zwischen Vater und Sohn. Pierres schreckerfüllte Miene ruft bei dem Sterbenden ein schwaches Lächeln hervor, das Pierre erschüttert und $z u$ Tränen rührt. Pierre zeigt, als er dem Bann des alles beherrschenden Rituals für einen Augenblick entzogen ist, als einziger wahres Mitleid, er ist als einziger einer wirklich menschlichen Reaktion fähig. Die Kluft zwischen dem lebendigen Pierre und einer Gesellschaft, deren Leben auf bloßes Zeremoniell reduziert ist, wird am Sterbebett des alten Grafen Bezuchov noch deutlicher als auf der Abendgesellschaft bei der Hofdame Anna Pavlovna. Nur stellt Pierre diesmal - obwohl es ihn unglüklich macht - seinen eigenen willen schon hintan, um sich dem Zugriff der Gesellschaft zu beugen.

6. DaB Pierre durch den Tod seines Vaters ein reicher Mann und ein Graf Bezuchov wird, macht inn zum allseits beanspruchten ${ }^{1}$ und umschmeichelten Mittelpunkt dieser Gesellschaft. Die Intensität der gesellschaftlichen Beanspruchung erweist sich dabei als das gröBere tbel, weil sie kein staunendes Beobachten mehr zuläßt. Hatte Pierre sich im Hause seines sterbenden Vaters gewundert uber die Aufmerksamkeit, die ihm plötzlich zuteil wurde, so erscheint es ihm jetzt "natülich, dab alle ihn lie-

\footnotetext{
1 "Er mußte Papiere unterzeichnen, hatte mit Behörden zu tun, von deren Wweck er keine klare Vorstellung hatte, muBte den Hauptverwalter nach irgendeiner Sache fragen, auf sein Gut bei Moskau fahren und eine Menge Leute emplangen, die vorher nicht einmal von seiner Existenz hatten wissen wollen..." . (Buch I, S. 248) - "Unaufhörlich hörte er die Worte: 'Bei Ihrer auBerordentlichen Güte', oder: 'Bei Inrem guten Herzen'... oder: 'Wenn er so klug wäre' wie Sie', usw...". (ebd.)
} 
ben...". (Buch I, S. 249) Hatte er sich dort bewußt fremdem Willen untergeordnet, so wird seine eigene Willensbildung jetzt gänzlich unterdrückt - er kommt nicht mehr zu sich selbst.' Pierre wird von den Gepflogenheiten gesellschaftlichen Lebens wie von einem Sog ohnmächtig mitgerissen: "Er fühlte sich als das Zentrum irgendeiner wichtigen, allgemeinen Bewegung; fuhlte, daß ständig irgendetwas von inm erwartet wurde...". (ebd.) Manipulation von außen, vor allem von Seiten des Fürsten Vasilif Kuragin, ${ }^{2}$ läßt Pierre - unmerklich für ihn selbst - seinen Willen verlieren. Dennoch, so zeigt Tolstoj, ist Pierre seiner gesellschaftlichen Umgebung nicht gänzlich ausgeliefert: als er plötzlich feststellt, daB man ihn mit Hélène Kuragina verheiraten will, daB sich zwischen ihm und Hélène eine Beziehung entwickelt hat, "die von der AuBenwelt anerkannt wird" (Buch $I$, S. 251), wird ein unabhängig vom Willen funktionierender Warnmechanismus ausgelöst: "das moralische Gesetz" in ihm wehrt sich gegen eine solche Verbindung. Er spürt, daB "etwas Abscheuliches...etwas Verbotenes" in dem Gefühl liegt, das Helène in ihm wachruft (S. 255), weil sie ihn nur mit ihrem Körper lockt, weil es zwischen ihnen "keine Schranken" gibt. 3 Pierre sieht in den Kuragins die verkörperte Amoral: "Man hat mir erzählt, ihr Bruder Anatole sei in sie verliebt gewesen, und sie in ihn, daB da eine ganze Geschichte gewesen sei und man Anatole deshalb fortgeschickt habe... Fürst Vasilif ist

\footnotetext{
1 "Pierre... fülte sich derart umringt und beschältigt, daß er nur noch im Bett mit sich allein sein konnte." (Buch I, $S$. 248)

2 "Mehr als alle anderen bemächtigte sich in dieser ersten Zeit Furst Vasilif sowohl der Angelegenheiten Pierres als auch seiner selbst." (Buch I, S. 249) 3

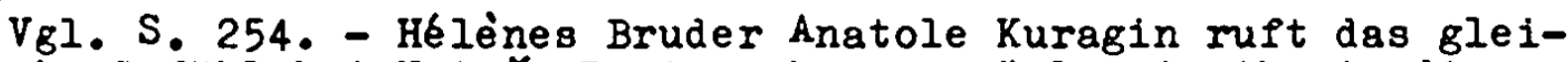
che Gefuhl bei Natała Rostova hervor: "Als sie inm in die Augen schaute, bemerkte sie jedoch voller Angst, daB zwischen ihm und ihr durchaus nicht jene Schranke der Schamhaftigkeit war, die sie immer zwischen sich und anderen Männern fühlte ... Und wieder fühlte sie mit Schrecken, daB es zwischen ihm und ihr keine Schranken gab." (Buch II, S. 334 f.)
} 
ihr Vater...Das ist nicht gut...". 1 Der Konflikt, in dem Pierre sich befindet - alle warten auf seine Entscheidung fur Helène, während ihn bei dem Gedanken an diesen Schritt eine "unverständliche Furcht"erfulllt ${ }^{2}$ - wird während Hélènes Namenstagsfeier von außen gelöst. Fürst Vasilif vertraut auf den Druck, den das Zeremoniell einer feierlich arrangierten Namenstagsfeier auf Pierre ausüben muß. ${ }^{3}$ Das Zeremoniell ist von eindeutiger Zielgerichtetheit. Allen Geladenen wird zu verstehen gegeben, daß sich das Schicksal des Namenstagskindes nun entscheidet. Pierre und Hélène werden nebeneinander gesetzt. Fürst Vasilif unterhält alle Anwesenden außer Pierre und Helène - er betont somit ihre Familienzugehörigkeit. Brennende Kerzen, schimmern-

${ }^{1} V_{g l}$. S. 255 in Buch I. - Die religiöse Mar'ja Bolkonskaja, die von Anatole Kuragin als reiche Erbin umworben wird, errät die Amoralität des inr unbekannten Verehrers instinktiv. Er stellt sich ihr als teuflische Figur dar: "Soll etwa er mein Mann sein, ausgerechnet dieser fremde, schöne, gute Mann; er ist gut, das ist die Hauptsache,' dachte Prinzessin Mar'ja, und es kam eine Angst über sie, wie sie sie fast niemals empland. Sie fürchtete, sich umzusehen; es kam ihr so vor, als stünde dort jemand hinter dem Wandschirm, in der dunklen Ecke. Und dieser jemand war er, der Teufel, und er, dieser Mann mit der weiBen Stirn, den schwarzen Brauen und dem roten Mund." (Buch I, S. 280 f.) - Tolstoj gibt Anatole Kuragin hier die aus der romantischen Schauerliteratur bekannten Züge.

Den Fursten Vasilif zeichnet Tolstof als einen Menschen, dem moralisches Emplinden abgeht. Obwohl es den Fursten nur zu Menschen hinzieht, die ihm nützlich sein können, die reicher und höherstehend sind als er, hält er sein Bemuihen um Pierre fur "charite" und "dobrota". Vgl. Buch I, S. 247, 250, 256.

${ }^{2}$ Pierres innerer Widerstand gegen eine Bindung mit Helène Kuragina spiegelt sich in dem mit negativer Emotion befrachteten Wortvorrat der Seiten 256 - 264 (Buch I): "... zenit'ba na Elen byla by nesčastie"; "s užasom Curstroval"; "éto budet uzasno"; "kakoj-to neponjatnyj uzas ochvatyval ego pri odnoj 3 mysli ob étom strašnom šage...".

"...ich werde ein parr Gäste einladen, und wenn er nicht versteht, was er zu tun hat, wird das eben meine Sache sein."

(Buch I, S. 256)

Es ist in diesem Zusammenhang vielleicht von Interesse, darauf hinzuweisen, dab David Riesman in "Die einsame Masse" (1968) seine Theorie der AuBen-Ienkung $u$. a. an Stepan Arkad'it Oblonskij aus Tolstojs "Anna Karenina" exemplifiziert. 
des Silber, glänzendes Kristall und auserlesene Toiletten machen den äußeren Rahmen prachtvoll und festlich. Niemand kann sich der Hirkung dieses Zeremoniello entziehen. Pierre und Helène sitzen schweigend nebeneinander und erwecken den Eindruck schamhafter Verliebtheit. Die Gäste sind befangen: "...irgendwie war zu spüren, dab...das Lachen und Speisen nichts als Heuchelei war, daß nämlich diese ganze Gesellschaft ihre Aufmerksamkeit mit ganzer Kraft nur diesem Paar, Pierre und Hélène, widmete...die Lakaien, die bei Tisch bedienten, schienen das Gleiche zu empfinden und vergaben beim Servieren die Reihenfolge... Selbst das Licht der Kerzen schien sich nur auf diesen beiden glücklichen Gesichtern zu konzentrieren." (Buch I. S. 259 f.)

Pierre fühlt, daB er im Zentrum der Aufmerksamkeit steht. Doch treibt die Atmosphäre gespannter Erwartung ihn nicht entsprechend dem Kalkül des Fürsten Vasilij - zu einem Entschluß, sondern in einen quälenden Gewissenskonflikt. Er weiB, daB die Heirat mit Hélèe ein unausweichlicher Tribut an die Gesellschaft ist. ${ }^{1}$ Er weiB aber nicht, wie es dazu kam, daB er diesen Tribut überhaupt zahlen muB, ${ }^{2}$ und er ist sicher, ihn eigentlich nicht zahlen zu dürfen. "Irgendeine innere Stimme" sagt ihm: "Nicht für dich ist dieses Glück...dieses Glück ist für jene, die das nicht haben, was du hast. (ebd., S. 262) Es ist das Wirken dieser inneren Stimme, des "moralischen Gesetzes" in ihm, das Fierre von seiner gesellschaftlichen Umgebung unterscheidet. ${ }^{3}$ sein Gewissen läBt ihn das rein physische Begehren, das Hélène in inm geweckt hat, im Unter-

1"...dlja vsech \& $t$ o dolžno neizbežno soveršit'sja. Oni vse tak ždut \& t 0 \& 0 ...". (ebd., s. 260)

"I kak éto vse sdelalos'?... čto že ja sdelal dlja etogo? Kogda éto nacalos'?" (ebd.)

${ }^{3}$ Pur den Füsten Vasilij ist das Wort "Gewissen" inhaltsleer. Er benutzt es zur effektvollen Ausschmückung seiner Reden. So sagt er zu seinem berechnenden Bemuihen um den reich gewordenen Pierre Bezuchor: "...ja éto sdelal dlja sebja, dlja sroej sovesti, i menja blagodarit' nezego." (ebd., S. 250) Auch Hélène Kuragina kennt die moralische Instanz des Gewissens nicht. Sie vertraut sich einem "directeur de conscience" an. (Buch III, S. 290) 
bewuBtsein als sündhaft empfinden. 1 Ein ihm unbewubtes Schuldgefühl lähmt seine EntschluBkraft. 2 In diesem Zustand der Hilflosigkeit wird Pierre iberrumpelt. Fürst Vasilij wickelt das Zeremoniell so ab, als hätte Pierre sich für Hélène entschieden: er kommt frohen Schrittes und mit feierlicher Miene auf Pierre zu und beglückwinscht ihn: "Gott sei Dank!... Meine Frau hat mir alles gesagt!... Ich bin sehr, sehr glücklich...Gott segne euch!..." (ebd., S. 263) Fürst Vasilijwird bei seiner Inszenierung des Verlobungsrituals nun von einer allgemeinen feierlichen Rührung unterstützt und erringt einen äuBerlichen Sieg: Pierre akzeptiert den Lauf der Dinge als Erlösung aus seiner Gewissensqual: "Alles das muBte so sein und konnte gar nicht anders sein...deshalb hat es keinerlei Zweck zu fragen, ob es gut oder schlecht ist. Es ist gut, weil es entschieden ist und weil es den früheren quälenden Zweifel nicht mehr gibt." 3

Pierre versucht also, von seinem Gewissen abzusehen. Er versucht sogar, das begonnene Zeremoniell nun situationsgerecht mitzuvollziehen, indem er sich daran erinnert, was man "in solchen Fällen" sagt. Das Ergebnis ist jedoch eine unglückliche Zwiespältigkeit. Pierres Gedanken "Nun ist es zu spät, es ist alles aus..." (S. 264) folgt eine Liebeserklärung, die den Ritus seiner verlobung formell untadelig beschliebt, ob deren inhaltsleerer Armseligkeit er sich jedoch schämt. 4 Pierre kann

1 Pierre meidet das Wort "Heirat" - wie etwas Unreines - sogar in Gedanken: er spricht von "eto". Vgl. die FuBnoten auf $S$. 117 .

2"P'er prinadležal k Eislu tech ljudej, kotorye sil'ny tol'ko togda, kogda oni Curstrujut sebja vpolne Zistymi...nesoznannoe cuvstro vinovatosti etogo stremlenija paralizovalo ego resimost'." (Buch I, S. 258) - Pierres tberlegungen münden so nicht in einen EntschluB, sondern in hilfloses Gestammel: "... ne mogu, ne mogu obmanut' ich. No kak éto budet? Ne znaju; $a$ budet, nepremenno budet! .. Nado neizbežno perełagnut', no ne mogu, ja ne mogu...". (ebd., S. 260, 262)

${ }^{3} \mathrm{DaB}$ Pierre auch hier wieder von "éto" spricht, beweist seine innere Distanziertheit: "Vse éto tak dolzno bylo byt'...choroso $1 i$ eto...". (ebd., s. 263)

4 " 'Je vous aime!' - sagte er, als er sich erinnert hatte, was man in diesen Fällen sagen muB; doch klangen diese Worte 80 ärmlich, daß er sich für sich selbst schämte." (Ebd.. S. 264) 
von seinem Gewissen nicht absehen - darin liegt die Ursache für seinen zuküftigen Konflikt mit der Gesellschaft, die ihn jetzt nach außen hin integriert hat.

7. Einen endgültigen Beweis dafür, daB Pierre Bezuchov äuBerlich in die groBe Gesellschaft integriert ist, stellt seine standesgemäße Forderung Dolochovs zum Duell dar. Während eines Festessens, das zu Ehren des Füsten Bagration im Englischen Klub in Moskau gegeben wird, sitzt der eben verheiratete Pierre ${ }^{1}$ seinem ehemaligen Freund aus der Petersburger Junggesellenzeit gegenuber. Pierre ist in niedergedrückter und disterer Stimmung, weil man ihn in einem anonymen Brief uber angebliche Beziehungen zwischen Dolochov und seiner Frau informiert hat. Als er während des Essens bewuBt von Dolochov provoziert wird, steigern sich seine Gefühle von Traurigkeit zur Raserei. Beim Anblick der "huibschen, unverschämten Augen" Augen Dolochovs und bei dem Gedanken an dessen skrupelloses Draufgängertum ${ }^{2}$ fühlt er "etwas Schreckliches, Abscheuliches" in seiner Seele aufsteigen, das schlieblich von inm Besitz ergreift, ihn bleich werden und seine Lippen zittern läßt. (Buch II, S. 23 ff.) Der gewaltige Emotionsstau wird indes in den Bahnen konventionellen Handelns kanalisiert, als Pierre seinen Beleidiger zum Duell fordert: "'Sie... Sie sind ein gemeiner Mensch!...ich fordere sie' sagte er, schob den Stuhl zurück und stand vom Tisch auf." (ebd., S. 25) Pierres Orientierung an einem standesgemäßen Verhaltens-

${ }^{1}$ Im November 1805 findet die Verlobung Pierres und Hélènes statt, eineinhalb Monate später ihre Hochzeit. Der Emplang für den Fürsten Bagration fällt auf den 3. März 1806.

2 Dolochov wird als Tunichtgut und Zecher in den Roman eingefuhrt: "I Kuragin $i$ Dolochov $v$ to vremja byli znamenitostjami $v$ mire poves i kutil Peterburga." (Buch I, S. 41) - Anna Michajlovna nennt ihn einen Draufgänger (sorvigolova), Buch II, S. 16. Für Nikolaj Rostov ist er ein bekannter "Raufbold und Draufgänger" (bujan, bretër), ebd., S. S. 29. Dolochovs Precher Blick wird immer wieder betont (Buch I, S. 41; Buch I, S. 234 etc.). Pierre erinnert sich daran, dab Dolochov grausam aussehen kann (Buch I, S. 23), daB er ohne jeden Grund jemanden zum Duell forderte und das Pferd eines Kutschers mit der Pistole tötete (ebd., S. 23 P.) Petja Rostov hat von Dolochovs Grausamkeit als Partisane gehört. (Buch IV, S. 144) 
muster verhindert nicht nur den Ausbruch eines ererbten Jähzorns, 1 sondern auch die Erwägung der Gefahr, die sich für ihn, der nie eine Pistole in der Hand gehabt hat, im Duell mit einem gefährlichen Schützen ergibt. 2

Die Forderung Pierres wird von Dolochov kommentarlos akzeptiert. Für beide Kontrahenten finden sich sogleich Sekundanten, die unverzüglich über die Bedingungen des Duells in Verhandlungen treten. - Die von Arnold Gehlen betonte Entlastungsfunktion von Institutionen tritt hier klar zutage: "Solche Institutionen bedeuten... fur den einzelnen eine Entlastung von Grundentscheidungen und eine eingewöhnte Sicherheit der maßgeblichen Orientierungen, so daß das Verhalten reflexionsfrei und stetig, auch in der Gegenseitigkeit gleichförmig erfolgen kann." 3 Die tberzeugungskraft des Natürlichen, mit der das Duell zwischen

${ }^{1}$ Man vergleiche diese gezügelte Reaktion mit dem Verhalten Pierres in dem kurz danach stattfindenden Streit mit seiner Frau - hier gibt er sich ungehemmt einem Wutanfall hin: "Pierre stand vom Diwan auf und stuirzte taumelnd auf sie zu. 'Ich erschlage dich! - schrie er, riB mit einer ihm bisher unbekannten Kraft die Marmorplatte vom Tisch, ging einen Schritt auf sie zu und holte gegen sie aus." (Buch II, S. 33)

"Und ich füchtete mich ja auch wirklich vor ihm..." hatte Pierre sich vorher eingestanden, als es ihm durch den Kopl ging, dab es Dolochov nichts bedeute, einen Menschen umzubringen. (Buch I, S. 24)

3A. Gehlen, "Anthropologische Forschung" (1961), S. 68. - Tolstoj zeigt das Duell nicht nur an dieser Stelle als gesellschaftlich sanktioniertes Verhaltensmuster. Nach der versuchten Entführung von Natała Rostova furchtet deren Tante Mar'ja Dmitrievna, der alte Graf Rostov oder Fürst Bolkonskij könnten Anatole Kuragin zum Duell fordern. (Buch II, S. 365 f.) - Bolkonskif sieht im Duell das einzig denkbare Mittel, sich von Kuragin Genugtuung $2 u$ verschaffen - es erscheint inm lebensnotwendig: "...er wuBte, würde er inn treffen, würde er nicht anders können, als ihn zu fordern, so wie ein Hungriger nicht anders kann, als sich auf Nahrung zu stürzen." (Buch III, S. 36) Ohne Duell ist für Bolkonskij "die Beleidigung noch nicht abgewaschen", hat "der Zorn kein Ventil gefunden, sondern lastet auf seinem Herzen...". (ebd.) Das Duell als Plattform zur Austragung von Konflikten hat fur Bolkonskij die "tberzeugungskraft des Natürlichen", die nach Arnold Gehelen eine intakte Institution charakterisiert. Vgl. "Anthropologische Forschung" (1961), S. 72 . 
Pierre Bezuchov und Dolochov gefordert und akzeptiert wird, steht zu seiner Realisierung allerdings in auffälifem Kontrast: Pierre erweist sich auch bei dieser dritten Konfrontation mit seiner gesellschaftlichen Umgebung als AuBenseiter, der in dem Prokrustesbett akzeptierter Riten eine sehr unglückliche Figur macht. So reflexionsfrei er mit der Forderung Dolochovs den Weg normierten Verhaltens eingeschlagen hat, so selbstverständich und ihm unbewubt weicht er wieder davon ab.

8. Die beiden Kontrahententreffen in sehr verschiedenem Zustand am Rendezvous-Platz ein.' Dolochov hat nach einem Pröhlichen Abend eine unbeschwert ruhige Nacht verbracht. Für ihn ist das Duell ein rein technisches Problem, ein Ritus, den es geschickt und unter Ausschaltung allen Fuihlens und Denkens auszuführen gilt. Seine Duellerfahrung hat ihn ein Patentrezept entwickeln lassen: "...wenn man die feste Absicht hat, seinen Gegner zu töten, und $z$ war so schnell und gewiB wie möglich, ist alles in Ordnung." (Buch II, S. 25) Dolochor ist also ganz auf die praktische Ausfuhrung des Zweikamples konzentriert. Nicht so Pierre. Für ihn, der mit gelbem, eingefallenen Gesicht auf dem Kampfplatz erscheint, ist das Duell ein moralisches Problem, das sein Fühlen und Denken absorbiert. Ihn beschäftigen "ausschlieBlich zwei tberlegungen: die Schuld seiner Frau, an der er nach einer schlaflosen Nacht auch nicht im geringsten mehr zweifelt(e) und die Schuldlosigkeit Dolochorg....". (ebd., S. 26) In Gedanken hält er das Duell deshalb schon für überflüssig, für Mord, für eine Gefahr, vor der er sich verstecken möchte. Doch ist Pierre auch diesmal noch nicht imstande, seine moralische Einsicht in einen Willensakt gegen das sich abwickelnde Zeremoniell umzusetzen, durch eine persönliche Entscheidung das Duell abzubrechen. Vielmehr fuihrt die tberzeugungskraft seiner moralischen Einwände zur Spaltung seiner Persönlichkeit. Neben dem vernünftig argumentierenden Pierre steht der besinnungslos

${ }^{1}$ Das Duell findet am 4. März um 8 Uhr morgens im Sokol'nikiWald statt. Die Sekundanten Dolochovs sind Denisov und Nikolaj Rostov - Pierre Bezuchov kommt in Begleitung Nesvickijs. 
agierende Duellant: "...im selben Augenblick", als Pierre an einen Duellabbruch denkt, fragt er mit besonders ruhiger und zerstreuter Miene: "Ist es bald soweit, und ist alles bereit?" (Buch II, S. 26) Obwohl ihm das Plädoyer seines Sekundanten Nesvickij für einen Duellabbruch einleuchtet, ${ }^{1}$ obwohl er auf dessen Feststellung "Sie waren im Unrecht, sie waren erregt..." antwortet "Ach ja, es ist furchtbar dumm...", stößt Nesvickijs Wunsch nach einem Abbruch des Zweikamples bei dem Duellanten Pierre auf taube Onren: "Nein, wieso denn verhandeln....Sind wir also bereit?" (ebd.)

$\mathrm{Da}$ in Pierres gespaltener Persönlichkeit das Handeln also nicht mehr der eigenen Moral unterstellt ist, sondern dem Diktat eines Ritus, da dieser Ritus dem Kampfhahn Dolochov eine Selbstverständlichkeit ist, die ohne Versöhnungsversuch vollzogen werden soll, 2 beherrscht nun der Automatismus eines Pistolenduells mit Barrieren die Szene: ${ }^{3}$ Dolochovs Sekundant Denisor gibt das Kommando - er zählt bis drei; bei "drei" gehen die Kontrahenten auf den markierten Linien aufeinander $z u$; Pierre schieBt als erster

1 Der Versuch, die Kontrahenten unmittelbar vor dem Duell zu versöhnen, war Pflicht der Sekundanten und gehörte zum Zeremoniell des Zweikampfes. Vgl. das "Duellbuch" von H. Kufahl und $J$. Schmied-Kowarzik (1896), S. 224: "Es ist Ehrensache, an der aber jedenfalls festzuhalten ist, die Gegner nochmals zu einer Versöhnung aufzufordern. Die Sekundanten geben sich, wenn sie ihr Amt, das sie übernommen, richtig aufgefaßt haben, ohnedies in allen Fällen die größte Mühe, einen friedlichen Ausgang der Angelegenheit zu ermöglichen, es wird daher der Versöhnungsversuch auf dem Kampfplatz selbst erfolglos sein, allein er sollte nie unterlassen werden."

2 "Keine Entschuldigungen, kommt uberhaupt nicht in Frage", antwortet Dolochov auf den Vermittlungsversuch seines Sekundanten Denisov. (Buch II, S. 27)

${ }^{3}$ Das Duell wird - entsprechend den Konventionen - diskret ausgefürt: zu früher Morgenstunde, auf einer Waldlichtung, die 80 Schritt vom Weg entfernt liegt. Die Duellanten stehen 40 Schritt voneinander entfernt. Zwischen den Säbeln, die die Barrieren markieren, liegen 10 Schritte.

Das Duell zwischen Pierre Bezuchov und Dolochov wird anschließend vertuscht, so dab es "trotz der damaligen Strenge des Zaren in Bezug auf Duelle weder fur die beiden Kontrahenten noch für ihre Sekundanten unangenehme Folgen hatte." (Buch II, S. 87) 
und wartet unbeweglich den Gegenschuß $a b$; der verletzte Dolochov verfehlt seinen Gegner; da er kraftlos am Boden liegt, ist das Duell nach diesem einmaligen Schußwechsel zu Ende.

Die Tyrannei des Zeremoniells, die Tolstoj am Sterbebett des alten Grafen Bezuchov und während der Namenstagsfeier der Hélène Kuragina indirekt als unheilvoll darstellt, verurteilt er unmittelbar vor Beginn des Duells direkt: "Die Situation war nun entsetzlich. Es war offensichtlich, daß die Sache, die so ohne weiteres ihren Anfang genommen hatte, durch nichts mehr verhindert werden konnte, dab sie nun von selbst, unabhängig vom Willen eines jeden, ihren Lauf nahm und $z u$ Ende geführt werden muBte." (Buch II, S. 27) Dolochor bewegt sich dabei leicht und selbstverständlich: er geht auf Kommando langsam los, schaut seinen Gegner mit hellen, glänzenden Augen an, zeigt - "wie immer"! - einen Anflug von Lächeln, vergißt dann trotz seiner Verletzung nicht eine Sekunde die Spielregeln, sondern weist den auf ihn zulaufenden Pierre hinter die Barriere zurïck. Dolochov ist $e$ i $n$ s mit den Institutionen der Gesellschaft. Auf sein Verhalten im Duell trifft die Feststellung Gehlens zu: "Es gibt...Fälle, in denen man das Verhalten der Menschen von der Logik ihrer Institutionen her mit großer Wahrscheinlichkeit voraussagen kann, die Interpretation von innen, vom Charakter her, wird dann sogar irrefuhrend." 1 Daß der rücksichtslose Duellant Dolochov ein zärtlicher Sohn und Bruder ist, der mit seiner Mutter und einer buckligen Schwester zusammenlebt, entdeckt Nikolaj Rostov bei der Wahrnehmung seiner Pflichten als Sekundant Dolochors nur zufällig - und "zu seinem großen Erstaunen." 2

Das Schauspiel des Duells zwischen Dolochov und Pierre Bezuchov erinnert an Bilder aus Kleists "Marionettentheater": Dolochov wird in seinem Tun von der Institution "Duell" gelenkt

1A. Gehlen, "Anthropologische Forschung" (1961), S. 68. ${ }^{2} \mathrm{Vgl}$. Buch II, S. 29. - Die Beurteilung Dolochovs durch seine Mutter, eine Interpretation "von innen, vom Charakter her", wirkt absurd: Dolochovs Mutter glaubt, ihr Sohn sei "zu edel und reinherzig" für die Welt, in der er lebt; sle hält ihn für eine "hohe, himmlische Seele!" (Buch II, S. 44) 
we die Puppe im "Marionettentheater" vom Maschinisten. Er agiert unbewußt - daher glatt und geschmeidig. Der Ritus macht den Schwerpunkt seines Handelns aus - somit trifft das Lob der Marionette auch auf ihn zu: "Und der Vorteil, den diese Puppe vor lebendigen Tänzern voraus haben würde? Der Vorteil? Zurörderst ein negativer...nämlich dieser, daß sie sich niemals $z$ i e $r t e$. Denn Ziererei erscheint... wenn sich die Seele (vis motrix) in irgendeinem anderen Punkt befindet, als in dem Schwerpunkt der Bewegung. Da der Maschinist nun schlechthin, vermittelst des Drahtes oder Padens, keinen anderen Punkt in seiner Gewalt hat, als diesen: so sind alle ubrigen Glieder, wie sie sein sollen, tot, reine Pendel, und folgen dem bloßen Ge- . setz der Schwere..."."

Wie verkrampft wirkt dagegen Pierre Bezuchov, dessen Handeln seinem Bewußtsein zuwider läuft, dessen moralische Einsicht seinem Agieren als Duellant hinderlich im Wege steht: er lächelt "unnatürlich", als man ihm den Gebrauch seiner Pistole erklärt, geht nach dem Kommando "mit schnellen Schritten" voran und weicht von der markierten Linie ab. Die rechte Hand hält er "weit vorgestreckt", weil er Angst hat, sich selbst zu verletzen. Die linke Hand hält er "sorgfältig" hinter dem Rücken, um nicht in Versuchung $z u$ geraten, die rechte Hand zu stuitzen - er weiß, daB das unzulässig ist. ${ }^{2}$ Nach sechs Schritten sieht Pierre

${ }^{1}$ Heinrich von Kleist, "Sämtliche Werke und Briefe", Bd. 2 (1970), S. 341 P.

${ }^{2} \mathrm{Vgl}$. das "Duellbuch" von H. Kufahl und J. Schmied-Kowarzik (1896), S. 226: "Die Pistole ist mit $e$ i $n$ e $r$ Hand zu erfassen und $z u$ halten und darf die andere Hand nie zur Unterstutzung $b$ e $i \mathrm{~m} S \mathrm{c} h \mathrm{u} s \mathrm{~s}$ e zugezogen werden, ein Umstand, den wir nirgends e rwähnt fanden!"

Tolstof hält sich ziemlich genau an die fur ein Pistolenduell mit Barrieren fixierten Regeln: dazu gehört auch, dab Pierre nach Abgabe seines Schusses unbeweglich stehen bleibt, vgl. S. 230 im "Duellbuch": "Wer geschossen hat, muß unbeweglich den Schuß des Gegners abwarten, dem hierzu aber nur eine Minute Frist gegeben ist. Selbst der Verwundete hat nur eine Minute zur Abgabe des Schusses, dem Gesturzten sind aber zwe1 Minuten eingeräumt."

Dolochov bereitet sich trotz seiner Verletzung sofort auf den Gegenschuß vor. 
zunächst zu Boden, dann auf Dolochov, drückt mit dem Finger $a b$ "wie man es ihm beigebracht hat", zuckt bei seinem eigenen Schuß zusammen und lächelt dann über seine erschreckte Reaktion. Nur einen Moment handelt Pierre natürlich: als er realisiert, dab Dolochov verletzt ist, ist er augenblicklich ganz er selbst und läuft schluchzend auf seinen Kontrahenten zu. Dieser besteht jedoch auf einer Fortsetzung des Zweikampfes, so daB Pierre seinen Standpunkt hinter den Barrieren wieder einnehmen und seinen Part als Duellant weiterspielen muß. "Hilflos" und mit einem "sanften Iächeln des Bedauerns und der Reue" stellt er sich in zehn Schritt Entfernung vor dem Gegner auf. Er steht weder seitlich $z u$ ihm noch deckt er sich mit seiner Pistole.' Er steht "mit gespreizten Beinen und ausgebreiteten Armen" da und sieht Dolochor traurig an. Der Anblick eines Duellanten, der sich selbstmörderisch zur Zielscheibe seines Gegners macht, ist allen anwesenden Sekundanten derart unerträglich, dab sie die Augen schließen. ${ }^{2}$

Im Gegensatz zu Dolochov befindet sich bei Pierre "die Seele ... in irgendeinem anderem Punkte...als in dem Schwerpunkte der Bewegung", seine unbeholfene Figur gleicht dem lebendigen Tänzer im Kleistschen "Marionettentheater": "Sehen Sie nur die P... an....wenn sie die Daphne spielt, und sich, verfolgt von Apoll, nach ihm umsieht; die Seele sitzt inr in den Wirbeln des Kreuzes; sie beugt sich, als ob sie brechen wollte, wie eine Najade aus der Schule Bernins. Sehen Sie den jungen F...an, wenn er, als Paris, unter den drei Göttinnen steht, und der venus den Apfel überreicht: die Seele sitzt ihm gar (es ist ein Schrekken, es zu sehen) im Ellenbogen." 3

Als jedoch mit Dolochovs verfehltem SchuB das Duell vorbei ist und der Rollenzwang entfält, bricht sich Pierres künstlich in Schranken gehaltenes BewuBtse in endgültig Bahn. Pierre ar-

\footnotetext{
1"'Zakrojtea'! - ne vyderžav, kriknul daže Denisov svoemu protirniku." (Buch II, S. 28)

"Denisov, Rostov i Nesvickij zažmurilis'." (ebd.)

${ }^{3}$ Heinrich von Kleist, "Sämtliche Werke und Briefe", Bd. 2 $(1970)$, S. 341 1.
} 
tikuliert jetzt - wenn auch noch unzusammenhängend - was er vor dem Duell nur gedacht hatte: "Dumm...dumm! Tod...Lüge..." . (Buch II, S. 29) Pierres Gebaren - er greift sich an den Kopf und läuft blindlings vom Duellterrain in den Wald - zeigt symbolisch, daß sich bei ihm eine Erkenntnis durchgesetzt hat, die ihn zum gesellschaftlichen AuBenseiter macht.

9. Ein Zustand äuBerster Unruhe zwingt Pierre nach dem Duell, über seinen ZusammenstoB mit Dolochov nachzudenken. 1 Nachdem er mit seiner bruchstuickhaft vorgebrachten Kritik am Duell den magischen Kreis konventionellen Handelns durchbrochen hat, sucht er nun in einem Dialog mit seinem Gerissen eine Antwort auf die Frage: "Wie bin ich dazu gekommen...worin besteht denn meine Schuld?" (Buch II, S. 30) Pierres "innere Stimme" sieht die Ursache allen schuldhaften Verhaltens in seiner Verbindung mit Hélène Kuragina - gegen die er sich ja innerlich gesträubt hatte - und in der Liebeserklärung "je vous aime", mit der er sich und Hélène betrog. Hatte Pierre während der Namenstagsfeier dieser inneren Stimme unter dem Druck des Zeremoniells nicht nachgegeben, so beugt er sich jetzt dem Schuldspruch seines Gewissens. Er gesteht sich ein, $d a B$ er Hélène Kuragina, um deren Verderbtheit er von Anfang an wuBte, nicht hätte heiraten durfen. Pierres Ausflucht "Sie ist an allem schuld, an allem ist nur sie schuld" weicht somit dem Bekenntnis "Ich bin schuld...". (ebd., S. 31) Dieses Eingeständnis seiner persönlichen Schuld führt für Pierre zu einer eminent wichtigen irkenntnis, die ihn aus dem starren Rahmen der ihn einfassenden Institutionen befreit: "...sowohl die Schande meines Namens als auch die Ehre - das alles ist relativ, das alles hat mit mir nichts zu tun." (ebd.)

Das Duell wirft Pierre also letztlich auf seine eigene Person zurück. Sein Wunsch zu $l$ e $b$ e $n$ bedeutet, nach der Tren.-

1 "Er legte sich auf den Diwan und wollte schlafen, um alles zu vergessen, was mit ihm geschehen war, aber er konnte nicht. Ein solcher Sturm von Gefihlen, Gedanken und Erinnerungen erhob sich plötzlich in seiner seele, dab er nicht nur nicht schlafen konnte, sondern vom Diwan aufspringen und mit schnellen Schritten im Zimmer auf und ab gehen muBte." (S. 33 f.) 
nung von seiner Frau selbst herauszufinden, was gut und was schlecht ist, um in ein neues Bezugssystem seiner Wahl integriert zu werden. 1

10. Das Duell in Tolstojs "Krieg und Frieden" hat weder die undiskutierbare Verbindlichkeit wie bei Puskin und Lermontov noch wird es polemisch als antiquiertes ritterliches Gehabe verspottet wie bei Turgenev. Tolstoj behandelt das Duell distanzierter als Turgenev, indem er nach seinem Sinn fragt. Er handhabt es nicht so selbstverständich wie dieser, weil er den Duellvorgang erklärt. ${ }^{2}$ Das Duell wird den Lesern des Jahres 1869 als $r$ e $l$ a $t i v$ intakte Institution des Jahres 1806 dargeboten, d. h. es wird nicht in Bausch und Bogen abgelehnt, doch kommt die wichtigste Figur im Roman zu dem SchluB, daß Ehre und Ehrenkränkung konventionelle Begriffe sind, die mit der eigenen Person nichts zu tun haben, dab es aber ausschlieblich auf die eigene Person ankommt. Der Ehrenzweikampl wird somit nicht an den Stand, sondern an die Person gebunden: wenn der ehrenwerte Fürst Bolkonskij für die Entführung Natała Rostovas Genugtuung fordert, wird das als angemessen empfunden. Wenn hingegen der charakterlose Anatole Kuragin den Ehrenstandpunkt einnehmen will, sieht Pierre Bezuchov darin ein Unding. 3

Diese relativierende und subjektivierende Betrachtungsweise ruttelt am Fundament der Institution "Duell" und beraubt sie ihres Sinns als "Basis problemlosen Schon-verständigt-

"A Ziv - i Kivi: zavtra umrëł'...". (ebd.) - Zu Pierres Suche nach einem neuen, sinnvollen Lebensinhalt vgl. besonders die ersten Kapitel des 2. Teils von Buch II.

2 Tolstoj erläutert seinen Lesern, daß bei einem Pistolenduell mit Barrieren die Gegner bis zu diesen Barrieren vorrücken und nach Belieben schieben durfen: "...sabli votknuty $v$ sneg, označaja bar'er, do kotorogo sledovalo schodit'sja...Protivnik1 imeli pravo, schodjas' do bar'era, streljat', kogda kto zachotet." (Buch II, S. 26 ^.)

3"... aber sie haben mir gegenüber solche Worte gebraucht wie 'gemein' und Ähnliches, die ich comme un homme d'honneur niemandem gestatte.' Pierre schaute ihn verwundert an, außerstande $z u$ begreifen, was er damit sagen wollte...'Wie denn, Sie fordern Genugtuung?' - eragte Pierre spöttisch." (Buch II, S. 370) 
seins". 1 Bei dieser Sicht des Duells hätte Pečorin den lächerlichen Grułnickij nicht fordern können. Hier gilt nicht mehr, was Arthur Schnitzler zur Verteidigung des Duells sagt: "DaB man überhaupt mit der Möglichkeit oder gar der Unausweichlichkeit von Duellen innerhalb eines gewissen Kreises wenigstens rechnen mußte, - das allein...gab dem gesellschaftlichen Loben eine gewisse Würde... Und den Menschen dieser Kreise, auch den nichtigsten oder lächerlichsten, eine gewisse Haltung, ja, den Schein einer immer vorhandenen Todesbereitschaft..." ."

Die Kritik Tolstojs an einer nur noch bedingt gütigen Institution fällt entsprechend weniger engagiert aus als die Duellkritik Pußkins im "SchuB" oder die Lermontovs im "Held unserer Zeit". Dem Tolstojschen Duell fehlt die Grausamkeit der Zweikämpfe in den genannten Werken. Seine Funktion ist es weniger, zu einem Nachdenken speziell über d $i$ e s e Institution anzuregen, als wieder einmal zu demonstrieren, wie konventionelle Riten bewußtes individuelles Handeln zum Nachteil der betroffenen Personen lähmen, wie Lebendigkeit abgetötet und Marionettenhaftigkeit erzeugt wird. Das Duell in "Krieg und Frieden" ist Teil einer umfassenden Institutionenkritik Tolstojs. Dabei ist die Betrachtungsweise $j$ e $g$ i c h e $r$ Institution durch die grelle Beleuchtung eines einzigen Aspekts gekennzeichnet: Tolstoj sieht nur die tbermacht des Ritus, die alle lebendigen Impulse im Menschen erstickt - niemals die positiven Seiten normierten Verhaltens. "Die allen Institutionen we-

1Vgl. A. Gehlen, "Urmensch und Spätkultur" (1964), S. 43. Man vergleiche auch die Beurteilung, die das Dueil im Folgenden durch Bolkonskij und Pierre Bezuchov erfährt. Bolkonskij hätte es als gut empfunden, "einen bösen Hund" wie Dolochov im Duell zu töten, während Pierre argumentiert: "Nein, einen Henschen zu töten ist nicht gut, ist ungerecht..." . Bolkonskif lehnt es jedoch ab, in diesem Zusammenhang uberhaupt von gerecht und ungerecht zu sprechen: "Was gerecht und ungerecht ist, können die Menschen nicht beurteilen." (Buch II, S. 112)

2 Arthur Schnitzler, "Der Sekundant", in: Arthur Schnitzler, "Spiel im Morgengrauen" (1970). 
senseigene Entlastungsfunktion von der subjektiven Motivation und von dauernden Improvisationen fallweise $z u$ vertretender Entschluisse" ist für Arnold Gehlen eine der "groBartigsten Kultureigenschaften" der Menschheit, "denn diese Stabilisierung geht...bis in das Herz unserer geistigen Positionen." Gehlen weist immer wieder darauf hin, dab "die Habitualisierung des Verhaltens selbst produktiv ist, da sie die Entlastungschance für höhere kombinationsreiche Motivationen herstellt und diese damit geradezu ermöglicht." 1

Bei Tolstof wirken die Institutionen entmenschlichend. Die sich mit ihnen identifizieren werden boshaft als leblose Puppen, als "Tote Seelen" gezeichnet: Anna Pavlovna Scherer, Hélène Kuragina und andere Mitglieder der Petersburger und Moskauer Salons. Als positiv ist bei Tolstoj nur gestaltet, wer nach einer Phase der Begeisterung für gewisse Institutionen und der Identifikation mit diesen Institutionen $z$ u sich selbst findet und seinen eigenen Weg geht. Positiv in diesem Sinne sind vor allem Fürst Andrej Bolkonskij und Pierre Bezuchov. 2

11. Bolkonskif fluichtet aus seiner Ehe und der Petersburger Gesellschaft, weil er sein Leben als schal und ziellos empindet. ${ }^{3}$ Auf ihn ubt der Name "Napoleon" als der Name eines Mannes, der nur seinem $\mathrm{ziel}$ lebt, das er Schritt für Schritt erreicht, magische Anziehungskraft aus. Fur ihn ist Napoleon ein "groBer

${ }^{1} V_{g}$. A. Gehlen, "Urmensch und Spätkultur" (1964), S. 43. ${ }^{2} \mathrm{Vgl}$. R. F. Christian, "Tolstoy's 'War and Peace'" (1962), S. 106: "They are both seekers, spiritually restless, changing and evolving, not content to accept for long what is generaliy accepted... It is not $n$ e $c e s s$ a $r$ to be a seeker in order to earn Tolstoy's commendation; but all seekefs are commended by him."

E. E. Zajdenğnur kommentiert Fürst Andrej, Nataša Rostova und Pierre Bezuchor ausfinrlich als positive Helden in "Vojna $i$ mir' . N. Tolstogo" (1966).

Desgleichen A. A. Saburov, der von Pierre Bezuchor sagt: "P'er vstupaet na put' iskanij." In: "Vojna 1 mir' L. N. Tolstogo" (1959), S. 183.

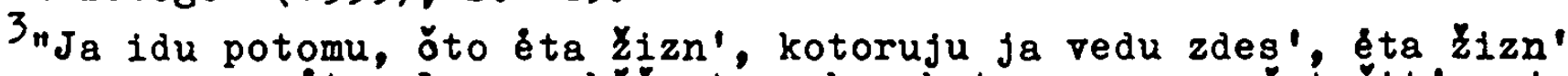
ne po mne..éto glupoe obscestro, bez kotorogo ne možet žit' moja Zena, 1 éti Zenšliny..Je suis un home fini." (Buch I, S. 33 ff.) 
Feldherr", ein "genialer Held", an den er nicht denken kann, ohne nicht fur sich selbst auf Ruhm zu hoffen. ${ }^{1}$ Ihn lockt der Verkehr in höchsten militärischen Kreisen als der Weg zum Erfolg. ${ }^{2}$ Er ist begierig, sich in der Schlacht bei Austerlitz auszuzeichnen, und stürzt sich in einem Taumel der Begeisterung ins Kampfgetümmel. 3 Erst als Bolkonskij schwer verletzt auf dem Schlachtfeld zurückbleibt, lassen ihn Todesnähe und der Anblick des weiten Himmels mit den dahinziehenden Wolken erkennen, $d a ß$ er einer Verfuhrung erlegen ist, daß Schlachten und militärisches Genie nicht wichtig für ihn sind, sondern

${ }^{1} \mathrm{Vgl}$. Buch I, S. 129 und Buch I, S. 203: "...vspominal on slova prikaza Bonaparta svoej armii pered nacalom kampanii, $i$ slova eti odinakovo vozbuzdali $v$ nem udivlenie k genial' nomu geroju, čuvstro oskorblennoj gordosti $i$ nadeždu slavy." 2"... on nachodilsja vblizi toj sredy, kotoraja davala uspech 1 kotoraja pritjagivala ego k sebe." (Buch I, S. 308)

3"Vot ona, nastupila resitel'naja minuta..."; "Vot ono! dumal knjaz' Andrej, schvativ drevko znameni i s naslazdeniem slysa svist pul'...Rebjata, vpered! - kriknul on detskipronzitel'no...Ura! - zakričl knjaz' Andrej". (ebd., S. $343 \mathrm{ff.}$ ) - Schwärmerischen Enthusiasmus fü das Militär zeigt auch Nikolaj Rostov. Institutionelle Prachtentfaltung und die Anwesenheit des Zaren während einer Truppenparade treiben inn in einen Zustand ekstatischer Hingabe: er glaubt vor Gluck sterben $z u$ mussen; den Worten des Zaren lauscht er wie einer "Stimme vom Himmel"; aus Leibeskräften schreit Rostor "hurra", er möchte sogar seinen Stimbändern schaden, um seine Begeisterung fuir den Zaren unter Beweis zu stellen. Rostov ermüchtern die Schlacht bei Austerlitz und die Verbruderung von Franzosen und Russen in Tilsit, die den vorhergegangenen Krieg sinnlos macht. (Buch I, S. $302 \mathrm{f}$., Buch II, S. 153) Ungleich Bolkonskij und Bezuchor kann Rostor seine Erfahrungen jedoch nicht geistig verarbeiten und zu einer Lebensphilosophie werden lassen. Er zieht sich auf einen pragmatischen Standpunkt zuruick: "Unsere Sache ist es, unsere Pflicht zu erfüllen, zu kämpfen und nicht zu denken". (ebd.) Rostov entwickelt sich durch Erfahrung von einem begeisterten zu einem loyalen Offizier. Wie Bolkonskij und Bezuchov findet er sein endgultiges Gluck in der Liebe - in seiner Heirat mit Mar'ja Bolkonskaja. - Nikolaj Rostovs Bruder Petja hat keine Zeit sich zu entwickeln. Ihm wird seine hysterische Begeisterung fur Krieg und Militär zum Verhängnis: er stirbt mit 15 Jahren einen sinnlosen Tod als Partisane. (Buch IV, S. 155 f.) Fuir Petja gilt, was Tolstoj über die polnischen Ulanen sagt, die vor Begeisterung fur Napoleon beim Durchschwimmen eines Flusses ertrinken: "Quos vult perdere - dementat." Buch III, S. 13) 
daB er in einem größeren Zusammenhang steht. ${ }^{1}$ (Ähnlich denkt Pierre Bezuchov als französischer Gefangener angesichts des Sternenhimmels - Buch IV, 2. Teil.)

Eine zweite Telle der Begeisterung trägt Bolkonskif einige Jahre spëter in den Bereich der hohen Politik zu Speranskif, den er als den genialen Oberkommandierenden einer "riesigen zivilen Schlacht" empfindet: "In der ersten Zeit seiner Bekanntschaft mit Speranskif empland Fürst Andrej ein leidenschaftliches Geflihl der Begeisterung fur inn, ähnlich dem, das er einstmals für Bonaparte gehegt hatte." (Buch II, S. 172) Doch wird Bolkonskif auch diesmal in einer Phase der Ernüchterung auf sich selbst zurückverwiesen: "Kann mich das alles etwa glucklicher und besser machen?" (ebd., S. 210) Bolkonskif findet die Erfullung seines Iebens weder in militërischen noch in zivilen Institutionen, 2 sondern in der Llebe zu Nataša Rostova. Als er stirbt, bekennt er sich zur Liebe als zu seiner Lebensphilosophie und Religion: "Die Liebe lst das Leben. Alles, alles, was ich verstehe, verstehe ich nur, weil ich liebe. Alles ist, alles lebt nur, weil lch liebe. Alles lst nur durch sie miteinander verknuppt. Die Liebe ist Gott, und zu sterben bedeutet fur mich, einem winzigen Teil der Liebe, zur allgemeinen und ewigen Quelle zuríckzukehren." (Buch IV, S. 66)

12. So wie Bolkonskif durch seine begeisterte Hinwendung zu MiIitär und Politik neue, sinnvolle Abschnitte in seinem Loben elnzuleiten glaubt, sich aber getäuscht sieht, geht auch Plerre Bezuchov auf der Suche nach einem neuen Lebensziel zunächst Irrwege. Bei den Freimaurern, die ihn mit einem aufwendigen Zeremoniell in ihre Bruderschaft aufnehmen, erhofft er "Fubrung"

$1^{1}$ Kak Xe Ja ne vidal preże \&togo rysokogo neba?...Da! vae pustoe, vse obman, krome etogo beskonelnogo neba.... Napoleon kazalsjs emu stol malen'kim, ni ¿toznym Celovekom $\nabla$ sravnenil $s$ tem, cto proischodilo teper' mezdu ego dusoj 1 etim rysokim

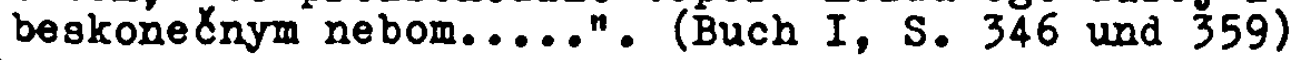

2 Tolstof geht soweit, am Beispiel Rastoplins zu beweisen, das nur verbrecherische Elemente das öfeentliche Wohl, "le bien publique", auf ihre Fahnen schreiben. (Buch III, S. 350 f..) 
und "H1lfe" fúr seinen Neubeginn und bei der "Besserung des Menschengeschlechtes", der er sich fortan widmen möchte. (Buch II, S. 78 ..) Doch muB Plerre festatelien, daB die Freimaurerei "nur auf ÄuBerlichkeiten" beruht, daß er im Grunde immer noch das alte Ieben flibrt und seine Logenbrider zum großen Teil "schwache und nichtgwirdige" Charaktere aus der ihm wohlbekannten groBen Gesellschaft sind. 1 (Buch II, S. 174 f.) Pierre ist auch nicht wie er glaubt - von der Vorsehung dazu ausersehen, ein Attentat auf Napoleon zu veruben und sich dabei für alle Russen zu opfern. (Buch III, S. 365 fl.) Nicht dieses kinstliche Ringen um ein sinnrolles Leben, sondern sein Schicksal als Gefangener der Franzosen ${ }^{2}$ und die Begegnung mit dem Bauern Platon Karataer geben ihm die "Rube und Zufriedenheit mit sich selbst, nach der er vorher vergeblich gestrebt hatte." (Buch IV, S. 100) Von Platon Karataer lernt er, sein Leben als sinnvolien Teil eines ihm unbekannten Ganzen zu begreifen. Er fublt sich somit als Tell des Kosmos, den gefangenhalten zu wollen ihm lächerlich er-

${ }^{1}$ Schon die Aufnahmeriten erlebt Pierre nicht ohne Skepsis: "To bin 1ch? Was tue 1ch? Lacht man auch nicht uber mich? Wird es mir nicht peinlich sein, hieran zurlickzudenken?" (Buch II, S. 83) - Er läBt sich jedoch auch hier von einem Ritus vergeraltigen, hat Angst, "auf halbem Tege" steckenzubleiben und gibt seinem Zweifel nicht nach.

2 Auch in seiner Gefangenschaft erlebt Pierre institutionelles Zeremoniell bewuBt als etwas Negatives, das die Menschen verhërtet, sie unmenschlich macht. So die gerichtliche Untersuchung gleich nach seiner Gelangennahme: "Diese Fragen, die das WesentIlche der Sache, um die es wifklich ging, beiseite lieBen und es unmöglich machten, dieses Wesentliche herauszufinden, bezweckten wie alle Pragen, die bel Gericht gestelit werden, nur, die Rinne bereitzustellen, durch die gemab dem Wunsch der Richter die Antworten des Angeklagten flieben sollten, um ihn zum gewïnschten Ziel, d. h. zur Verurtellung zu führen." (Buch IV, S. 37) - Der französische Korporal, der sich gegenuber dem Gelangenen Bezuchor stets froundschaftilch rerhalten hatte, eracheint Pierre beim Auszug der Pranzosen aus Moskau - in marschmäBiger Ausristung und unter der Einwirkung des Trommelwirbels - als "ein anderer, ihm unbekannter" Mensch. "In dem veränderten Gesicht des Korporals, in dem Klang selner Stimme, in dem erregenden und ohronbetáubenden Trommelwirbel erkannte Pierre jene geheimnisvolle, rom Menschen losgeloste Kraft, die die Menschen gegen ihren Willen zwang, ihresgleichen zu töten..." . (Buch IV, S. 103 f.) 
scheint: deshalb ist ihm im Lager der Franzosen der Anblick des Sternenhimmels ein Trost. (ebd., S. 106 ff.) Pierres neue Heltanschauung schließt gleichzeitig aus, das Leben in eigener Regie durch ehrgeizige Pläne gestalten zu wollen. Die (von Tolstof durchgehend geschmähte) Sorge um das "öffentliche Wohl" scheint Pierre jetzt überflüssig: "Er dachte auch nicht mehr im entferntesten an RuBland, den Krieg, die Politik, Napoleon. Ihm war klar, daß alles das nicht ihn betraf...". (ebd., S. 101) Glück bedeutet für diesen in $\mathrm{s} 1 \mathrm{c} h$ gekehrten Pierre Bezuchov von nun an, persönlich keinem Leid und keiner Entbehrung mehr auggesetzt zu sein. Als gröBtes Glück empiindet er seine Liebe zu Natała Rostova: "Der ganze Sinn des Lebens schien ihm nicht nur fuir sich, sondern für die gesamte Welt - in seiner Liebe und in der Möglichkeit ihrer Liebe beschlossen." (Buch IV, S. 236$)^{1}$

13. Der Epilog zeigt, daß Pierre Bezuchov, den Bolkonskif im Jahre 1805 als den "einzigen lebendigen Menschen" der Gesellschaft bezeichnet hatte, auch im Jahre 1820 nicht unter der Kruste gesellschaftlicher Konventionen verhärtet ist. Pierre ist der geliebte Mittelpunkt einer großen Familie, ${ }^{2}$ er ist ein geistig aktiver Mensch, der die Probleme seiner Zeit diskutiert, der für den fïnzehnjährigen Sohn Andrej Bolkonskijs ein bewundertes und inspirierendes vorbild ist und von dem Nikolaj Rostor sagt: "Er ist solch ein Kind." (Epilog, 1. Teil,

${ }^{1}$ Zweimal fällt Pierres Blick zum Sternenhimmel mit dem Gedanken an seine Liebe zu Natasa Rostova zusammen: am Ende des zweiten und im letzten Teil des dritten Buches.

${ }^{2}$ Das positive Verhältnis zur Familie ist eine wichtige Komponente in der Tolstojschen Ideologie. Von einem negativen Typus wie dem Fürsten Vasilif Kuragin wird gesagt, die zärtliche Beziehung zu seinen Kindern sei bel thm nicht naturlich, sonderm nur in Nachahmung anderer Eltern vorhanden. (Buch I, S. 262) 
S. 293) ${ }^{1}$ Pierre, dem das Duellerlebnis (gemäB der institutionenfeindlichen Position Tolstojs) zum ersten Mal bewuBt gemacht hat, daß es nur auf die eigene Person, auf eigene Erfahmung und eigene Verantwortung ankommt, sucht also immer noch sich weiterzuentwickeln. Das in seiner Figur gestaltete Ideal Tolstojs könnte man mit Worten aus Rilkes "StundenBuch" fassen: "Ich lebe mein Ieben in wachsenden Ringen, die sich über die Dinge ziehn. Ich werde den letzten vielleicht nicht vollbringen, aber versuchen will ich ihn."

1Vgl. hierzu E. Gunn, "A Daring Coifleur" (1971), S. i6 f.: "There is nothing Tolstoy abominates so much as poses, selfdeception (a Berg, a Prince Vasili), what does not spring from the heart, insincerity - all largely adult failings. Conversely the virtue he sets above all else is simplicity ... What he prizes in the adult is the child. This outlook finds its natural culmination in the central, not un-Myshkinlike Pigure of Pierre Bezhukov."

S. 78: "Pierre is the glorification of a man whom society cannot corrupt. For society can only corrupt. This is what 'War and Peace' is about." 
F. M. Dostoevskij, "Die Dämonen"

Wenn man an nichts glaubt, wenn nichts einen Sinn hat und wenn wir keinen Wert bejahen können, ist alles möglich und nichts von Wichtigkeit.

Albert Camus, "Der Mensch in der Revolte"

Oh, du wankelmuitiges Volk, stets haltlos und ungetreu, unstet und schwankend wie der Wetterhahn, du Preust dich jedes Lärms, wenn er nur neu ist! Du wechselst wie der Mond in seiner Bahn, und de in Geschwätz ist keinen roten Heller wert! Ein Narr, wer deinem Urteil folgt!

Geopprey Chaucer, "Canterbury-Erzählungen"

1. Zur Tolstojschen Vorstellung eines wohlgeordneten Kosmos und $z$ seiner von starren Institutionen beherrschten fiktionalen Welt findet sich schwerlich ein gröBerer Gegensatz als das Chaos in Dostoevskijs "Dämonen". " Die dem Roman vorangestellten Epigraphe ${ }^{2}$ aus einem Gedicht Pukkins und dem Lukasevangelium deuten an, was in der dister ausgemalten Fiktion beherrschend 1st: Orientierungslosigkeit, böse, irrationale Mächte und Bese ssene.

Durch den Chronisten der Romanereignisse ist der Leser von Anfang an auf Ungereimtes, ja Absurdes eingestimmt. Der Chronist liebt es, seine emphatisch vorgetragenen Herturteile mit $2 u-$ sätzen zu versehen, die das Gesagte zum Tell oder gänzlich annullieren. So bleiben beispielsweise Stepan Trofimovit Vercho-

${ }^{1}$ In den 1873 erschienenen "Dämonen" verarbeitet Dostoevskif bekanntlich revolutionäre Untriebe der 60-er Jabre, in deren Mittelpunkt der berichtigte Netaev stand. Die Ermordung eines Mitverschworenen, der Nečaev nicht gefügig war, brachte ihn vor Gericht und in die Peter-Pauls-Pestung. Vgl. neuerdings C. Stief, "Den russ1ske nihilisme" (1969).

${ }^{2}$ Chot' ubej, sleda ne vidno/ Sbilis' my, čto delat' nam $v$ pole bes nas vodit, vigno,/ $\mathrm{D}_{\mathrm{a}}$ kružit po storonam/.../Skol'ko ich, kuda ich gonjat/Cto tak Zalobno pojut?/...

Tut na gore paslos' bol'šoe stado svinej, 1 oni prosill Ego, čtoby pozvolil im vojti v nich. On pozvolil im. Besy, vy̌edsl iz Celoveka, vošli $v$ svinej... 
venskija gelstige Fähigkeiten unklar: "Und dabel war er doch ein sehr kluger und höchst begabter Mann, sozusagen sogar ein Mann der Wissenschaft...nun, mit einem Wort, in der Wissenschaft hat er nicht soviel geleistet und, so scheint es, liberhaupt nichts." ${ }^{1}$ Ähnlich verunsichernd wirkt die Meinung des Chronisten zur Schönheit Lizaveta Nikolaemas ${ }^{2}$ oder zum gesellschaftlichen Rang Varvara Petrovnas. 3 Eine immense Fulle erzählerischer Detalls - in langen, verschachtelten Sätzen dargeboten - zerrinnt zu einem Nichts an objektiver Information, ${ }^{4}$ baut aber eine Atmosphäre wachsender Unsicherhe1t auf.

So wenig verläblich das Urtell des Chronisten 1st, so 1rritierend wirt das Gebaren der Personen, die sich in dieser Atmosphäre bewegen. Es gibt keine ausgewogenen Stimmungen, keinen eindeutis beurtellbaren, in ofch ruhenden Charakter, sondern nur extrem reizbare Wesen unter der Einwirkung rätselhafter Gemütsschwankungen. Inmitten seiner Schwermutsperioden pelegt Stepan Trofimovič "plötzlich" in Gelächter auszubrechen (S. 14), nach den "intimsten Herzensergussen unter vier Augen mit Varvara Petrovna" opringt er unvermittelt auf, um mit seinen Päusten gegen die Wand zu hämmern. (S. 15) Zu Lizaveta Nikolaevnas hyoterischer Pröhlichkeit gehört der jähe Stimmungaumschlag,

1F. M. Dostoerakif, "Sobr. soc. v 10 tt.", Bd. 7 (1957), s. 9. Alle Zitate sind dieser Ausgabe entnommen.

2

"Ich will nicht anfangen, die Schönheit Lizaveta Nikolaevnas zu beschreiben. Die ganze stadt hat sich bereits uber ihre Schönheit ausgelassen... Jetzt, wo $1 \mathrm{ch}$ mich an das Vergangene erinnere, wurde lch nicht mehr sagen, daB sie die Schönheit war, als die sie mir damals erschien. Vielleicht war sie sogar ausgesprochen unschön." (S. 116 f.)

3"Sie war uberhaupt nicht wiederzuerkennen. Es hatte direkt den Anschein, als habe sie sich aus der fruheren unnahbaren

'höheren Dame' (ein Ausdruck Stepan Trofimovičs) in die allergewöhnlichste verruckte Dame von Welt verwandelt. Im Ubrigen mochte das auch nur so scheinen." (S. 353)

${ }^{4} \mathrm{Vgl}$. $z$. B. "Stepan Trofimorid lehnte das damalige Angebot Varvara Petrovnas ab und heiratete schnell ein zweites Mal, sogar vor Ablauf eines Jahres, eine schweigsame kleine Deutsche aus Berlin, und, was die Hauptsache war, ohne jede besondere Notwendigke1t." (S. 12) 
alles in ihr lat - we der Chronlat sagt - "chaotisch, in Aufrukr, in Unruhe. ${ }^{1}$ (S. 117) Varvara Petrova gibt alch "eigensinnig und leidenschaftlich" jeder Idee hin, die sle fesselt, ${ }^{2}$ und bel Sator und Kirillor wechseln Pinstere Schweigsamkeit m1t erregten Zornesausbrüchen. ${ }^{3}$

Diese Figuren sind physisch schwächlich und ron gespenst1scher Blässe: Varvara Petromas Geslchtsfarbe 1st gelblich, blelch oder bläulich ( $\nabla$ gl. 2. B. S. 18 lf.), Lizaveta Nikolaerna hat ein blasses mageres Gesicht. ${ }^{4}$ Kirlilor prapplert durch leblose Augen in einem bleichen Gesicht (S. 98, 411 11., 634). Šator zeigt eine labile Konstitution, ${ }^{5}$ Verchorenokijo Gesichtsausdruck "scheint kränkl1ch", 6 und die ron ihm geleltete Flinlergruppe 1at ihren Aufgaben physisch nicht gewachoen. 7

${ }^{1}$ Vor dem Ausflug zu Semen Jakovlerid erscheint Lizaveta N1kolaerna dem Chronisten "sohon uber die MaBen glúcklich" (S. 342); im 21 mmer des Gottesnarren kommt es dann zu einer "hysterischen Szenen (S. 351). Die Ereignisse des turbulenten Sonntags am Ende des ersten Romantells lassen Lizaveta Nikolaevna abwechselnd hysterloch lachen und weinen, bis sie schlieblich nach einem "schrecklichen Schre1" in Ohnmacht fällt. (S.210 f1.)

${ }^{2} V_{g}$. S. 76. - An dem erwähnten ere1gnisrelchen Sonntag rechtPertigt Varvara Petrovna 1hren Sohn in einem Zustand "höchster Erregung"; sein Vorgehen nennt sie "he111g" (S. 201, 203, 208). Nachdem sie Stepan Troflmovid lässig die Freundschaft aufgekündigt bat, zelgt gle sich am Sterbebett 1 hres Freundes hysterisch besorgt. (S. 682 1.)

3" 'Šator muB man zuerst einmal anbinden, dann kann man mit ihm diskutieren', - pllegte Stepan Trofimoric mitunter zu scherzen...". (S. 32) - Man betrachte auch das Verhalten Kirillovs, als er Stepan Trofimovid zusammen mit Liputin einen Besuch abstattet. (S. 97 f .)

${ }^{4}$ Der Chroniat sagt von ihr: "Sie war wirklich krank." (S. 117) ${ }^{5}$ Als Starrogin ihn besucht, he1Bt es: "Er hatte in dieser Woche abgenommen und schien jetzt Fieber zu haben." (S. 254) Verchovenak1f trifft ihn krank im Bett (S. 396), und auch als seine Frau zu ihm zuruckkehrt, liegt Sator mit Kop pschmerzen und Schuttelfrost im Bett. (S. 589)

${ }^{6}$ Der Chronist relativiert diese Aussage aber sogleich: "... aber das scheint nur so." (S. 191)

7 Ijambin wird vor der Ermordung Satove krank und erleidet nach dem Mord einen Nervenzusammenbruch (S. 629); V1rginskif 18t dem Zuaammenbruch nahe und wird fleberkrank verhaftet $\left(s_{\text {. }} 698\right.$ ); Iiputin lebt nach der Tat in Petersburg so, als habe er "jeden gesunden Menschenverstand" verloren. (S. 699) 
Alle Personen sind in ihrem Verhalten so unerklärlich und physisch und psychisch so labil wie die Figur, der sie als Leitbild fanatisch ergeben sind: Nikolaj Vsevolodovit Stavrogin.

2. Stavrogin ist ein exzentrischer Einzelgänger, eine Mischung aus spätem Nachfahren dämonischer Byronscher Helden - er 1st schwarzhaarig, von weiber Gesichtsfarbe, hat rote Iippen, und auf seiner Seele lastet das romantische "verhängnisvolle Geheimnis" (S. 46) - und Baudelaireschen Dandy: einer faszinierten Umwelt erscheint er als erlesen gekleideter Elegant mit feinsten Manieren und frappierendem Selbstbewubtsein. ${ }^{2}$ Er folgt der Baudelaireschen Doktrin $z u$ erstaunen, ohne selbst Jemals erstaunt zu sein.

Stavrogin ist der letzte SprOB eines aussterbenden Adelsgeschlechts. Er verkörpert indes nicht eine Dekadenz, die "köstlich lst wie ein verlöschendes Gestirn, ohne Wärme und voll Melancholien, 3 sondern eine elgentümlich irritierende Dekadenz. Stavrogin ist, wie der Chronist sagt, eine abstobende, gleichsam maskenhafte Schönhe1t. Seine Haare sind "irgendwie schon zu schwarz", seine Gesichtsfarbe ist "irgendwie schon zu zart und weiB", das Rot seiner Lippen "irgendwie schon zu krältig und rein". (S. 46) Dieses Zuviel macht Stavrogin unheimlich; läbt ihn nicht mehr nur eine "untergehende Sonne" 4 sein, son-

'Wie Leonid Grossman in seinem Buch "Trorčestro Dostoevskogon (1928) anfuhrt, sind in Stavrogin züge berihmter revolutionärer Zeitgenossen wiederzuerkennen: es werden Änlichkeiten mit Michail Bakunin nachgewiesen, den Dostoevskif im September 1867 auf einer internationalen Konferenz in Genf sah und horrte, und mit Nikolaj Aleksandrovid Spernev, einem Mitglied des Petrasevskij-Kreises, den Dostoevskij aus den 40-er Jahren kannte.

2 Uber seine Wirkung schreibt der Chronist: "Allen unseren Damen verdrehte der Neuankömmling den Kopf... Unsere Modenarren betrachteten ihn neidvoll und gaben sich ihm gegenüber vollis elngeschüchtert." stavrogin lebt inmitten dieger Bewunderung "träge, still und ziemlich mürrisch." (S. 46)

${ }^{3} \mathrm{Vgl}_{\text {. " }}$ "harles Baudelaire in Selbstzeugnissen und Bilddokumenten" , Rowohlts Monographien (1967), S. 67. 4 ebd. 
dern birgt Aggressives in s1ch, dessen Verquickung mit dem Absterbenden eben das Chaos ausmacht, das Stavrogin verkörpert und nicht verkraftet: als es dem streng nach Gouvernementset1kette lebenden Dandy aus heiterem Himel einfält, einige Skandale zu provozieren ${ }^{1}$ - die ersten, von denen der chronist als Augenzeuge berichtet - liegt er anschlleBend mehr als zwe1 Monate fleberkrank danieder. 2

3. Zwe1 der in diesen Skandalen beleidigten Personen aind Leute von Stand. Doch fordern weder der Gutabesitzer noch der Gouverneur Genugtuung im Duell, 3 während der subalterne Beamte L1putin als dritter Beleidigter später liebedienerisch zu Stavrogin sagt: "Ich konnte sie doch wohl nicht zum Duell fordern?" (S. 56) Er splelt hierbel durchaus nicht auf die Standesgebundenheit des Duells an, derzufolge er nicht als satisfaktionsfähig gegolten hätte, sondern auf seine Antipathie gegenüber allem aus Frankre1ch Importierten. DaB L1putin im Zweikamps nur ausländschen Firlefanz sieht, würde die Güligkeit dieser Inotitution noch nicht in Frage stellen (sowenig wie das Unverständn1s der Festungsleute in Puskins "Hauptmannstochter"). Entscheidend lst vielmehr die Reaktion des Adligen Starrogin: "Ach ja doch! Irgendsowas habe lch ja gehört, daB sie das Duell nicht mögen...". (S. 56) Stavrogin verneint hier einmal die

${ }^{1}$ Starrogin zieht den Gutsbesitzer Gaganov im Klub der Stadt vor aller Augen an der Nase, be1Bt dem Gouverneur ins Ohr und kUBt während elner Geburtstagsfeler die Frau des Hauses öffentlich auf den Mund. (S. $47 \mathrm{ff.}$ )

${ }^{2} \mathrm{~V}_{\mathrm{gl}}$. die Gedanken $z u$ den Stavroginschen Kraftproben in J. Lavrin, "Dostoevsky" (1947), S. 103: "Even his last reluge strength for strength's sake - fails him. He maintains a superhuman composure when Shator insults him publicly: He calmly acknowledges his 'shameful marriage', faces Gaganov's pistol with insulting boredom; yet far from intoxicating him, his 'Immense power' once more turns against him, since he is unable to give it a creative direction. 'I have tried my strength everywhere,' he writes before his end."

${ }^{3}$ Als Starrogin Gaganov an der Nase im Saal herumgefuhrt hat, erhebt sich nur "ein ganz fürchterlicher Lärm", und man umringt thn - sonst geschleht nichts. (S. 48) Dafur, daB Stavrogin den Gouverneur ins Ohr gebissen hat, wird er verhaftet. 
Standesgebundenhe1t des Duells und stellt es zum anderen als elne Sache des Bellebens dar. Diese Antwort und das Verhalten seiner beleidigten Standesgenossen verdeutlichen, daB es in der geach1lderten Romanwirklichke1t wohl ganz "unmögl1che Frechhe1ten" (S. 48), nicht aber Ehrenkränkungen mit den unauswe1chlichen Folgen gemäß einem adligen Ehrenkodex glbt. Die Institution "Dueli" 1st tot. Dennoch widmet Dostoevakif dem vier Jahre nach den ewähnten Skandalen atatteindenden Duell zwiachen Stavrogin und dem Sohn des ehedem beleidigten Gaganor mehr als ein Kapitel. Dieses Duell und der nachfolgende gesellschaftliche Aufruhr aind ein wesentlicher Beitrag zum Verständnis der Rolle Stavrogins und deg für diesen Roman so wichtigen Institutionenproblems.

4. Der Zweikampe zwischen Stavrogin und Gaganor ${ }^{1}$ wird nicht auggetragen als Folge einer konkreten Ehrenkränkung, für die spontan Genugtuung gefordert wird. Seine Ursache scheint 1rrational. Gaganov geht aus der weitschwe1figen Charakterisierung durch den Chronlsten bestenfalls als ein Mann ohne Elgenschaften, elgentlich aber als ein Gelstesgestörter hervor. Wegen der Beleidigung, die sein Vater von Stavrogin erfuhr, quittiert er den Dienst, im Glauben, für das Regiment eine Schande zu sein. Niemand im Regiment wubte indes von der Beleidigung. Gaganov lst stolz auf seinen alten Adel, kann aber rusische Geschichte nicht ausstehen und hält das russische Leben ntellweise fur eine Schweinere1." (S. 301) Jeder seiner Charakterzüge und Beweggründe wird durch einen anderen ad absurdum gefuhrt. Wichtig ist vor allem folgender Umatand: als Gaganov Stavrogin vier Jahre nach dem beleidigenden Vorfall im Klub und einen Monat vor

\footnotetext{
"Vgl. Romain Naziror in "Dostlerski" (1973), S. 284 : "Ies h6ros de Dostolersk1 parlent sourent de duels, ma1s 'ce n'est pas l'epoque' pour cela: l'unique duel qui a lieu eat celul de Stavroguine et du jeune Gaganov...".

Geredet wird rom Duell in den "Erniedrigten und Beleidigten", den "Aufzelchnungen aus dem Untergrund", dem "Spieler", dem "Idioten", im "Jungling" und in den "Brudern Karamazorn.
} 
dem Duell ${ }^{1}$ zum ersten Mal in seinem Leben in Petersburg trifft, verliert er "fast den Verstand" (S. 301), tritt Stavrogin dann in der gemelnsamen Heimatstadt "schon in vollständiger Raserei" entgegen (S. 247) und beleidigt thn trotz aller Versöhnungsversuche Stavrogins ${ }^{2}$ muindich und schriftlich, um inn zu einem Duell zu provozleren. Obwohl das Fuhlen und Denken last aller Romanfiguren fast magisch auf Stavrogin bezogen ist, ${ }^{3}$ zeigt niemand einen so unaussprechlich irrsinnigen $\mathrm{HaB}^{4}$ wie sein Standesgenosse Gaganov. Für ein besseres Verständnis des Duells soll zunächst versucht werden, diesen HaB zu ergründen. Dies wiederum kann nur über eine Analyse des Verhältnisses Stavrogin Šator gelingen.

5. Auch Sator habt Stavrogin, er ohrleigt inn sogar öflentlich und bekennt ihm später warum: "Weil sie gefallen sind...weil Sie so viel in meinem Leben bedeutet haben...". (S. 255) Šator

${ }^{1}$ Dieser Zeitpunkt geht aus einem Gespräch zwischen Stavrogin und Kirillov hervor. (S. 247)

${ }^{2}$ Laut Duellkodex würde Gaganor nicht als Beleidigter gelten: "Der Beleidigte, der sich mit einer von den Sekundanten als völlig genügend bezelchneten Entschuldigung und Ehrenerklärung nicht befriedigt erklärt, verliert das Recht des Beleldigten." $\mathrm{Vgl}$. das "Duellbuch" von H. Kufahl und J. Schmied-Kowarzik (1896), S. 214. - Gaganovs Sekundant Mavrikij Nikolaevid bemerkt unmittelbar vor Beginn des Duells, er könne angesichts der Versöhnungsbereitschaft Stavrogins nicht erkennen, worin die Beleidigung liege. (S. 302)

${ }^{3}$ Man betrachte den jewelligen AbschluB der drei Romantelle: Te11 I endet mit der Aufdeckung einiger Geheimnisse um Stavrogin in Anwesenheit aller wichtigen Personen. Teil II endet damit, daß Starrogin in eben diesem Kreis seine skandalöse the mit Mar'ja Timofoerna Lobjadkina eingesteht. Te1l III schlieBt mit dem Selbstmord Stavrogins. - "Stavrogin 1irst appears in the novel at the climax of Varvara Petrovna's Sunday gathering. By the time the gathering is over, Dostoersky has managed to make Stavrogin the towering figure of fatal attraction, power, and mystery that he will remain throughout the novel...". Vgl. E. Wasiolek, "Dostoersky" (1964), S. 125.

${ }^{4}$ Der erste Briel, den Gaganor an Starrogin adressiert, ist beleidigend, doch ohne Sinn und Verstand abgelaBt: "...r nem sovsem ne ob-jasneno bylo poroda, po kotoromu ono pisano." (S. 247) 
leidet unter dem moralischen Verfall seines Idols Stavrogin, unter dessen gesetzlicher Ehe mit einer schwachsinnigen, verkruppelten Bettlerin. Er - Sohn eines ehemaligen Leibeigenen sehnt sich nach einem Leitbild. ${ }^{1}$ Es peinigt ihn, den Adligen Starrogin als "mübiges, herumstreunendes Herrensöhnchen", ja als "letzten Herrensohn" bezelchnen zu müssen (S. 270 f.), dessen dekadenter Hand die Geschicke RuBlands entglelten. ${ }^{2}$ Satovs Anklage gipfelt in der Versicherung, er werde Stavrogin "sogleich ...auf der Stelle" töten, wenn dieser gewisse sadistische Verbrechen begangen habe, die man ihm zuschreibe. ${ }^{3}$ Das Wissen un eine ruchlose, verbrecherlsche Dekadenz Stavrogins - die dieser tatsächlich verkörpert - wäre Šatov unerträglich.

\section{Das ganze Ausmaß der moralischen Zersetzung Stavrogins} scheint Gaganor - Im Gegensatz zu Šator und ganz wie die gelstesschwache Lebjadkina ${ }^{4}$ instinktiv zu erfassen: allein der Anblick des abstoßend schönen Starrogin läBt inn wie besessen das Zlel einer Vernichtung Stavrogins im Zweikampf verfolgen. Er wird "gelb vor Wut", als Stavrogin hoch zu ROB auf dem Kamplplatz erscheint - statt mit einer Equipage fur seinen eventuelien $A b-$ transport als Verwundeter. (S. 299) Gaganov möchte Stavrog in töten. Nicht in einer Art Lynchjustiz wie Šatov, ${ }^{5}$ sondern stan-

1 Şator wünscht sich sehnlichst, Starrogin möge die einst von thn selbst hervorgebrachte Ideologie rom russischen Volk als einem "Gottesträgervolk" verfechten: "Sie, nur Sle könnten diese Pahne erheben!.." (S. 269)

2 nEs wird eine neue Generation kommen, unmittelbar aus dem Herzen des Volkes, und Sie werden sie nicht einmel erkennen, auch die Verchovenskijs, Vater und Sohn, nicht, auch $1 \mathrm{ch}$ nicht...". (S. 271)

${ }^{3}$ Dem ehemaligen Bischof Tichon beichtet Starrogin sein Verbrechen an der kleinen Matreš.

${ }^{4}$ Als Starrogin Mar'ja Timoleerna besucht, hebt sie wie zum Schutz die Hand, zittert, bittet ihn, sie nicht anzuschauen und blickt selbst zu Boden, während sie mit Starrogin spricht. Sie $f$ u h l t seinen Fall : "Net, ne možt togo byt', Etoby sokol filinom stal." (S. 293)

${ }^{5}$ Stavrogin wurde wie Sator handeln: der Chronist betont ausdrícklich, daB Starrogin jemanden, der ihn schlagen wirde, "auf der Stelle", ohne Duell, töten wrirde. (S. 217) 
desgemäB im Duell. Er klammert sich fanatisch an diese Institution, die sein Kontrahent in Grunde längat miBachtet. ${ }^{1}$ Er muß Starrogin einen Monat lang geduldig mit immer gröberen Beleidigungen provozieren, ${ }^{2}$ bis dieser schlieblich mit einer Forderung reagiert. Stavrogin fordert Gaganor nicht, weil er "1mmerhin...noch die Angewohnheiten eines ordentlichen Menschen" hat, ${ }^{3}$ sondern weil er flihlt, sich dem HaB des Gegners anders nicht entzlehen zu können: "Wenn 1ch ihn nicht gefordert hätte, hätte er mich so getötet - obne Duelln, erklärt er nach dem 2weikampf seinem Sekundanten Kirillov. 4

7. Zur Durchfiuhrung des Duello ${ }^{5}$ treffen sich Gaganor und Starrogin mit ihren Sekundanten um zwei Uhr nachmittage ${ }^{6}$ in einem nahe der Stadt gelegenen Wäldchen. ${ }^{7}$ Der Zweikampl dieser beiden Adligen veranschaulicht die totale Dekadenz der tonangebenden

${ }^{1}$ Wie der Chronist berichtet, provoziert Stavrogin Duelle zur Befriedigung seiner zigellosen Rauflust. Seine grausamen Zwe1kämple haben ihm den Ruf eines Mörders eingetragen. (S. 44 11.)

2 Der AnlaB zur Porderung ist ein Briel, "wie ihn wahrocheinlich noch niemals jemand erhalten hat." (S. 247)

${ }^{3}$ So charakterisiert Stavrogin sich selbst in seinem Abschiedsbrief an Dar'ja Pavlorna. (S. 702)

${ }^{4} v_{g l}$. S. 306. - Am Vorabend des Duelle sind sich Stavrogin und Kirillor bewuBt, daB Gaganor die libertrieben versöhnlichen Zugeständnisse seines Gegners ablehnen wird. "Er möchte sich schlagen" - sagt Kirillov. (S. 248)

${ }^{5}$ Vereinbart ist ein Pistolenduell mit Barrieren. Die Distanz zwischen den Barrieren beträgt zwölf Schritt, die Gegner werden jeweils zehn Schritt von den Barrieren entfernt aufgestellt. Wie Tolstoj e $r k l \ddot{a} r t$ Dostoevskij unauffällig (mittels der Anwelsungen, die Stavrogin geinem Sekundanten gibt), wie ein derartiges Duell vor sich geht: dab die Gegner auf ein gegebenes Signal hin ibren Standort verlaseen und während des Vorrückens zur Barriere nach Belleben den Kugelwechsel eröffnen durfen. Eine Kenntnis des Duellritus erwartet Dostoevekif bei seiner Leserschaft also nicht.

6

Im "Duellbuch" von H. Kuhfahl und J. Schmied-Kowarzik (1896) heibt es: "Die fruihen Nachmittagsetunden sollen sich besser als die Zelt Pruh morgens für den Kampl eignen und hält man es für vorteilhalt, erst ein frugales Mahl und ein Glas Wein zu elch zu nehmen." (S. 227)

7 Die stadt in dem Roman bleibt namenlos. 
gesellschaftlichen Schicht. Pormell 18t Gaganor noch Verteldiger des adligen Ehrenstandpunktes: so wenig er verstehen kann, daB Stavrogin seine Beleldigungen nicht gleich mit einer Forderung quittierte, daB er sich ron Šator ohne welteres ohrelgen lieB (S. 298), so verurte1lt er Starrogins Verstob gegen die Duellregeln auf dem Kamplplatz. Dooh lat Gaganor kein ernat zu nehmender Gegenpol zu Stavrogins der Ruchlosigkeit, de er in Stavrogin spüt, kann er nichts Positives, sondern nur "krankhaften HaBn entgegensetzen (S. 298). DaB er unerschüterlich darauf besteht, mittels elnes in Verfall begriffenen Ritus gegen Stavrogin vorzugehen, macht lhn nur lächerlich. Mit zitternden Händen erwartet er Starrogin auf dem Terrain, in "schreckltcicr Unrube" nimmt er seinen Standort ein, und der obligatoriache iersöhnungsversuch der Sekundanten unmittelbar vor Beginn des 2we1kamples läBt $1 \mathrm{hn}$ vor Zorn mit dem FuB aufstamplen und Spelchel von seinen Lippen spritzen. (S. 299 f .) Helser schrelend wehrt er sich dagegen, daB Starrogin zwe1 seiner Schüsse - nicht sehr aufäll1g, aber doch lestatellbar - in die luft feuert. 1 Gaganov verkörpert den Abscheu und dle obnmächtige Auflebnung gegen seinen Standesgenossen Starrogin. Er bedenkt nicht, daB sein Bestehen auf einem dreimaligen Kugelwechsel nicht ausechlieblich elne Gelahr für Stavrogin lot, sondern auch Selbstzerstorung bedeuten kann. ${ }^{2} \mathrm{DaB}$ er Starrogin nicht im Duell zu vernichten ver-

${ }^{1} \mathrm{Vgl}$. "Die konventionelien Gebräuche beim Zwe1kampen von $M . V$. Wedel (1909): "Wenn einer der Duellanten in demonstrativer We1se in die luft schleBt und damit deutlich zu erkennen gibt, $d a B$ er seinerge1ts auf einen Kampl mit dem Gegner verzichtet, so haben die sekundanten sofort elnzuschreiten... und den betrel. fenden Duellanten vor elner Wlederholung dieser Handlungsielse, die gegen die Duellregeln verstbBt, zu warnen... Macht alch der Dueliant nochmals dieser Verletzung der Regel des Zweikamples schuldig, so 18t...der Betreffende als " $\mathrm{n} 1 \mathrm{c}$ h $t$ s a $t$ i -

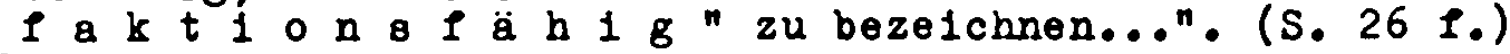

2 "Weahalb schont or mlch?" - tobt Gaganov, als Stavrogin über 1 hn hinwegzlelt. "Ich verachte seine Schonung... Ich spucke ....Ich...". (S. 303)

Gaganorg Raserel richtet slch gegen ibn selbst. Sie 1ot das Gegentell elner vorbildlich-kongtruktiven Haltung, die er als Vertreter der Normen setzenden gesellschaftlichen Schicht zeigen sollte. 
mag, läBt ihn gebrochen auf dem Kamplplatz zuruickble1ben: "Gaganor atand wie zerachmettert da. Mavrikif Nikolaevič ging auf thn zu und begann über etwas zu reden, doch er echien 1hn nicht zu verstehen." (S. 305)

Starrogins Verhalten im Duell weist ibn - wie die abstoBend schöne Portraitierung durch den Chronisten - als einen Dekadenten mit dem etras unheimlichen, agreseiven zuviel aus seine innere Telinahmolosigke1t in Bezug auf den zu vollziehenden Ritur bewelot er mit dem eroten SchuB: er hebt die Pistole, aber "1rgendwle zu hoch", und schlest "fast obne zu zielen" (S. 303). Sein Eingestindn18, willentlich zu hoch geschoseen zu haben, bestatigt, daB hier elne Form Ihren Inhalt verloren hat "Ich habe das Recht, zu schleBen wie 1ch w1ll, wenn nur alles regelgerecht verlëuft.... Ich habe deshalb in die luft geschossen, we1l 1ch niemanden mehr töten will...das hat mit Ihnen nichts zu tun." (S. 303) Auch den zwe1ten SchuB leuert Starrogin in die luet $a b$, obrobl er sich mit Rucksicht auf seinen Kontrahenten und die Sekundanten den Anschein glbt, ernothaft zu zielen. Der dritte SchuB 18t jedoch ostentatir beleidigend: die fasoungslose Reaktion Gaganors und der Vorwure K1r1llors ${ }^{1}$ bestatigen das. Starrogin wabrt hier nicht einmal mehr ein Minimum an Forms er ochaut seinen Gegner an, wendet sich dann zur Selte und ochlebt "diesmal bere1ts ohne jedes Feingerubl... In den Wald."

GruBlos, mit bösem Gesichtsausdruck, kehrt er seiner Gegenpartel den Rucken und reitet daron. Es genügt Starrogin nicht, mit desinteresolertem Verhalten den lebendigen Bewe1s für das Abgestorbensein der Institution "Duell" darzustelien - er muB diesen Tatbestand zynlsch mit elnem SchuB ins Abseits bekrëftgen.

8. Wleso löst Starrogino bösartigee Gebaren ale Duellant in der Gesellochaft der Stadt elnstimige Begeisterung aus? ${ }^{2}$ Elnes Mis-

1"Ja, Sie baben ihn noch elamal beleidigt...". (S. 305)

" "Die ganze stadt" veraamelt olch einen Tag nach dem Duell, un den Famenatag der Prau des Adelsmarschallo zu felern. Der Chronlat hebt die elnmutige Parteinahme der Gesellochaft fur stavrogin als etwas Besonderes hervor. (S. 311) 
verständalsses wegen - auf dessen Basis die Gesellschaft ihr Wunschbild von Stavrogin entwirft. Der Wortfuhrer in der Diskussion um das Duell zwischen Starrogin und Gaganor ist ein "altmodischer" Genersl, der "einst" selbst in zwe1 Duelle verwickelt war, somit als "kompetent" gilt - und die Ehrbegriffe seiner Leit euf Stavrogin überträgt. (Vgl. S. 313 1.) Er st1lisiert ibn zu einer edelmütigen, hohen seele, der seine Stirn einem wahnsinnig Gewordenen "einzig mit dem gelanten Ziel" bot, sich "von ihm zu befreien." Der General betont: "Das war in den 2 wanziger Jahren in der Garde Sitte." Begierig greift die Gesellschset das Lob aus kompetentem Munde auf und beweist ihr uberstarkes Bedüfnis nech einem positiven Leitbild: Stavrogin wird als "Stern", als "neuer Mensch" gepriesen, von dem 8ls "unbezwelfelbaren Adligen" und noch dazu als "reichstem Gutsbesitzer des Gouvernements" Hilfe und Tatkraft zu erwarten se1. Durch die Besinnung auf den adligen Ehrenkodex scheint der Gesellschaft überdies für ein e 1 n 1 g e 8 Mal das Verhalten des sonst geheimnisvollen Stavrogin durchsichtig. Die Hinnahme der Ohrfeige Satovg, die eine Plut von Spekulationen und Gerüchten in der Stadt ausgelöst hatte, 1 ist jetzt einleuchtend: "Er konnte doch seinen ehemaligen Leibeigenen nicht zum Duell fordern!" (S. 313) Ein einziges Mal im Roman heiBt es: "Dies war ein einfacher und klarer Gedanke" - und nur hier ist die Gesellschaft glucklich, in Stavrogin einen Mann "mit fast ideal strengen Anschauungen" sehen zu können.

9. Die Vorstellung von Stavrogin als elner vorbildlichen Fúnrungspersönlichkeit muB jedoch Wunschbild bleiben. Zwar weiB Stavrogin un seine natürliche Autorität; er erlebt es sogar, daß Petr Verchovenskij the als "schrecklichen Aristokraten", als "Fuhrer" und "Sonne" verzückt die Hand kuBt und ihn in wahnsinnig anmutenden Visionen als Inkarnstion zukünetigen He1ls betrachtet: "Ein Beben wird einsetzen, wie es die Telt noch nicht gesehen hat...RuBland wird sich verfinstern, die

\footnotetext{
InVse skandsl'noe 1 spletnlČskoe, vse melkoe 1 anekdotičeskoe razom otodvinuto bylo na zadnif plan...". (S. 313)
} 
Erde nach ihren alten Göttern weinen...Nun, und dann lassen wir ihn hervortreten...Wen?...Sie, sie!" (S. 438 fl.) - Doch bezelchnet Starrogin aich selbat als schwachen Menschen ${ }^{1}$ und lehnt elne inm von Geburt aus zukommende Fuihrungsrolle $a b .^{2}$ vielmehr erzeugt er das Chaos: "Morde noch mehr, stiehl noch mehr" - rät er dem Zuchthäusler Fed'ka. (S. 296) Immer wieder erliegt er der "schrecklichen Versuchung", 3 Verbrechen $z u$ begehen. Die Heirat mit der Lebjadkina, das Verbrechen an Matre und der Wunsch nach Bigamie sind für ihn ein schauerlich-genuBvoller Nervenkitzel. Wer in den Bann der magischen Anzlehungskraft Stavrogins gerät, kommt zu Schaden: Kirillov wird zum Selbstmörder - an der Ermordung der Lebjadkins und Liza N1kolaevnas 1at Stavrogin indirekt schuld. ${ }^{4}$ Für alle, die mit Stavrogin in Beruhrung kommen, gilt, was Liza Nikolaevaa von sich sagt: "Ich habe mich an einer Kerze verbrannt...". (S. 546)

${ }^{1}$ Zu Kirillov aggt Stavrogin nach dem Duell: "Ich weiB, daB Ich ein nichtiger Charakter bin, aber 1ch will ja auch nicht als stark gelten." (S. 306) - Im Abschiedabrief ar Dar'ja Parlovna he1Bt es: "Melne Wünsche sind zu schwach; sie können mich nicht leiten... Immer ist alles seicht und energielos." (S. 701 ff.)

$2_{n}$

...warum erwarten alle von mir etwas, was sie von anderen nicht erwarten?" - fragt Stavrogin Kirillov. (S. 305)

Kirillov, Sator und Lobjadkin bekennen aich zu Stavrogin als zu ihrem Vorbild: "Erinnern sie sich daran, was sie in meinem Leben bedeutet haben", sagt Kirillor. (S. 253) Lebjadkin klagt: "...Sie haben doch soviel fur mein Schlcksal bedeutet!...Jetzt aber stehe 1ch groBe Angst aus und erwarte nur von Ihnen Rat und Heil." (S. 279) - In seiner schriftlichen Beichte, die Stavrogin dem Bischol Tichon zu lesen gibt, heiBt es an einer Stelle: "Prochor Malov bemerkte, "wenn Nikolaj Vsevolodovid zufrieden und nicht schwermitig sind, dann sind wir alle zufrieden und reden vernunftig'." (z1tiert nach:

F. M. Dostoerskif, Poln. sobr. sod. $\nabla 30$ tt.", Bd. 11 (1974), S. 19)

${ }^{3} V_{g l}$. die Belchte Starrogins, s. 23 in der zitierten 30-bëndigen Dostoevsk1f-Ausgabe. - In seiner Beichte ist Stavrogin der "Held Byrons, zur Liebe unfäh1g oder nur zu elner unmöglichen Llebe fähig....Er lat allein, auggelaugt, sein Zustand erschöpft ihn. Will er sich leben fuhlen, muB es im schreckIichen tberschwang einer kurzen und verzehrenden Tat geschehen.": A. Camus, "Der Mensch in der Revolte" (1969), S. 43. ${ }^{4}$ Starrogina Brief an Dar'ja Parlorna enthält ein Eingeständnis seiner Gewissensschuld. (S. 700 f.) 
Starrogin wird so zur negativen Loitfigur. Wie er Gut und Böse nicht mehr zu unterscheiden vermag, werden in der Stadt Loute mit Orden geschmuickt, die "ein Gerichtsurteil und Sibirien" verdient hätten. (S. 361) Nicht nur die Institution "Duell", Jegliche Institution hat in dieser Gesellschaft ihre Funktion eingebubt und wird durch ein geheimnisvolles und PurchteinflöBendes "tam, ottudan" ersetzt. Anonyme Briele zirkulieren, und die ganze Stadt lebt von Geruchten und Verdächtigungen, ${ }^{2}$ die einerseits "mit Appetit" zur Kenntnis genommen werden, ${ }^{3}$ andererse1ts aber eine "myst1sche Angst" erzeugen. (S. 634) A 11 e Schichten dieser Gesellschaft werden zu meinungslosem, wetterwend 1schen, durch Ideologien verführbaren Pöbel. ${ }^{4}$ Die enttäuschten, haltlosen Anhänger Starrogins - Verchovenskij, Šatov, Kirillov,

1 Mit dieser andeutungsweisen Erwähnung geheimer Institutionen schreckt Petr Verchovenskij den Gouverneur von Lembke. (S. 376)

${ }^{2}$ Verchovenskif 1st das verkörperte Gerücht: "Er geht und bewegt sich sehr schnelin von einem zum anderen (S. 19i); "er spricht schnell, hastig", seine Worte rieseln wie "gleichmäBige groBe Perlen" (ebd.). Neue, skandalöse Nachrichten häufen sich dadurch, daB Stavrogin (Teil II, Kap. I), Verchovenskif (Te1I II, Kap. VI) und der Chronist jewe1ls ganze Serien von Besuchen abstatten. In Teil II, Kap. II sagt der Chronist z. B.: "... ja...pobežl k Julil Michajlorne" (S. 514), "Bros1lajak Stepanu Trofimoricu..." (S. 522). "...zabežal k Dar'je Pavlovne..." (S. 523), "Ot nee napravilaja k ee bratu." (S. 523)

${ }^{3}$ Zum Gerücht über ein Verhältnis zwischen Stavrogin und Liza N1kolaevna heiBt es: "...vse...slusali s appetitom" (S.223). Prinzipiell sind alle Bewohner der Stadt an den skandalösen Vorgängen und ihrer Verbreitung interessiert: "Yes' gorod zagovoril. Razumeetsja, vae chochotal1." (S. 338) "Eto $\nabla$ zdesnich nravach... vse smejutsja, a negoduete odna $\nabla y_{j}$ " (ebd.) "... $4^{2}$ proneslas' po vaemu gorodu vest'..." (S. 340) etc.

Das Ansehen hochgesteliter Personen in der Stadt ist kontinulerlich starken Schwankungen ausgesetzt. Der ne1dvollen Bemuderung, die Starrogin nach seinem Auftauchen in der Stadt erregt (S. 46), folgt ein Ausbruch "allgemeinen Hasses" (S. 50). Die "alte Peindseligkeit" lebt auch nach einer Auslandareise Stavrogins wieder auf (S. 223), um nach dem Duell in allgemeine Bewunderung umzuschlagen.

Ähnlich wechselvoll - von den Jeweiligen Ereignisgen abhängend - ist das Ansehen Julia Michajlovnas, Varvara Petrovnas und Stepan Trofimovičs (vgl. S. 481, 60/168, 504). 
Lebjadkin - gehören $z u$ dem revolutionëren Kre1s, der die Stadt tyrannisiert und im Namen einer nicht definferten Ideologie der "gemeinsamen Sache" mordet. ${ }^{1}$ Die zwischenmenschlichen Beziehungen oind auf ein einfaches Grundmuster reduziert: es gilt, "sich als der Wirksamste, d. h. der Stärkste zu erweisen." Die Welt "ist nicht mehr in Gerechte und Ungerechte geteilt, oondern in Herren und Knechte." 2 so furchtet Verchovenskij Stavrogin, die Punfergruppe fürchtet Verchovengkij, Varvara Petrona beherracht Stepan Trofimovic, Dar'ja Pavlorna u. a.

Dostoevakifo düsterer Roman veranschaulicht die Thesen Arnold Gehlens zum Abbau ron Institutionen - den helfenden Fiktionen: "Der unmittelbare Effekt besteht in einer $v e r u n$ a $c h e-$ $r$ u 8 der betroffenen Personen, und zwar bis in die riefe

${ }^{1} V_{g l}$. R. Hingley, "The Undiscovered Dostoevsky" (1962), S. 133: "This is the most sanguinary and crime-ridden of his works. Four of the main characters are murdered and two commit ouic1de. Together with as8assination and arson go minor misdemeanours including scenes in which the chief hero pulls an elderly member of the respectable local club acrose the floor by h1s nose and bites the ear of the Provincial Governor. There are also several essays in sacrilege which include the introduction of a live mouse into the case containing an ikon the insertion of pornographic literature into the bundle of Gospels carried by an itinerant bible-seller, and reference to a scene where a holy man pelts a visitor with boiled potatoes. All this takes place in an atmosphere of gossip, rumours, threatening letters, blackmail, spying and denunciation to the police."

Die auggesprochen boshafte Darstellung revolutionärer Aktivitäten in den "Dämonen" iat von der Sowjetkritik heftig angegriffen worden. Vgl. z. B. V. V. Ermilov, "P. M. Dostoevgkij" (1956), S. 216 ff.: "Klevetničeskim paskvilem, dy žă̌im mračnoj zloboj, 'Beay' 1 jarljajutsja imenno potomu, ¿to oro1ch Stavroginych, Verchovenskich, II putinych 1 prodich Dostoevskif pytalsja, chotja 1 ne prjamo, moźno skazat truslivo, ovjazat' s aamym peredorym i luckim, tto bylo v tognarnej Rossil."

M. Gus, "Idei i obrazy Dostoerakogo" (1971) schreibt: "Besy' chudozestrennaja neudaca Dostoerskogo: on ne mog $v$ realistiCeaki vernych, ubeditel'nych obrazach peredat' svoju ideju, ibo Eta ldeja byla ložnoj, šla vrazrez a pravdoj žizni, s latori2 ceakoj pravdoj razvitija Rosiil." (S. 396)

Vgl. Albert Camus, "Der Mensch in der Revolte" (1969): die

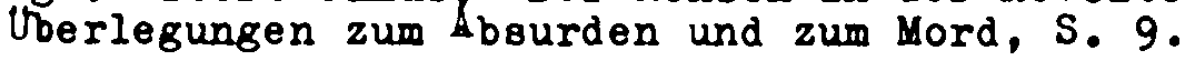


h1nein: Die Desorientierung ergre1ft die moralischen und geistigen Zentren, weil auch dort die Gewibheit des Selbotverstänlichen gestrandet 1st...der Ausfällungsbestand 1st der $S u b-$ J e k t 1 v 1 o m u a ...elne Ichverhaftethe1t, derart, daB der einzelne $\mathrm{e}$ in $\mathrm{n}$ zufälligen inneren Verelgenschaftungen, s e $1 \mathrm{n}$ e gerade $1 \mathrm{hm}$ zugewachsenen tberzeugungen und Gedanken und $s$ e $1 \mathrm{n}$ e Gefuhlsreaktionen ohne weiteres und unmittelbar so erlebt, als ob sie uberpersönl1ch belangroll wären." 1

10. D1e Ingtitution "Duell", die in den "Dämonen" exemplarisch den Verfall sozialer Verhaltensmuster veranschaulicht, ist mit Dostoerskif also zur bedeutungslosen Einrichtung geworden. Puskin, Lermontor, Turgener und Tolstof sind Adlige, für die der 2weikamp Lebenowirklichke1t 1st, die sich seinen Regeln unterwerfen (Pukkin und Lermontov), ihn spöttisch attackieren (Turgenev) oder in seiner Güligkeit relativieren (Tolstoj). Dostoevakif hingegen beschrelbt den unaufhaltbaren Verfall adliger Lobensformen und den glelchzeltigen Untergang der Schicht, die von diesen Lebensformen eingelabt wurde. ${ }^{2}$

Die "Dëmonen" sind Dostoerskijs hoffnungslose Bestandsaufnahme der gesellschaftlichen Verhëltnisse seiner zeit und eine boshafte Darstellung ihrer revolutionären Elemente. Dostoerskif sleht weder eine staatstragende Schicht noch zukunftaweisende Perspektiven. ${ }^{3}$ Sein Urtell lat das der Romanfigur Karmazinov: "So wie RuBland 1st, hat es keine Zukunft." (S. 388)

1A. Gehlen, "Anthropologische Forschung" (1961), S. 72 11. Vgl. auch E. Wasiolek, "Dostoersky" (1964), S. 130: "Starrogin represents the totally free will, which in Dostoersky's logic becomes the despotic will. The very act of 'Preeing' la an act of 'emptying'. The will is threatened by every engagement, belief, emotion. To prove his freedom, Stavrogin must triumph over every attachment to life."

2 "Le roman "Los démons" est conçu par Dostolersk1 trente ans après que l'a été celui de Lermontov; pendant cette période la noblesse russe a épuisé ses possibilités de progrès." Vg. R. Nazirov, "Dostofevski" (1973), S. 286.

${ }^{3}$ Starrogins Abscheu vor sich selbst als vernichtungowurdigen "schäbigen Insekt" (S. 702) fuhrt zum Selbstmord. Sein unehel1ches Kind stirbt. Vgl. H.-J. Gerigk: Dostoevsk1jo Selbotrerständ nie als bermeneutisches Problem. In: Russian Literature 4. 
A. P. Čechor, "Das Duell"

1. Dostoevskijs Thema einer dekadenten adligen Fürungsschicht kehrt bei Cechor unter anderem Aspekt wieder. In die Gedankenweit seiner "Menschen der achtziger Jahre" ${ }^{1}$ haben Darwinsche Theorien Eingang gefunden, die der Zoologe von Koren zum Fundament seiner radikalen, gegen den dekadenten Romanheld Laevskif gerichteten Philosophie macht: "... in ihren Anfängen murde die Menschheit vor Typen wie Laevskif durch Existenzkampe und Selektion geschützt; jetzt aber hat unsere Kultur Kampl und Selektion weitgehend schwächer werden lassen, und wir müssen uns selbst um die Vernichtung der Schwachen und Untauglichen kümmern..." . 2

Die Dekadenz präsentiert sich bel Čechor als aufreizende Lebenshaltung, die eine militante Gegenposition provoziert.

2. Auf der einen Seite steht die schmächtige, ungepflegte Gestalt des jungen Laevakif, blond, bleich, Fingernägel kauend, in schiefgetretenen Pantoffeln und mit zerknitterten Manschet-

${ }^{1}$ Diese Zeitangabe ist in der Charakterisierung Laevakifo durch von Koren enthalten: "my ljudi ros'midesjatych godor". In: A. P. Cechov, "Sobr. Boč. v 12 tt.", Bd. 6 (1962), S. 396. Alle nachfolgenden 21 tate werden diesem Band entnommen. - Der Roman "Duel'" entstand 1891 und wurde in diesem Jahr auch erstmals veröflentlicht.

${ }^{2}$ In den EFinnerungen ron $M . P$. Cechov an seinen Bruder heiBt es, daB Cechor während der Arbeit am "Dueli" oft mit dem Zoologen Wagner die damals aktuellen Themen der Degeneration, des Rechts des Stärkeren usw. diskutiert habe. Vgl. S. 534 in dem zitierten Band.

E. J. Simmons schreibt in "Chekhor" (1962), S. 244 f1.: "The zoologist Wagner, an enthusiastic admirer of Chekhor's fiction, was at this time engaged on a study of spiders. Chekhor admired the scientific precision of his mind, and in the evenings, when the company gathered, exciting discussions developed on such subjects as natural selection, will power, and inherited characterist1cs. Tagner stoutly opposed Chekhov's oonviction that will power and wisely directed education could overcome inherited evil traits. He insiated that nature did not joke with its victims. Clear echoes of the se debates can be heard in the theories of the scientist Von Koren in "The Duel", which Chekhor was writing at this time." 
ten, unglücklich über sein Verhältnis mit einer verheirateten Prau - deren er überdrüssig geworden ist - und durch das he 1 Be Schwarzmeerklima, in dem er lebt, unfähig zur Arbeit. ${ }^{1}$ Laevokif leidet unter seinen Unzulänglichkeiten "wie ein Kranker unter seinen Wunden" (S. 474), ist aber nicht imstande, ihre Ursachen in sich selbst zu suchen. Zu seiner Rechtfertigung und zu seinem Schutz flieht er in die Literatur, klebt sich das Etikett eines "überflüssigen Menschen" auf (S. 381) und sieht sich als Nachkomme Onegins, Pecorins, Bazarovs, Cains und sogar Hamlets (S. 392, 396). Laevskijs Verhältnis zur Realität ist gestört. ${ }^{2}$

Laevskif gegenüber steht der Zoologe von Koren, dunkelhäutig, schwarzhaarig, geckenhaft gepflegt und selbstbewuBt. ${ }^{3}$ Fir den Zoologen sind Arbeit und Selbstdisziplin erstes Gebot. ${ }^{3}$ Durch seine geselischaftliche Stellung fült er sich zu einer verantwortungsbewußten, beispielhaften Lebensweise verpflichtet. (S. 421)

Laevskif und von Koren stellen somit zwei Pole dar, in deren Spannungsfeld sich die Ereignisse des Romans abspielen.

3. Obwohl es von den beiden Kontrahenten heiBt, sie sähen einander an "wie Wöle" (S. 425), ist das feindliche Vernältnis eher mit einem Katz-und-Maus-Spiel zu vergleichen, bei dem der schwache Laevskif schlieblich in die Gewalt seines stärkeren Wider-

${ }^{1}$ Diese Charakterisierung Laevskijs ergibt sich in Kap. I aus geinen eigenen Worten und aus der Sicht seines Freundes, des Arztes Samojlenko.

${ }^{2}$ Seinen HaB auf Nadežda Fedorovna sucht Laevskij durch einen Ver. gleich mit dem $\mathrm{HaB}$ Anna Kareninas auf ihren Mann zu rechtfertigen. (S. 388) Die Krankheit Nadežda Fedorovnas bedeutet für inn die Zerstörung seiner "Illusion" von Liebe und Ehe. (S. 391)

${ }^{3} \mathrm{Vgl}$. die Selbstbetrachtung von Korens vor dem Spiegel. (5. 393)

${ }^{4}$ Von Koren zeigt ein fast missionarisches Sendungsbewubtsein. Er verurte1lt nicht nur den MüBiggang Laevskijs (S. 401), sondern versucht, auch den Diakon Pobedov zu disziplinierter Arbe1. anzuhalten und beruflichen Ehrgeiz in ihm zu wecken: "...vy nikogda ne budete zanimat'sja delom." (S. 394) "Ne sleduet balovat'sja. Nado sebja v rukach deržat'." (S. 403) "...vernuvšis' iz èkpedicil, ¿erez éti že desjat' let vy budete drugim čelovekom, vy obogatites' soznaniem, čto vami koe-cto sdelano." (S. 411) 
sachers gerät. Von Korens unbeirrbarer Glaube an das Recht des Stärkeren, sein Bewubtsein um die Pflicht, "1m Interesse der Menschheit und im eigenen Interesse" schwache Glieder der Gesellschaft zu vernichten (S. 401), lähmen Laevskijs Widerstandskraft. Die Verachtung von selten eines Mannes, den er respektiert, fördert seine Selbstverachtung. (S. 419) Dies wird deutlich in den Begegnungen 2 wischen von Koren und Laevakif (als Mitgliedern desselben gesellschaftlichen Kreises), die der Zoologe zu immer gezielteren Attacken nutzt.

Während des Picknicks (Kap. VI - VII) grelft von Koren jede Aủerung Laevskijs mit überlegenem Spott oder in der Pose des tadelnden Lehrmeisters auf. 1 Diese apriorische Ablehnung von se1ten eines unduldsamen Gegners emplindet Laevskif gleichsam als physische Bedrohung und Peinigung: "... in seiner Gegenwart kam es ihm vor, als müBten alle sich beengt fühlen und als stünde jemand hinter einem... Laevskif spurte ein Unwohlsein: in se1nen Rücken schlug die Hitze des Lagerfeuers und in seine Brust und sein Gesicht der HaB von Korens...". (S. 414, 419)

Unter dem Diktat dieser Emplindungen verzichtet Laevakif nicht nur auf Gegenwehr, sondern läBt sich zu unwürdigem Verhalten hinreiben: er schüzt sich, indem er seinem Gegner schmeichelt. 2

EIne noch schmählichere Verunsicherung erlebt Laevskif be 1 seiner nächsten Begegnung wit dem Zoologen während der Geburtstagsfeier im Hause der Mar'ja Konstantinorna (Kap. XII - XIII). Laevakif lat monomanisch fixiert auf den Gedanken an Abreise und Plucht aus seinem Verhältnis mit Nadežda Fedorovna. Gleichzeitig ist er höchst beunruhigt daruber, dab sein Freund Samoj-

1 "Budto by? - cholodno sprosil fon Koren... Budto by? - portoril on...". (S. 413) "K לemu éto govorit'? Ne novo 1...voobšce strannaja manera." (S. 419) Von Koren wird mehrfach als kalt charakterisiert: vgl. S. 397, 453.

2"Ich liebe die Natur leidenschaftlich und bedaure, kein Naturwissenschaftler zu sein. Ich beneide Sie." (S. 419)

Als Laerskif seinem Gegner auf Kostjas Geburtstagsfeier die Hand relcht, lächelt er beflissen: "...2alskivajuǧe ulybnulsja." 
lenko den Betrug an Nadezda Pedorovna ahnt und verhindern will.' In dieser nervösen Verfassung trifft ihn ein Angriff von Korens, der durch Samojlenko in die Reisepläne Laevakijs eingeweint 1st. Der 200 loge benutzt sein Wissen gegen Laevskif und läBt $1 \mathrm{hm}$ während elnes Gesellschaftssplels zwel Briefchen zukommen, die hämisch die Unmöglichkelt elnes Ausbruchversuches andeuten. ${ }^{2}$ Laerskijs Wehrlosigkeit gegenuber seinem Angreifer äuBert sich in hysterischem Gelächter und einem völligen körperlichen Zusammenbruch. ${ }^{3}$ Die Schmach dieser öflentlichen Demultigung ${ }^{4}$ empeindet Laevskif als unerträglich. Er lot entschlossen, se ine Pluchtpläne nun unter allen Jmständen, selbst ohne Pinanzielle Hilfe Samojlenkos, zu realisieren. ${ }^{5}$

Als Laerskij einen Tag nach diesem $2 w 1 s c h e n f a l l$ seinen Freund Samojlenko aufsucht, um sich Geld von ihm zu erbitten, komnt es zu einem unerwarteten Zusammentreffen mit von Koren (Kap. XV). Der erschrockene und beschämte Laevskif erwidert die boshaften Bemerkungen des Zoologen $z u$ seinem hysterischen Anfall ${ }^{6}$ mit zwanghafter Freundlichke1t und Mittellsamke1t. Er lächelt gegen

${ }^{1}$ Laerakij muB sich das Geld für seine geplante Abreise von Samojlenko leihen. Er gibt vor, Nadezda Pedorovna später nachkommen lassen $2 u$ wollen. Samojlenko seinerseits mu sich das Geld ron dem Zoologen lethen. Dieser errät Laevskijo wirkliche Absicht und will nur unter der Bedingung helfen, dab Nadezda Pedorovna mit abreist. Samojlenko muB diese Bedingung notgedrungen ubernehmen. (S. 442)

"Ne uezźaj golubcik moj....A kto-to $v$ subbotu ne uedet." (S. 445 P.)

3"Schon grife man thm unter die Arme, stutzte von hinten seinen Kopl und fuhrte ihn 1rgendwohin; schon glänzte ein Glas vor seinen Augen und schlug gegen seine Zähne, und das Wasser rann auf seine Brust...". (S. 446)

4nEr sah erstaunte Blicke, das ernste, erschrockene Gesicht Samojlenkos und den Blick des Zoologen, der nichts als kalten Spott und Ekel ausdruckte, und begriff, daB er einen hysterischen Anfall hatte. 'Wle entaetzlich, welch elne Schande,' dachte er und spurte, daB sein Gesicht von Tränen warm murde.." . (S. 446)

5Laerskif will notfalls in einem "demütigenden Telegramm" seine Mutter um Geld bitten. (S. 452)

$6_{B 1 s}$ gestern hatte ich angenomen, daB nur Damen hysterisch sein können, und deshalb dachte lch zunächst, sie litten unter Veitstanz." (S. 453) 
seinen Willen und begründet seine Hysterie trotz der instinktiven Gewibheit, sich damit seinem Gegner auszuliefern. ${ }^{1}$ In der Tat reagiert von Koren auf die Bekenntnisse Laevskijo mit einem vernichtenden Urteil, das den Lebensnerv des schwächeren Gegners trifet: "Ja, Ihre Lage 18t aussichtslos...". (S. 453) Laevskij spürt, daB der Zoologe die Grenzen des Zumutbaren uberschritten hat. Das Lächein von seinem Gesicht schwindet, und statt Unterwurfigke1t als Selbstschutz gegen die Attacken von Korens zeigt er erstmalig den Versuch zur Gegenwehr. Laevak1fo Gegenwehr ist allerdings ungezielt und hilflos - sie fuhrt zu seinem eigenen Erstaunen zur Vereinbarung eines Duells mit dem Beleidiger.

4. Laevak1f fuhlt, daB lhm das HaBgefühl gegen den Zoologen Brust und Hals so beengt, daB er nur lelse sprechen kann. Er 1at ble1ch, schwankt vor Erregung und furchtet eine wiederholung seines hysterischen Anfalls. Seine Angriffe formuliert er unkontrolliert - or lenkt sie überdies nicht gegen von Koren, den er nur noch wie "im Nebel" sieht (S. 455), sondern gegen den hinzutretenden Samojlenko. 2 Inmitten geines HaBtaumels 3 sieht sich Laerskif plötzlich ron Samojlenko in die Enge getrieben: er soll seine Beleidigungen zurücknehmen, weis aber nicht, was er einen Augenblick zuvor gesagt hat. Aus dieser Situation sucht er sich durch einen neuerlichen Angrife gegen Samojlenko zu befreien: "Lassen Sie mich in Ruhe! Ich will gar nichts! Ich will nur, daB sie und deutsche Judenabkömmlinge

${ }^{1}$ Laevikif weist unter anderem auf seine zerruttete Gesundheit, seine Langeweile und seine ständge Geldnot hin.

2"Uvažajte l1X̌nost'!...Ét1 postojannye razgovory na cuzoj stet, ochi da ach1, postojannye vyslezivanija, podslusivanifa, \&ti sočurstrija družeskie...k Certu! Mne dajut den'gi vaajmy 1 predlagajut uslovija, kak mal'čiške! Menja tretirujut, kak cert znaet tto! Nicego ja ne zelaju!...n (s.455) - In seinen wirren Vorwurfen beginnt Laerskij, Samojlenko zu giezen.

${ }^{3}$ Dem unbetelligt zuschauenden Diakon bietet sich folgendes Bild: "...als er sah, wie Laevskij bleich und mit den Armen fuchtelnd dastand und seltsame Worte an das Portrait des Puraten Voroncor richtete, blieb er wie angewurzelt an der Tur stehen." (S. 455) 
mich in Ruhe lassen! Sonst ergreife ich meine Maßnahmen! Ich werde mich schlagen!" (S. 456) Laevak1js wütende Drohung "Ich werde mich schlagen!" hat nichts mehr gemein mit der konventionelien Forderung nach Genugtuung eines in seiner Ehre Gekränkten. In einer Situation äuBerster Empörung macht Laevakif vielmehr u $n$ $b$ e $u$ B $t$ Gebrauch von einem Vokabular, das den Menschen der achtziger Jahre noch im Ohr lag. Von Koren, der die ganze zeit ruhig dagestanden hat, $n u t z t$ die Gelegenheit und macht aus dem an Samojlenko gerichteten hysterischen Ausbruch eino an seine Person gerichtete Forderung zum Duell: "Jetzt iat es klar, - sagte von Koren und trat hinter dem Tisch hervor. Herr Laevakif möchte sich vor seiner Abreise mit einem Duell zerstreuen. Ich kann thm dieses Vergnügen bereiten. Herr Laevakif, 1ch nehme Ihre Porderung an." (S. 456) Der Zoologe oleht in dem Duell eine Chance, seinen $\mathrm{HaB}$ gegen Laevak1j auszuleben. Sein Motir für einen Zneikampl liegt in dem unbezwingbaren Tunsch, ein "welkes, skrofulöses, sittlich verderbtes Geschlecht" zu vernichten. ${ }^{1}$ DaB Laevakif sich überrumpeln läBt und einem nicht beabsichtigten Duell sein Placet gibt, ist ebenfalls das Resultat von ubermächtig werdenden HaBgefülen. "'Meine Forderung? fragte Laevakif le1se. Er trat auf den Zoologen zu und sah voll Haß auf dessen dunkle Stirn und die krausen Iocken. - Melne Forderung? Von mir aus! Ich hasse Sie! - Ich hasse Sie!... Ich hasse Sie! - sagte Laevakif mit le1ser Stimme und atmete schwer. Ich hasse Sie schon lange! EIn Duell! Ja! 'n'2

${ }^{1}$ Dies sind Worte von Korens aus einem seiner Gespräche mit dem Diakon. (S. 463) - Vgl. Th. Winner, "Chekhor and h1s prose" (1966), S. 103: "Von Koren speaks of h1s desire to destroy Laevakl and his opportunity comes when Laevakl challenges him to a duel following a wild argument!"

${ }^{2}$ In seiner Phantasie fuihlt sich der ewig unterlegene Laevakif nun als grausamer Rächer: "...ein tiefer, leidenschaftlicher, gieriger $\mathrm{HaB}$ begann in seiner Brust $z$ wihlen und verlangte Genugtuung. In Gedanken warf er von Koren zu Boden und begann, mit den FüBen auf ihm herumzutrampeln... Man mübte ihm ing Bein schieBen oder in die Hand, thn verletzen und dann uber ihn lachen, und we ein Insekt mit abgerissenem Bein aich im Gras verliert, soll er dann mit seinem dumpien Schmerz in der Menge untergehen, die aus ebenso erbärmlichen Menschen besteht wie er." $(s .457)$ 
Beide Kontrahenten haben keine Beziehung zum traditionellen arlatokratiochen Ehrenzweikampl mit seinen atreng kodifizierten Regeln. Der Zoologe betont ausdrucklich, daB er das Duell fúr obsolet hält, daB olch der Zweikampe für lhn prinzipiell in nichto "von einer Schlägere1 zwischen Betrunkenen in einer Wirtsohaft" unterscheidet. (S. 462) Laevikif amisiert sich Im Kreise oeiner Preunde daruber, dab er "fast gar nicht" schieben kann. Er nennt sich einen "Schützenkönig und W1lhelm Tell". (S. 457)

Auch den unmittelbaren Zeugen der manipulierten Herausforderung, Samojlenko und dem Diakon, ist das Duell als Ehrenzwe1kampl bereits fremd. Samojlenko betrachtet es einerseits als "tberrest mittelalterlicher Barbare1" (S. 465) und 1deal1siert es andererse1ts in naiver Gutherzigkeit als von der "Vorsehung" bestimmtes "Mittel zur Versöhnung" der beiden Kamplhähne. (ebd.) Der Diakon sieht in dem berorstehenden Zweikampl ein "heidnisches Spektakel", das unter Umständen sehr spabig abläuft."

Be1 niemandem 1ot das Duell als Ehrenrettung mehr eine Inst1tution im Sinne Gehlens, $d$. h. elne Institution, die bis in die "Wortgefuhle und Willensentschlusee" durchgreift, die dann "obne Bremsung und Zweifel" wie von selbst verlaufen. 2 Die Unsicherheiten und Mibverständnisee in Bezug auf einen Ritus, der zwar noch bekannt, aber nicht mehr lebendig ist, zeigen sich am deutlichsten auf dem Rendezvous-Platz.

5. Gewiseen klischeeheften Vorstellungen von der Austragung e1nes Duella wird Rechnung getragen. Die Kontrahenten treffen sich zu fruher Morgenstunde auf einem zehn Kilometer auBerhalb der Stadt liegenden Kamplplatz in Anwesenheit eines Arztes ${ }^{3}$ und in Begleitung von je zwe1 Sekundanten. Insgesamt verlau-

${ }^{1} V_{g l}$. S. 471 I. - Die Gedanken des Diakon erinnern zum Tell an die naive Argumentation der Festungeleute in der "Hauptmannstochter".

2Vgl. A. Geblen, "Anthropologische Porschung" (1961), S. 72. ${ }^{3}$ In den "Konventionelien Gebräuchen beim Zreikampl" von $M_{\text {. }} \nabla$. Wedel (1909) heiBt es: "Alle vier Sekundanten stellen olch auf die日elbe Selte der Duellanten und zwar so, das jedem ein gegnerischer sekundant am nëchoten steht; hinter den Sekundanten stehen die Ärzte." (S. 26) 
fen Vorbereltung und Austragung des Kamples jedoch regelwidrig. Von Koren verletzt das Gebot der Plinktlichke1t und erwartet nach seiner Ankunft auf dem Terrain nicht schweigend die Anordnungen der Sekundanten, 1 sondern eragt ungeniert: "Ich habe mich doch nicht verspätet?" (S. 475) Im librigen wendet er sich ausschlieblich den Strahlen der aufgehenden sonne $2 u,{ }^{2}$ so das seine Sekundanten, zwei junge offiziere, in Verwirmang geraten und sich gegenseitig ansehen, "als wollten sie fragen, wozu sie hier seien und was sie tun sollen." (S. 475) A 1 le Anwesenden haben das Gefühl, "daB es nun leit sel zu beginnen oder das zu beenden, was bereits begonnen hatte," stehen jedoch unsicher herum und rauchen. (s. 476) Da die 0ffiziere annehmen, dieses "zivile, Ihrer Meinung nach überflüssige Duelln" werde in Wirklichkeit gar nicht stattinden, wird der obligatorische Versöhnungeversuch seitens der Sekundanten nur von Laevskifs Sekundant Śeśkorskif durchgeführt - und dies zu spät und in unzulänglicher Form. Erst auf dem Kamplplatz tritt Šłkovakij an den Zoologen 4 heran und erbittet "vertraulich" den Verzicht auf das Duell: "... und 1ch argumentiere nicht als sekundant und was alles dazugehört, sondern als Mensch und alles." (S. 477)

1 "Die Duellanten finden olch einige Minuten vor der bestimmten Zeit auf dem Kamplplatze ein. Die Gegner haben, nachdem sie höfliche GrüBe getauscht, vollkommen schweigsam sich zu verhalten und abseits die Anordnungen ihrer Sekundanten zu erwarten... Bleibt eine Parte1 15 Minuten uber die verabredete Zeit aus, so kann die wartende Partel den Platz verlassen...". In: H. Kufahl und J. Schmled-Kowarz1k, "Duellbuch" (1896), S. 222. ${ }^{2}$ "Das sehe ich zum ersten Mal in meinem Leben! Wie herrlich!... Sehen Sie nur: grüne Strahlen!" (S. 475)

${ }^{3}$ Die Gedanken der Offiziere bewelsen, das es in Militarkreisen noch zu Duellen kommen konnte. Auf diesen Punkt wird in der folgenden Bearbeltung der Romane Kupring und Arcybabevo ausruhrlich eingegangen.

${ }^{4}$ Regelgerecht wäre folgendes gewegen: "Die beidergeitigen Sekundanten treten, nachdem sie genaue Weisungen sowie ausre1chende Auskunft über den Fall von ihren Klienten emplangen haben, zur Beratung zusammen, stellen den Grad der Beleidigung, sowie die Person des Beleldigten fest, insofern nëmlich Angriffe von beiden Seiten erfolgten. Es ist thre Pflicht, die Angelegenheit womöglich eriedlich auszugleichen..." . Vgl. S. 216 im "Duellbuch" von H. Kufahl und J. Schmled-Kowarzik (1896). 
Der anschließend an beide Kontrahenten gerichtete Versöhnungsversuch Šeškovskijs wird - ihm unbewußt - zu einer $P$ a $r$ o d i e auf den herkömmlichen Duellritus: "Meine Herren, wir sehen keinen ursächlichen Zusammenhang zwischen einer Beleidigung und einem Duell. Eine Beleidigung, die wir uns aus menschlicher Schwäche mitunter zufügen, und ein Duell haben nichts miteinander gemeinsam. Sie haben die Universität absolviert und sind gebildete Männer und sehen im Duell gewiB selbst nur eine veraltete, leere Formalität und alles. Auch wir sehen es so an, sonst wären wir nicht hierher gelahren, denn wir können es nicht zulassen, daB man in unserer Gegenwart aufeinander schiebt und alles... Ehrenwort, meine Herren!n (S. 478) ${ }^{1}$

Da die beiden gegnerischen Parteien um den Sinn des traditionellen Ehrenzweikamples nicht mehr wissen, muß ihnen die Komik dieser Versöhnungsrede verborgen bleiben. Doch gestaltet sich der weitere Verlauf der Duellvorbereitungen so grob farcenhaft, dab allgemeine Verlegenheit und sogar Heiterkeit die Folge sind. Als von Koren auf der Durchpuihrung des Duells besteht, stellt sich heraus, dab ron allen Anwesenden noch niemand jemals einem Duell beigewohnt hat. "...niemand wuBte genau, wie man sich aupzustellen hat und was die Sekundanten sagen und tun müssen." (S. 478) Die scherzhaften Emplehlungen des Zoologen, sich an die literarischen Duelle Lermontovs und Turgenevs zu erinnern, unterbricht schlleblich der ungeduldig gewordene Arzt Ustimovic mit einigen kurzen Anweisungen. Ein $Z$ wischenraum wird abgemessen, und die Kontrahenten werden an den Endpunkten augestellt. Da der Kugelwechsel von hier aus - obne Vorrucken - erfolgt, handelt es sich bei dem Zweikampf, zu dem es nun zwischen von Koren und Laevskif kommt, um ein sogenanntes Pistolenduell mit Pestem Stand punkt. ${ }^{2}$

1Vgl. Thomas Winner, "Chekhor and his prose" (1966), S. 103: "The duel itself is presented as a parody of all literature duels: no one knows the rules and the seconds try to remember the procedure by recalling lamous duel scenes in literature." ${ }^{2} \mathrm{Vgl}$. S. 229 im "Duellbuch" von H. Kufahl und J. SchmiedKowarzik (1896). 
6. Das Duell 2wischen von Koren und Laevakif lat ein sinnfälliger Ausdruck inrer Beziehungen zueinander. ${ }^{1}$ Die Konfrontation mit dem stärkeren AgBressor lëhmt Laevakijs Widerstandskraft, sie raubt $1 \mathrm{hm}$ die Herrschaft uber seine Sinne und wird $1 \mathrm{hm} z$ ur physischen Qual. Die Worte der Sekundanten Šeškovikif und Bojko dringen nicht in sein Bewubtsein. Er spannt mechanlsch den Hahn und hebt die Platole "als der Moment dazu gekommen war". Er fült sich in seinem Mantel beengt und hebt den Arm so ungelenk, als stecke dieser in einem Ärmel "aus Blech". (S. 479) Laevskif lit nicht nur auBerstande, auf den spött1sch lëchelnden Zoologen zu schieBen, sondern versucht, sich der Kamplo1tuation auf unwirdige We1se zu entziehen: "In der Angst, die Kugel könnte von Koren Irgendwie unerwartet treflen, hob er die Plotole imer höher und höher und fülte, dab diese viel zu offensichtliche GroBmut wenlg feinfülig und groBmiutig war, aber er konnte einfach nicht anders." (ebd.)

Der Zoologe verhält alch ebenfalls typlach: er zielt auf Laerskif und läBt lhn Todesangst ausstehen. DaB sein SchuB schlieblich fehlgeht, ist nur auf einen Elngriff von auBen zurückzufúhren. Der Dlakon, der die ganze Szene aus elnem Versteok heraus beobachtet - als Gelstlicher scheut or sich, co ram publico Zeuge des Duells zu seln - zerstört die hypnotislerende Fasination, die dieser ritualisierte Tötungsversuoh offensicbtlich auf die schweigend und blab dastehenden Anwesenden ausubt, mit dem verzweifelten Schre1: "Er tötet 1hn!n" Dleser plötzliche Schrel in die St1lle erschreckt ron Koren und lëBt ihn am 2101 vorbelschieBen.

Von allen Anwesenden folgt der Diakon allein dem Impuls sei-

1Vgl. B. I. Aleksandror, "Seminarij po Čechoru" (1957), S. 181: "Skvoz'ves' roman prochodit étot ldeologideskiJ poedinok druch protirnikor, urelilivaja s každy gragom silu 1ch vzaimnoj nenarist1. P1stoletnye vystrely u Cernoj redk1 - tol'ko logizeskif 1tog, kul'minacionny punkt étoj dolgoj duelil Zaglarie arazu nacelivalo na glavnyj konflikt romana, 1 eochor uporno otetalval ego, otvergaja predložennuju Surorinym zamenu.

${ }^{2} V_{\text {gl }}$. dazu P. B1c1ll1, "Anton P. Čechor" (1966), S. 37: "Der D1akon...der hinter dem Busch hervorruft, 'on ub'et ego'...eplelt elne Rolle, die der von Savel'it bel Púkin analog iat." 
nes Gewisaens, das frevelhafte Handeln zu entlarven und inm Einhalt zu gebieten. DaB ron Koren im Duell eine Möglichkelt sieht, seine Theorie von der gerechtfertigten Ausmerzung des Schwächeren durch den Stärkeren zu realisieren, wird dem Diakon gleich zu Beginn des Zweikamples bewuBt, als er die Kontrahenten mit Maulwirfen vergleicht. ${ }^{1}$ Er muB an ein Gespräch zwischen von Koren und Samojlenko zurückdenken (S. 436), in dessen Verlauf der Zoologe das Recht des Stärkeren an einem Kampl zw1achen zwe1 Maulwirfen veranschaulichte, bel dem der Schwächere auf der Strecke blieb. Für den Diakon ist die Position des Zoologen Frevel - unmenschlich und unnatürlich. ${ }^{2}$ Er glaubt nlcht, daB es eln zuverlässiges Kriterium für die Unterscheldung von Schwachen und Starken gibt, sondern fragt eher demilig: "Mit welchem MaBstab soll man die Elgenschaften der Menschen messen, um gerecht uber sie zu urteilen?" (S. 472)

Unter dem Aspekt des Prevelhaften und des alarmierten Gewissens sind die melsten ÄuBerungen der am Duell Betelligten nlcht mehr komisch - weil inkompetent - sondern Ausdruck einer angetvolien Verunsicherung. So der Monolog des Diakon: "Sie sind zwar unglëubig, aber sie sind gute Menschen und werden gerettet werden...Sie werden bestimmt gerettet werden." (ebd.) Auch die Beteuerung des Sekundanten Škkovaklf verliert so jede Lächerlichkeit: "Ich kenne die Duellregeln nicht, der Teufel mag sle alle holen, und lch will sie nicht kennen..."."

Der geschickte Rückgriff von Korens auf eine im BewuBtsein der Menschen überlebte Form des Zweikamples 4 wird ron allen instinktiv als verkappter Totungsversuch begriffen. Gegen die

1'"Kroty', - vapomil d'jakon, siderálj v kustach." (S. 479)

2nkak eto protirno prirode celoveceskoj! Do kakoj stepen1 éto protivoestestrenno!... Kak éto protivno prirode Celoredeskoj!" (S. 480 I.)

${ }^{3}$ Mit diesen Worten versucht Se $k$ kovskif von Korens Sekundanten (S. 476) und ron Koren selbst (S. 477) zu uberreden, auf das Duell zu verzichten.

4 In Strafge日etzbuch der Zeit existiert das Duell nochs der 200loge erkundigt alch voralchtghalber bel Samojlenko, welche Strafe darauf steht. (S. 465) 
Frevelhaftigkeit dieses Plang ${ }^{1}$ bäumt sich selbst die Natur auf. In der Nacht vor dem Duell geht ein schweres Gewitter nieder. Am Morgen des Zweikamples scheint alles in der Natur "unschön und ergrimmt." (S. 472)

Wie schwer alle Beteiligten daran getragen haben, im Innersten um den Frevel dieses Duells zu wissen, zeigt sich erst nach dem glücklichen Ausgang: der Diakon lächelt "irgendwie seltsam" und schwenkt seinen nassen Hut. Sełkovskif lacht vor Freude, beginnt dann $z u$ weinen und geht zur Seite. Der Zoologe fuhlt sich so geschwächt, $a a B$ er die Augen schliebt. Die Natur lächelt jetzt Ireudig, Regentropfen glitzern in der Sonne wie Diamanten, und Laerskif fühlt sich "wle aus dem Gefängnis entlassen." Er wundert sich darüber, daB so etwas Alltägliches wie nTische, Fen. ster, Stühle, Licht und Meer eine lebhafte, kindliche Freude in ihm wecken, wie er sie schon lange nicht mehr empeunden hatte." (S. 480 ff.)

7. Čchor nutzt den Ritus des sinnlos gewordenen Ehrenzweikampfes zur symbolischen Darstellung der aktuellen Frage nach dem Recht des Stärkeren. Cechov ergreift in diesem Roman eindeutig Partei. 2 Er sträubt sich dagegen, einen Menschen nach dem Nützlichkeitsprinzip $z u$ bewerten und hëlt der rigorosen Philosophie des Zoologen nicht nur die Skrupel des Diakon entgegen, sondern auch die Weitherzigkeit des Arztes Samojlenko, der zwar die Fehler Laevskijs sieht, ihn aber un der Eigenschaften willen liebt, die er an ihm $n i c h t$ versteht. Er hält Laevskif für kluger als sich und achtet in ihm den Intellektuellen. (s. 385)

${ }^{1}$ Samojlenko weigert sich von vornherein, Zeuge des Duells zu sein: "Net, boze menja sochrani, ja 1 tak zamucilsja." (S. 464)

2 Thomas Winner sieht darin zu Recht die Schwäche des Romans: "The Duel' is the only one of the searching otories in which Chekhov has attempted to resolve the philosophical conflicts within the dramatic context of the story; and this attempt, as well as the uncharacteristically wordy conclusion, constitute its weakest parts." Vgl. "Chekhor and his prosen (1966), S. 105). 
Samojlenko ist in diesem Roman die wahrhaft humane Figur - das Duell steht als eindringliches Symbol für Inhumanität.

8. Wenn das Duell als Sinnbild aufgefaBt werden kann, das zur Deutung des besonderen Verhältnisses 2 wischen von Koren und Laevskif beiträgt, so gewinnt der Roman als Ganzes durch sein letztes Kapitel die Bildhaftigke1t eines barocken Emblems, das

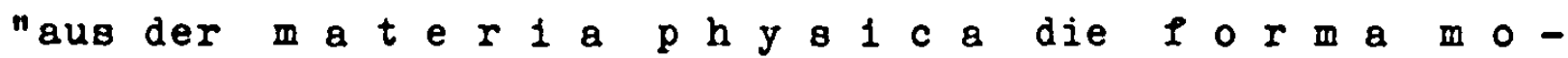
$r$ a 118 entwickelt". 1

Die Ereignisse des letzten Kapitels im "Dueli" sind von dem elgentlichen Romangeschehen durch einen Zeitraum von dreleinhalb Monaten getrennt. Es zeigt sich eine veränderte Situat1on. Bel Laerskij haben Todesangst in der Nacht ror dem Duell und das gleichzeitige Erlebnis eines öfentlichen Skandals um seine Geliebte Nadezda Fedorovna zur Katharsis geführt. Die Verwandung des ehemals labilen Laevskif in einen Menschen mit untadeliger Lebensweise ist für alle - insbesondere aber für den Zoologen - ein unfaßbares Phänomen. (S. 484) Von Koren betrachtet seinen Irrtum in Bezug auf Laevskif indes nicht als

${ }^{1} \mathrm{Vgl}$. A. Schöne : Emblemata. In: DVjs. 37 (1963), S. 216. Die dreiteilige Form des Emblems wird hier so definiert: "Zu Jedem dieser Bilder gehört ein Motto und ein Epigramm in lateinischen Alexandrinem. Diese Verbindung von Bild und Text in einem dreiteiligen Aufbau bestimmt...die äuBere Form des Emblems. Die p 1 c t u $r$ a (Icon, Imago) zeigt etwa eine bestimmte Ortlichkeit, eine Pflanze oder ein Tier, einen Gegenstand oder Vorgang des menschlichen Lebens, eine Personifikation oder eine historische, mythologische, biblische Figur oder Szene. Uber dieser plctura, bisweilen noch in ihr Blickfeld einbezogen, erscheint eine kurzgefabte lateinische, mitunter auch griechische in s c r i p t 10 (Motto, Lemma). Darunter steht als $s$ u b s c $r 1 p t i o$ ein Epigramm von unterschledlicher Ienge...". (s. 199)

Zur Funktion des Emblems heibt es: "...die emblematische pictura... repräsentiert ganz unmittelbar, nämlich auf anschaubare Weise ein Stick Wirklichke1t, das rom Hersteller des Bildes mehr oder minder geschickt dargestellt und durch die subscriptio dann ausgelegt wird, indem diese die in der pictura beschlossene, uber die res picta hinausweisende significatio offenbar macht. Jedes Emblem ist insofern ein Beitrag zur Erhellung, Deutung und Auslegung der Wirlichke1t." (ebd., S. 204) 
persönliche Verfehlung. Als er nach Abschlub seiner wissenschaftlichen Untersuchungen den kleinen Schwarzmeerort verläBt, spricht er in einem versöhnlichen Abschiedsgespräch mit seinem ehemaligen Todfeind vom "Los des Menschen": "Behalten Sie mich nicht in schlechter Erinnerung, Ivan Andreit... Ich habe aufrichtig gehandelt und bin seither meinen Uberzeugungen nicht untreu geworden... Ich habe mich zwar, wie ich jetzt zu meiner groben Freude sehe, in Bezug auf Sie geirrt, aber man kann auch auf einer ebenen Straße stolpern, und das Los des Menschen ist eben so...Niemand kennt die eigentliche Wahrheit." ${ }^{1}$ (S. 485)

DaB die Erkenntnis "Niemand kennt die eigentliche Wahrheit" als subscriptio zu einer pictura gehört, zeigt das Bild vom Schiffchen auf dem Meer, ${ }^{2}$ mit dem der Roman endet. Der Zoologe kämpet sich in dem kleinen Boot, das ihn zu seinem Dampler bringen soll, nur mühsam gegen den Wellengang voran. Immer wieder wird das Boot durch eine hohe Welle um ein Stück zuríckgeworfen. Für den zuschauenden Laevskif wird dieses Bild zum Sinnbild: "Ja, niemand kennt die eigentliche Wahrheit..." der:t Laevskif und sieht traurig auf das dunkle, unruhige Meer. "Das Boot wird zurückgeworfen...macht zwei Schritte vorwärts und einen zurück...". (S. 487)

Das letzte Kapitel in Cechovs "Duell" liefert die ausdeutende subscriptio zum Romanganzen, zur pictura. Beiden ist als Motto das "Los des Menschen" zugeordnet. Das ganze, Literatur gewordene Emblem kann in der Diskussion um das Recht des Stärkeren als ein Aufruf Cechovs zur Demut gesehen werden. 3

${ }^{1}$ Die Versöhnung zwischen von Koren und Laevskif ist oft als unüberzeugend kritisiert worden. Vgl. S. $525 \mathrm{ff}$. In Bd. 6 der zitierten Cechov-Ausgabe. Winner nennt die Versöhnung "quite artificial". Vgl. "Chekhor and his prose" (1966), S. 103.

${ }^{2}$ Nach M. Windfuhr gehören Lebens- und Liebesschiff zu den verbreitetsten Bildfeldern der Barockliteratur. "Nach der Barockzeit bleibt das Bild der Schiffahrt noch lange lebendig. Es gehört zu den Lieblingsbildern der Goethezeit und wird auch später, noch in Rimbauds 'Bateau ivre'... wegen seiner allegorischen und symbolischen Möglichkeiten gern verwendet." Vgl. "Die barocke Bildlichkeit und ihre Kritiker" (1966), S. 85.

"Nikolaj Vasil'ið...Sie müssen wissen, daß Sie heute den größten Feind des Menschen besiegt haben - den Stolz!" - sagt der Diakon. (s. 486) 
A. I. Kuprin, "Der Zweikampe"

1. Unter den zahlreichen positiven und negativen Reaktionen auf den 1905 erschienenen Roman Kupring verdient das Urteil der symbolistiachen Zeitschrift "Vesy" wohl besondere Beachtung: Valerij Brjusor stellt den "Zweikampe" hier als ein kunstlerisch schwaches Werk vor, dessen beste Szenen "nicht mehr als...Anekdoten aus dem Soldaten- und Offiziersleben" seien." Offensichtlich ist Kuprin in seinem Roman darum bemüht, die Verhältnisse in der russischen Armee vor der Jahrhundertwende ${ }^{2}$ darzustellen und $z u$ kritisieren. Im Zentrum des Geschehens steht der junge Offizier Romasov. Durch die Sichtweise und den Charakter dieses Einundzwanzigjährigen ${ }^{3}$ kommt es im "Zweikampe" zu einer unbarmherzig desillusionierenden Analyse der Armee der neunziger Jahre.

2. Romalov hat ein hohes Potential an Begeisterungsfähigkeit. Die von Marschmusik begleitete militärische Prachtentfaltung anläBlich einer Heerschau ubt eine derartige Faszination auf thn aus, daB es ihn kalt iberläuft. Er schaut den General und die Suite der eleganten Stabsoppiziere "mit ergebenen Augen" an, Pühlt sich "stark" und "stolz" durch das BewuBtsein, "daB auch er zu dieser wohlformierten, unbeweglichen, riesigen Menge von Menschen gehört, die auf geheimnisvolle Weise, durch einen unsichtbaren Willen, in Reglosigkeit erstarrt sind...". (S.

1Zitiert nach: A. I. Kuprin, "Sobr. sot. $\nabla 9$ tt.", Bd. 4 (1971), S. 467. Alle Zitate zum "Zweikampe" werden diesem Band entnommen.

2 Man kann annehmen, daB die geschilderten Ereignisse in das Jahr 1894 fallen. In Kap. VIII des Romans diskutieren Offiziere über Duelle, "die damals soeben erlaubt worden waren.." . Wie bereits erwänt ( $\mathrm{g}$ l. die Darstellung der Geschichte des Duells, S. 12), war in der russischen Militärgesetzgebung seit 1894 - Im Unterschied $z u$ anderen Staaten - der Duell$z$ a $n$ \& verankert. Wer den 2weikampe verweigerte, wurde aus der Armee ausgeschlossen. - Kuprin diente von 1890 - 1894 in der Armee ( $v g l$. S. 248 in Bd. 9 der zitierten Auggabe). Es ist bekannt, daB Personen und Begebenheiten im "Zweikampe" z. T. authentisch sind.

${ }^{3}$ Dag Alter Romałovs geht aus Kap. III, S. 28 hervor. 
146 1.) In seinen Tagträumen sieht Romašov elne glänzende militärische Karriere vor sich. Er schlägt aufständische Massen nieder, riskiert sein Leben als Spion im feindlichen Ausland, fuhrt in entscheidenden Schlachten Soldaten an, die "wie Löwen" kämpfen und ist siegreich in dem BewuBtsein, dab "Zar und Vaterland" mit Stolz auf ihn blicken. (S. 22 f.) Derartige Visionen Romašovs erinnern an die These Arnold Gehlens, daB es "Institutionen mit großen Ansprüchen (gibt), die geradezu habituelle Gesinnungen vorschreiben: seit alters her im religiösen und militurischen... Bereich. Eine $G$ e $s$ i n $n$ u $g$ im strengen Sinne ist ein 'mitverpelichteter' Komplex von Ideen, Gefühlen, Affekten und Verhaltensbereitschaften, der von außen, vom tätigen Handeln und Unterlassen her vorgeformt sein muß, der durch konsequente Kontrolle der llotivbildung herangefuihrt und entwickelt wird und so schlieblich die Person von der Motivbildung überhaupt entlastet, also nur noch Anwendungsfälle motiviert." 1

Die Gesinnung Romašovs in seinen Tagträumen 1st mit der alltäglichen Realität des Militärdienstes jedoch nicht in Einklang zu bringen. Der militärische Alltag ist so wenig geeignet, den hohen Ansprüchen Romašvs zu genügen und seine Bege1sterungsfähigkeit zu nutzen, daß der junge offizier nicht nur unintegriert bleibt, sonderm in der Rolle des kritisierenden AuBenseiters auf immer größere Distanz zur Institution Armee geht.

3. Die AuBenseiterposition Romasovs hebt Kuprin gleich im ersten Romankapitel anhand von zwei Beispielen gegen übliche

1A. Gehlen, "Urmensch und Spätkultur" (1964), S. 72. In den von $M$. $v$. Hedel verfaßten "Konventionellen Gebräuchen beim Zweikampe" (1909) heiBt es zu den traditionell groBen Ansprúchen im militärischen Bereich: "...wir haben die unbedingte Pflicht, mit allem Ernste an uns selbst zu arbeiten und den inneren Menschen $z u$ immer größerer Reife zu bringen bis zur endichen Vollkommenheit. Keinem Stande ist das so leicht gemacht wie gerade den offizieren, wenn sie sich nur wahrhaft in den Geist einleben, der die Armee von alters her groß gemacht hat, wenn sie sich nur die Einleitung zu den ehrengerichtlichen Verordnungen vom 2. Mai 1874...als Richtschnur für ihre Handlungen und Unterlassungen nehmen." (S. 8) 
Verhaltensweisen $a b$. In einer Unterhaltung 2 wischen jungen Offizieren wird die Meinung vertreten, daB man sich im Falle einer Beleidigung durch einen Zivilisten auf der Stelle mit Revolver oder Säbel blutig rächen müsse. Einzig Romałov spricht sich "vor Verlegenheit errötend und unnötig seine Brille zurechtruckend" dafür aus, von dem Beleldiger im Duell Genugtuung zu fordern. Seine Begruindung: "Immerhin sind wir doch Leute von Kultur...". (S. 13) DaB der idealistisch gesinnte Romašov hier einem längst überlebten Ritus huldigt, bewelst die Reaktion seiner Gesprächspartner: "Ach, Sie reden Unsinn, Romał̌ov...Sie fordern Genugtuung, und er wird sagen: 'Nein... äh, äh, äh...1ch, wissen Sie, äh, äh...erkenne das Duell prinzipiell nicht an .'" (ebd.) - Kuprin erklärt somit von vornherein, daB in den neunziger Jahren selbst in offizierskreisen als Trottel gilt, wer noch an die Wirksamkelt des Duells als Ehrenrettung glaubt.

Im AnschluB an dieses Gespräch engagiert sich Romašov ein zweites Mal in unublicher We1se. Gekränkt, mit klopfendem Herzen und "fast unerwartet fur sich selbst" begegnet er einem als ungerecht empfundenen Tobsuchtsanfall des vulgären Regimentskommandeurs Šul'govič mit zaghafter Selbstverteidigung.' Diese "MiBachtung militärischer Disziplin" (S. 17) wird nicht nur mit vier Tagen Hausarrest bestraft, sondern ist fur Hauptmann Sliva AnlaB zu der Peststellung, daB Romasor in der Armee fehl am Platze ist: "Tarum zum Teufel hat man Sie in me1ne Kompanie gesteckt? Ich brauche S1e so nötig wie der Hund ein funftes Bein." (S. 18)

Romařovs quälende Einsamkeitsgefühle (S. 18) und eine unausgesetzte Konfrontation mit physischer Brutalität ${ }^{2}$ und sitt-

${ }^{1}$ Romašov wehrt sich dagegen, einen seiner soldaten schlecht ausgebildet zu haben: "Eto - tatarin, gospodin polkornik. On nicego ne ponimaet po-rusgki, 1 krome togo...". (S. 17) ${ }^{2} \mathrm{Vgl}$. Insbesondere das Kapitel XV: hier wird berichtet, daß offiziere ihre Soldaten wegen Geringfügigkeiten blutig schlagen, an den Haren über den Boden schleifen; daB infolge brutaler Strafmaßnahmen Zähne ausgeschlagen und Trommelfelle zerstört werden. 
licher Verderbtheit ${ }^{1}$ führen dazu, daB er in der Armee immer weniger elne große, ihn elnfassende Institution sieht und sich immer mehr der eigenen Person zuwendet: "... ist nicht mein Ich doch wichtiger als alle diese Begriffe von Pelicht, Ehre und Liebe?" (S. 62) Die zunehmende Ichrerhaftethe1t Romažrs wird von seinen älteren Freund Nazansk1j, der wegen Trunksucht se1nem offiziersdienet nicht nachkommen kann und dadurch ebenfalls abseits steht, unterstutzt: "Sie sind der Zar der Welt, sind ihr Stolz und inr schmuck." (S. 208) An die Stelle habitueller Gesinnung tritt bel diesen beiden offizieren der Versuch, durch eigenes Philosophieren eine akzeptable Sinngebung fur thr Leben zu finden. 2 (Vgl. insbesondere die Kap. VI und XXI) $\mathrm{Zu}$ einer endgültigen Entscheidung für oder wider sein Verble1ben in der Armee wird Romałov von auBen gedrängt: durch die Konsequenzen einer Schlägere1, in die er sich verwickeln läBt.

4. Als während eines Offizierggelages bereits "schwere, allgemeine Trunkenheit" herracht (S. 100), exponiert Romasor sich dadurch, daB er seine Kameraden durch einen wutenden Paustscilag auf den Tisch daran hindert, ihren lästerlichen Gesang 3

${ }^{1}$ Alg Romasor seine "langen, schmutzigen und langweiligen Bezlehungen" zu Raisa Peterson abbricht (S. 28), rächen sich seine Geliebte und ihr Mann (!) dadurch, dab sie ihn in anonymen Briefen diffamieren.

Romašovg Freund Nazanskif sagt über die Offiziere des Reglments: "Sie sind doch alle unbrauchbar, Gesindel, AusschuB." (S. 203) Interessant ist seine Begruindung: "...weil niemand von thnen an den Dienet glaubt...". (S. 205)

${ }^{2}$ GewiB sind die philosophischen Verouche Nazanskijs und Romaźro elner der Gründe dafü, daB der "Zweikampl" et.n schwaches Werk 1st. So heiBt es bei Gehlen in "Urmensch und Spätkultur" (1964), S. 116: "...wenn sich das Sichselbstrerstehen uber sie hinweg verbreitet, wird in den Köplen kleinerer Gelster die Selbstauffassung des Menschen sich herabbilden und... In einen Zustand geraten, an dem man ein wesentliches Interesse nicht mehr hat."

Die enthusiastischen Erklärungen Nazanskijs beruhren Romakor mitunter peinlich: "Romabov, vzvolnovannyj, potrjasennyj, prolepetal poblednerăimi gubami: 'Nazanskij, éto mecty, eto fantazi1! in (S. 209)

3"Ne pozvolju! Moldite!" schreit Romåor "pronzitel'nym, stradatel'nym golosom". "Zatem smejat'sja?..." (S. 191) 
der Totenmesse fortzusetzen. Dieser Versuch sittlicher Bevormundung wird mit Befremden aufgenommen und allgeme in als Kamplansage emplunden. ${ }^{1}$ Elner der Offiziere - Nikolaev, der in Romaḱov vor allem den Verehrer seiner Frau Šurocka habt - artikuliert den Ärger über die moralische Zurechtweisung: "Sie sind gelbst eine Schande fü das Regiment! Wagen Sie nicht, etwae zu sagen." (S. 192) N1kolaers anschlieBende nebulöse Anspielung auf das Verhältnis zu Surođka ${ }^{2}$ läBt Romašov die Kontrolle über sich verlieren und handgreiflich werden. Folgenreich für Romašor lat jedoch nicht seine Rauferel mit Nikolaev, 3 sondern eine witend hingeworfene Drohung, nachdem man die beiden Kampfhähne mit Gewalt voneinander getrennt hat: "Ich werde...es ihm noch zeigen!... Ich fordere ihn!.." (S. 192) Es erwe1st sich nun, daB der soeben in der russischen Armee eingefuhrte und allseits diskutierte 4 Duellzwang zumindest bel der älteren Generation das Sensorium in Bezug auf gewisse Floskeln geschärft hat und eine automatische Verhaltenswelse auslöst: "Der alte (!) Lech, der bis dahin am Ende des Tisches sus geschlummert hatte", wird plötzlich hellwach und sagt "nuchtern und ernst...mit ungewöhnlich gebieterischer Strenge: 'Als älterer Offizier befehle 1ch Ihnen, meine Herren, unverzüglich auseinanderzugehen." (Die Kontrahenten sind längst auseinandergegangen.) "Hören Sie, meine Herren, sofort. Ich werde dem Regimentskommandeur am

1 "Sredi obšcego mgnovennogo molčanija tol'ko odin \ej-to golos promolvil a nedoumeniem: - On p'jan? No totça...vae zagudelo, zastonalo, vokotilo s mesta 1 svernulos' $v$ kakoj-to pestryj, dvizużijaja, kriklivyj klubok." (ebd.)

$2^{n} v_{y}-1$ raznye Nazangkie!...n (ebd.): auch Nazanskif hatte engere Beziehungen zu Surocka.

${ }^{3}$ Man bedenke in diesem Zusammenhang die Bemerkung $M$. $v$. Wedels in den "Konventionellen( $n)$ Gebräuchen beim Zweikampen (1909): "Die s c h ör $\rho$ s t e B e l e 1 d 1 g ung $i s$ t d $1 e$

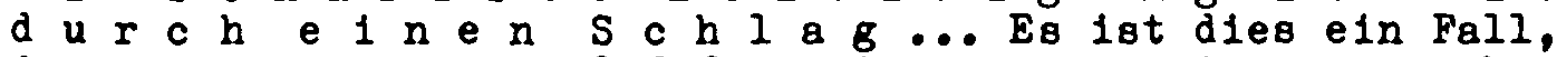
der $z w 1$ s c h e $n$ $m e n d u r f t e$, und der stets Dienstentlsssung zur Folge haben wird." (S. 7)

${ }^{4} \mathrm{Vgl}_{\text {. S. }}$ 82: "Im Spe1sesaal murde das Gespräch nun lauter und gleichzeltig fur alle Anwesenden interessanter. Man sprach uber offiziersduelle, die soeben erlaubt worden waren, und die Meinungen gingen auseinander." 
Morgen über alles Bericht erstatten." Das hiermit angekündigte offizielle Nachspiel des Streites zwischen Romašor und Nikolaev - eine ehrengerichtliche Untersuchung also - ist n 1 e m a $\mathrm{n} d \mathrm{e} m$ der Anwesenden eine Selbstrerständlichkeit oder gar ein Bedürnis: "...alle gingen verwirrt und niedergedrückt auseinander und vermieden es, einander anzusehen." (S. 193)

5. Die ehrengerichtliche Untersuchung des Streitfalles stellt sich dem um Aufrichtigkeit bemihten Romasov als Farce dar. (S. 194 19.) Während Romašov dem aus sieben Offizieren bestehenden Ehrengericht "ehrlich und detailliert" seinen ZusammenstoB mit Nikolaev schildert, finden die offiziere entweder naiven Gefallen an ihrer richterlichen Funktion und spielen "die Rolle eines Richters" (Migunor), "die Rolle eines strengen und unbeugsamen Verteidigers der Offiziersehre" (Lech) - oder sie miBbrauchen die Untersuchung, un ihren persönlichen Haß gegen Romažor zu befriedigen (Osadłif und Peterson). Romašor hat den Eindruck, daB das Ehrengericht seine Aufgabe "unerfahren, inkompetent und unendlich nachlässig" wahmimmt. Die Verhandlungergebnisse, die geheimzuhalten gewesen wären, werden Stadtgospräch. Uber den Ausgang des von allen erwarteten Duells zwischen Romašor und Nikolaev werden Wetten abeschlossen. ${ }^{1}$ Vor e1nem derartigen Hintergrund wird der Spruch dea Ehrengerichts, der ein Duell zwigchen den beiden Kontrahenten "als einziges Mittel zur Wiederherstellung beleldigter Ehre und oppizierswïde" erachtet, eine Verhöhnung.

6. Romałov und Nikolaev haben infolge des ehrengerichtlichen Spruchs nun die Wahl, sich zu schlagen oder den Dienst zu quittieren. Schon bevor das Duell für beide zum akuten Problem wird, hat Kuprin ausreichend deutlich werden lasen, dab dieser abgestorbenen Institution nicht kraft Gesetzes neues Loben

${ }^{1}$ Das ehrengerichtlich verordnete Duell, von dem Šurocka in Kap. IV erzählt, nimmt sich wie ein sensationelles Spektakel aus: alle Offiziere des Regiments kommen als Schaulustige, ebenfalls einige Damen des Regiments, "und irgendwo in den Sträuchern steckte sogar ein Fotograf." (S. 37) 
eingehaucht werden kann. Man erinnere $81 \mathrm{ch}$ daran, daB bei der Einsetzung der Ehrengerichte im preuBischen Heer Rucksicht auf "die eigenthümlichen Verhältnisse des 0ffizierstandes" ${ }^{1}$ genommen wurde, d. h. auf einen ganz besonders empeindlichen Ebrbegriff. Kuprin stellt den offizierstand jedoch als brutal und ehrlos dar. ${ }^{2}$ Die $D 18 \mathrm{k}$ u 81 o $\mathrm{n}$ un das Duell in Offizierskreisen beweist, ${ }^{3}$ dab der zweikampl kein bindendes kulturelles Verhaltensmuster mehr sein kann. Der Versuch der Neubelebung der Institutiom "Duell" zeitigt das gleiche Resultat wie ihr beginnender Verfall in "Krieg und Frieden": "...menn die Daseinsbedingungen und folglich auch die Verhaltensweisen einer Gruppe verunsichert werden, entstehen aus ihr heraus oder von auBen Beobachter, die das Bedüenis haben, zu "verstehen" und kritisierend oder reformideologisch tätig zu werden." 4 so diskutieren hier die offiziere - bel Tolstof grübelt Pierre Bezuchor.

Fur Romakov, der in einer verrohenden Offizlersgesellachaft als elnziger wirkliches Ehrgefuhl zeigt, ist es spontan selbstverständlich, dem Spruch des Ehrengerichtes zu folgen und sich mit Nikolaer zu duelilerens "Er hat mich geschlagen... ins Gesicht!" (S. 201) Da - we bere1ts erwähnt - Romağors hohe Anspruche von auBen jedoch keine stützung erfabren, kann sein Freund Nazanskif ihn leicht umbtimmen. Dem Argument, ein Duell mit todlicher Ausgang se1 Mord, ein durch Duellverzicht bedingtes Ausscheiden aus der Armee hingegen kein Verlust, da Romaśov keiner "Interessanten, guten, nützlichen" Sache diene (S. 203), beugt sich der desillusionierte offizier. Mit seinem

${ }^{1} V_{\text {gl }}$. A. V. Boguslarski, "Die Ehre und das Duell" (1896), S. 60. 2 Beispielsweise kann Romałor den kaukasischen 0ffizier BekAgamalov nur mit Mühe davon abhalten, seinen Säbel über einer Frau niedersausen zu lassen. (S. 185)

${ }^{3}$ ArČakprskif hält das Duell fur "Unsinn", Bobetinskif verlangt "Blut", OsadXij vertritt die Ansicht, ein Duell musse unbedingt einen ernsten Ausgang nehmen, sonst sel es "absurd". Michin kann sich nicht artikulieren: "Manchmal ist ein Dueil nütalich, das ist gewiB....Aber manchmal, wissen Sie...ist es...vielleicht besteht die höhere Ehre darin, das man...das ist...man sollte unbedingt verzeihen." (S. 84 f.)

${ }^{4}$. Gehlen, "Urmensch und Spëtkultur" (1964), S. 67. 
EntschluB "Ich gehe in die Reserve" (S. 210) ist er gewillt, einen Bruch zu vollziehen, den alle vorhergehenden Erlebnisse und therlegungen vorbereitet haben.

7. DaB Romašova Schicksal sich letzlich auf eine ganz unerwartete Weise verhängnisvoll gestaltet, hat seine Ursache in der dubiosen Rolle, die das Duell als eine an sich funktionslose und nur küstlich bedeutsam gemachte Institution ${ }^{1}$ in der offiziersgesellschaft spielt. Nikolaevs fanatisch ehrgeizige Frau Surokka, die im Duell etwas "Herolsches, Starkes" sieht, glaubt, es sei der Karriere ihres Mannes dienlich, sich "mit würde" dem Schub des Gegners zu stellen. Sie nutzt die Verehrung, die Romašov ihr entgegenbringt, um thn zu einem Duell zu überreden, dem ein eigens von ihr ausgedachter Plan zugrunde liegt. RomaSov kann dazu bewogen werden, seinen Part in einer angeblichen Duellfarce $z u$ spielen - die beiden Kontrahenten sollen allen Formalitäten des Zweikampfes genügen, aber aneinander vorbeischieBen. In pathetischen - und dadurch unklaren - Worten läbt Surotka das Einverständnis ihres Mannes durchblicken: "Nein, fragen sie mich nicht nach meinem Mann, er weiB Bescheid. Ich habe alles, alles, alles getan." (S. 215 f.)

Aus dem Rapport uber das Duell der beiden Offiziere ${ }^{2}$ geht hervor, daß Surozka ihre Abmachungen nur mit Romašov getroflen hat und dieser somit einem Mordplan zum Opfer fällt. Der erste wohlgezielte Schuß seines Gegners tötet ihn.

8. Bei Cechor wird ein Duell, das nicht mehr als Ehrenzweikampe empfunden wird, nur durch einen glücklichen Zufall - das Ein-

${ }^{1}$ Der Duellzwang wird von den Offizieren als MaBnahme zur Hebung der allgemeinen Moral angesehen. Dies geht aus einer Bemerkung Osadijs hervor, als er sich gegen Duelle mit zu leichten Bedingungen ausspricht: "Ein solches Duell ist Unsinn, meine Herren. Und es bewirkt keinerlei Besserung in unserer Gesellschaft."

2 Wie ebenfalls aus dem Rapport hervorgeht, handelt es alch um ein Pistolenduell mit Vorricken, das in aller Prihe in einem Wäldchen dreielnhalb Werst von der Stadt entfernt statteindet. (Kap. XXIII) 
greifen des Diakons - nicht zum Mordinstrument. Be1 Kuprin verwirklicht das Duell einen Mordplan, der nicht erahnt und von niemandem aufgedeckt wird. Kuprin zeigt, wie ein absolut sinnentlehrter und entbehrlicher, aber zur Pflicht gemachter Duellritus den bösesten Instinkten im Menschen dienstbar gemacht werden kann.

Indirekt, ex negativo, ist der Kuprinsche Roman ein Beweis für die These Arnold Gehlens, daB intakte Institutionen "stets der Schutz des Menschen gegen seine eigene Natur" sind. "Kuprins direktes Anliegen ist sicher Kritik an den Verhältnissen in der russischen Armee der neunziger Jahre im Allgemeinen - und ein Appell zur Abschaffung des Duellzwangs im Besonderen.

'A. Gehlen, "Urmensch und Spätkultur" (1964), S. 116. 
M. P. Arcybašev, "Sanin"

But now I'm going to be 1mmoral; now

I mean to show things really as they are, Not as they ought to be.

Byron, "Don Juan"

1. Insolern als Sanin, der Held von Arcybasevs 1907 erschienenen gleichnamigen Roman sich in stolzer und selbstgewählter Einsamke1t für ein Leben auBerhalb der Gesellschaft entscheldet, zeigt er noch blasse Konturen Byronscher Helden wie Childe Harold, dem Glaour oder dem Korsaren - ohne durch deren düstere GröBe und Leidenschaftlichke1t zu faszinieren. Sanin lehrt seine exzentrische, primitive Philosophie von der absoluten Priorität der naturlichen Bedurfnisse des Menschen ${ }^{1}$ in ewig lächelnder Gleichmiligke1t. ${ }^{2}$ Seine morbide gesellschaftliche Umgebung ver-

${ }^{1}$ A. Stender-Petersen sagt zum "Bild des jenseits von Gut und Böse stehenden Amoralisten": "Das Motiv entsprach recht gut gewissen Ideen und Stimmungen, die sich während der allgemeinen Desillusion nach der miBlungenen Revolution in der russischen Intelligenz geltend machten. Die Idee der freien Liebe und der Befriedigung der ungezügelten Begier trat in diesem Roman nackt zu Tage...": "Geschichte der russischen Literatur", Bd. 2 (1957), S. 495.

Die zeitgenössische Kritik sah den Roman in der Tat als Reaktion auf die Revolution von 1905. Vgl. M. Schneidewin: Die angebliche tberwindung des revolutionären Geistes durch Arzybaschevs Roman "Ssanin". In: PreuBische Jahrbiicher 134 (1908), S. 532 1.: "Im August 1908 las 1 ch kurz hintereinander von 2 we 1 Seiten, $d a b$ es ein $R \circ m$ a $n$ se1, der die russische Revolutios niedergeschlagen und die russische Gesellschaft ungewandelt habe, Indem derselben durch ihn statt des revolutionären Geistes ein ganz anderer, der erotische, suggeriert se1." (Schneidewin bezleht sich auf einen Aufsatz von Werner Daya "1m Augustheft der Slagnus Hirschfeldschen Zeitschrift" und auf die Vorbemerkung des tbersetzers André V1llard zur ersten deutschen Ausgabe des "Sanin".)

Vgl. auch Paul Barchan: Sanin und die erotische Bewegung. In: Die neue Rundschau 1 (1909), S. 123 - 128.

2 néta vnimatel'naja ulybka...éta ulybka, sama po sebe krasivaja 1 simpatidnaja..."; "Sanin...ulybalsja 1 ulybka u nego byla vnimatel'naja 1 laskovaja...", etc. Sanin spricht vorzugsweise "laskovo, nežno, dobrodušno, radostno, veselo". VGl. S. 4, 12 und Rap. XIX und XX in M. Arcybašev, "Sanin" (1969), Rarity Reprints Nr. 10, Bradda Books. Die Orthographie ist den heutigen Gepplogenhe1ten angepaBt. 
mag er zu verwirren, nicht zu schockieren. Er verläBt sie schlieblich - nicht wie die Byronschen Helden in dem BewuBtsein von Sundhaftigkeit und Schuld - sondern aus purem tiberdruB.

2. Der alttestamentliche Spruch vom Menschen als an sich guten Geschöpf Gottes, 1 den Arcybašev seinem Roman vorangestellt hat, bereitet vor auf ein Menschenbild, das ohne Institutionen auskommt. Die Charakterisierung des Helden zu Beginn des ersten Kapitels entspricht dieser Erwartung: "Jene wichtige Zeit im Leben, da sich unter dem EinfluB erster Kontakte mit den Menschen und mit der Natur der Charakter formt, verlebte viadimir Sanin auBerhalb der Familie. Niemand achtete auf ihn, niemandes Hand drickte ihn nieder, und das Wesen diesejs Menschen entwikkelte sich frei und auf seine Art wie ein Baum im Felde." (S. 3) Mit der Rückkehr Sanins in das "alte, herrschaftliche" Haus seiner Familie (S. 6) beginnt der Roman. Arcybašev konzipiert ihn als die Begegnung eines freien Menschen mit einer Welt von vorurteilen.

3. Auf unverrückbare Prinzipien stöBt Sanin in der älteren Generation: bei seiner Mutter, Mar'ja Ivanovna. Fur sie ist der Mensch nicht in erster Inie ein durch gewisse natürliche EIgenarten charakterisiertes Individuum, sondern Angehöriger einer bestimmten sozialen Schicht, die seine Verhaltensweisen festlegt und ihn dadurch verstänlich werden läBt. Für sie ist "jeder Student" Revolutionär, "jeder Beamte" Bourgeois, "jeder Künstler" Freidenker und "jeder offizier" von ubertrieben edler Gesinnung. (S. 18) Die Gedanken Mar'ja Iranovnas zeigen ein Bedurenis nach intakten Institutionen im Sinne Arnold Gehlens, Institutionen, die "den Individuen gegenüber etwas wie eine Selbstmacht gewinnen, so dab man das Verhalten des einzelnen in der Regel ziemlich sicher voraussagen kann, wenn man seine Stellung im System der Gesellschaft kennt...".2

\footnotetext{
"Tol'ko èto našel ja, čto Bog sozdal čeloveka pravym, a Ifudi pustilis' vo mogie pomysli. 7,29: Ekkleziast."

2A. Gehlen, "Anthropologische Forschung" (1961), S. 71.
} 
Mar'Ja Ivanornas Erwartungen in Bezug auf Ihren Sohn werden enttäuscht. Sanin ist nicht bereit, eine seinem Stande angemessene Position in der Gesellachaft $z u$ bekleiden. 1 Seine Weigerung sich einzuordnen, läBt lhn der Mutter rätselhaft erscheinen. Sie we1B nicht, "wann er scherzt und wann er ernst redet, was er denkt und was er fühlt...". (S. 17)

Die jüngere Generation in Sanins Heimatstadt iat in ihren Wertvorstellungen unsicher, sie ist unausgefullt und gelangweilt. 2 Sie sucht nach einem Vorbild und drängt sich um den helmkehrenden Sanin als eine Schar wibbegieriger Jünger. Ivanov schaut Sanin bei ihrer ersten Begegnung "mit Neuglerde" an (. 41); Jurif SvarožiC lst es angenehm, In Sanín auf elnen rätelhaften Menschen zu stoßen, den er nicht gleich zu beurteilen vermag (S. 90); Solovejčik gerät in größte Verwirrung, als er Sanin vorgestellt wird (S. 170), und für die Karsavina bringt Saning Gegenwart etwas "Neues, Interessantes und Aufregendes" mit alch (S. 275). Der Ruf eines unabhäng1g denkenden Sonderlings geht Sanin überall voran. ${ }^{3}$ Wie sieht die Lehre Sanins nun im elnzelnen aus, und welche Konsequenzen hat sie für seine Umgebung?

4. Die Frage nach dem Sinn dog Lebeng weiB Sanin eindeutig zu beantworten: "...1ch lebe und möchte, daB das Loben für mich keine Qual ist...Deshalb muB man vor allem seine natürlichen Bedürfnisge befriedigen...Das Bedürfnis ist alles: wenn die Bedurenisse im Menschen absterben, stirbt auch sein Leben ab..." . (S. 88) Dieser Kernthese lugt Sanin erläuternd hinzu, daB die Bedurenisse des Menschen mit oiner kindlichen Ehrlichkeit zu

${ }^{1}$ Auf die Frage der Mutter, wie er sein Leben gestalten möchte, antwortet Sanin: "Kak nibud'!" (S. 6)

2 Uber Langeweile klagen vor allem Novikov und Jurij Svarožić. $\mathrm{Vgl}$. Kap. II und IX.

3nIvanor wubte schon einiges übef Sanin, und was er von ian gehört hatte, gefiel ihm." (S. 41) - "Ich habe schon so viel von Ihnen gehört...", sagt Solovejčik. (S. 170) - "S1e...hörte dauernd von ihm als von einem durch und durch eigenwilligen Menschen reden..." - heibt es von der Karsavina. (S. 275) 
befrledigen seien, "denn Kinder unterscheiden nicht Gut und Böse", 1 und daB der Mensch bel der Befriedigung seiner Bedürfnisse auf niemanden Rücksicht zu nehmen habe als auf sich selbst. ${ }^{2}$ Durch diese radikal asoziale und amoralische, einzig auf $n$ a $t$ i $r l i c h$ e Bedurenisse ${ }^{3}$ abgestimmte Lobensphilosophie wird Sanin für seine gesellgchaftliche Umgebung die personffizierte MiBachtung Ihrer Institutionen und Tabus, ihrer tradierten Ideale, auf die "die Welt lange ihr Gluck und thre Hoffnungen aufgebaut hat" (S. 149), und Ihrer revolutionären Ideen. Sanin macht keinen Hehl aus dem libidinösen Verhältnis zu seiner Schwester Lida. ${ }^{4}$ Er beleidigt seine Mutter durch unübliche Ansichten zum Liebes- und Eheproblem ${ }^{5}$ und fuihlt sich durch seine Liebe zur Karsavina zu nichts verpflichtet. Sanin verspottet Novikov, der seine romantigche Liebe zu Lida Sanina nicht in erster Linie als physisches Verlangen begreift und der sich für seine pollt1schen Ideale, für seine Vorstellungen von einer Konstitution inhaftieren lassen wüde. (Kap. II) Auf einer Versammlung revolutionär gesinnter Altersgenossen zeigt Sanin demonstrativ, daB er alch gelangweilt fuhlt. (Kap. XXV) Er emplindet die kirchlichen Riten am Sterbebett Semenors als störend (Kap. $X$ ) und beschränkt sich in der Grabrede fur Jurff

${ }^{1}$ An anderer Stelle findet olch eine gröbere Formulierung dieses Standpunktes: "...meiner Ansicht nach lebt nur ein Betrunkener wie man leben solite...ein Betrunkener tut nur das, was er tun möchte...". (S. 47)

2 In elnem Gespräch mit Iranor und Rjazancer bemerkt Sanin, daB thn "andere, in der Tat, Uberhaupt nichta" angehen. (ebd.) Seine Schwester Lida versucht Sanin davon zu überzeugen, daB sie sich um thres eigenen Lebensglucks willen un die Meinung anderer nicht kummern darf. (Kap. XIX)

${ }^{3}$ Entsprechend bezeichnen die Personen des Romans sich gegense1tig als "zver', Zivotnoe, skotina, samec, samka". Vgl. S. 7, $25,47,121,132,149,187,191,195$ 1., 200.

${ }^{4}$ Lida lat durch die Annäherungoversuche ihres Bruders verwirrt und ron Gewissensbissen geplagt. $\nabla_{g l}$. S. 7, 17, 53, 143.

5tber Lida sagt Sanin: "Sie hat einen geliebt, ole hat einen anderen gellebt, morgen wird sie einen dritten lieben...Nun, und Gott gel mit ihr." - Auf Saning Frage "Haben Sie etwa in 1hrem Leben nur einen geliebt?" antwortet Mar'ja Iranoma: "So opricht man nicht mit seiner Mutter!" (S. 190) 
Srarožį auf die zynische Feststellung, daß die Welt nun un einen Narren ärmer sei. (S. 302) Sanin entpoetisiert und zerstört die Formen des Zusammenlebens der Menschen, die auf ihn hören und wird - so will es die Ideologie Arcybalevs - doch zu inrem Leitbild. Dies zeigt sich in besonderer Weise im Zusammenhang mit dem Duell, dem Sanin sich stellen soll.

5. Von der innerfiktionalen Logik her könnte die Duellerage nicht zum Problem werden - Ehre und Ehrenkränkung sind in einem primär mit dem Geschlechtstrieb befabten Personenkreis belang10s. Arcybašer problematisiert das Duell dennoch, weil sich hier eine Möglichkeit zu besonders polemischer Darstellung und Rechtfertigung der institutionenfeindlichen Position sanins ergibt.

Sanin hat den Verfuhrer seiner Schwester, den offizier Zarudin, des Hauses verwiesen und erwartet als Reaktion eine Forderung zum Duell. Sanins Warten könnte bedeuten, daB das Duell innerfiktional als üblich emplunden wird. Dem widerspricht das Benehmen der Sekundanten, die die Forderung überbringen. Sie erheben sich "unentschlossen", als Sanin auf sie zugeht, und wissen "offensichtlich nicht, wie sie sich weiter verhalten" sollen. von Deitz ist rerwirrt und traurig, "wegen dieser Sache einen interessanten Bekannten zu verlieren". (S. 202 11.) Sanin entzieht sich der Forderung - wie jeder anderen normierten Verhaltensweise - mit spöttischer Souveränität ${ }^{1}$ und mit der prosaischen Begründung, daB er keine lust habe, sich an einem derart gefährlichen Unternehmen $z u$ beteiligen. "Ersiens möchte ich Zarudin nicht töten, und zweitens möchte ich noch viel weniger selbst sterben... Ich möchte eben nicht und damit basta!" (S. 204) Sanins Freund Ivanov billigt diese Haltung. Tanarov, offizier und Sekundant Zarudins, findet die Weigerung Sanins

${ }^{1}$ Sanin nennt die Sekundanten Zarudins in Gedanken Idioten und Dummköpfe. Er zeigt ostentativ sein Desinteresse an ihrer Mission und entläßt sie mit einer weiteren Beleidigung Zarudins: "Denken Sie, was Sie wollen und sagen Sie Zarudin, er sei ein Dummkopf...". (S. 202 11.) 
verächtlich," doch nicht unmöglich. Seine Bemerkung "Das ist thre Sache..." (S. 204) macht das Duell zur Ermessensfrage. Unter diesen Umständen muß der weitere Verlauf der Ereignisse, auf den es Arcybašev ankommt, unglaubwürdig wirken.

6. Zarudin versucht, ein Duell zu e $r z$ w $\mathrm{n} g \mathrm{e} n$, indem er Sanin öffentlich zu einer Schlägere1 provoziert. DaB Sanin einen Zweikampl ablehnt und seinen Angreifer durch einen Faustschlag niederstreckt, demütigt 2 arudin und treibt ihn zum Selbstmord. Zarudin sieht sich als verzweifeltes Opfer seiner Lebensumstände. Ohne den Sittenkodex der Armee hätte er Sanin weder zum Duell gefordert noch versucht, ein Duell zu provozleren. Ohne Duellzwang wäre ein Fausthieb nicht schmählicher als eine Kugel, und ohne Ehrengericht wïrde er nicht aus der Armee verstoßen und um seine Existenz gebracht. Zarudin gesteht sich selbst ein, dab Reputation inm nichts bedeutet. ${ }^{2}$ Seine rachsilchtigen Vostellungen von Genugtuung für die Bele1digung Sanins haben mit den Regeln des Zweikamples nichts geme1n: "Den Revolver nehmen, sich auf thn werfen und ibn töten ...eine Kugel nach der anderen abgeben. Und inm mit den FuBen ins Gesicht treten, wenn er umfältt...direkt ins Gesicht, in die Zähne, in die Augen!..." (S. 220)

1Tanaror glaubt, dab nur ein opfizier "tapfer und edelmutig" genug sein kann, um sich zu schlagen. (S. 204)

Die Unterhaltung zwiachen Sanin und Ivanor ist ein uberzeugender Bewe1s dafur, daB das Duell in der dargestellten Gesellschaft einer ernsthaften Diskussion nicht für würdig befunden wird: " 'So', sagte Iranor, 'du wirst dich also schlagen? Schlag dich nur, 1ch werde dein Sekundant sein... sollen sie slch doch gegenseltig die Nase abschieBen.' 'Warum...Die Nase ist ein edler Körperteil... Ich werde mich nicht ochlagen!', entgegnete Sanin lachend. 'Auch gut', nickte Iranov: 'Tarum soll man sich schlagen, es gehört sich nicht, sich zu schlagen!'" (S. 207)

Ildas Bedauern darüber, daB ihr Bruder sich nicht schlägt, fällt fur die Prage nach der Innerfiktionalen Bedeutung des Duells nicht ins Gewicht: sie hat sich ihr Weltbild hauptsächlich durch die Lektüre melodramatischer Bücher geformt. Vgl. S. 4 .

2 "Reputac1ja? Kakoe mne delo do reputacill Cto znalit reputac1ja, kogda nado umirat'?" (S. 221) 
Zarudin erinnert sich daran, dab elne frühere blutige Schlägerel mit elnem Regimentskameraden versöhnlich endete und fúr seine Offizierskarriere ohne Polgen blieb. Arcybašer läbt ihn die Frage, wieso seine Lage nach der Schlägerel mit Sanin dann aussichtslos sein kann, nicht zu Ende denken: "Na étot polnyj bezrychodnoj toski ropros ne bylo otveta $\checkmark$ ume Zarudina." (S. 219) Es zeigt sich hier, daB der Konflikt um der Ideologie Arcybaševs willen konstruiert 1st. Zarudin kommt in seinen tberlegungen zu folgendem Faz1t: "War 1ch denn 1rgendwann elnmal Prei? Ich aterbe doch jetzt, weil mein Leben niemals Prei, niemals mein eigenes Leben war...". (S. 220)

Auch Jurif Svarožle und Ivanov führen den Selbstmord Zarudins darauf zurück, dab er "in einem gewissen...dummen Milieu" lebte, dem er sich "unterwaren. (S. 232) Sanin sieht in Zarudin einen Sklaven, der nach dem "Gesetz seines Lebeng" gehandelt hat. Die Argumentations Sanins liefert überdies den besten Bewe1s dafur, wie gänzlich unverstanden die Institution "Duell" in der Gesellschaft des Jahres 1907 ist: "Die Leute lernen, andere zu töten und ihren elgenen Körper zu pllegen und verstehen uberhaupt nicht, was sie tun und wozu sie es tun... Das sind Verruckte, Idioten!n

Sanin sieht sein Handeln somit als gerechtfertigt an: "Worin besteht denn meine Schuld! DaB $1 \mathrm{ch}$ mich vor solch einem Verruckten geschutzt habe?" (S. 225)

Zaruding Selbstmord macht inn in den Augen seiner Altersgenossen durchaus nicht zum bemitleidenswerten Mëtyrer. In Gogentell: das Duell wird nachdrücklich als "Dummbelt" verurteilt und Zarudin ein "Narr" genannt. (S. 232) Saning unzeremonielles Verhalten, seine "Kraft und Entschlossenhelt" wirken imponierend. 1 Zarudins Schicksal soll indirekt, aber nachdricklich den Wert der Saningchen Lobensphllosophie bestätigen: das Leben meistert nur, wer entsprechend seinen eigenen Bedurfnissen und wunschen handelt. Wer sich in seinen Wertvorstellungen

${ }^{1}$ Rjazancers Argumentation bleibt unklar. Jurif Svarožič und die Karsartna machen sich aber daruber lustig, dab der grobe, sinnliche Rjazancer das Duell für "kultiviert" hält. (S. 233) 
und seinem Handeln von einer Institution leiten läßt, muB untergehen.

7. Arcybarevs Roman ist die Apologie einer Gesellschaft, die sich ausschlieBlich von Instinkten leiten läBt. Das Duell in seinem Wesen als Ehrenzweikampl bereits vollkommen auBerhalb der Vorstellungawelt der handelnden Personen und nur noch aufgrund einer Militärgesetzgebung existent - funktioniert als abschreckendes Beispiel für eine Institution. Die Figuren sind allegoriache Piguren: Mar'ja Ivanovna verkörpert ein von Institutionen geprägtes Denken. Sie 1st dumm, ihre Augen zeigen einen "stumpeen und tierischen" Ausdruck. " Zarudin zahlt mit dem Leben dafur, daß er sich einer Institution unterordnet. Der schwärmerische Jurij Svarožiz, der das Duell zwar lür eine "Dummheit" hält (S. 233), die amoralische Position Sanins letztlich aber doch verurteilt ${ }^{2}$ und $z u$ dem SchluB kommt, daB die Menschen sich nicht ihren Bedürnissen unterordnen sollen, 3 endet wie Zarudin durch Selbstmord. Desgleichen Solovejčik, der ein Leben ohne Ideale unerträglich findet. ${ }^{4}$ Zarudins Sekundanten (von Deitz, Tanarov) und die idealistische revolutionäre Jugend der Stadt (Šarfov, Solovejzik, Gozienko, die Dubova) aind physisch, charakterlich oder intellektuell kuimmerliche Gestalten. Lida Sanina, die Karsavina und Novikov spielen mit dem Gedanken an Selbstmord, söhnen sich aber mit dem Leben aus, indem sie ihre "Vorurtelle" liberwinden und ihre Vorstellungen von Llebe und Ehe der Priorität des Geschlechtstriebes unterordnen. ${ }^{5}$ Sanin, des Lebens im engen Familien-

${ }^{1} \mathrm{Vgl}_{\text {I }}$. S. 191. Sanin sagt ron 1hr: "Vot Zirotnoe!" (ebd.) "Jurij uze jasno 1 tverdo znal, tto Sanin durnoj 1 pollyj Celovek." (S. 99)

3"...ljudi ne bezsmyslennye zveri 1 dolzny napravljat' svol zelanija $k$ dobru 1 ne davat' im vlast' nad soboju...". (S. 106 1.)

${ }^{4}$ Solorejčik beugt sich zwar den Ansichten Sanins, kann sie aber nicht verkraften. Vgl. S. 232 f.

${ }^{5} V_{g}$. Xap. XIX, XX, XI. - Auch Jurija Schwester Ljalja arrangiert aich mit Rjazancev, weil sie die Frage nach den moralischen Vorstellungen ihres Verlobten ausspart. (Kap. XV) 
und Freundeskreis bald liberdrüssig, verläBt seine Heimatstadt zum Zeichen dafur, daß das höchste Glück in der Negieruns aller herkömmlichen Bindungen liegt, und geht lächelnd, mi:

"weitausholenden, kräftigen" Schritten einer aufgehenden Sonnie entgegen. (S. 309)

Die Herabbildung der Selbstaufassung des Menschen, dis nac:h Arnold Gehlen "in den Köplen kleinerer Gelster" Hand in land geht mit dem Abbau von Institutionen," hat in Arcybarers "Sanin" einen Tlefpunkt erreicht.

1A. Gehlen, "Urmensch und Spätkultur" (1964), S. $116-V_{3}$. das ausfihrliche 21 tat in der Behandlung von Kuprins "Zveikampe" 
I SCHLUSSBETRACHTUNG. BESONDERHEITEN DES RUSSISCHEN LITERARISCHEN DUELLS - AUCH IM VERGLEICH ZUM DUELI IN ANDEREN LITERATUREN

Die hier vorgenommenen Werkanalysen lassen sich mit einer durchaus interessanten Feststellung beschlieBen. Bel aller Verschiedenhelt des literarischen Kontextes findet sich nämlich ein wesentliches gemeinsames Charakteristikum: keines der hier vorliegenden Duelle wird regelgerecht durchgefochten. Mehr oder weniger handelt es sich in jedem einzelnen Fall um ein Abweichen von der Vorschrift. Der erwartete Kausalnexus zwischen Gütigkeitsgrad der Institution "Duell" und Duellritus besteht nicht. Für Silvio, Onegin, Švabrin und Pecorin bedarf es bei der Forderung zum Duell im Falle einer Ehrenkränkung keiner tberlegung durchaus unkonventionell und unehrenhaft ist indes ihr Verhalten im Zweikampe. Bazarov und Stavrogin, die den Ehrenstandpunkt nicht mehr ernst nehmen, inszenieren ein unerwartet frivoles Spektakel. Pierre Bezuchov vollzieht mehr oder weniger besinnungslos einen Ritus, $z$ dem er überhaupt kein Verhältnis hat. Von Koren sucht mit einem sinnentleerten Duellritus seine Mordabsichten zu tarnen, und Romašov wird das Opfer eines scheinbar regelgerechten, in Wirklichkeit zum Mordinstrument pervertierten Ritus. Ob also die Institution "Duell" von absoluter Gultigkeit ist (Puskin, Lermontov), ob sie in ihrer Guiltigkeit angefochten wird und verfällt (Turgenev, Tolstoj, Dostoevskij) oder ob ihr kraft Gesetzes neue Gultigkeit verschrieben ist (Kuprin, Arcybašev): die kodifizierten Regeln des hergebrachten Ehrenzweikamples werden in einem oder mehreren Punkten verletzt. Dies wird angesichts der Grausamkeit der Duelle im "SchuB" und im "Held unserer Zeit" sowle angesichts der Mordabsichten bel Kuprin und Cechov gewiB besonders offensichtlich, doch läBt sich ganz allgemein leststellen, daB es den standesgemäßen, kompetenten, verantwortungsbewußten und rechtzeitig um Versöhnung bemuhten Sekundanten der Duellkodizes in der untersuchten Literatur nicht gibt. Es sei noch einmal zitiert, was Gustav Hergsell 
in seinem "Duell-Codex" betont: "Es sind nicht die Kugeln und die Degenspitzen, welche tödten, es sind die Secundanten.". 36) Die von Croabbon konstatierte gefährliche Regellosigkelt der Zweikämple des russischen Lebens findet sich in der Literatur wieder. Wie Robert Baldick zum Duelltod Púkins sagt: "Most of the duels fought in France in the nineteenth century by men of letters were innocuous affairs in comparison...", so ist ihm von den zahlreichen Duellen der Weltilteratur besonders "Pechorin's horrifying duel" erwähnenswert." In seiner knappen Darstellung des Duells in der Literatur weist Baldick nach, daB das Duell von der Mehrheit der Schriftsteller lächerlich gemacht wurde. Er geht ein auf Shakespeare, Volture, La Fontaine, Steele, Sheridan, Dr. Johnson, Rousseau, Tom Moore, Pǔkin, Sainte-Beuve, George Moore, Joséphin Péladan, Maupassant, Lermontor.

In der russischen Literatur des 19. Jahrhunderts wird das Duell nicht überwiegend lächerlich gemacht. Diese Literatur ist vielmehr großenteils Anklage gegen einen unmenschlich gehandhabten R1tus. Wenn Arthur Schnitzler den Helden seiner Kurzgeschichte "Der Sekundant" sagen läBt: "Im Zweikampl hat doch immer das eigene Belieben mitzureden gehabt, auch dort, wo es sich scheinbar um einen Zwang, um eine Konvention oder um Snobismus handelte...", so ist fur die russischen literarischen Duelle festzustellen, das das eigene Belieben hier $z u s$ e $r$ mitzureden hatte. In allen Phasen der Güligkeit der Institution "Duell" - von Puškin b1s Arcybaßer - wird der von den Du-

1Vgl. R. Baldick, "The Duel" (1965), Kap. 12: "The Pen and the Sword ${ }^{n}$.

Auch die eingangs erwähnte und hier nicht behandelte Erzählungoliteratur mit dem Duell als selbstverständichen, unproblematischen Requisit (s.S. 14 dieser Arbeit) zeigt Ausnahmeduelle: In der Erzählung Bestužev-Marlinskijs "Vecer na bivuake" 2. B. he1Bt es lapidar "Wir schossen uns auf funf Schritte...". In der Erzählung "Ispytanie" des gleichen Autors vereinbaren lustig scherzende Sekundanten ein Duell auf sochs Schritt Distanz: "Von einer größeren Distanz will der Fúrst erst gar nichts hören...". Diese unseriöse Duellpraxis geht einher mit unseriösen Ansichten zum Ehrenzweikampl: "Es dreht sich doch immer um Schauspielerinnen, Karten, Pferde oder eine Portion Eis." Vgl. A. A. Bestuzev-Marlinskif, "SoC. $v 2$ tt.", Bd. 2 (1958), S. 51 und 222. 
ellkodizes traditionellerwelse eng abgesteckte Handlungsrahmen zu einem weiten Feld, in dem man sich je nach Charakter bewegt. In den untersuchten Werken kann das Verhalten im Duell als MaBstab für den Charakter genommen werden: wie sich einer duelliert, so ist er. Dieses Faktum gibt der russischen Duelliteratur lare spezifische Prägung.

An der vorranglgen Rolle des Pergönlichen, Privaten liegt es wohl auch, dab die tragischen Aspekte der Institution "Duell" in der russischen Iiteratur nicht zum Tragen kommen. Robert Bald1ck erwähnt Maupassants Kurzgeschichte "Un láchen." Hier erschiebt sich ein junger Mann am Vorabend des Duells aus Angst davor, auf dem Kamplplatz in Erwartung der Kugel seines Gegners nervlich $z$ versagen: "Maupassant's story....represents better than any other piece of fiction or indeed any autobiographical work the feelings of a sensitive young man on the eve of his pirst duel...". ${ }^{2}$

Es se1 auch an Fontanes "Ef 1 Briest" erinnert: Innstetten emplindet weder $\mathrm{HaB}$ noch Rachegefuhle gegenüber dem ehemaligen Verehrer seiner Frau, Crampas. In seinem "letzten Herzenswinkel" 1st er aus Liebe zu seiner Frau sogar zum Verzethen geneigt. Dennoch kommt es zu dem für Crampas tödlichen Duell. Innstetten entscheidet sich letztlich für den 2weikampp, weil er seinen Freund und Sekundanten Willersdorf zum Mitwisser seines ehelichen Unglücks gemacht hat: "Ich ging zu Ihnen und schrieb Ihnen einen Zettel, und damit war das Spiel aus meiner Hand. Von dem Augenblicke an hatte meln Ungluck und, was schwerer wegt, der Fleck auf meiner Ehre einen halben Mitwiser, und nach den ersten Worten, die wir hier gewechselt, hat es einen ganzen. Und weil dieser Mitwisser da 1st, kann 1ch nicht mehr zurück." Innstetten ist der Uberzeugung, daB sich im menschlichen Zusammenleben "ein Etwas" herausgebildet hat, "das nun mal da lat und nach dessen Paragraphen wir uns gewöhnt haben, alles zu beur-

\footnotetext{
1Vgl. Guy de Maupassant, "Contes et nouvelles", Bd. 2 (1964). ${ }^{2}$. Baldick, "The Duel" (1965), S. 189.
} 
teilen, die anderen und uns selbst. Und dagegen $z u$ verstoßen geht nicht; die Gesellschaft verachtet uns, und zuletzt tun wir es selbst und können es nicht aushalten und jagen uns die Kugel durch den Kopf." Wüllersdorf muB dem zustimmen: "Ich finde es furchtbar, dab sie recht haben, aber sie b a b e $n$ recht... unser Ehrenkultus ist ein Götzendienst, aber wir müssen uns ihm unterwerfen, solange der Götze gilt." 1

Das aus Westeuropa von RuBland libernommene Duell machte in der russischen Wirklichkeit eine Entwicklung durch, die durchaus nicht im eigentlichen Sinn des Ehrenzweikamples lag, und wurde schließlich verächtlich als etwas Fremdartiges flir null und nichtig erklärt.

Das Schicksal des russischen literarischen Duells ist ähnlich: dem Wesen des Ehrenzweikamples trägt es nicht Rechnung. Schon bei Puskin und Lermontov ist es Spiegel einer miBverstandenen und miBbrauchten Institution. In dem BewuBtsein Čechovscher Figuren ist es bereits nichts mehr als eine literarische Reminiszenz. Bei Arcybałev wird es in letzter armseliger Verzerrung mit Hohn bedacht.

Wan beachte zum Vergleich: daB Fontanes "Effi Briest" etwa zur gleichen Zeit spielt wie Kuprins "Zweikampe" und daß das Duell hier eine absolut intakte Institution ist; daB Settembri$\mathrm{ni}$ in Thomas Manns 1924 vollendetem "Zauberberg" die Forderung zu einem Duell mit den Worten akzeptiert: "...mit solchen 2wischenfällen muß jeder Mann im Leben rechnen. Ich miBbillige theoretisch das Duell, ich denke gesetzlich. Mit der Praxis Jedoch ist es eine andere Sache...kurzum, ich stehe diesem Herm zur Verpuigung." 2

\footnotetext{
Theodor Fontane, "Werke in funf Bänden", Bd. 3 (1974), S. 42819 .

2 Thomas Mann, "Werke". Darin: "Der Zauberberg", Bd. 2 (1967), S. 738 .
} 
Zur Kulturgeschichte des Duells

Anonym, "Das Duell als Emancipation der Ehre" oder "Beleuchtung des Duells vom geschichtlichen, moralischen und polit1schen Standpunkte" (Freiburg im Breisgau: Herder'sche Verlagsbuchhandlung, 1846)

Baldick, Robert, "The Duel. A History of Duelling" (London, 1965) - Enthält eine 25 Titel umfassende Auswahlbibliographie von Lodowick Bryskett, "A Discourse of Civill Iife" (London, 1606) bis Noel Boston "Old Guns and Pistols" (Lond on, 1958)

Below, Georg von, "Das Duell in Deutschland. Geschichte und Gegenwart" (Kassel: Verlag von Max Brunnemann, 1896)

Below, Georg von, "Das Duell und der germanische Ehrbegriff" (Kassel: Verlag von Max Brunnemann, 1896)

Boguslawski, A. v., "Die Ehre und das Duell" (Berlin: Schall und Grund, 1896)

"Bol'šaja Sovetskaja Énciklopedija", Bd. 15 (Moskau, 2. Aufl., 1952)

Brang, Peter: Vom Zweikampe im russischen Leben und in der russischen Literatur. In: Zeitschrift für Slavische Philologie 29 (1961) S. 315-345.

Croabbon, A., "La science du polnt d'honneur. Commentaire raisonne sur l'offense - le duel. Ses usages et sa cegislation en Europe. La responsabilite civile, pénale, religieuse des adversaires et des témoins" (Paris, 1894) Enthalt elne 67 Titel umfassende Bibliographie.

Fehr, Hans, "Der Zweikampe" (Berlin, 1908)

Frenzel, Elisabeth, "Motive der Weltliteratur. Ein Lexikon dichtungsgeschichtlicher Längsgcinitte" (Stuttgart: Kröner, 1976). Darin: "Dueli", S. 114-128.

Pürich, W. v., "Das Duell. Kritiscn beleuci.tet" (Frankfurt a. M. und Luzern, 1886)

Hergsell, Gustar, "Duell-Codex" (Wien, Pest, Le1pzig: A. Hartleben's Verlag, 2. Aufl., 1897)

Kohut, Adolph, "Das Buch beruhmter Duelle" (Berlin, 3. Aufl., 1888)

Kufahl, Hans und Schmied-Kowarzik, Joseph, "Duellbuch. Geschichte des Zweikamples nebst einem Anhang enthaltend Duellregeln und Paukcomment" (Leipzig: Verlagsbuchhandlung von J. J. Teber, 1896)

Schulmann, Otto von, "Duell und Strafgesetz. Mit besonderer Berucksichtigung der strafrechtilchen Behandlung des Dueils in Deutschland, Frankreich, England und RuBland" (Leipzig: Rudolf Hartmann, Reval: Kluge \& Ströhm, 1914) Enthklt eine 85 Titel umfassende Bibliographie. 
Seitz, Don C., "Pamous American Duels" (Freeport, New York, First printed 1929, Reprinted 1966)

Stökl, Günther, "Russische Geschichte. Von den Anfängen b1s zur Gegenwart" (Stuttgart: Kröner, 1962)

"Die konventionellen Gebräuche beim Zweikampl. Unter Berücksichtigung des Offizierstandes". Von einem älteren aktiven Offizier (Max von Wedel). Neu bearbeitet von (Clemens Joseph) Spohn (Berlin, 7. Aufl., 1909)

\section{Zum theoretischen Fundament der Arbeit}

Gehlen, Arnold, "Anthropologische Forschung" (Reinbek be1 Hamburg: Rowohlt Taschenbuch Verlag GmbH, 1961)

Gehlen, Arnold, "Urmensch und Spätkultur. Philosophische Ergebnisse und Aussagen" (Frankfurt a. M., Bonn: Athenëum Verlag, 2. Aufl., 1964)

Hartfiel, Gunther, "Wörterbuch der Soziologie" (Stuttgart: Kröner, 1972

"International Encyclopedia of the Social Sciences", Ed. David I. Sills, Bd. 13 (USA: The Macmillan Company \& The Free Pres8, 1968)

Textausgaben der Primärliteratur

Arcybašev, M., "Sanin". Rarity Reprints Nr. 10 (Letchworth, Hertfordshire: Bradda Books, 1969)

Baudelaire, Charles, "Dle Blumen des Bösen" (Les Pleurs du Mal). (Frankfurt 8. M., Hamburg: Fischer Bucherei KG, 2. Aufl., 1966)

Bestužev-Marlinskif, A. A., "Soc. $v 2$ tt.", Bd. 2 (Moskau: Gosudarstrennoe izdatel'stvo chudozestrennof literatury, 1956

Bierce, Ambrose, "Die Mittelzehe des rechten FuBes" (The Middle Toe of the Right Foot). In: "Ghost and Horror Stories of Ambrose Bierce" (New York: Dover Publications Inc., 1964)

"The Works of Iord Byron. In Four Volumes." Bd. 1: "Childe Herold's Pilgrimage", Bd. 2: "The Giaour", Bd. 3: "The Corsair" (London: John Murray, Albemarle Street, 1823)

Camus, Albert, "Der Mensch in der Revolte" (I'Home rérolt6). (Hamburg: Rowohlt Verlag GmbH, 1953)

Cechor, A. P., "Das Duell" (Duél'). In: "Sobr. ooč. 12 tt.", Bd. 6' (Moskau: Gosudaratrennoe izsatel'stro chudožestvennof literatury, 1962)

Dostoerskif, F. M., "Die Dämonen" (Besy). In: "Sobr. soc. $r 10$ tt.", Bd. 7 (Moskau: Gosudarstrennoe 1zdatel'stro ghudokestrennof Iiteratury, 1957) und "Poln. sobr. sot. $\nabla$ 30 tt.", Bd. 11 (Leningrad: Izdatel'stro 'Nauka', 1974) 
Fontane, Theodor, "Efl1 Briest". In: "Werke in funf Bänden", hrag. Von Rainer Bachmann und Peter Bramböck, Bd. 3

(Muinchen: Nymphenburger Verlagshandlung, 1974)

Kle1st, Heinrich von, "tber das Marionettentheater". In: "Sämtliche Werke und Briele", hrag. von Helmut Sembdner,

Bd. 2 (Minchen: Carl Hanser Verlag, 5. Aufl., 1970)

Xuprin, A. I., "Der Zweikampen (Poedinok). In: "Sobr. sod. 9 tt.", Bd. 4 (Moskau: Izdatel'stro 'Chudozestrennaja litersturs', 1971)

Lermontov, M. Ju., "Ein Held unserer Ze1t" (Geroj našgo vremen1). In: "Poln. sobr. soc.", Bd. 4 (Moskau, Ieningrad: Gosudarstrennoe izdatel'stro chudozestrennoj I1teratury, 1948)

Mann, Thomas, "Der Zauberberg". In: "Werke" Taschenbuchausgabe in zwölf Bänden (Frankfurt a. M. und Hamburg: Fischer Buichere1 GmbH, 1967)

Maupassant, Guy de, "Un lâche". In: "Contes et nouvelles", hrsg. von A. M. Schmidt, Bd. 2 (Paris, 1964)

Porter, K. A., "Fahles Pferd und fahler Reiter" (Pale Horse, Pale Rider). (New York and Scarborough, Ontario: New American Library, 1967)

Puškin, A. S., "Der SchuB" (Vystrel). In: "Poln. sobr. soX. v 10 tt.", Bd. 6 (Moskau, Leningrad: Izdatel'stro Akademi1 Nauk SSSR: 1950)

Puǧkin, A. S., "Eugen Onegin" (Evgenif Onegin). In: "Poln. sobr. soc. 10 tt.", Bd. 5 (Moskau: Izdatel'stro 'Nauks', 3. Aufl., 1964)

Puškin, A. S., "Die Hauptmannstochter" (Kapitanskaja doð̌ka). In: "Poln. sobr. soc. v 10 tt.", Bd. 4 (Moskau, Leningrad: Izdatel atvo Akademil Nauk SSSR, 1950)

Schnitzler, Arthur, "Der Sekundant". In: "Spiel im Morgengrauen" (Diogenes Verlag, 1970)

Tolstoj, L. N., "Krieg und Frieden" (Vojna 1 mir). In: "Sobr. sod. v 14 tt.", Bd. 4-7 (Moskau: Gosudarstvennoe 12d8tel'stro chudoze日trennof literatury, 1951)

Tolstoj, L. N., "tber das Loben" (0 zizni). In: "Poln sobr. sod.", Serija pervaja, Bd. 26 (Moskau, 1936)

Turgener, I. S., "Väter und Söhne" (Otcy 1 det1). In: "Poln. sobr. sot. 1 pisem $\nabla 28$ tt ${ }^{n}$, Bd. 8 (Moskau-Leningrad: Izdatel'stro 'Nauka', 1964)

\section{Sekundärliteratur zu den Werkanalysen}

(Es werden auch Titel angefuhrt, die unseren tberlegungen nutzlich waren, sich aber nicht im Text niedergeschlagen haben.) 
Belinskij, V. G., "Poln. sobr. soč.", Bd. 1 (Moskau, 1953) Blagoj, Dmitrij, "Masterstro Puškina" (Moskau, 1955)

Busch, Ulrıch: Puškin und Sil'vio. (Zur Deutung von 'Vystrel'; eine Studie uber Puškins Erzählkunst. In: Slawist1sche Studien zum V. Internationalen Slawistenkongre $B$ in SoP1a 1963. Ed. Maximilian Braun und Erwin Koschmieder. Opera Slavica 4 (1963), S. 401-425.

Éjchenbaum, Boris, "O poèzil" (Leningrad, 1969)

Eng, Jan van der: The Tales of Belkin by A. S. Puskin. In: Dutch Studies in Russian Literature 1 (1958).

Grossman, Leonid, "Puškin" (Moskau, 1960)

Grossman, Leonid: Istoričskij fon 'Vystrela'. In: Stat'1 o Puskine. Russian Study Series Nr. 69 (Chicago, 1968), S. 203-235.

Hauser, Arnold, "Sozialgeschichte der Kunst und Literatur" (München, 2. AuPl., 1972)

Izmajlov, N. V., "Puškin. Itog1 1 problemy izuXenija" (Moskau, Leningrad, 1966)

Praz, Mario, "Liebe, Tod und Teufel. Die schwarze Romantik." (Muinchen, 1963. Zuerst erschienen Florenz, 1930)

Setschkareff, Vsevolod, "Alexander Puschkin. Sein Leben und sein Werk (Wiesbaden, 1963)

Shaw, J. Thomas: Pushkin's 'The Shot'. In: Indiana Slavic Studies III (1963), S. 113-129.

Slonimskij, B. A., "Masterstvo Puskina" (Moskau, 1963)

Zu A. S. Pus̆kin, "Eugen Onegin"

Alexander Sergeevich Pushkin, "Evgenif Onegin". The Russian Text Edited with Introduction and Commentary by Dmitry Cizevaky (Cambridge, Mass., 1967)

"Eugene Onegin". A Novel by Aleksandr Pushkin. Translated from the Russian, with a Commentary, by Vladimir Nabokor (New York, 1964)

Blagoj, D. "Sociologija trorčestva Puß̌kina. Étjudy" (Moskau, 1929); Slavica Reprint Nr. 28 (Düsseldorf, Vaduz, 1969)

Brodskij, N. D., "Ergenij Onegin. Posoble dlja uXitelej" (Moskau, 1964)

Gukorskij, G. A., "Puškin 1 problemy realistiðeskogo otilja" (Moskau, 1957)

Matlaw, R. E: The Dream in 'Evgenif Onegin'. In: SEER (1959), S. 487-503. 
Mejlach, B. S., "Evgenij Onegin". In: "Puškin. Itogi i problemy izuCenija". Kollektivnaja monogralija pod red. B. P. Gorodeckogo, N. V. Izmajlova, B. S. Mejlacha (Moskau, Leningrad, 1966)

Reeve, F. D. "The Russian Novel" (London, 1967)

Pia, Pascal, "Charles Baudelaire. In Selbstzeugnissen und Bilddokumenten" (Rowohlts Monographien, 3. Aufl., 1967)

Sandomirskaja, V. B., "Prižiznennaja kritika". In: "Puškin. Itogi i problemy izučenija". Kollektirnaja monogralija pod red. B. P. Gorodeckogo, N. V. Izmajlova, B. S. Mejlacha (Moskau, Leningrad, 1966)

Šklorskij, Viktor, "Evgenij Onegin. (Puškin i Stern)". In: "oxerki po poétike Puskina". Slavistic Printings and Reprintings. Ed. C. H. van Schooneveld (The Hague, Paris, 1969)

Tangl, E: Tatjanas Traum. In: ZslPh 25 (1956/57), S. 230-260. Tschižewskij, D., "Russische Literaturgeschichte des 19. Jahrhunderts", Bd. 1 (Muinchen, 1964)

Wedel, E: Onegin-Peðorin-Čackij. Versuch einer vergleichenden Betrachtung. In: Die Welt der Slawen 6 (1961), S. 355367 .

Zu A. S. Puskin, "Die Hauptmannstochter"

Avrich, Paul, "The Russian Anarchists" (Princeton, New Jersey, 1971)

Bergson, Henri, "Das Lachen" (Meisenheim am Glan, 1948)

Brang, Peter, "Pułkin und Krjukov. Zur Entstehungsgeschichte der 'Kapitanskaja docka'" (Berlin, 1957)

Ermilov, V. V., "Nał Puß̌kin" (Moskau, 1949)

Gerigk, Horst-Jürgen, "Von der Kommentarunbedurftigkeit des Kunstwerks: 'tberlegungen mit Rücksicht auf Pugkins 'Hauptmannstochter". In: "Entwurf einer Theorie des literarischen Gebildes" (Berlin, New York 1975)

Izmajlov, N. V., "Orenburgskie materialy Puškina dlja 'Istorii Pugałeva' i 'Kapitanskoj docki"". In: "Purkin. Issledovanija i materialy" (Moskau, Leningrad, 1953)

Jakubovic, D. P. "Kapitanskaja docka' i romany Val'tera Skotta". In: "Puskin. Vremennik Puskinskoj kommissi1" . IV-V

(Moskau, Leningrad, 1939)

"Istorija russkoj literatury", hrsg. von D. D. Blagoj, B. P. Gorodeckij, B. S. Mejlach, Bd. 4 (Moskau, Leningrad, 1953)

Izmajlov, N. V., "Kapitanskaja dotka". In: "Istorija russkogo romana v dvuch tomach" (Moskau, Leningrad, 1962)

Oksman, Ju. G., "Ot 'Kapitanskoj dočki' k 'Zapiskam ochotnika'" (Saratov, 1959) 
Schamschula, W., "Der EinfluB Walter Scotts in 'Kapitanskaja docka". In: "Der russische historische Roman rom Klassizismus bis zur Romantik" (Meisenheim, 1961)

Schmidt, Arno, "Berechnungen II". In: "Rosen \& Porree" (Karlsruhe, 1959)

Šklorskif, Viktor, "Theorie der Prosa" (Frankfurt a. M., 1966))

Zu M. Ju. Lermontov, "Ein Held unserer Zeit"

Duchesne, M. E., "Michel Iourévitch Lermontov. Sa vie et ses oeurres" (Paris, 1910)

Ejchenbaum, Boris, "Lermontov. Opyt istoriko-literaturnof ocemk1". Nachdruck der Leningrader Ausgabe von 1924 (München, 1967)

Ejchenbaum, Boris, "Stat'1 o Lermontove" (Moskau, Leningrad, 1961)

Gusk1, Andreas, "M. Ju. Lermontovs Konzeption des literarischien Helden" (Múnchen, 1970)

Ievin, $V$. "Ob 1stinnom smysle monologa Pecorina". In: "TrorEestro M. Ju. Lermontova" (Moskau, 1964)

Manuiflov, V. A., "Roman M. Ju. Lermontova 'Gerof nǎ̧go vremieni'. Kommentarif" (Moskau, Ieningrad, 1966)

Mersereau, John, "Mikhail Lermontor" (Carbondale, 1962)

Mersereau, John: The Patalist as a Keystone of 'A Hero of Our T1mes'. In: SEEJ 4 (1960), S. 137-146

Nazirov, R. G., "Trois duels. Balzac, Lermontor, Dostolerski". In: I'herne. Série Slave "Dostolevsk1" (Paris, 1973)!

\section{Zu I. S. Turgenev, "Väter und Söhne"}

P. M. Dostoerskij, "Die Dämonen" . In: "Sobr. sod. v 10 tt.", Bd. 7 (Moskau, 1957)

Gierens, Michael, S. J., "Ehre, Duell und Mensur" (Paderborn. 1928)

Gifford, Henry, "The Novel in Russia. Prom Pushkin to.Pasternakn (London, 1964)

Petrov, S. M., "I. S. Turgener" (Moskau, 1957)

Pustorojt, P. G., "Roman I. S. Turgenera 'Otcy 1 det1' 1 1dejnaja bor'ba 60-ch godor XIX veka" (Moskau, 1960)

Schmidt, Molf-Heinrich, "Nihilismus und Nihilisten" (Munchen, 1974)

Terz, Abram, "Der ProzeB beginnt" (Prankfurt a. M., 1966) 
Tschižewskif, D., "Russische Literaturgeschichte des 19. Jahrhunderts", Bd. 2 (München, 1967)

Yarmolinsky, A., "Turgenev. The Man, his Art and his Age" (New York, 1959)

Zu L. N. Tolstof, "Krieg und Frieden"

Christian, R. F., "Tolstoy's 'War and Peace'" (Oxford, 1962)

Ermilov, V. V., "Tolstoj-romanist: 'Vojna 1 mir', 'Anna Karenina', 'Voskresen'e'" (Moskau, 1965)

Fejn, G. N., "Roman L. N. Tolstogo 'Vojna 1 mir'. Celostnyj analiz. Iz opyta raboty ucitelja" (Moskau, 1966)

Gunn, Elizabeth, "A Daring Colffeur. Reflections on 'War and Peace' and 'Anna Karenina'" (London, 1971)

Hamburger, Käte,"Tolstoi. Gestalt und Problem" (Göttingen, 2. Aufl., 1963)

Kandiev, B. I., "Roman-èpopeja L. N. Tolstogo 'Vojna 1 mir'. Kommentarif" (Moskau, 1967)

Potapor, I. A., "Roman L. N. Tolstogo 'Vojna 1 mir'" (Moskau, 1970)

Riesman, David, "Die elnsame Masse" (Darmstadt, Berlin-Frohnau und Neuwled, 12. Aufl., 1968)

Saburov, A. A., "Vojna 1 m1r' L. N. Tolstogo" (Moskau, 1959)

Šklovskif, V. B., "Mater'al 1 otil' v romane L'va Tolstogo 'Vojna 1 mir'" (Moskau, 1928/The Hague, 1970)

Wedel, Erwin, "Die Entstehungsgeschichte von L. N. Tolstojs 'Krieg und Frieden'" (Wiesbaden, 1961)

Zajdenšnur, E. E., "Vojna 1 mir' L. N. Tolstogo" (Moskau, 1966)

Zu F. M. Dostoevskij, "Die Dämonen"

Carr, E. H., "Dostoevsky" (London, 1962)

Ermilov, V. V., "F. M. Dostoevskif" (Moskau, 1956)

Gerigk, H.-J.: Dostoevskifs Selbstverständnis als hermeneutisches Problem. In: Russian Literature 4 (The Hague, 1973)

Grossman, Leon1d, "TrorČestro Dostoevskogo" (Moskau, 1928)

Gus, M., "Ide1 1 obrazy Dostoevskogo" (Moskau, 1971)

Hingley, Ronald, "The Undiscovered Dostoevsky" (London, 1962)

Lavrin, Janko, "Dostoevsky" (New York, 1947)

Stief, Carl, "Den russiske nihilisme. Baggrunden for Dostoevskijs roman 'De Besatte'" (Kopenhagen, 1969)

Wasiolek, Edward, "Dostoevaky. The Major Fiction" (Cambridge, Mass., 1964) 


\section{Zu A.P. Eechov, "Das Duel1"}

Aleksandrov, B. I., "Seminarif po Cechoru" (Boskau, 1957) Bicilli, Petr M., "Anton P. Xechov. Das Werk und sein Stil" (Muinchen, 1966)

Matlaw, R. E., "Cechov and the Novel". In: "Anton ¿echov", hrsg. von T. Eekman (Leiden, 1960)

Schöne, Albrecht: Emblemata. Versuch einer Einführung. In: DVjs 37 (1963), S. 197-231

Simmons, Ernest J., "Chekhov. A Biography (Boston, Toronto, 1962)

Winner, Thomas, "Chekhov and his prose" (New York, Chicago, San Francisco, 1966)

Windfuhr, Manfred, "Die barocke Bildlichkeit und thre Kritiker" (Stuttgart, 1966)

\section{Zu A. I. Kuprin, "Der Zweikampe"}

Afanas'ev, V. N., "A. I. Kuprin. Kritiko-biografičeskif ocerk" (Moskau, 1960)

Berkov, P. N., "A. I. Kuprin. Kritiko-biograficeskij ołerk" (Moskau, Leningrad, 1956)

Volkov, V. A., "Trorðestvo A. I. Kuprina" (Moskau, 1962)

Vorovskif, V. V., "A. I. Kuprin". In: "Literaturno-kriticeskie stat '1" (Moskau, 1956)

\section{Zu M. Arcybasev, "Sanin"}

Barchan, Paul: Sanin und die erotische Bewegung. In: Die neue Rundschau 1 (1909), S. 123-128

Pachmuss, T.: Michail Artsybashev in the Criticism of Zinaida Gippius. In: SEER (XIIV), S. 76-87

Schneidewin, M.: Die angebliche tberwindung des revolutionären Geistes durch Arzybaschers Roman 'Ssanin'. In: PreuBische Jahrbicher 134 (1908), S. 532-540

Stender-Petersen, Adolf, "Geschichte der russischen Itteratur", Bd. 2 (München, 1957)

Vorovskij, V. V., "Bazarov 1 Sanin. Dra nigilizma". In: "I1teraturno-kritičeskie stat' '" (Moskau, 1956) 


\section{ARBEITEN UND TEXTE ZUR SLAVISTIK HERAUSGEGEBEN VON WOLFGANGKASACK}

1 Sabine Appel: Jurij 0leša. "Zavist" und "Zagovor čuvstu". Ein Vergleich des Romans mit seiner dramatisierten Fassung. 1973.234 S. DM 24.-

2 Renate Menge-Verbeeck: Nullsuffix und Nullsuffigierung im Russischen. Zur Theorie der Wortbildung. 1973. IV, $178 \mathrm{~S}$. DM 18.-

3 Jozef Mistrik: Exakte Typologie von Texten. 1973.157 S. DM $18 .-$

4 Andrea Hermann: Zum Deutschlandbild der nichtmarxistischen Sozialisten. Analyse der Zeitschrift "Russkoe Bogatstvo" von 1880 bis 1904. 1974. IV, 198 S. DM 20.-

5 Aleksandr Vuedenskij: Izbrannoe. Herausgegeben und eingeleitet von Wolfgang Kasack. 1974. 116 S. DM 15.-

6 Volker Levin: Das Groteske in Michail Bulgakovs Prosamit einem Exkurs zu A. Sinjavskij. 1975. J58 S. DM 18.-

7 Геннаяий Айги: Стихи 1954 - 1971. Редакиия и вступительная статья В. Kазака. 1975. 214 S. DM 20.-

8 Влаяимир Казаков: Ошибка живых. Роман. 1976. 201 S. DM 20.-

9 Hans-Joachim Dreyer: Petr Veřsigora. "Ljudi s čistoj sovest'ju". Veränderungen eines Partisanenromans unter dem Einflub der Politik. 1976. 101 S. DM 15.-

10 Николай Эраман: Мандат. Пьеса в трех действиях. Редакиия и вступительная статья B. Kaзака. 1976. 109 S. DM 15.-

11 Karl-Dieter van Ackern: Bulat Okudžava und die kritische Literatur über den Krieg. 1976.196 S. DM 20.-

12 Михаил булгаков: Ранняя неизданная проза. Составление и предисловие Ф. Левина. 1976. 215 S. DM 24.-

13 Eva-Marie Fiedler-Stolz: 01'ga Berggol'c. Aspekte ihres lyrischen Werkes. 1977. 207 S. DM 20.- (im Druck)

14 Christine Scholle: Das Duell in der russischen Literatur. Wandlungen und Verfall eines Ritus. 1977. 194 S. DM 20.(im Druck)

München. Verlag ot to sagner in Kommission 